SIDNEI ONO

\title{
SISTEMA DE SUPORTE A DECISÃO PARA GESTÃO DE ÁGUA URBANA - URBSSD
}


SIDNEI ONO

\section{SISTEMA DE SUPORTE A DECISÃO PARA GESTÃO DE ÁGUA URBANA - URBSSD}

Dissertação apresentada à Escola Politécnica da Universidade de São Paulo para obtenção do título de Mestre em Engenharia

Área de Concentração:

Recursos Hídricos

Orientador:

Professor Titular Mario Thadeu Leme de Barros

São Paulo

2008 
Este exemplar foi revisado e alterado em relação à versão original, sob responsabilidade única do autor e com a anuência de seu orientador.

São Paulo, 01 de julho de 2008.

Assinatura do autor

Assinatura do orientador

\section{FICHA CATALOGRÁFICA}

Ono, Sidnei

Sistema de suporte a decisão para gestão de água urbana URBSSD / S. Ono. -- São Paulo, 2008.

$148 \mathrm{p}$.

Dissertação (Mestrado) - Escola Politécnica da Universidade de São Paulo. Departamento de Engenharia Hidráulica e Sanitária.

1.Recursos hídricos 2.Hidrologia 3. Sistema de informação geográfica 4. Água (Gerenciamento) I.Universidade de São Paulo. Escola Politécnica. Departamento de Engenharia Hidráulica e Sanitária II.t. 
Aos Meus Pais, que esforçaram para formar um filho engenheiro e aos pequenos Tomoki e Augusto 


\section{AGRADECIMENTOS}

Primeiramente aos meus pais, Francisco e Sumiko pelo amor, carinho e dedicação.

Ao Prof. Dr. Mario Thadeu Leme de Barros pela orientação, conselhos, amizade e por permitir o desenvolvimento do trabalho, que me abriu as portas para a minha carreira em recursos hídricos.

Ao Prof. Dr. João Luiz Boccia Brandão pela orientação, amizade e grande colaboração neste trabalho. Foi o meu maior incentivador durante a graduação para caminhar na profissão. Nunca esquecerei os seus conselhos.

Ao Prof. Dr. Rubem La Laina Porto pela amizade, apoio, paciência e por permitir crescer profissionalmente no LABSID. Agradeço suas sábias recomendações.

À Dra. Silvana Susko Marcellini pela amizade, incentivo, sugestões, revisão e imensa ajuda na elaboração do trabalho.

Ao Prof. Dr. Kokei Uehara pelo carinho, apoio e conselhos no meu mestrado.

Ao Prof. Dr. José Alberto Quintanilha pela amizade, orientações e indicações.

Aos meus amigos e sócios, André Schardong, Joaquin Bonnecarrère Garcia e Ana Paula Zubiaurre Brites pelo companheirismo, apoio e alegrias em todos os momentos.

Aos colegas de longa jornada, Ludmílson Abritta Mendes, Letícia Santos Masini, Camila Brandão Borges e Fernanda Cunha Pirillo pela amizade, conselhos e colaborações.

Aos meus irmãos Adriana Yaeko Ono Sabioni e Edgar Ono, que me ajudaram nos momentos mais difíceis da minha vida, mesmo distantes.

Aos meus colegas e engenheiros da ENERCONSULT S.A., Maurizio Raffaelli, José Roberto dos Santos Vieira, Fabio Luiz Ramos de Abreu e Luciano Teixeira Mendes pelo apoio e a oportunidade de conciliar o trabalho e o mestrado. Sem esquecer de agradecer aos meus companheiros engenheiros Eduardo França Barbosa, Rafael Yamamoto, Paulo Gimenez Gonçalves, Cláudio de Almeida Prado e Luiz Antônio Chierighini de Souza.

À Ana Paula Norie Fujii pelos anos de companhia e paciência.

À CT-HIDRO / CNPq pelo um ano de bolsa de mestrado e à FINEP pela concepção do Projeto Cabuçu de Baixo.

E aos colegas do LABSID, LABGEO e CEPEUSP, que passei momentos felizes na Universidade de São Paulo e me ajudaram a desenvolver como ser humano. 


\section{RESUMO}

ONO, SIDNEI. Sistema de suporte a decisão para Gestão de água urbana - URBSSD. 2008. 148p. Dissertação (Mestrado) - Escola Politécnica da Universidade de São Paulo, São Paulo, 2008.

Grande parte das cidades brasileiras apresenta muitos impactos ambientais causados pelo processo de urbanização. O gerenciamento de recursos hídricos em pequenas bacias é um fator crucial para resolver estes problemas. Esta dissertação apresenta uma grande ferramenta no suporte de gerenciamento à água urbana: um Sistema de Suporte a Decisão (SSD) para planejar e gerenciar bacias urbanas. O SSD pode manipular diferentes tipos de dados e pode integrar produtos em SIG para diferentes tipos de interfaces de modelos matemáticos hidrológicos. O SSD foi aplicado numa pequena bacia localizado na cidade de São Paulo, na bacia do rio Cabuçu de Baixo. Os resultados mostram a importância deste tipo de ferramenta no planejamento e elaboração de projetos.

Palavras-chave: Recursos Hídricos, Hidrologia, Sistemas de Informações Geográficas, Água (Gerenciamento). 


\begin{abstract}
ONO, SIDNEI. Sistema de suporte a decisão para Gestão de água urbana - URBSSD. 2008. 148p. Dissertação (Mestrado) - Escola Politécnica da Universidade de São Paulo, São Paulo, 2008.
\end{abstract}

Many Brazilian cities present a lot of negative environment impacts caused by the urbanization process. The water resources management of the urban small catchments is crucial to deal with these problems. This dissertation presents a very important tool to support urban water resources management: a Decision Support System (DSS) for planning and management of urban basins. The DSS can manipulate different kind of data and can integrate GIS products with different kind of hidrology design mathematical models. The DSS was applied to a small catchments located in São Paulo city, the Cabuçu de Baixo River. The results show the importance of this kind of tool in planning and design projects. 


\section{Lista de Figuras}

Figura 3.1 - Estrutura típica de um SSD .......................................................... 22

Figura 3.2 - Sobreposição de informações espaciais ou "Overlay” ............................... 29

Figura 4.1 - Metodologia do URBSSD ............................................................... 40

Figura 4.2 - Abrindo um novo modelo de simulação............................................... 41

Figura 4.3 - Tela inicial do modelo para a seleção dos arquivos Shapefile e Raster......... 41

Figura 4.4 - Indicação que os dados geográficos de $\mathrm{TC}$ e $\mathrm{CN}$ foram importados na

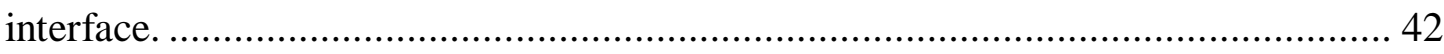

Figura 4.5 - Comando para definir as precipitações.............................................. 43

Figura 4.6 - Tela de escolha de um modo de definição de precipitação. ......................... 43

Figura 4.7 - Opção 1 - Análise de gráfico para cada evento (hietograma para uma chuva de TR=50 anos em São Paulo). .................................................................. 44

Figura 4.8 - Opção 2 - Escolher a data do evento chuvoso (evento do dia 17/02/2003).... 44

Figura 4.9 - Opção 3 - Inserir os blocos de precipitação. ........................................... 45

Figura 4.10 - Visualização das alturas de chuva na interface...................................... 45

Figura 4.11 - A interface permite a mudança do parâmetro $\mathrm{CN}$ obtido pela importação de

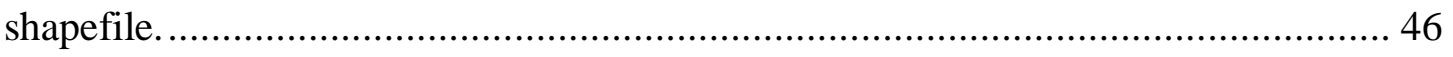

Figura 4.12 - Seleção do processamento do modelo de chuva-vazão............................ 47

Figura 4.13 - Visualização dos hidrogramas em qualquer sub-bacia (1). Vazões de contribuição da sub-bacia (2) e vazão total ou acumulada (3). 47

Figura 4.14 - Visualização da Precipitação (1), é obtida os ietogramas para cada sub-bacia.

Precipitação total horária (2), acumulada (3) e a excedente (4). 48 
Figura 4.15 - Seleção do processamento do módulo hidrodinâmico. 49

Figura 4.16 - Tela de aviso do processamento hidrodinâmico. ..................................... 49

Figura 4.17 - Tela inicial do pós-processamento hidráulico...................................... 49

Figura 4.18 - Tela de visualização das cotas da seção longitudinal............................... 50

Figura 4.19 - Comando para visualizar os picos de vazões na seção longitudinal. ........... 51

Figura 4.20 - Visualização do gráfico e tabela de Cota x Tempo da seção escolhida. ....... 51

Figura 4.21 - Visualização do gráfico e tabela de Vazão x Tempo da seção escolhida...... 52

Figura 4.22 - Indicação do botão que mostra a envoltória de NA máximos. .................... 52

Figura 4.23 - Comando para exportar o DXF da mancha de inundação. ......................... 53

Figura 4.24 - Seqüência de passos proposto para um estudo de drenagem urbana ............ 54

Figura 4.25 - Configuração da entrada de dados do shapefile (atributos) ......................... 57

Figura 4.26 - Hidrograma Unitário Curvilíneo Adimensional e o Hidrograma Unitário

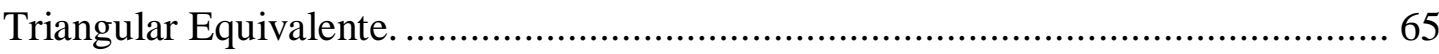

Figura 4.27 - Saída de dados do modelo hidrológico pelo módulo CABC ...................... 67

Figura 4.28 - Esquema da seção transversal ....................................................... 69

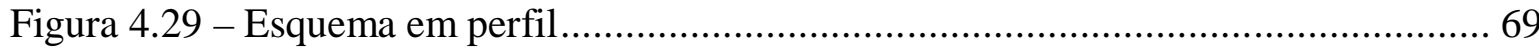

Figura 4.30 - Perfis de linha d' água em declividade fraca ..................................... 71

Figura 4.31 - Perfis de linha d' água em declividade rápida. .................................. 72

Figura 4.32 - Perfis de linha d' água em declividade crítica. ..................................... 72

Figura 4.33 - Perfis de linha d' água em declividade nula. ..................................... 72

Figura 4.34 - Perfis de linha d' água em declividade negativa................................... 73

Figura 4.35 - Esquema de diferenças finitas de 4 pontos. ......................................... 77

Figura 4.36 - Malha de diferenças finitas. ......................................................... 81

Figura 4.37 - Esquema de representação da seção transversal. .................................... 85 
Figura 4.38 - Saída de dados do modelo hidráulico pelo módulo hidráulico. 88

Figura 4.39 - Saída de dados do modelo hidráulico pelo módulo CLIV com o gráfico de perfil de lâmina d' água 89

Figura 5.1 - Localização da bacia do rio Cabuçu de Baixo ....................................... 91

Figura 5.2 - Mapa da evolução do uso do solo 1985 - 1997 ......................................... 93

Figura 5.3 - Localização dos novos loteamentos em estudo realizado em 2002.............. 94

Figura 5.4 - Principais cursos d'água da bacia do Cabuçu de Baixo: Bananal, Itaguaçu, Guaraú, Bispo e Cabuçu de Baixo trecho final. 96

Figura 5.5 - Foto aérea da bacia do Bananal com a localização dos principais afluentes e piscinões construídos e propostos. 97

Figura 5.6 - Fotos das áreas críticas de inundações na sub-bacia do Bananal................... 98

Figura 5.7 - Evolução da ocupação urbana, de acordo com a sequiência de quadros de 1 a 4 (anos 2000, 2002, 2003 e 2008) respectivamente, no sentido horário.

Figura 5.8 - Foto panorâmica do CEU-Paz 100

Figura 5.9 - Foto aérea da sub-bacia Itaguaçu e o loteamento residencial da empresa Imobel 101

Figura 5.10 - Foto aérea da sub-bacia do Bispo e o detalhe da ocupação da margem esquerda. 101

Figura 5.11 - Foto aérea da sub-bacia Guaraú e detalhe do Piscinão Guaraú ................ 102

Figura 5.12 - Foto aérea da sub-bacia Cabuçu de Baixo e detalhe do canal. .................. 103

Figura 5.13 - Divisões das sub-bacias para serem utilizadas no modelo hidrológico....... 104

Figura 5.14 - Variação espacial do $\mathrm{CN}$........................................................ 107

Figura 5.15 - Seção transversal do posto Campos Lemos ....................................... 110

Figura 5.16 - Precipitação Média Mensal na Bacia do rio Cabuçu de Baixo ................... 112 
Figura 5.17 - Esquema dos postos pluviométricos e pluviográficos considerados no estudo.

Figura 5.18 - Esquema de Thiessen dos postos pluviográficos considerados no estudo. . 116

Figura 5.19 - Hietograma - Evento de 15/03/2002 ........................................... 121

Figura 5.20 - Hietograma - Evento de 05/03/2003 ............................................ 121

Figura 5.21 - Hietograma - Evento de 07/03/2003 ............................................... 122

Figura 5.22 - Calibração na interface do Modelo Hidrológico - Evento 15/03/02 _......... 123

Figura 5.23 - Gráfico obtido na calibração do Modelo Hidrológico - Evento 15/03/02 .. 123

Figura 5.24 - Calibração na interface do Modelo Hidrológico - Evento 05/03/03 ......... 124

Figura 5.25 - Gráfico obtido na calibração do Modelo Hidrológico - Evento 05/03/03 .. 124

Figura 5.26 - Validação na interface do Modelo Hidrológico - Evento 07/03/03........... 126

Figura 5.27 - Gráfico obtido na validação do Modelo Hidrológico - Evento 07/03/03 ... 126

Figura 5.28 - Aferição do Coeficiente de Rugosidade - Posto Vista Alegre .................. 127

Figura 5.29 - Aferição do Coeficiente de Rugosidade - Posto Campos Lemos.............. 128

Figura 5.30 - Interface do Modelo Hidráulico - Evento 15/03/02.............................. 129

Figura 5.31 - Limnigrama final do Modelo Hidráulico - Evento 15/03/02 .................. 129

Figura 5.32 - Interface do Modelo Hidráulico - Evento 05/03/03............................. 130

Figura 5.33 - Limnigrama final do Modelo Hidráulico - Evento 05/03/03 .................. 130

Figura 5.34 - Interface do Modelo Hidráulico - Evento 07/03/03............................. 131

Figura 5.35 - Limnigrama final do Modelo Hidráulico - Evento 07/03/03 _.................. 131

Figura 5.36 - Área de inundação no URBSSD - Evento 15/02/02 .............................. 132

Figura 5.37 - Plano de Recuperação Ambiental e da Paisagem ................................. 134

Figura 5.38 - Parque Linear, antes e depois.................................................. 135

Figura 5.39 - Mapa de risco para água urbana na bacia do Bananal.......................... 137 


\section{Lista de Tabelas}

Tabela 4.1 - Classificação dos grupos hidrológicos dos solos e suas capacidades de

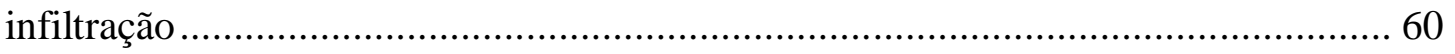

Tabela 4.2 - Estimativa de CN para áreas urbanas................................................ 61

Tabela 4.3 - Condições de solo US SCS ............................................................ 62

Tabela 4.4 - Correspondência entre os valores de CN para diversas condições de umidade

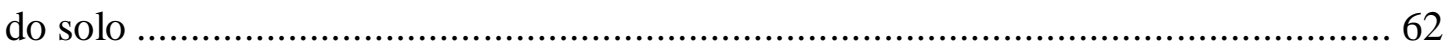

Tabela 4.5 - Relações para o cálculo do hidrograma curvilíneo do SCS e de sua curva de

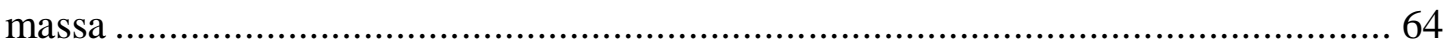

Tabela 5.1 - Parâmetros Físicos das Sub-Bacias de Drenagem ................................. 105

Tabela 5.2 - Valores do CN médio para cada sub-bacia. ...................................... 108

Tabela 5.3 - Características físicas das divisões das sub-bacias ................................. 108

Tabela 5.4 - Eventos significativos registrados pelo monitoramento de quantidade da água

Tabela 5.5 - Área relativa para cada posto pluviográfico ......................................... 116

Tabela 5.6 - Resultados da Calibração do Modelo Hidrológico .................................. 125

Tabela 5.7 - Informações espaciais utilizadas para gerar os produtos ........................ 133

Tabela 5.8 - Extensão e número de pessoas nas áreas de risco na sub-bacia do Bananal.. 137 


\section{Lista de Abreviaturas e Siglas}

\begin{tabular}{|c|c|}
\hline ABRH & Associação Brasileira de Recursos Hídricos \\
\hline ANA & Agência Nacional de Águas \\
\hline ASCE & American Society of Civil Engineers \\
\hline AT & Bacia do Alto Tietê \\
\hline BID & Banco Interamericano de Desenvolvimento \\
\hline CABC & Modelo de Análise de Bacias Complexas \\
\hline CETESB & Companhia de Tecnologia de Saneamento Ambiental \\
\hline CGE & Centro de Gerenciamento de Emergências \\
\hline CIAMB & Subprograma de Ciências Ambientais do PADCT \\
\hline CLIV & Modelo de Condutos Livres \\
\hline CNPQ & Conselho Nacional de Desenvolvimento Científico e Tecnológico \\
\hline COAPS & Center of Ocean-Atmospheric Prediction Studies \\
\hline CONAMA & Conselho Nacional do Meio Ambiente \\
\hline CPRM & Companhia de Pesquisa de Recursos Minerais \\
\hline DAEE & Departamento de Águas e Energia Elétrica do Estado de São Paulo \\
\hline DSS & Decision Support System \\
\hline DXF & Formato de arquivo em desenhos vetoriais \\
\hline EPA & Environmental Protection Agency \\
\hline EPUSP & Escola Politécnica da Universidade de São Paulo \\
\hline ESRI & Environmental System Research Institute \\
\hline FCTH & Fundação Centro Tecnológico de Hidráulica da USP \\
\hline GIS & Geographic Information System \\
\hline GPS & Sistema de Posicionamento Global \\
\hline HEC & Hidrologic Modeling System \\
\hline IAG & Instituto Astronômico e Geofísico da USP \\
\hline IBGE & Instituto Brasileiro de Geografia e Estatística \\
\hline IGEOG & Instituto de Geografia da USP \\
\hline INPE & Instituto Nacional de Pesquisas Espaciais \\
\hline
\end{tabular}


IPT Instituto de Pesquisas Tecnológicas

LABGEO Laboratório de Geoprocessamento da EPUSP

LABSID Laboratório de Sistemas de Suporte a Decisões da EPUSP

LANDSAT Land Remote Sensing Satellite

MCT Ministério da Ciência e Tecnologia

MEL Modelo Estocástico Linear

MMA Ministério do Meio Ambiente

MSDN Microsoft Developer Network

NA Nível d' Água

PADCT Programa de Apoio ao Desenvolvimento Científico e Tecnológico

PDMAT Plano Diretor de Macrodrenagem do Alto Tietê

PHD Departamento de Engenharia Hidráulica e Sanitária da EPUSP

PMSP Prefeitura Municipal de São Paulo

PNRH Política Nacional de Recursos Hídricos

RMSP Região Metropolitana de São Paulo

SABESP Companhia de Saneamento Básico do Estado de São Paulo

SAD69 South American Datum 1969

SAISP Sistema de Alerta a Inundações de São Paulo

SCS Soil Conservation Service

SGI Superintendência de Gestão da Informação

SIG Sistema de Informação Geográfica

SIGRH Sistema Integrado de Gerenciamento de Recursos Hídricos de São Paulo

SNIRH Sistema Nacional de Informações de Recursos Hídricos

SR Sensoriamento Remoto

SSD Sistema de Suporte a Decisões

UFRGS Universidade Federal do Rio Grande do Sul

UNESCO Organização das Nações Unidas para a Educação, a Ciência e a Cultura.

UNICAMP Universidade Estadual de Campinas

USP Universidade de São Paulo

WGS84 World Geodetic System 1984

VBA Aplicação em Visual Basic 


\section{Lista de Variáveis}

A

$A_{m}$

$A_{\text {imp }}$

$A_{\text {total }}$

$\beta$

B

C

CN

$d$

D

$\Delta$

$\Delta \mathrm{t}$

$\varepsilon$

$\phi$

$F_{r}$

$\gamma$

$g$

G

$h$

i

$I_{A}$

$k$

$P$

$P_{\text {exc }}$

$p$

Qeq

$q_{p}$
Área de drenagem em $\mathrm{Km}^{2}$

Área molhada da seção transversal

Área impermeável

Área total de drenagem da bacia

Coeficiente de Quantidade de Movimento

Largura à superfície livre

Constante para o cálculo de vazão

Número de Curva (Curve Number) do SCS

Densidade populacional em hab/ha

Duração ou tempo da chuva excedente em horas

Variação de uma grandeza com o tempo

Duração unitária no hidrograma unitário ou diferença de tempos

Correção dos métodos de cálculo numéricos ou viscosidade artificial

Parâmetro de infiltração "índice fi”" do Soil Conservation Service

Número de Froude

Ângulo da contribuição lateral com o eixo do canal.

Aceleração da gravidade $\left(9,81 \mathrm{~m} / \mathrm{s}^{2}\right)$

Grandeza genérica relacionada ao escoamento

Variável volumétrica para os métodos numéricos

Intensidade média em $\mathrm{mm} / \mathrm{h}$.

Abstração inicial em mm.

Coeficiente de amortecimento das oscilações de alta freqüência característica

Precipitação em mm

Precipitação Excedente ou Deflúvio em mm

Perímetro molhado em $\mathrm{m}$

Vazão em $\mathrm{m}^{3} / \mathrm{s}$

Vazão de pico em $\mathrm{m}^{3} / \mathrm{s}$ 
$q_{L}$

$R_{h}$

Re

$S_{D}$

$S_{f}$ :

$S(t)$

$\mathrm{T}$

$\mathrm{t}$

$t_{c}$

$t_{l}$

$t_{p}$

$t_{r}$

$\theta$

$x$

v

$y$

$y_{\text {normal }}$

$y_{\text {crítico }}$

$z$
Vazão Líquida de contribuição lateral específica $\mathrm{em} \mathrm{m}^{3} / \mathrm{s} / \mathrm{m}$

Raio hidráulico da seção do rio ou canal

Raio hidráulico de Engelund

Armazenamento máximo em mm.

Inclinação da linha de energia

Soma das ordenadas do hidrograma unitário

Período de retorno ou recorrência, em anos.

Variável atribuída ao tempo.

Tempo de concentração da bacia em horas.

Tempo de resposta do hidrograma unitário em horas

Tempo de pico do hidrograma unitário em horas

Tempo de recessão do hidrograma unitário em horas

Coeficiente de ponderação no tempo - Implicidade

Coordenada longitudinal

Velocidade da contribuição lateral líquida

Profundidade do nível da água

Profundidade associada ao escoamento em regime uniforme

Profundidade associada ao escoamento com número de Froude unitário.

Cota do nível da água 


\section{Sumário}

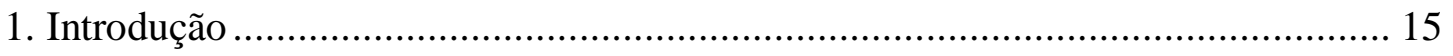

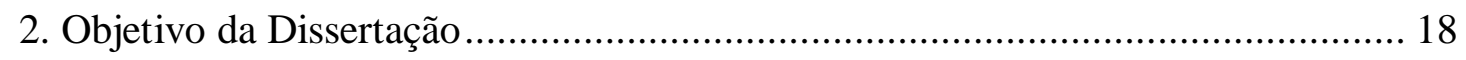

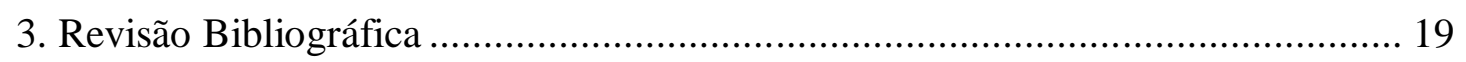

3.1. Sistemas de Suporte a Decisão (SSD) ................................................. 19

3.2. Sistemas de Informações Geográficas (SIG) _....................................... 28

3.3. Modelos Chuva-Vazão ....................................................................... 33

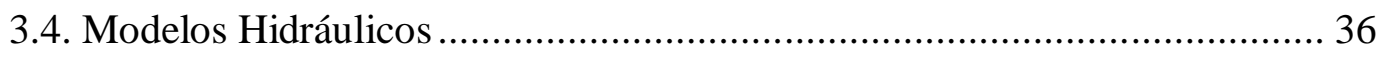

4. Base Conceitual de Formulação do SSD ...................................................... 39

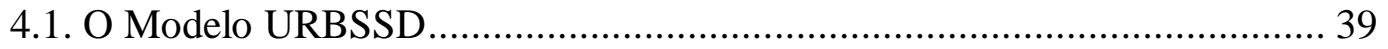

4.2. Módulo Hidrológico................................................................. 53

4.2.1. Definição do hietograma ...................................................... 54

4.2.2. Cálculo do Escoamento Superficial .......................................... 56

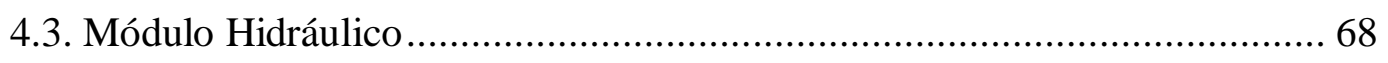

4.3.1. O Caso Particular do Escoamento Permanente................................ 70

4.3.2. Escoamentos Não Permanentes ............................................... 76

4.3.3. Caracterização das Seções Transversais......................................... 84

4.3.4. Implantação do Modelo CLIV .................................................... 86

5. Estudo de Caso: Bacia do rio Cabuçu de Baixo.............................................. 90

5.1. Características Físicas da Bacia .................................................. 91

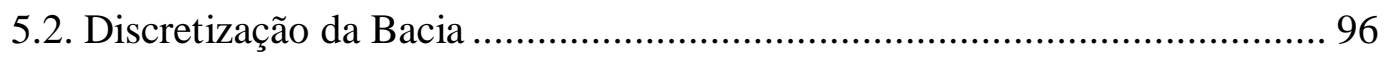




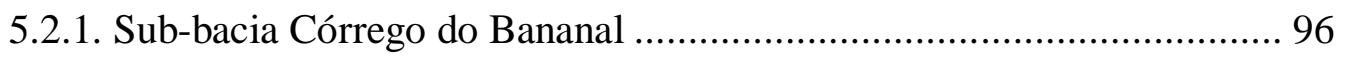

5.2.2. Sub-bacia Córrego Itaguaçu .................................................... 100

5.2.3. Sub-bacia Córrego do Bispo ................................................... 101

5.2.4. Sub-bacia Córrego Guaraú ...................................................... 102

5.2.5. Sub-bacia do rio Cabuçu de Baixo (curso inferior) .......................... 102

5.3. Dados Físicos da Bacia .................................................................. 103

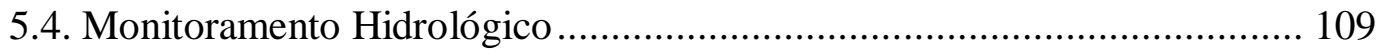

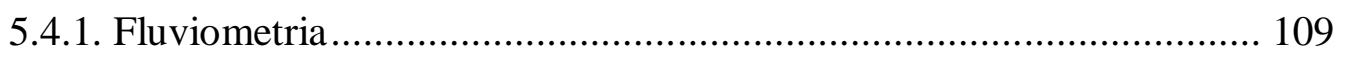

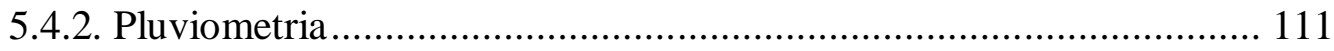

5.4.3. Estruturação hidrológica / hidráulica para aplicação dos modelos

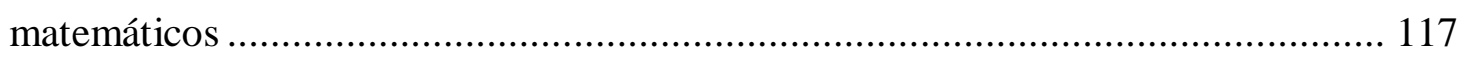

5.5. Aplicação do Modelo URBSSD ....................................................... 119

5.5.1. Verificação do Modelo Hidrológico ............................................ 119

5.5.2. Verificação do Modelo Hidráulico............................................ 127

5.5.3. Exemplos de aplicações das Áreas de Inundação ........................... 132

6. Conclusões e Recomendações ............................................................... 138

7. Referências Bibliográficas ................................................................. 142 


\section{Introdução}

O crescimento da maior parte das cidades brasileiras, sobretudo na Região Metropolitana de São Paulo, tem se dado de forma desordenada. Essa ocupação urbana ocorre em geral, sem uma maior preocupação com o meio físico, interferindo assim, de forma negativa, na qualidade de vida da população e, conseqüentemente, causando uma série de efeitos danosos ao meio ambiente, provocando o desequilíbrio dos sistemas ambientais e conseqüentemente risco à população.

Entre os riscos podem ser citados os relacionados ao meio físico e as atividades antrópicas indiscriminadas, tais como a ocupação de áreas de várzeas, áreas sujeitas às inundações, áreas com declividades acentuadas e áreas com alta suscetibilidade aos processos de erosão.

No âmbito da legislação brasileira, a Lei Federal 9.433 de 08 de janeiro de 1997 tem como um dos fundamentos a bacia hidrográfica como unidade territorial para a implantação da Política Nacional de Recursos Hídricos (PNRH) para a prevenção e a defesa contra eventos hidrológicos críticos de origem natural ou decorrente do uso inadequado dos recursos naturais e atuação do Sistema Nacional de Gerenciamento de Recursos Hídricos. Conceitualmente, o termo bacia hidrográfica refere-se ao divisor de águas e esta conceituação é utilizada no sentido de instrumentalizar a identificação de uma área geográfica bem delimitada pela hidrografia, onde questões ambientais se interpenetram, BARBOSA et al. (1997). A bacia hidrográfica é o objeto de estudo da maioria dos modelos hidrológicos, reunindo as superfícies que captam e despejam água sobre um ou mais canais de escoamento que desembocam numa única saída. A bacia pode constituir a unidade 
espacial para modelos agregados que consideram as propriedades médias para toda a bacia, ou então, é subdividida segundo diversas abordagens a fim de considerar suas características espacialmente distribuídas, RENNÓ E SOARES (2003). Assim, a bacia hidrográfica é utilizada também como unidade de estudo pelo fato que os recursos hídricos são afetados diretamente pelos resíduos sólidos e líquidos gerados pelas atividades antrópicas.

As alterações no uso e ocupação do solo originárias do processo de urbanização ocasionam importantes reflexos no comportamento hidráulico e hidrológico da bacia hidrográfica. Essas transformações sofridas pela bacia em fase de urbanização podem ocorrer rapidamente, gerando impactos na qualidade da água, nos níveis e freqüência de inundações e no transporte de sólidos.

Na Região Metropolitana de São Paulo (RMSP), de acordo com dados censitários do IBGE citado por BARROS (2005), o sistema de abastecimento público de água cobre praticamente toda a área urbana, contudo o sistema de distribuição é ineficiente e apresenta um índice de perdas de mais ou menos $30 \%$. A coleta de esgotos domésticos atinge a cerca de $70 \%$ dos domicílios. Porém, apenas $15 \%$ do esgoto é tratado adequadamente, sendo que o restante é lançado "in natura" nos corpos d' água. A maior parte do sistema de drenagem urbana é obsoleto e deteriorado, sendo ineficaz para atender os constantes aumentos das vazões devido à expansão contínua das áreas impermeáveis. Assim, as decisões sobre projetos envolvendo as águas da cidade envolvem aspectos de ordem social, econômica e ambiental.

Porém, segundo PORTO et al.(1997), estamos presenciando uma notável evolução nas áreas gerenciais e institucionais relativas ao aproveitamento integrado dos nossos recursos hídricos, atestada pela promulgação de uma série de leis estaduais, seguidas de 
providências efetivas para a implantação dos respectivos sistemas de gerenciamento de recursos hídricos. Além dos avanços internos, nota-se que organismos financeiros internacionais, como a UNESCO e BID, voltam a se interessar por investimentos no país e aumentam o fortalecimento do Estado e da União como condição para financiamento de empréstimos. A participação de comitês de bacia e usuários da água também tem sido exigida constantemente por estes organismos financeiros para lidar com os processos decisórios.

Estes fatos trouxeram novos atores ao palco decisório dotados de níveis de informação, interesses e ideologias diversificadas o que torna o processo de decisão mais democrático embora muito mais complexo.

Visando colaborar com esse processo, esta dissertação de mestrado objetiva desenvolver uma metodologia de auxílio à tomada de decisões baseada na intensa utilização de bases de dados e modelos matemáticos e também na facilidade com que a interface gráfica propicia o diálogo entre o usuário e o computador. O produto final é um sistema computacional, o Sistema de Suporte à Decisão (SSD), que dê apoio aos usuários para tomar decisões na solução de problemas referentes à água urbana. O conceito de suporte é fundamental para a compreensão da sua importância e do seu funcionamento, que deve ser entendido como um apoio computacional. Um SSD deve ser colocado à disposição dos usuários para auxiliá-los na organização de informações, na identificação e formulação de problemas, assim como a conceber e analisar alternativas, resultando na escolha do melhor curso de ação. 


\section{Objetivo da Dissertação}

O objetivo principal da dissertação é desenvolver um Sistema de Suporte a Decisão (SSD) para planejamento e projeto de controle de cheias em áreas urbanas. Este SSD resulta em um sistema computacional que integra informações sobre a água da bacia, processa modelos matemáticos para diversos cenários e permite gerar imagens e tabelas com os resultados obtidos. Assim, ajuda ao usuário (ou decisor) a avaliar quais as medidas estruturais (que compreendem as obras de engenharia) e não estruturais (que consideram aspectos sociais, legais, institucionais e gerenciais do problema) devem ser executadas para minimizar os efeitos das inundações.

O sistema computacional utiliza um modelo hidrológico para o cálculo de vazões, um modelo hidráulico para o cálculo das ondas de cheias e uma interface em Sistema de Informação Geográfica (SIG) para a leitura e processamento dos dados geográficos. Todos os modelos e a interface foram programados em uma linguagem de programação orientada a objetos.

Em outras palavras, o SSD deve dar suporte para o planejamento de drenagem de bacia urbana, deve ser entendido como uma parte de um abrangente processo de planejamento urbano e coordenado com os demais planos, principalmente os de saneamento básico (água e esgoto), uso do solo e transportes. 


\section{Revisão Bibliográfica}

\subsection{Sistemas de Suporte a Decisão (SSD)}

Os Sistemas de Suporte a Decisão (SSD) constituem uma metodologia de auxílio à tomada de decisão baseada na intensa utilização de bases de dados e modelos matemáticos, bem como na facilidade com que propiciam o diálogo entre usuário e computador, PORTO E AZEVEDO (1997).

Para BARROS (2004), os SSD direcionados para a água urbana são sistemas computacionais que têm por objetivo ajudar os usuários a tomar decisões na solução de problemas não estruturados (ou parcialmente estruturados). Problemas não estruturados são aqueles para os quais não existem soluções através de algoritmos bem definidos. Esse tipo de problema, via de regra, não é facilmente tratável por soluções computacionais. Tendo como conseqüência, a solução destes problemas exige uma interação entre homem e máquina. Sendo assim, o conceito de suporte (ou ajuda, ou apoio) é fundamental para a compreensão da utilidade e do funcionamento.

Um Sistema de Suporte a Decisão deve ser colocado à disposição de um usuário para auxiliá-lo a acessar os dados e informações, a identificar e formular problemas, a conceber e analisar alternativas e finalmente ajudá-lo na escolha do melhor curso de ação. Em outros termos, a finalidade não é tomar decisões, mas auxiliar a missão de decidir, segundo PORTO (2003).

PORTO et. al. (1997) afirma que o conceito para SSDs complexos e de grande porte tem grandes bases de dados e modelos também complexos, necessitando de uma equipe de desenvolvimento. Mas para a aplicação no projeto proposto, o desenvolvimento e a 
posterior operação de um SSD podem ser processados em várias etapas, por uma só pessoa, por ter a finalidade de pesquisa e não comercial.

O decisor ou tomador de decisões é a figura central e "pensante" do SSD. O decisor deverá consultar o sistema como ferramenta e receber informações que serão utilizadas para melhorar a qualidade de suas decisões. Embora esteja se referindo no singular, o "decisor" não necessariamente precisa ser apenas um usuário. No campo dos Recursos Hídricos, por razões compreensíveis, esta figura está ficando com o passar do tempo rara. As tomadas de decisões em conselhos, comitês e audiências públicas estão cada vez mais comuns e os decisores podem se posicionar em qualquer nível hierárquico.

Também é comum que o decisor, seja ele experiente ou não, sinta um pouco incomodado em operar um software visual com muitos comandos, como são os casos da maioria dos SSDs. Por isso, terceiros operam com mais freqüência e assim, a delegação da operação do sistema é fato muito comum, principalmente nos níveis hierárquicos mais altos.

Para contribuir na facilidade de uso do decisor, o próprio desenvolvedor do SSD deve solucionar os problemas relacionados com a interatividade entre os modelos utilizados. Mesmo assim, em muitos casos, resta ao decisor solucionar muitos problemas de adaptação do software, ocorrendo tendência ao abandono. Caso isso ocorra por parte do usuário final, recomendam-se algumas ações:

- Revisão do projeto do SSD para adaptá-lo às necessidades e características do usuário;

- Revisão do programa de treinamento;

- Caso seja inevitável a delegação da operação do sistema a terceiros, deve ser 
assegurado que estes tenham conhecimento adequado dos problemas decisórios em questão. Mas é preferível treinar, no caso, uma pessoa de bom nível técnico para operar o sistema e discutir os resultados com o usuário final.

A manutenção e alimentação do banco de dados são importantes para contribuírem melhor com as séries históricas e obter melhores estatísticas. Em sistemas individuais é comum que e o próprio criador e / ou executor do SSD faça também a manutenção do sistema ou encarregue um auxiliar próximo de fazê-la. A documentação do sistema é essencial para o bom funcionamento e manutenção. Sistemas mal documentados e mantidos tendem a deteriorar-se após algum tempo e serem finalmente abandonados.

LABADIE e SULLIVAN (1986) destacam um outro importante aspecto. Um SSD deve possuir um nível adequado de generalização e flexibilidade para que possa se adaptar a mudanças que venham a ocorrer no problema analisado ou no contexto do processo decisório.

As funções dos diversos componentes da estrutura de um SSD são propostas por PORTO et. al. (2003):

- A Base de Modelos é geralmente constituída por modelos matemáticos que reproduzem o comportamento do sistema real, permitem analisar cenários alternativos (modelos de simulação) e ajudam o usuário a encontrar dimensões ou políticas ótimas de operação. A missão essencial dos modelos é transformar dados em informações de boa qualidade. Por terem sido utilizados com sucesso no SSD do projeto Gerenciamento Integrado de Bacias Hidrográficas em Áreas Urbanas, BARROS et. al. (2004), os modelos utilizados nesta base são de dois tipos: o modelo hidrológico de chuva-vazão CABC, FCTH (2002) e o modelo hidráulico CLIV (FCTH, 2002). Nos capítulos 4.2. e 4.3. são descritos as 
metodologias matemáticas dos modelos.

- A Base de Dados, composto por um Sistema de Informação Geográfica (SIG) e por um módulo de precipitação (que elabora os hietogramas, ou seja, eventos chuvosos "reais" e sintéticos), deve permitir relacionar as informações sobre o sistema em questão e recuperá-las com facilidade e rapidez. Este módulo deve alimentar a Base de Modelos com os dados necessários e armazenar os resultados dos modelos para futuras análises e comparações.

- O Módulo de Diálogo é constituído por interfaces que facilitam a comunicação entre o usuário e o computador para fornecer dados, propor problemas, formular cenário e analisar resultados. O diálogo com o usuário pode ser simples, intuitivo e rico em recursos de comunicação, como gráficos, fotografias, mapas, entre outros. Ou seja, com a utilização dos Sistemas de Informações Geográficas, a ser descrita no Capítulo 4.

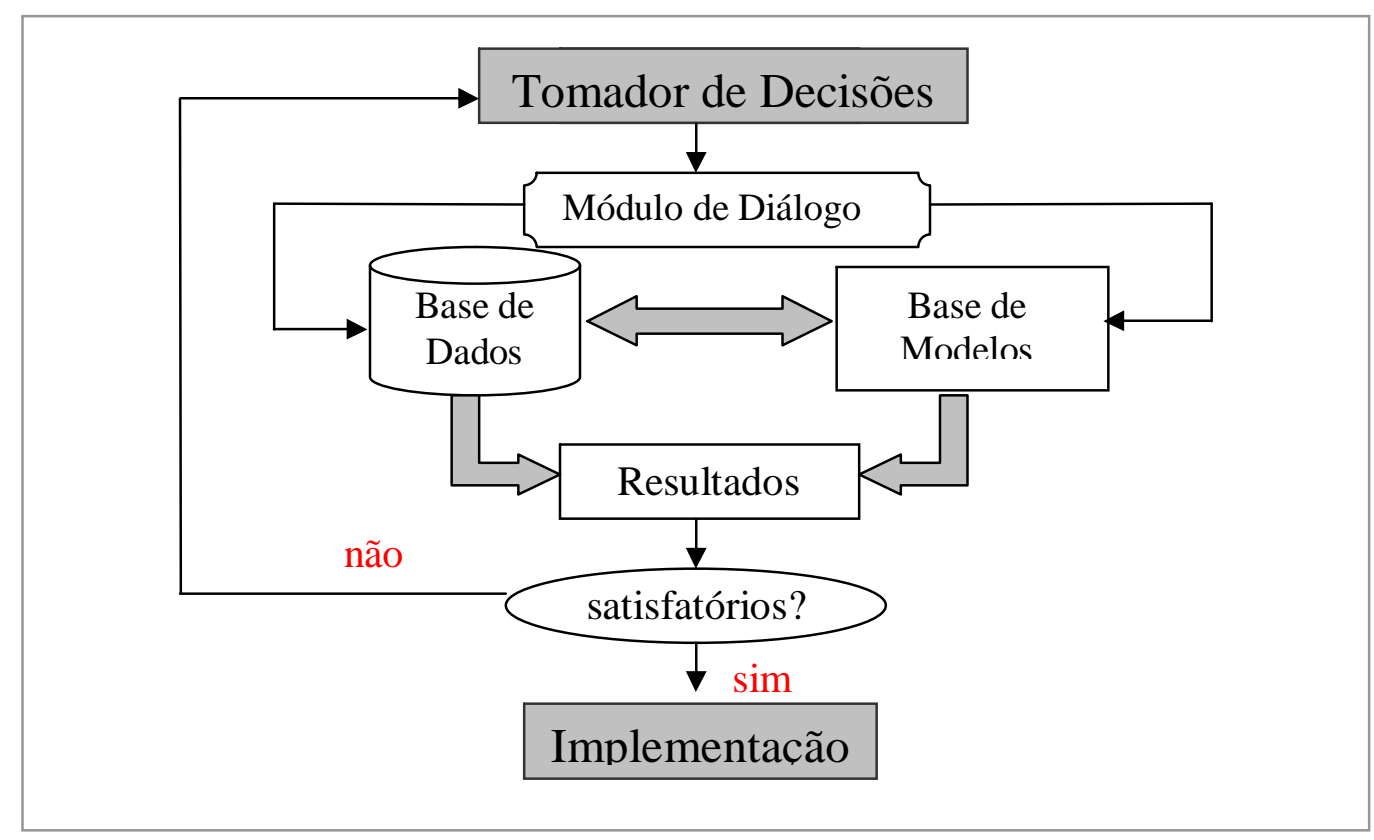

Figura 3.1 - Estrutura típica de um SSD (FONTE: PORTO, 2003, Adaptado). 
Este último módulo é um componente tão ou mais importante do sistema, porque é o que facilita aos participantes do chamado Grupos de Tomada de Decisões, PORTO (2003), a entender melhor a sistemática dos modelos matemáticos.

As experiências têm mostrado que os SSDs são instrumentos eficientes para auxiliar estes grupos, que naturalmente são heterogêneos, permitindo que cada um dos participantes avalie as consequiências da implementação de suas idéias com o auxílio de modelos aceitos por todos, a partir de uma base comum de informações. Para tanto, foram criados os comitês de bacia hidrográfica com a presença de governo, dos técnicos, dos usuários e da sociedade civil. É necessário que os responsáveis pela decisão consigam administrar seus conflitos em sistemas extremamente complexos, como é o caso do gerenciamento de recursos hídricos.

Os Sistemas de Suporte a Decisões têm sua maior utilidade justamente para minimizar estes conflitos. De acordo com PORTO (2002), a natureza dos conflitos pode ser destacada em três tipos. Embora possa prevalecer uma das naturezas a seguir apontadas, em geral se tem uma fusão das três:

- Cognitivos: quando os responsáveis pela decisão entram em conflito por não terem embasamento técnico suficiente para sua resolução. Por não conhecer suficientemente bem o problema, dão as posições baseadas em opiniões. É importante ressaltar que os SSDs não são projetados para suprir o conhecimento técnico destes responsáveis pelas decisões.

- Políticos: ocorrem quando as partes possuem interesses diferentes. Particularmente, quando os interesses são espúrios, ocorre a tendência de os interlocutores disfarçarem seus reais objetivos. Sua resolução se baseia na possibilidade de negociações, sendo que os interlocutores devem conhecer 
razoavelmente bem os benefícios ou perdas da assunção de determinadas posições. Mesmo assim, cabe aos técnicos quantificar o ganho ou perda destas negociações.

- Ideológicos: as partes entram em conflito porque possuem valores diferentes. Sem dúvida, são os conflitos cujas soluções existentes (quando existem) ainda estão longe de poderem ser consideradas satisfatórias. No entanto, esclarecimentos técnicos podem ajudar a minimizar tais situações.

Quanto à administração final dos conflitos, PORTO (2003) apresenta os seguintes desfechos:

- Ganha x Perde: trata-se da situação que a maioria das pessoas acha mais comum, e que mais enfrentam normalmente. Em geral, a parte mais forte, seja por maior poder decisório, econômico ou político, ganha a disputa. No entanto, este tipo de resolução não leva a uma situação sustentável, uma vez que o lado perdedor sai descontente da negociação e tende a buscar reverter, assim que possível, sua condição. Um exemplo comum é a concessão de licenças ambientais, antes não concedidos por proteção ambiental, para facilitar interesses políticos;

- Perde x Perde: é a situação que nenhuma das partes deseja, mas muitas vezes ocorre. Produz, obviamente, desfechos extremamente frágeis, podendo gerar situações de conflitos mais complexas que a original. Um exemplo é a perda de bens imensuráveis (vidas) numa ruptura de uma barragem construída de modo mais econômica, para suprir interesses de investidores;

- Ganha x Ganha: se existe uma situação de conflito, compreende-se que os 
recursos não são suficientes para a satisfação de todas as partes. No entanto, podem ser buscadas oportunidades, muitas vezes diferentes das situações que geraram o conflito, que talvez satisfaçam, mesmo que parcialmente, as diversas necessidades dos partícipes. É necessário que ambas as partes entrem na negociação com o intuito de ganhar e também disposta a fazer concessões, dando maior possibilidade de sucesso à negociação para que se possam estabelecer soluções sustentáveis de longo prazo. Para que se consiga uma relação ganha x ganha, é necessário que exista:

- Confiança entre as partes;

- Algo em comum com a qual as partes concordem (uma base de dados consistente, como exemplo);

- Ambos os lados devem procurar identificar oportunidades, mesmo que diferentes do objeto específico da negociação.

À medida que aumenta o contingente populacional nos grandes centros urbanos, situação verificada nos países de crescimento econômico, os problemas de escassez de recursos e, conseqüentemente, as possibilidades de conflitos, tendem a serem também majorados, principalmente os relacionados a aspectos ambientais, dentre os quais se destaca a questão dos recursos hídricos. No entanto, também tem sido cada vez maior o grau de conscientização das comunidades e a percepção de que tais problemas não são nem de simples resolução e muito menos que poderão ser resolvidos pelo Estado somente.

Desta forma, de acordo com PORTO (2002), os Sistemas de Suporte a Decisões têm conquistado importantes espaços também nesses fóruns de discussão, uma vez que podem esclarecer os aspectos cognitivos, pois englobam os dados que são necessários para conhecimento dos problemas (tomada de decisão). A seguir serão apresentados, como 
exemplo, alguns Sistemas de Suporte a Decisão, todos eles desenvolvidos para permitir um melhor gerenciamento dos recursos hídricos procurando minimizar as situações de conflitos.

Dependendo do tipo de utilização, existem diversos Sistemas de Suporte a Decisões desenvolvidos e aplicados no Brasil. ALMEIDA (2006) desenvolveu o ARENA (Análise de Recursos Naturais), que utiliza conceitos da Programação Orientada a Objetos (POO) e é composto por diversos módulos: um Sistema de Informações Geográficas, um simulador de fluxo de águas subterrâneas, um simulador do ciclo hidrológico superficial, uma base de dados georreferenciada e módulos de acesso aos dados. Em seu trabalho, o SIG não é apenas utilizado nas fases de pré e pós-processamento, e sim no processo de simulação. Mas não há afirmações de que pode ser aplicado em bacias urbanas, em escoamento não permanente.

Outro sistema, como o Sistema de Apoio a Decisão (SAD), é descrito por AZEVEDO et. al (1998) como um gerenciador de quantidade e qualidade das águas. Dentre as principais conclusões, se destaca a capacidade de gerenciamento integrado em bacias complexas.

SCHARDONG (2006), além de citar diversos trabalhos de SSD que incorporam técnicas de otimização, desenvolveu um sistema que analisa problemas de alocação de água em bacias hidrográficas, dispondo de uma ferramenta de otimização (Método de Pontos Interiores) para o SSD Acquanet, de ROBERTO E PORTO (2001).

Além dos sistemas supracitados, no Brasil existem teses de doutorado que utilizam os conceitos de SSD para várias aplicações em recursos hídricos, entre vários assuntos: previsão de chuvas e vazões de NAKAYAMA (1988), demandas de água para irrigação de CARVALHO (2005) e qualidade da água de RODRIGUES (2005). 
Na literatura internacional tem-se o ILRDSS - Illinois Rivers Decision Support System, de DEMISSIE e TIDRICK (2001). É um sistema disponibilizado pela Internet que permite um melhor gerenciamento dos recursos hídricos do estado norte-americano de Illinois. Possui um banco de dados de clima, topografia, nível da água, biologia, solo, economia, parâmetros físicos e químicos da água, geologia, química dos sedimentos e uso do solo. Utiliza modelos hidrológicos, hidráulicos, de qualidade de águas superficiais e subterrâneas, climatológicos, ecológicos, econômicos e de geometria fluvial.

O CDSS - Colorado's Decision Support Systems, DWR \& CWCB (2008) foi desenvolvido para prover informações confiáveis para uso na tomada de decisões nos recursos hídricos do Estado do Colorado, EUA. Este sistema possui um forte componente de banco de dados, tanto históricos quanto em tempo real, além de fornecer os dados administrativos e legais quanto à titularidade da água naquele estado. De acordo com PORTO (2003), a água na região oeste norte-americano é um bem de caráter particular. Desta forma, existem proprietários da água que possuem garantias de atendimento ao uso particular pelo Estado. O CDSS possui também modelos de simulação de água superficial (StateMod), de água subterrânea (ModFlow) e de uso consuntivo (StateCU). Todos estes modelos podem ser visualizados num modelo de Sistema de Informação Geográfica (CDSS Map Viewer) disponível na internet.

Novas aplicações analíticas baseadas na internet foram introduzidas. É claro que o SSD pertence a um ambiente com fundamentos multidisciplinares, incluindo (mas não exclusivamente) pesquisas de banco de dados, inteligência artificial, interação homemmáquina, métodos de simulação, engenharia de software e telecomunicações, que estão evoluindo em termos de velocidade de processamento e velocidade de transmissão a cada ano. 


\subsection{Sistemas de Informações Geográficas (SIG)}

Segundo afirmações de SINGH (1995) e posteriormente citado por RODRIGUES (1998), um Sistema de Informações Geográficas (SIG) pode ser definido como um sistema que visa à coleta, armazenamento, manipulação, análise e apresentação de informações sobre entes com localização espacial, ou seja, informações que possam ser georreferenciadas. É um complexo formado por uma base de dados, software, hardware e organização dos dados.

As técnicas convencionais, quando aplicadas para monitorar a expansão urbana e a ocupação de áreas de bacias hidrográficas, não têm conseguido acompanhar a velocidade com que o fenômeno se efetua. Sendo assim, deve-se alertar para a necessidade da busca de novos métodos, empregando tecnologias mais adequadas, para detectar a expansão urbana e as alterações ambientais decorrentes.

Um método eficiente em estudos ambientais, consiste nas superposições de mapas temáticos, como uso do solo, geologia, polígonos de inundação, etc. Um mapa de qualidade fornece mais adequadamente a informação espacial desejada do que pareceres técnicos e modelos, os quais, muitas vezes, são de difícil compreensão para a maioria dos legisladores e das pessoas incumbidas de tomar decisões.

Antes, os mapas "analógicos" apresentavam limitações, como, por exemplo, a dificuldade de atualização das informações nele contidas, tendo em vista a alteração dinâmica do espaço. O grande volume de informações, multiplicada à realização de tarefas monótonas e extensas (por exemplo, elaboração de cartas de declividade através da leitura de densas curvas de nível) contribuíram para a busca das melhores técnicas de geoprocessamento. 
Assim, a cartografia digital e o Sistema de Informações Geográficas (SIG) significaram uma melhora na coleção e armazenamento de dados para inventários, projetos básicos e executivos, monitoramento, análise e simulação ambientais. Os mapas temáticos, em formato digital, são armazenados num SIG como uma série de camadas georreferenciadas, onde cada camada ou plano de informação contém os dados de um único atributo, ou seja, uma camada para tipo de solo, outra para rede de drenagem, etc.

Um banco de dados alfanumérico complementa as informações espaciais que podem ser analisadas através de sobreposição de camadas (“Overlay”), modelagem, análise de rede, entre outros, por CONGALTON E GREEN (1995).

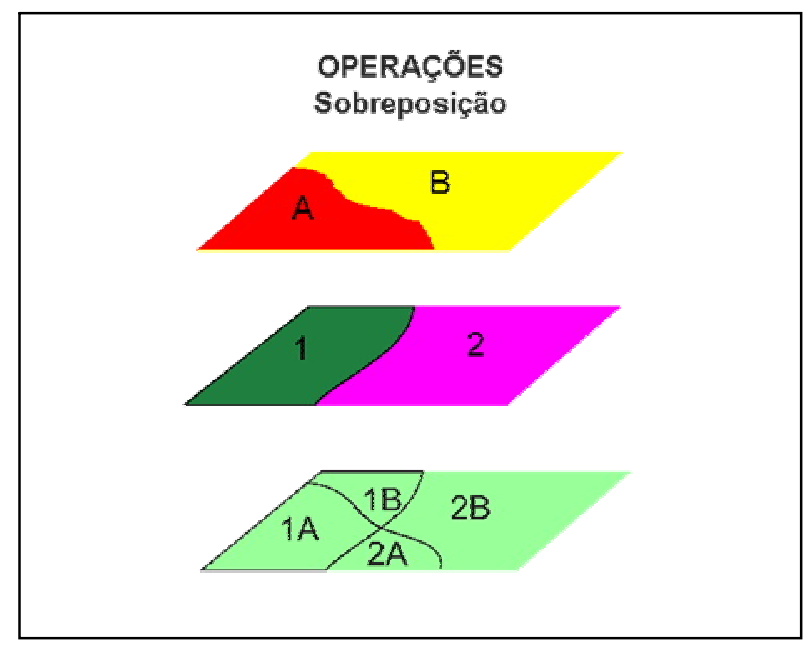

Figura 3.2 - Sobreposição de informações espaciais ou "Overlay" (FONTE: QUINTANILHA e FONSECA JR., 2002).

Com o advento do SIG, as aplicações voltadas para áreas urbanas adquiriram maior importância, ainda mais depois que a Constituição Federal de 1988 transferiu para os governos municipais novas responsabilidades e atribuições, como os Planos Diretores. O aumento da demanda em informações sobre serviços públicos tais como transporte, saneamento básico e saúde, por exemplo, exige respostas cada vez mais rápidas. Assim, o SIG surgiu como uma forma de facilitar o trabalho de análise geográfica automatizando o 
processamento de dados geográficos. Com esta tecnologia, os administradores urbanos, independentes de sua especialidade, têm a possibilidade de visualizar o seu ambiente de trabalho de forma única, integrando dados de diversas fontes à visualização da área desejada, VASCONCELOS BORGES (2004).

Com isso, as utilizações de técnicas de Sensoriamento Remoto (SR) aliadas ao recurso do SIG, constituem cada vez mais instrumentos fundamentais na análise dos fenômenos urbanos e conseqüentemente no fornecimento de subsídios relevantes para o planejamento físico territorial, de acordo com DA COSTA E CINTRA (1999).

Para que o planejamento e a administração dos recursos hídricos possam ser exercidos de forma racional e dinâmica, torna-se imperiosa a existência de informações organizadas e, sobretudo, de sistemas que articulem essas informações, de modo a processá-las para gerar subsídios às intervenções porventura necessárias e sua adequada operação, bem como a previsão e controle dos processos naturais ou induzidos pela ação do homem nas bacias hidrográficas, MENDES E CIRILLO (2001).

Existem diversas definições para sistemas de informações geográficas disponíveis que diferem pouco entre seus autores, principalmente em função da área do pesquisador e do propósito a que o mesmo se destina.

A atual geração de SIG configura uma tecnologia estabelecida para armazenar, organizar, recuperar e modificar informações sobre a distribuição espacial de recursos naturais, dados demográficos, redes de utilidade pública e muitos outros tipos de dados localizados na superfície da Terra. A modelagem de grande quantidade de processos físicos, em aplicações como morfologia, climatologia, dinâmica populacional, impacto ambiental e estudos urbanos, requer que os SIG tenham capacidade de representar os tipos de processos dinâmicos encontrados em estudos de sistemas físicos e sócio-econômicos, 
PEDROSA E CÂMARA (2003).

Atualmente o Sistema de Informações Geográficas têm sido empregado em diversos estudos de bacias hidrográficas, como uma importante ferramenta na integração e análise das informações. MARCELLINI (2002) apresenta uma boa revisão dos conceitos de SIG, conceitos básicos sobre cartografia e aplicações de SIG em estudos hidrológicos e de bacias hidrográficas.

Em termos de tipos de modelos SIG, SHAMSI (2002) descreve dois tipos: Os "programas de desenvolvimento SIG", em que o software é usado para criar o banco de dados geográfico e os "programas de aplicações em SIG", em que o software é usado para desenvolver aplicações customizadas, como um programa computacional de gerenciamento utilizando SIG e modelos hidrológicos e hidráulicos. Entre outros, sugere uma utilização do ArcView Versão 3.2, de ESRI (1995), em que os atributos do banco de dados geográficos podem ser criados e processados com a linguagem de programação em VBA Visual Basic for Applications). Atualmente o pacote de software da série ArcView (Versão 9), em ESRI (2007), necessita de uma série de licenças, como a licença para o uso do módulo $3 D$ Analyst (processamento em três dimensões), necessitando de um alto valor monetário a ser investido.

Porém, para diminuir os custos com dados geográficos, somado com o avanço da internet de alta velocidade e a existência de grande capacidade de armazenamento dos servidores que utilizam bancos de dados robustos, existem alguns sítios (websites) na internet que disponibilizam a visualização de dados em modo vetorial e raster para o público em geral. Não se tratam de sistemas em que o usuário seja o decisor, como o SSD, mas uma forma para consultar, visualizar e imprimir o conteúdo da base de dados georreferenciadas em sistemas referenciais mundiais, como o WGS84. Seguindo a 
abordagem de TEIXEIRA et. al. (1992), que consideram como informação geográfica o conjunto de dados cujo significado contém associações ou relações de natureza espacial, ANA (2007), IBGE (2007), CPRM (2008) e GOOGLE (2007) possuem sítios que podem ser considerados como sistemas de informação geográfica.

O sistema da ANA (2007) foi desenvolvido e atualizado pela Superintendência de Gestão da Informação do Sistema Nacional de Informações de Recursos Hídricos (SGI SNIRH) da Agência Nacional de Águas; possui em seu Monitoramento Hidrometeorológico informações como as localizações de estados, municípios, estações fluviométricas, pluviométricas e pluviográficas, hidrografia e base IBGE ao milionésimo. Também possui uma ferramenta de auxílio à visualização e quantificação de áreas de drenagem na parte à montante de qualquer ponto indicado no mapa. Todos os dados fornecidos estão em coordenadas geográficas em SAD69.

O Instituto de Brasileiro de Geografia e Estatística, IBGE (2007), deve disponibilizar um sistema que traz informações alfanuméricas, gráficos e imagens captadas por satélites. Sua base é estatística de vários órgãos governamentais, além das levantadas pelo próprio IBGE, que faz o cruzamento, a uniformização e a atualização dos dados, permitindo, por exemplo, que se saibam quantos e quais os tipos de unidades de saúde existentes em áreas onde foram detectadas as maiores incidências de doenças.

Para o campo da geologia, o CPRM (2007) disponibiliza em seu sítio um completo SIG que permite visualizar espacialmente dados vetoriais, imagens e tabelas. Muito semelhante à maioria dos softwares convencionais de computadores de mesa ("desktops"), o sistema oferece uma boa navegação e riqueza de informações, como Unidade, ÉON Máximo (divisão principal máxima da escala de tempo geológico), ERA Máxima (divisão máxima de um ÉON na escala de tempo geológico), Período Máximo, entre outros. 
Mais conhecido do público geral, GOOGLE (2007), possui um grande banco de dados de imagens que pode ser visualizado no seu software "Google Earth", permitindo visualizar com boa resolução, com imagens de satélite LANDSAT e fotos aéreas, qualquer lugar do mundo. Nas grandes cidades e outros locais de interesse, as imagens são obtidas por mosaicos aerofotogramétricos. HELLMEIER (2007) descreve a metodologia aplicada no Google Earth de coleta de dados espaciais, com varredura a laser ("laser scanning") utilizado no modelo em três dimensões. O sistema permite integrar as imagens com dados vetoriais como cidades, ruas, estradas, pontos turísticos, etc.

\subsection{Modelos Chuva-Vazão}

A hidrologia estuda a quantificação e movimentação da água na natureza, nos vários compartimentos terrestres e atmosféricos e o conhecimento dos mecanismos e processos intervenientes, ou seja, trata dos fenômenos naturais complexos encontrados no ciclo hidrológico. Os modelos hidrológicos, também chamados de modelos chuva-vazão, procuram simular parte do ciclo através da precipitação conhecida na bacia hidrográfica, simulando a vazão, na maioria das vezes, pelo escoamento superficial, UEHARA (2002).

TUCCI (2004) define o escoamento superficial como a parcela do ciclo hidrológico em que a água se desloca na superfície da bacia até encontrar uma calha definida. Nas bacias urbanas, o escoamento é regido pela interferência do homem através de superfícies impermeáveis e sistemas de esgotos pluviais. A representação do escoamento superficial em seus menores detalhes é difícil, devido à grande variabilidade das condições físicas das bacias. O escoamento é idealizado com profundidade pequena e grande largura. $\mathrm{Na}$ realidade existe uma combinação de planos contribuindo para pequenos canais direcionados por declividades predominantes. 
Evidentemente, quanto melhor a qualidade dos dados espaciais, como a topografia, comprimento do maior talvegue e as áreas de drenagem da bacia, melhor será a qualidade dos resultados da modelação hidrológica. ONO (2006) utilizou o software ArcView, ESRI (2007) para auxiliá-lo na determinação das áreas de influência de cada posto pluviométrico sobre as isócronas do Modelo Estocástico Linear utilizado (MEL-AT), que é um modelo hidrológico que torna possível a previsão de vazões com dados horários de chuva e vazão do posto à jusante. A grande limitação deste modelo está em obter os dados de precipitação que sejam confiáveis a ponto de poder calibrá-lo satisfatoriamente.

A calibração do modelo é um meio de justificar a confiabilidade do equacionamento matemático. São utilizadas séries históricas para comprovar que os parâmetros utilizados no modelo estão corretos. Assim, a credibilidade do modelo depende da confiabilidade dos dados observados num ou mais eventos de cheia de um rio.

Quanto à classificação, os modelos hidrológicos de transformação da chuva em vazão podem ser divididos em determinísticos e probabilísticos, de acordo com CANHOLI (2005). As mais utilizadas são os modelos determinísticos, onde as equações de transformação não possuem componentes aleatórios; assim, para uma mesma condição inicial e uma seqüência de precipitações ter-se-á a mesma seqüência de vazões.

De acordo com MAGALHÃES (2005), os modelos determinísticos não apresentam componentes aleatórias nem estatísticas. Desta forma, por executarem sempre as mesmas rotinas de cálculo, para um determinado conjunto de dados de entrada, estes modelos fornecem sempre as mesmas respostas. Por procurarem representar matematicamente os fenômenos físicos, também podem ser classificados como modelos hidrológicos físicos ou conceituais.

Uma metodologia utilizada nos modelos determinísticos é o método de cálculo do 
escoamento superficial direto do Soil Conservation Service (SCS) do Departamento de Agricultura dos Estados Unidos, associado com o método do Hidrograma Unitário Adimensional do SCS para transformação dos incrementos de escoamento superficial direto em vazões afluentes num determinado ponto da bacia. Os dois métodos são utilizados pelo software CABC, FCTH (2002). O modelo ainda oferece como opções para o cálculo da infiltração os métodos de Horton, Green-Ampt, Índice Fi $(\phi)$ e Soil Conservation Service. Para o cálculo dos hidrogramas, emprega os modelos Santa Bárbara, Clark e Hidrograma Triangular do SCS.

Seguindo a linha dos modelos chuva-vazão, existem os modelos contínuos, como o SMAP, de LOPES (1981). O desenvolvimento do modelo baseou-se na experiência com a aplicação do modelo Stanford Watershed IV em trabalhos realizados no DAEEDepartamento de Águas e Energia Elétrica do Estado de São Paulo.

O modelo Stanford Watershed IV realiza duas análises para a determinação de vazões. A primeira, Land, efetua a simulação das condições da bacia. A segunda, channel, utiliza o método de Muskingum para a modelação hidráulica das vazões. Conceitualmente o modelo subdivide o solo em duas zonas de armazenamento principais, a superior e a inferior. Funções de transferência físico-empíricas correlacionam os dois reservatórios teóricos. Há também expressões que representam as perdas de água por evapotranspiração e por escoamento subterrâneo, citado por BRAGA (1979). 


\subsection{Modelos Hidráulicos}

Dentro da engenharia hidráulica, a modelação matemática já comprovou ser indispensável nos campos específicos da hidráulica fluvial e drenagem urbana, principalmente quando o estudo das situações transitórias do escoamento é necessário. Neste particular, o emprego dos modelos matemáticos associados a suportes matemáticos que facilitam a entrada e manipulação de extensas quantidades de dados além da fácil obtenção de resultados, tem sido utilizado em todo o mundo com o objetivo de verificação e projeto de obras hidráulicas, FCTH (2007).

A modelação hidráulica é utilizada para se definir os perfis de linha d' água e as superfícies de inundação ao longo do sistema de macrodrenagem da bacia, BARROS (2004).

Os casos mais comuns considerados nesse tipo de modelagem são os de escoamento não permanente, que tem como característica a variação ao longo do tempo das condições de extremidade, que usualmente são hidrogramas de enchentes, limnigramas, equipamentos hidráulicos associados a esquemas operacionais e estações de bombeamento. Os produtos principais da modelagem hidrodinâmica em canais são os níveis de água para enchentes em função de diferentes condições operacionais da calha e dos efeitos introduzidos nas extremidades, tais como reservatórios, marés e estações elevatórias, BARROS (2005).

No modelo CLIV de FCTH (2002), o escoamento em canais é definido como um problema unidimensional, no qual todas as características são associadas à dimensão de comprimento do conduto. Os aspectos relativos às particularidades das seções transversais são considerados na forma dos parâmetros hidráulicos e geométricos das mesmas, como área e forma da seção transversal, rugosidade das paredes, declividade do trecho e distância 
entre as seções representativas, BARROS (2004).

De acordo com FCTH (2002), em termos de técnica de simulação, o modelo CLIV conta com os tradicionais métodos do momento para regime permanente e o de Preissmann e MacCormack para regime transitório não permanente.

Diversos projetos de engenharia utilizaram a modelagem hidráulica do CLIV, entre eles, ENGECORPS/HARZA (2000) utilizou-o no "Modelo Hidrodinâmico e Esquema Operacional", parte integrante do Projeto Básico do Eixo Norte, referente ao Projeto de Transposição de Águas do Rio São Francisco para o Nordeste Setentrional. DAEE (1999) elaborou o Plano Diretor de Macrodrenagem da Bacia Hidrográfica do Alto Tietê utilizando o CLIV em duas simulações: uma em regime gradualmente variado, considerando apenas as variações de vazão observadas em 1983 e outra em regime transitório, considerando os hidrogramas do Tietê na Penha e dos afluentes à calha, gerados pelo modelo CABC para o evento de 1983, desde a barragem da Penha até a região a montante da barragem móvel, localizada nas imediações da foz do rio Pinheiros.

Muito utilizado por ser um software de domínio público, o HEC-RAS, HEC (2006), é um sistema integrado de softwares, desenvolvido para o uso interativo em um ambiente de várias tarefas e vários usuários. O sistema é compreendido de uma interface gráfica para usuários, componentes de análise de separação hidráulica, dados de armazenamento e capacidade de gerenciamentos de gráficos e relatórios. O programa foi desenvolvido para cálculos hidráulicos unidimensionais para uma rede de canais naturais ou artificiais. ENOMOTO (2004) utilizou o modelo para simular inundações na bacia do rio Palmital, localizada na Região Metropolitana de Curitiba, nos municípios de Colombo e Pinhais.

CALÇADA (2004) aplicou o modelo hidráulico HEC-RAS para análise de cheias e delimitação de zonas inundáveis em Timor Leste, onde pressupôs duas fases: uma primeira 
fase em que os parâmetros hidrológicos são extraídos do Modelo Digital do Terreno (MDT) e conjuntamente com os dados hidrológicos, uma segunda fase é processada em que as informações referentes à geometria da rede de drenagem são extraídos a partir de uma Rede Irregular de Triângulos (RIT) e, em conjunto com os hidrogramas de cheia resultantes do processamento do programa HEC-HMS, HEC (2005), são importados para o programa HEC-RAS. Depois de executado este último modelo, os resultados são processados e analisados no SIG. 


\section{Base Conceitual de Formulação do SSD}

Este capítulo trata da base conceitual de formulação do SSD desenvolvido nesta dissertação. O SSD ao longo do texto é chamado de URBSSD. Inicialmente apresenta-se a formulação do modelo hidrológico, e na seqüência, o modelo hidráulico e o tratamento dos dados operacionais.

\subsection{O Modelo URBSSD}

A metodologia do SSD consiste em elaborar um Sistema de Suporte a Decisão que englobe a utilização de um modelo hidrológico e de um modelo hidráulico em diversas situações de chuvas intensas e usos do solo. Os dados geográficos essenciais para a análise do escoamento da chuva excedente como a área da bacia, comprimento do talvegue (ou canal) e o grau de impermeabilização do solo foram importados por um Sistema de Informações Geográficas (SIG), numa interface apropriada para a programação de software em Visual Basic, o MapWindow, em COAPS (2007). Esta interface permite a importação dos arquivos shapefiles (extensão "SHP”) e raster (extensão “TIF”).

O modelo do SSD segue uma sequiência passo a passo para a obtenção das séries hidrológicas. Primeiro são definidos os hietogramas, em seguida os hidrogramas e posteriormente os limnigramas. Não há a possibilidade de mudar esta ordem, como obter os hidrogramas ou limnigramas sem antes definir a precipitação. Assim como não é possível obter os limnigramas sem a simulação do modelo hidrológico.

A Figura 4.1 mostra a metodologia do URBSSD com os passos de simulação e onde

pode re-introduzir os novos valores, nas Tormentas de Projeto, Uso e Ocupação do Solo e 
Vazões de Projeto.

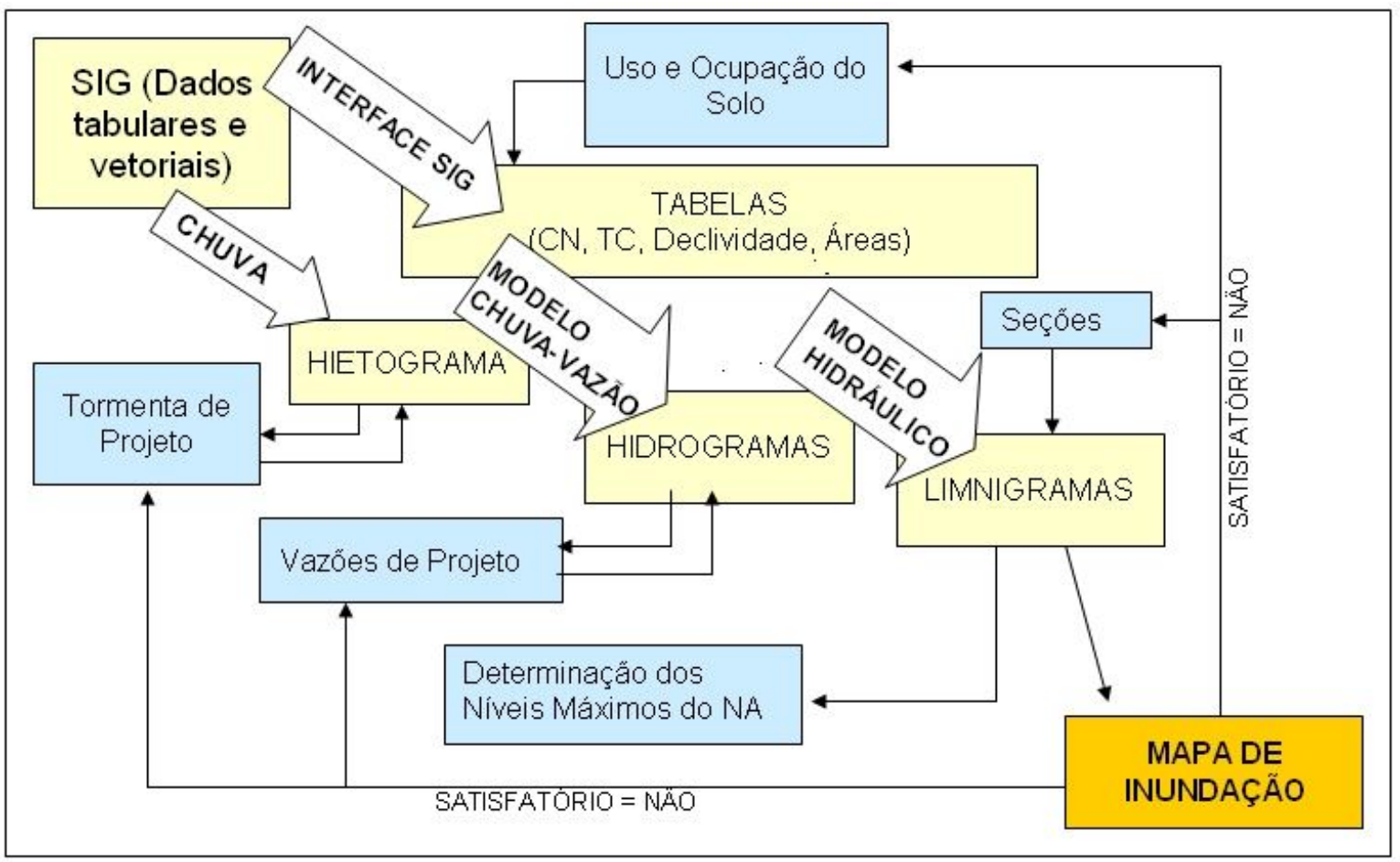

Figura 4.1 - Metodologia do URBSSD

A compilação do SSD final não inclui a calibração dos modelos. Para o usuário final, não é disponibilizada na interface, é apenas disponível para o desenvolvedor ou usuário avançado, por ter que entender algumas particularidades do modelo hidráulico e do modelo de chuva-vazão, a serem descritas posteriormente.

O software final do SSD foi desenvolvido na linguagem de programação Visual Basic MSDN (2007). Um exemplo de simulação é mostrado da Figura 4.2 até a Figura 4.23 .

Ao iniciar o Modelo URBSSD, é apresentada uma tela de boas-vindas com a identificação dos autores e a propriedade do software da Escola Politécnica da USP. A Figura 4.2 mostra em vermelho a recomendação das "Opções Regionais" do sistema operacional. Outra recomendação é adotar a resolução de vídeo como 1024 x 768 pixels. 
A Figura 4.3 mostra a tela inicial da interface do SSD, que visa a importação dos arquivos SIG em shapefiles (arquivo a ser detalhado no Capítulo 4.2). Estes arquivos automaticamente importam os valores de Curve Number $(\mathrm{CN})$ e Tempo de Concentração (Tc). A Figura 4.4 mostra a forma que a interface importa as classes do shapefile.

ESCOLA POLITÉCNICA DA UNIVERSIDADE DE SÃo PAULO

Sistema de Suporte a Decisão Para Gestão de Água Urbana URBSSD

Responsáveis:

Sidnei Ono

Mario Thadeu Leme de Barros [Orientador]

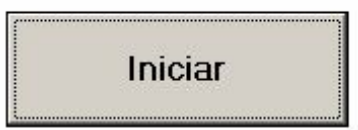

Versão 1.1

ATENÇב̃O: Verifique as Opçōes Regionais e de Idioma do seu microcomputador. Configure para o idioma em Português [vírgula como símbolo decimal) e utilize a resolução da tela como 1024 x 768 pixels

Figura 4.2 - Abrindo um novo modelo de simulação.

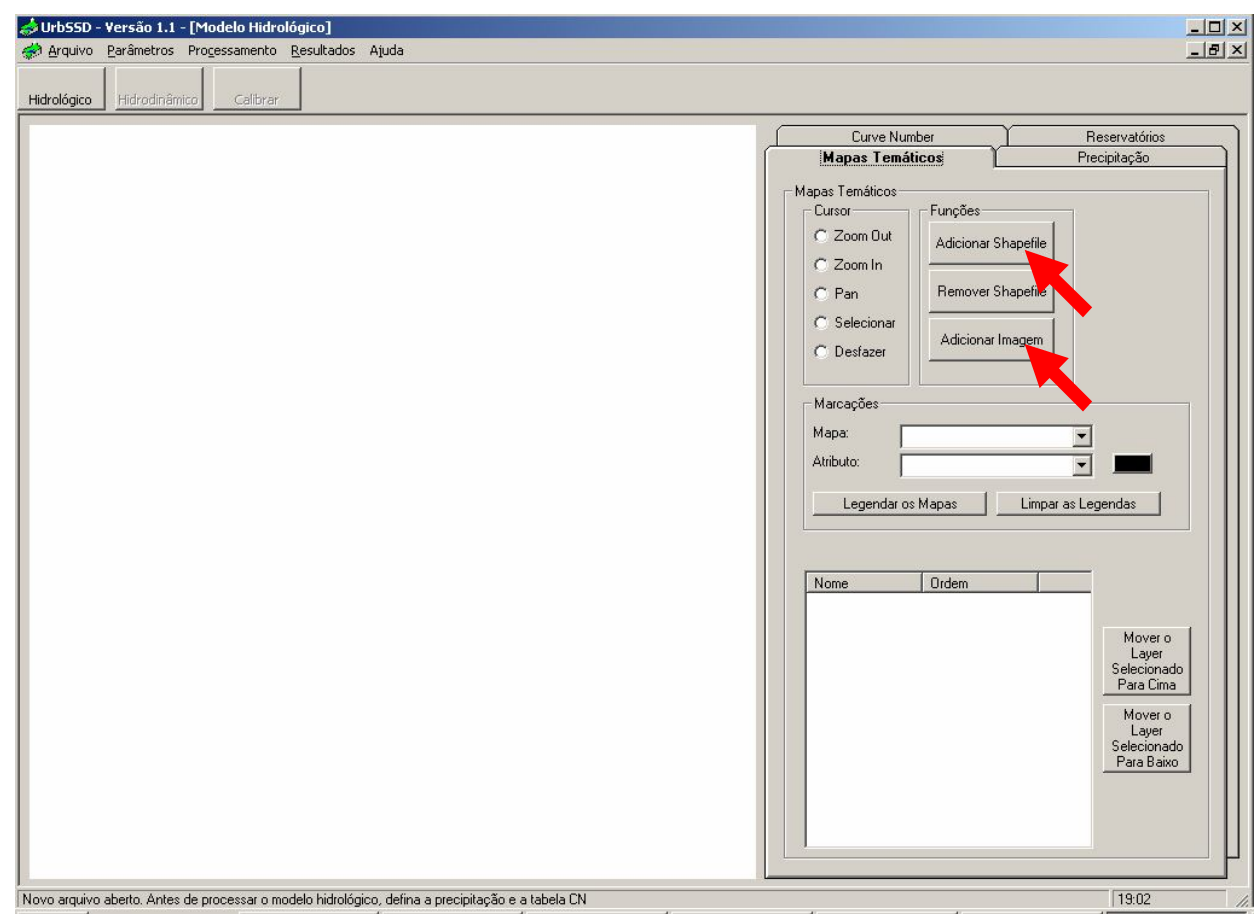

Figura 4.3 - Tela inicial do modelo para a seleção dos arquivos Shapefile e Raster. 


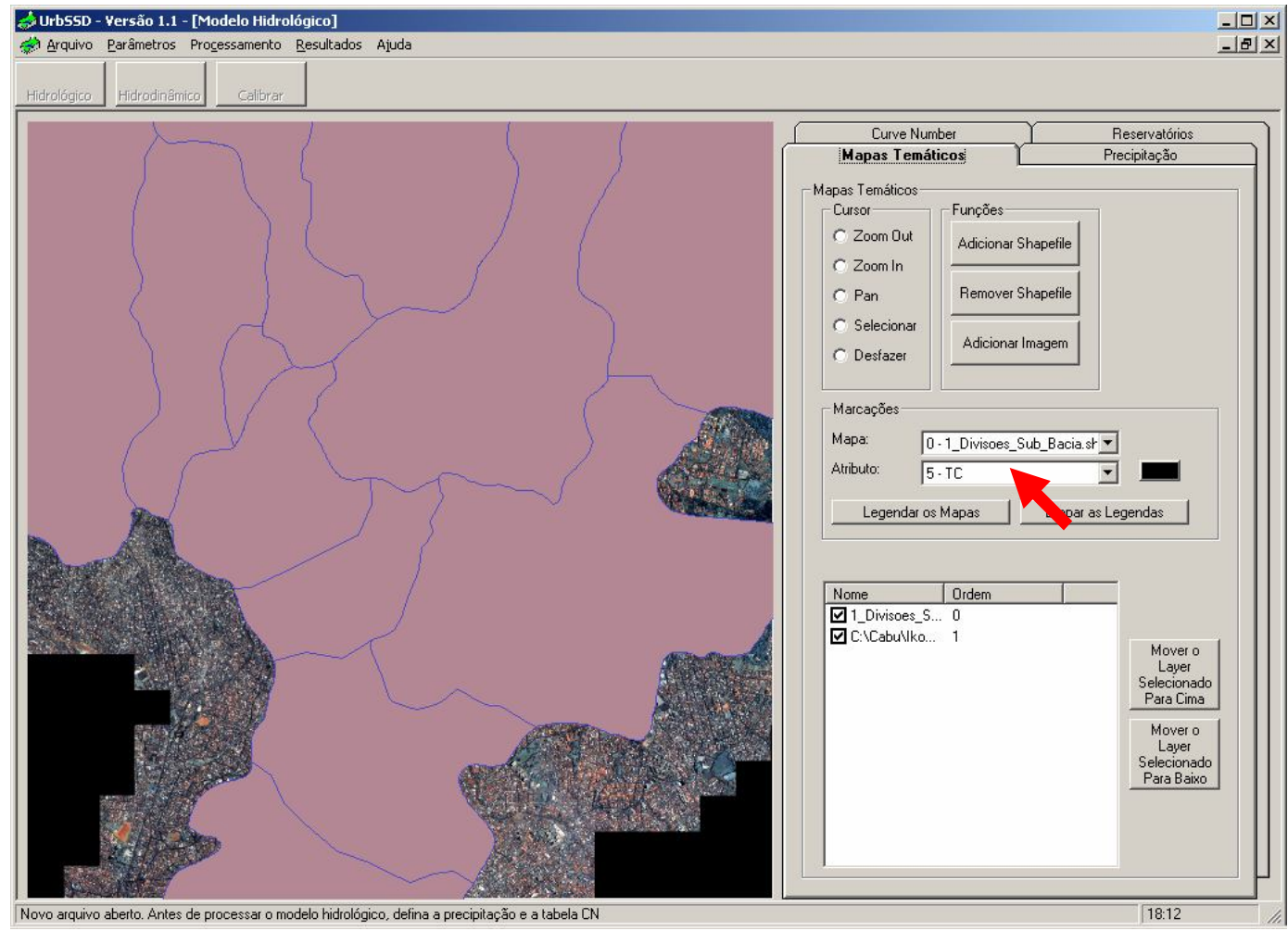

Figura 4.4 - Indicação que os dados geográficos de TC e CN foram importados na interface.

Em seguida, deve ser determinada a chuva que precipitará sobre a bacia (Figuras 4.5 e 4.6). Para definir o hietograma, deve ser escolhida uma das três alternativas a seguir:

- Alternativa um: Como na Figura 4.7, o hietograma é obtido pela equação de chuva intensa, o usuário deve fornecer o período de retorno em anos e o tempo da chuva em horas.

- Alternativa dois: O hietograma é elaborado por eventos já realizados, medidos pelo monitoramento hidrológico entre os anos de 2001 a 2003, como na Figura 4.8.

- Alternativa três: O hietograma é definido pelo usuário, digitando as alturas de precipitação a cada quinze minutos (Figura 4.9).

Estas alternativas são detalhadas no capítulo 4.1 seguinte, Módulo Hidrológico. 


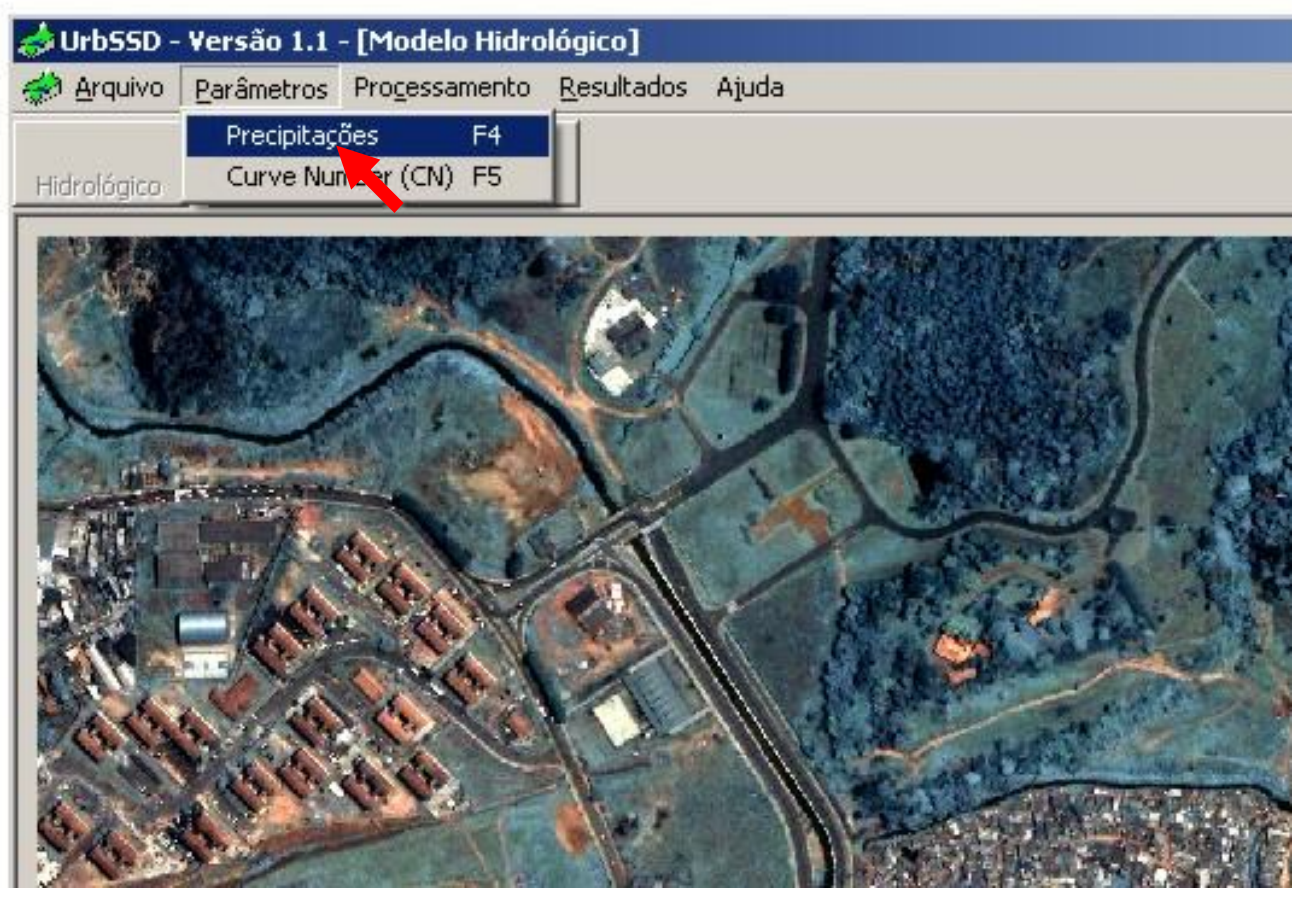

Figura 4.5 - Comando para definir as precipitações.

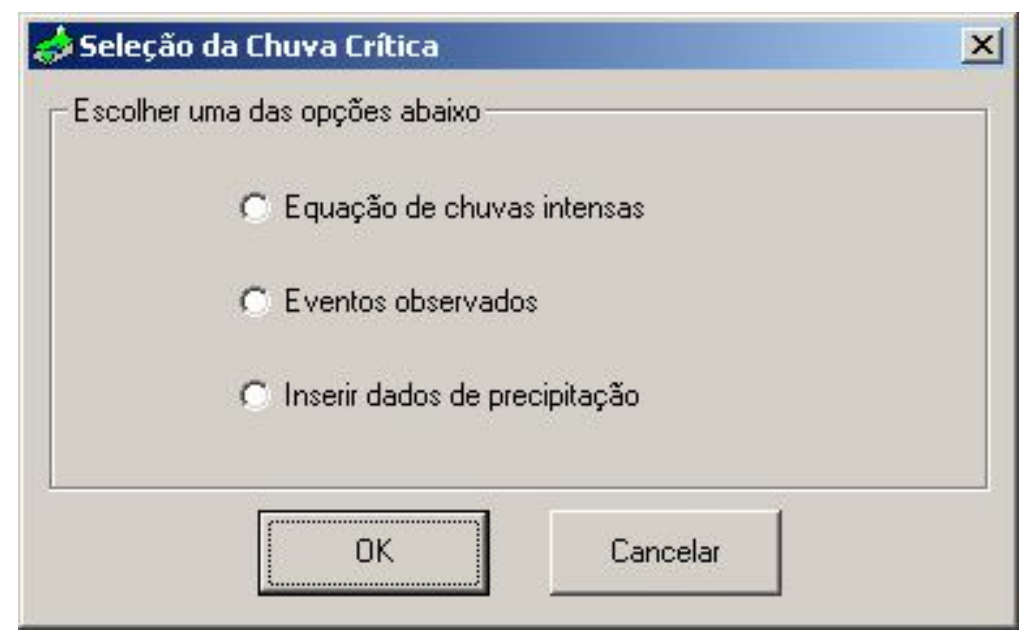

Figura 4.6 - Tela de escolha de um modo de definição de precipitação. 


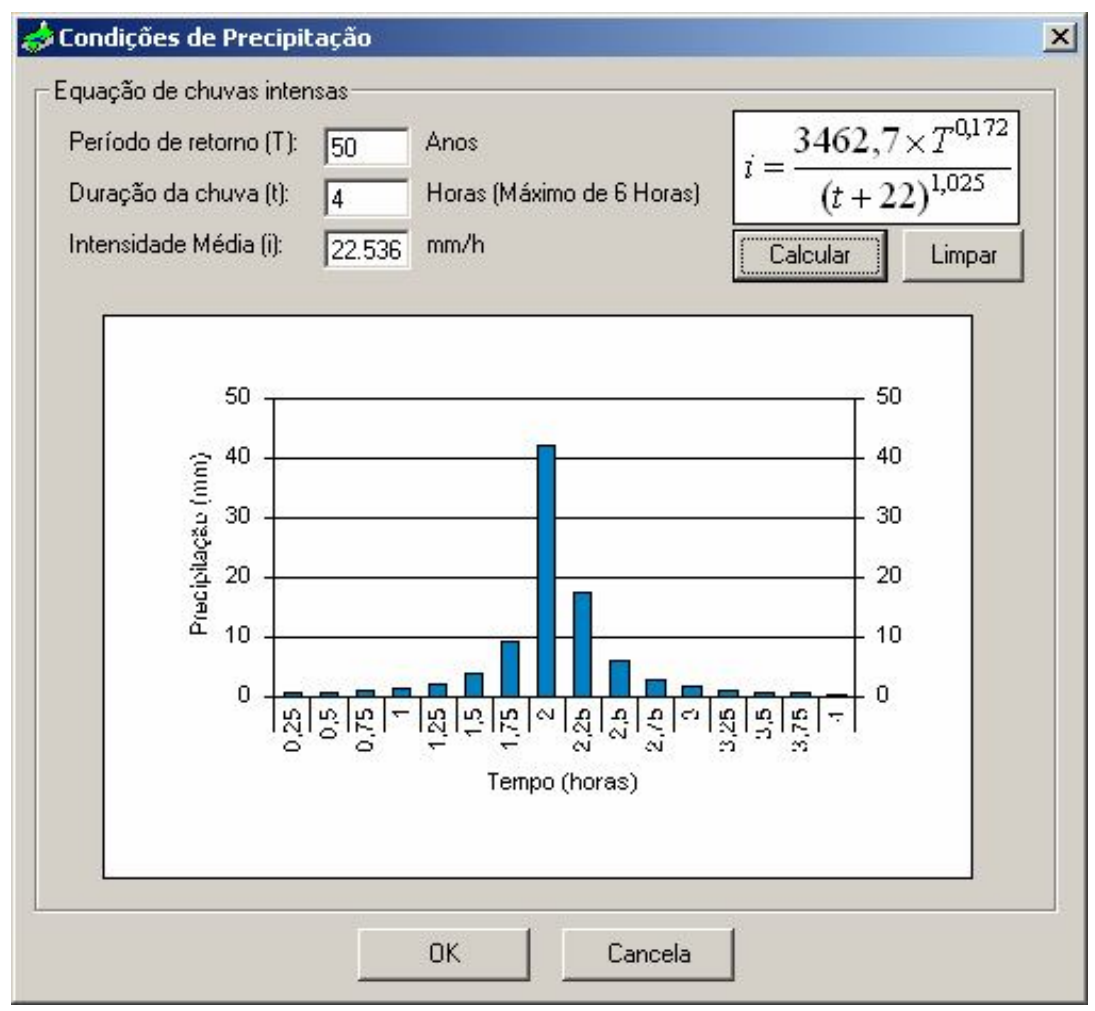

Figura 4.7 - Opção 1 - Análise de gráfico para cada evento (hietograma para uma chuva de TR=50 anos em São Paulo).

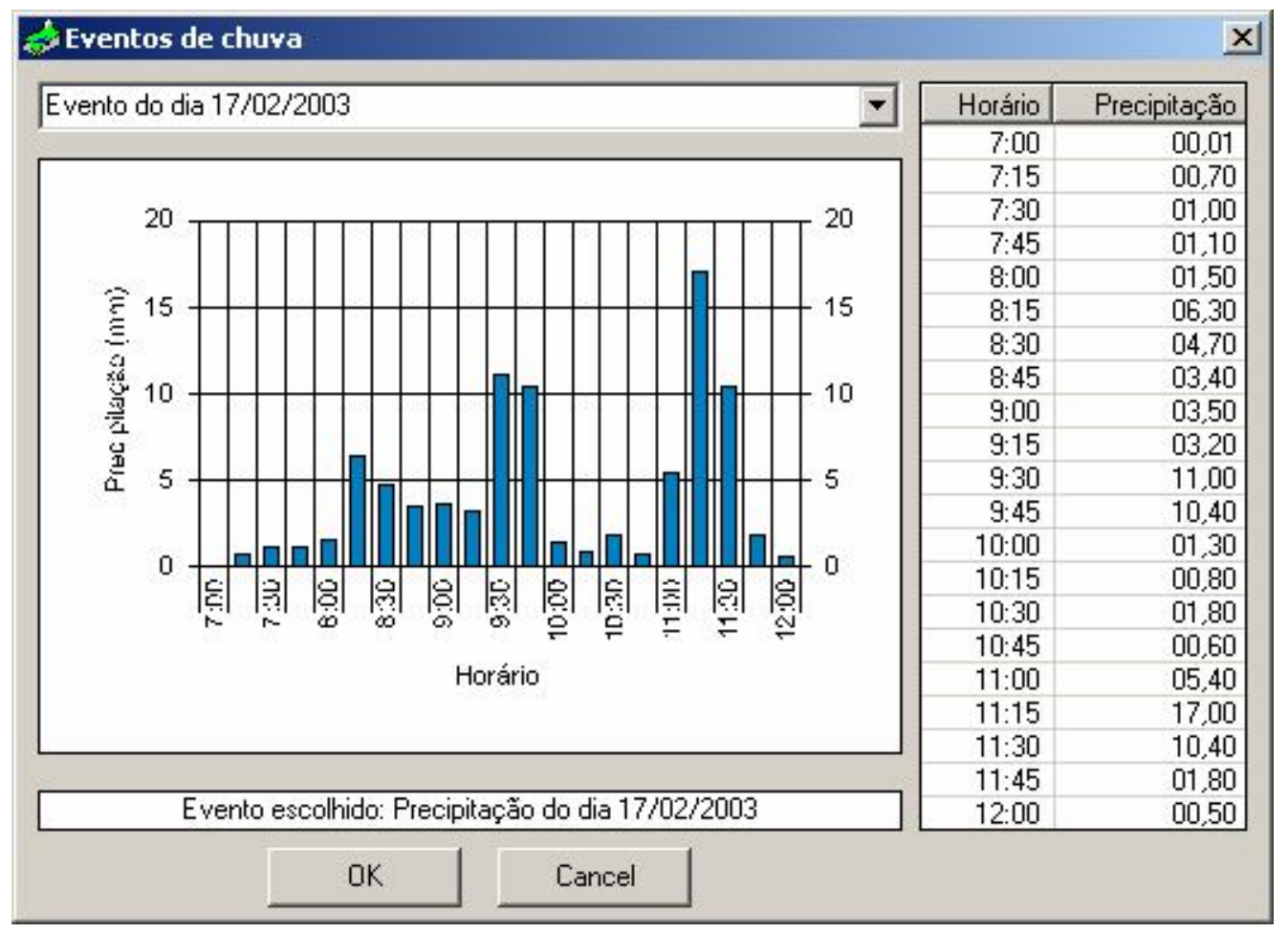

Figura 4.8 - Opção 2 - Escolher a data do evento chuvoso (evento do dia 17/02/2003). 


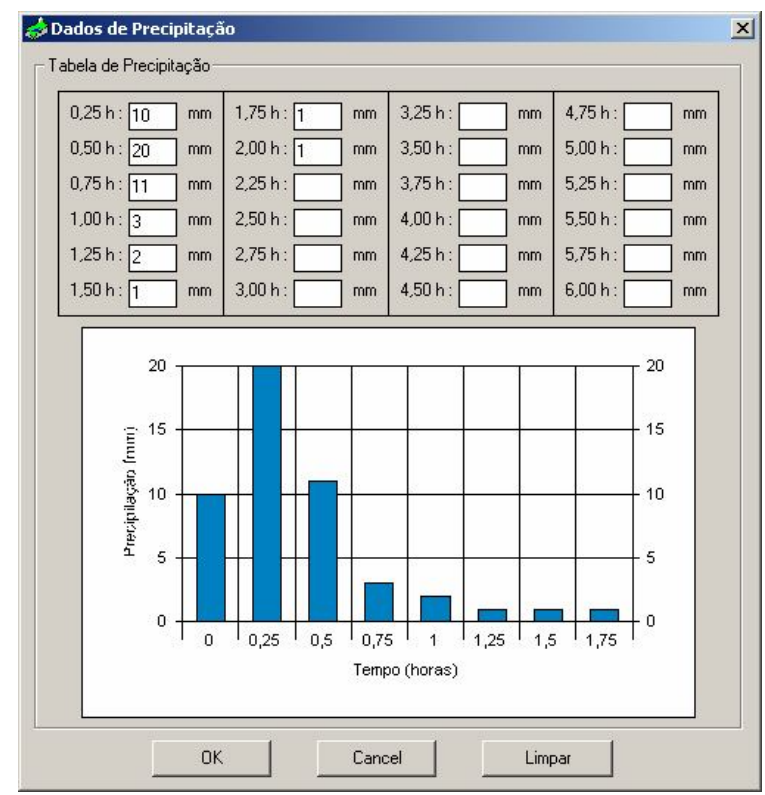

Figura 4.9 - Opção 3 - Inserir os blocos de precipitação.

O usuário poderá visualizar os blocos de precipitação uniforme sobre toda a bacia a cada quinze minutos, como mostra a Figura 4.10.

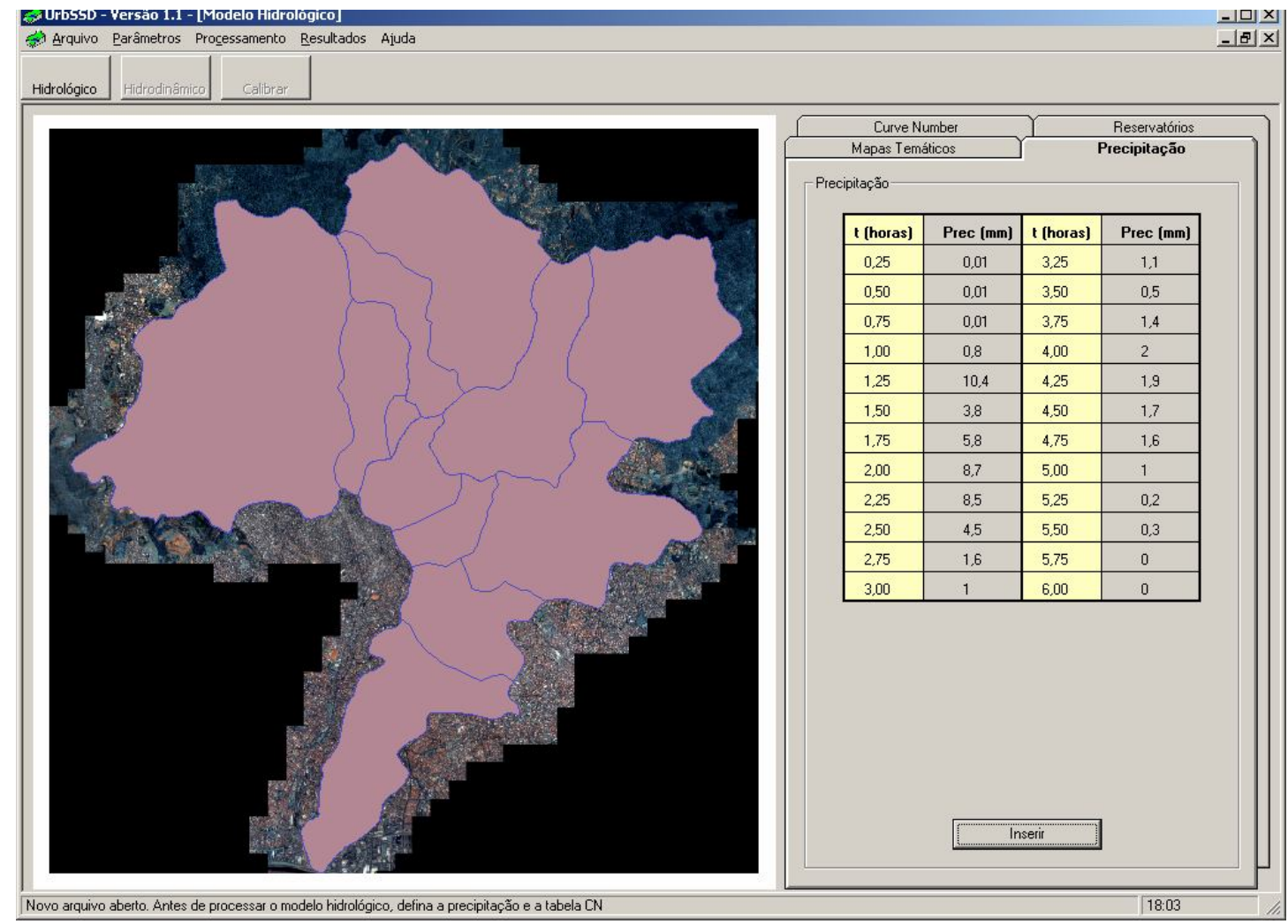

Figura 4.10 - Visualização das alturas de chuva na interface. 
Antes de iniciar o módulo hidrológico, o usuário deve verificar o parâmetro $\mathrm{CN}$ (Curve Number) no URBSSD, apesar destes valores já estarem definidos na importação do shapefile. Para não modificar os dados geográficos importados, a Figura 4.11 mostra a forma que o usuário pode modificar os valores $\mathrm{CN}$ diretamente no modelo.

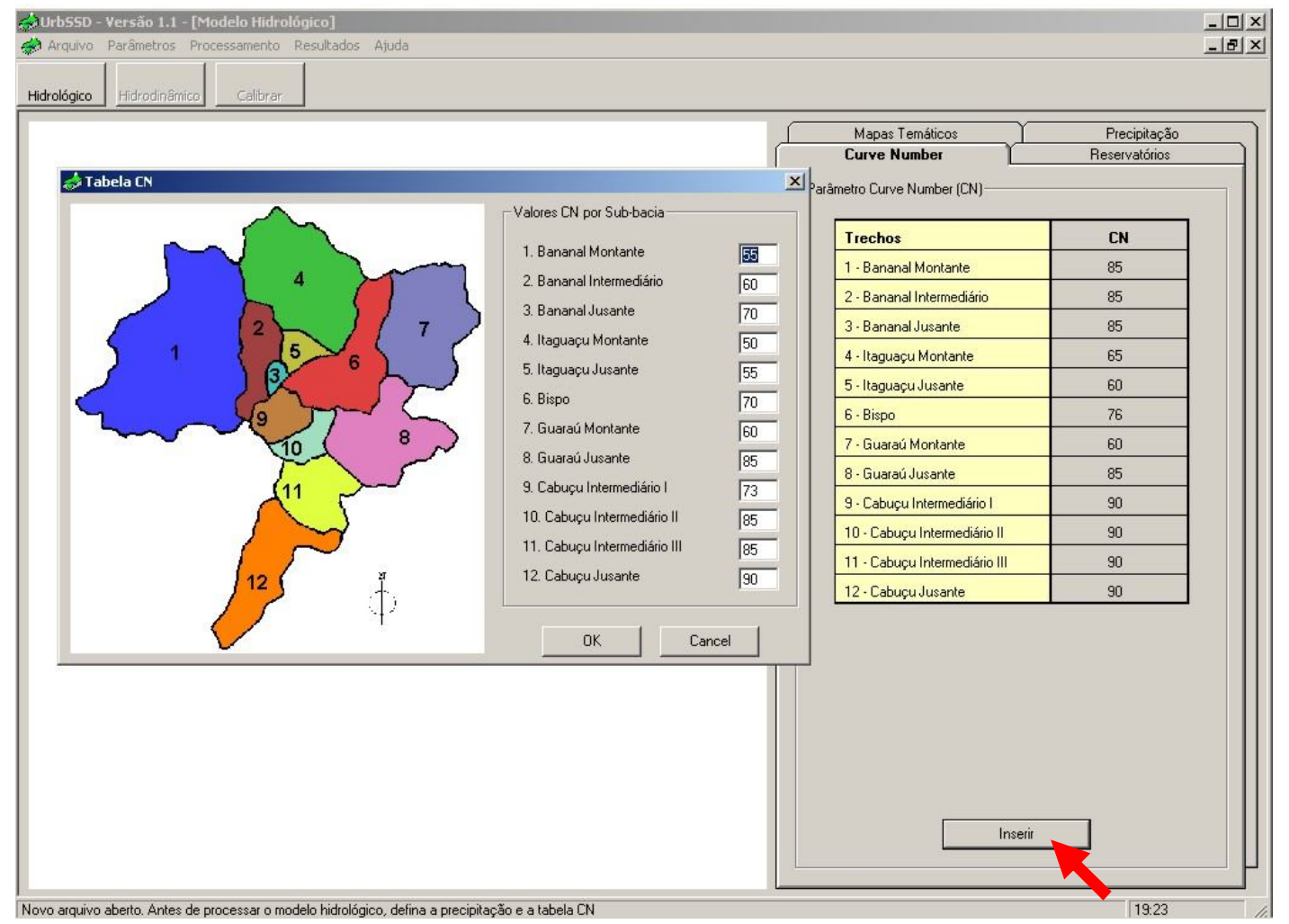

Figura 4.11 - A interface permite a mudança do parâmetro CN obtido pela importação de shapefile.

Após definir o parâmetro $\mathrm{CN}$ e Precipitação, é permitido ao usuário simular o modelo de chuva-vazão (Figura 4.12).

As figuras seguintes mostram a tela de visualização dos hidrogramas resultantes, com os hidrogramas de contribuição de cada sub-bacia e hidrogramas de jusante de cada sub-bacia (Figura 4.13) e onde o usuário pode visualizar os gráficos em forma de barras e valores das precipitações excedentes, acumulados e o volume precipitado sobre a área de drenagem (Figura 4.14). 


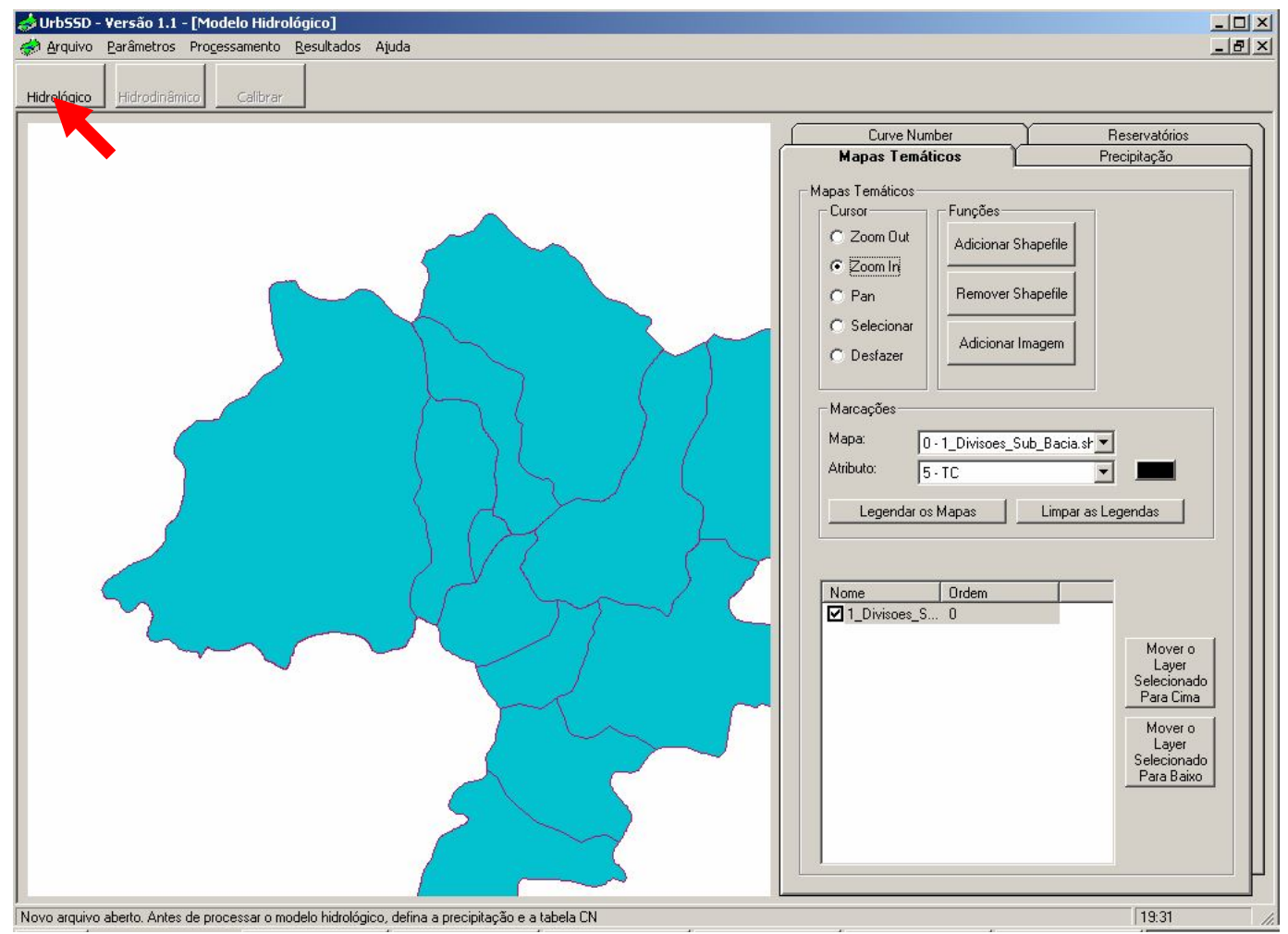

Figura 4.12 - Seleção do processamento do modelo de chuva-vazão.

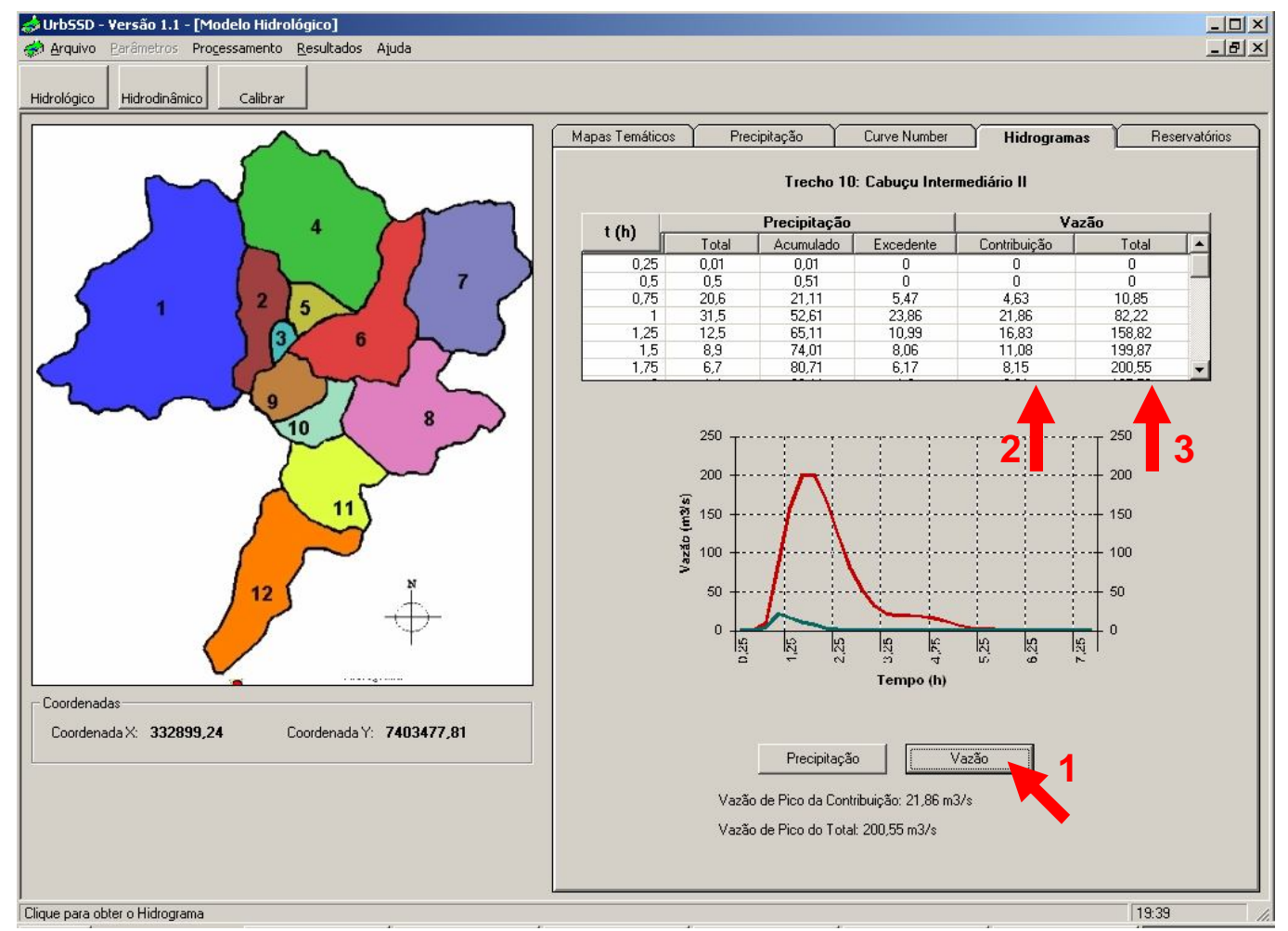

Figura 4.13 - Visualização dos hidrogramas em qualquer sub-bacia (1). Vazões de contribuição da sub-bacia (2) e vazão total ou acumulada (3). 


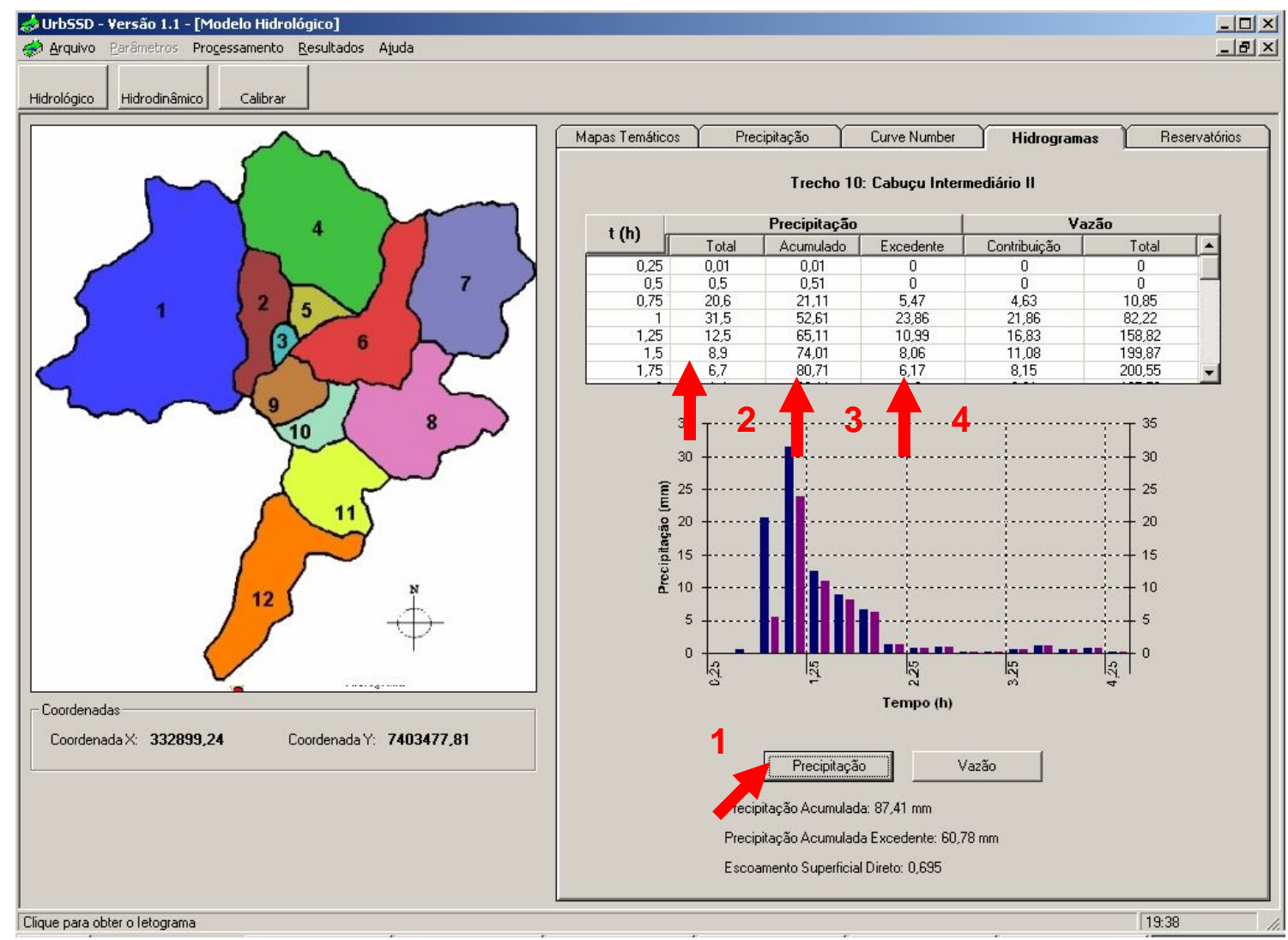

Figura 4.14 - Visualização da Precipitação (1), é obtida os hietogramas para cada sub-bacia. Precipitação total horária (2), acumulada (3) e a excedente (4).

Após a execução do módulo hidrológico, o usuário pode executar o módulo hidráulico, também chamado de hidrodinâmico. Nas figuras 4.15 e 4.16 mostram respectivamente o comando para executar o módulo hidráulico e a caixa de aviso do processamento hidrodinâmico, em que fica estático por aproximadamente um minuto porque o cálculo para a convergência das ondas de cheia é com muitas iterações.

A Figura 4.17 mostra a interface inicial do módulo hidráulico, onde a envoltória de drenagem sobre o mapa SIG corresponde à envoltória das mínimas cotas calculadas. 


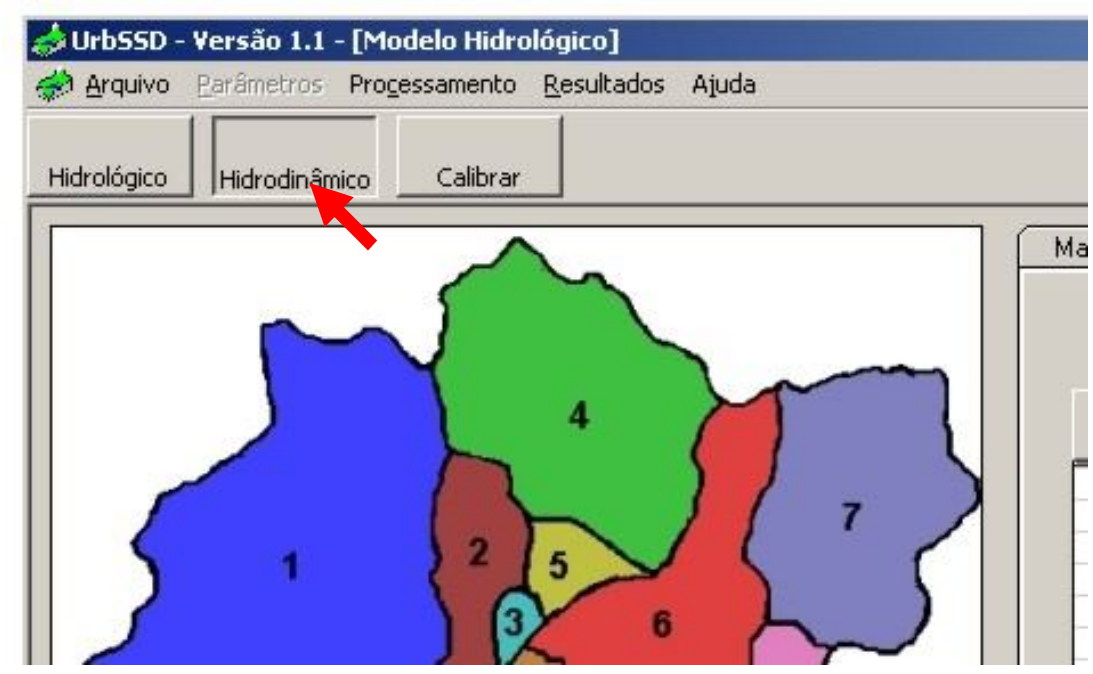

Figura 4.15 - Seleção do processamento do módulo hidrodinâmico.

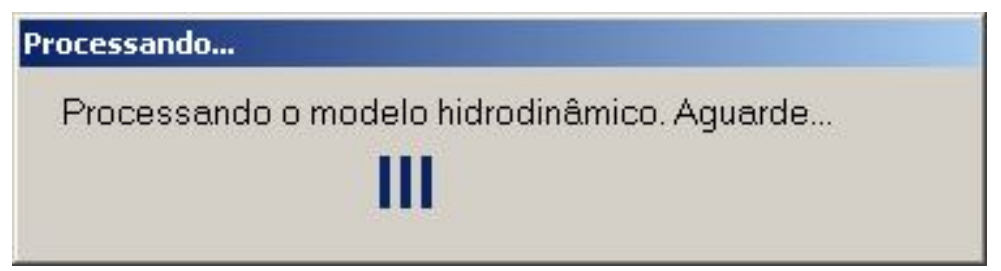

Figura 4.16 - Tela de aviso do processamento hidrodinâmico.

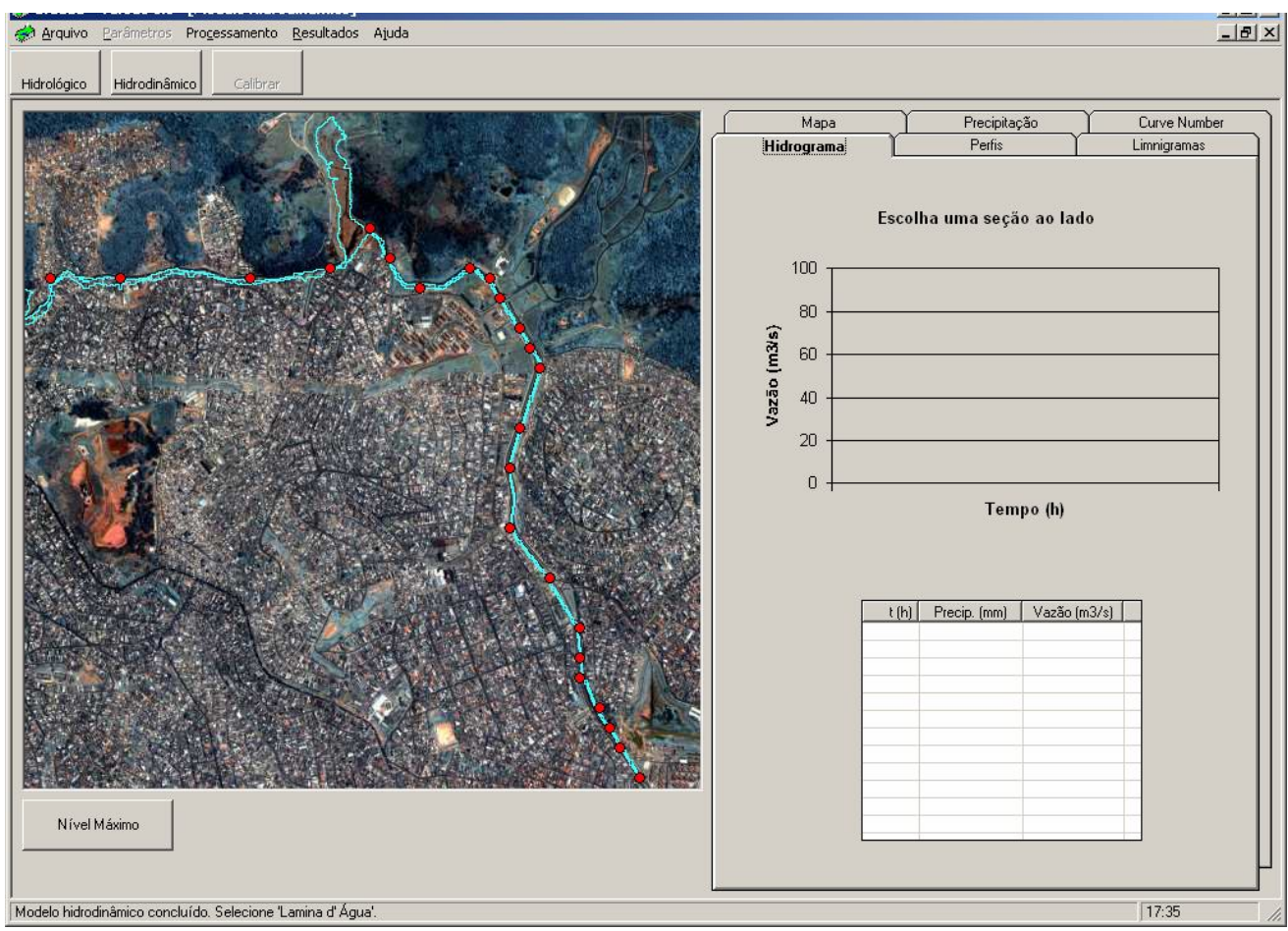

Figura 4.17 - Tela inicial do pós-processamento hidráulico. 
Antes de verificar os resultados em determinada seção, o usuário pode visualizar as cotas da seção longitudinal clicando na aba "Perfis" e no campo "Lâmina d'água". Para ver os picos de vazões na seção longitudinal, o usuário deve clicar no campo correspondente, como mostra a Figura 4.18.

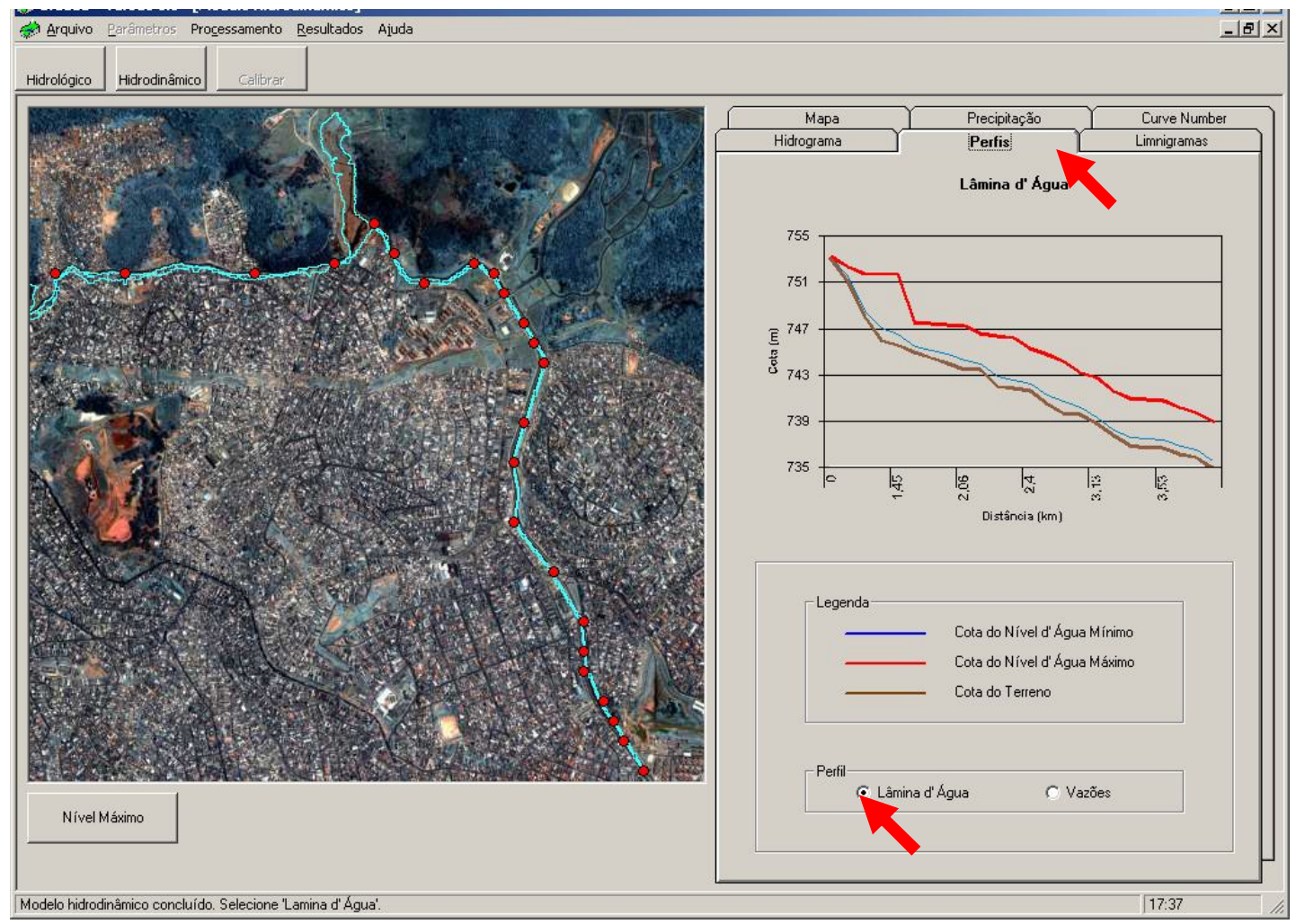

Figura 4.18 - Tela de visualização das cotas da seção longitudinal.

Para visualizar as vazões no mesmo perfil longitudinal, deve clicar na aba "Perfis" e no campo "Vazões" como mostra a Figura 4.19.

Os limnigramas em cada seção podem ser visualizados ao clicar num dos pontos vermelhos no mapa e posteriormente na aba "Limnigramas" como na Figura 4.20. Para poder visualizar os hidrogramas em cada seção, deve ser selecionada a aba "Hidrogramas" como na Figura 4.21.

A Figura 4.22 mostra como visualizar as cotas máximas, ou a mancha de inundação. 


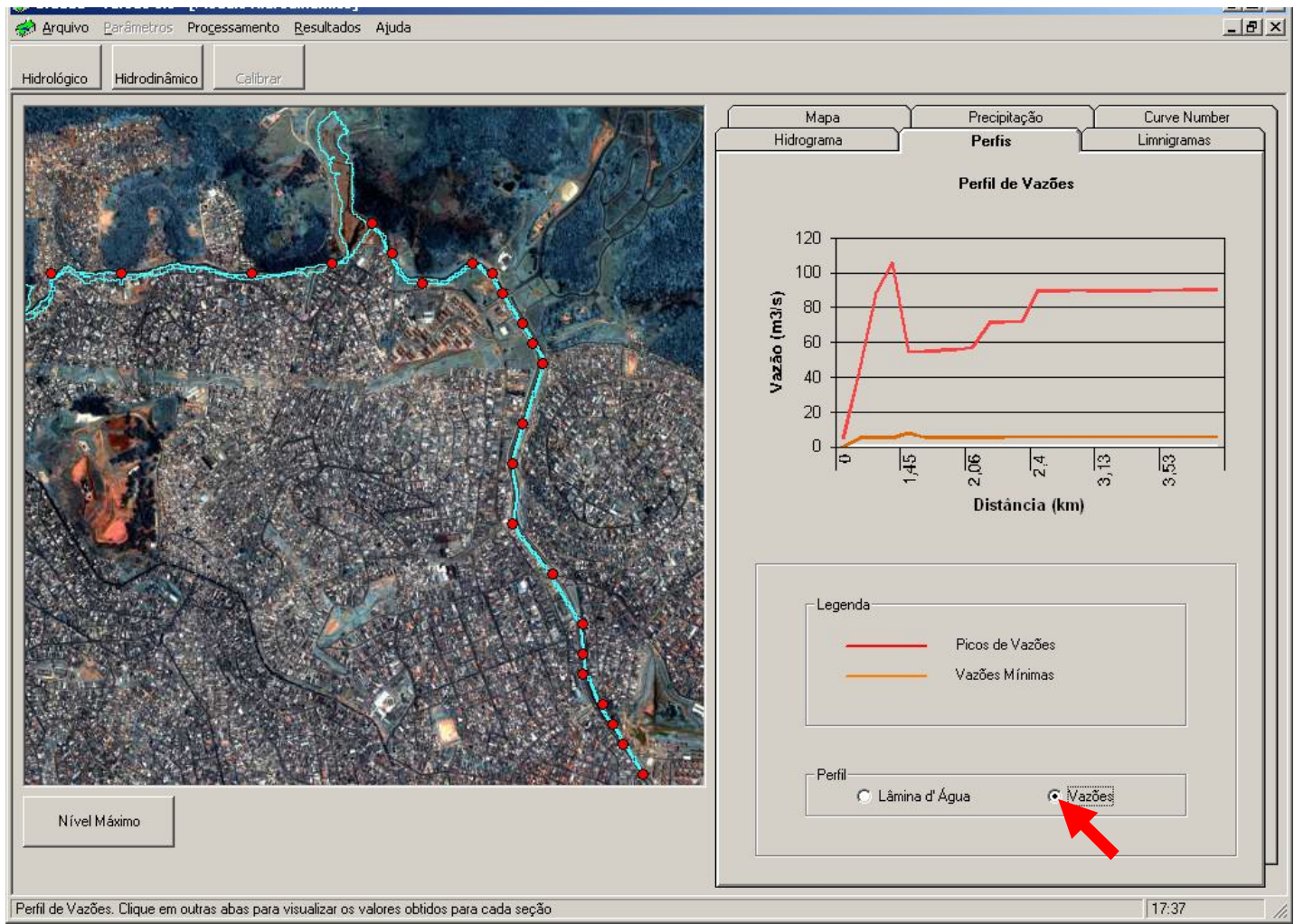

Figura 4.19 - Comando para visualizar os picos de vazões na seção longitudinal.

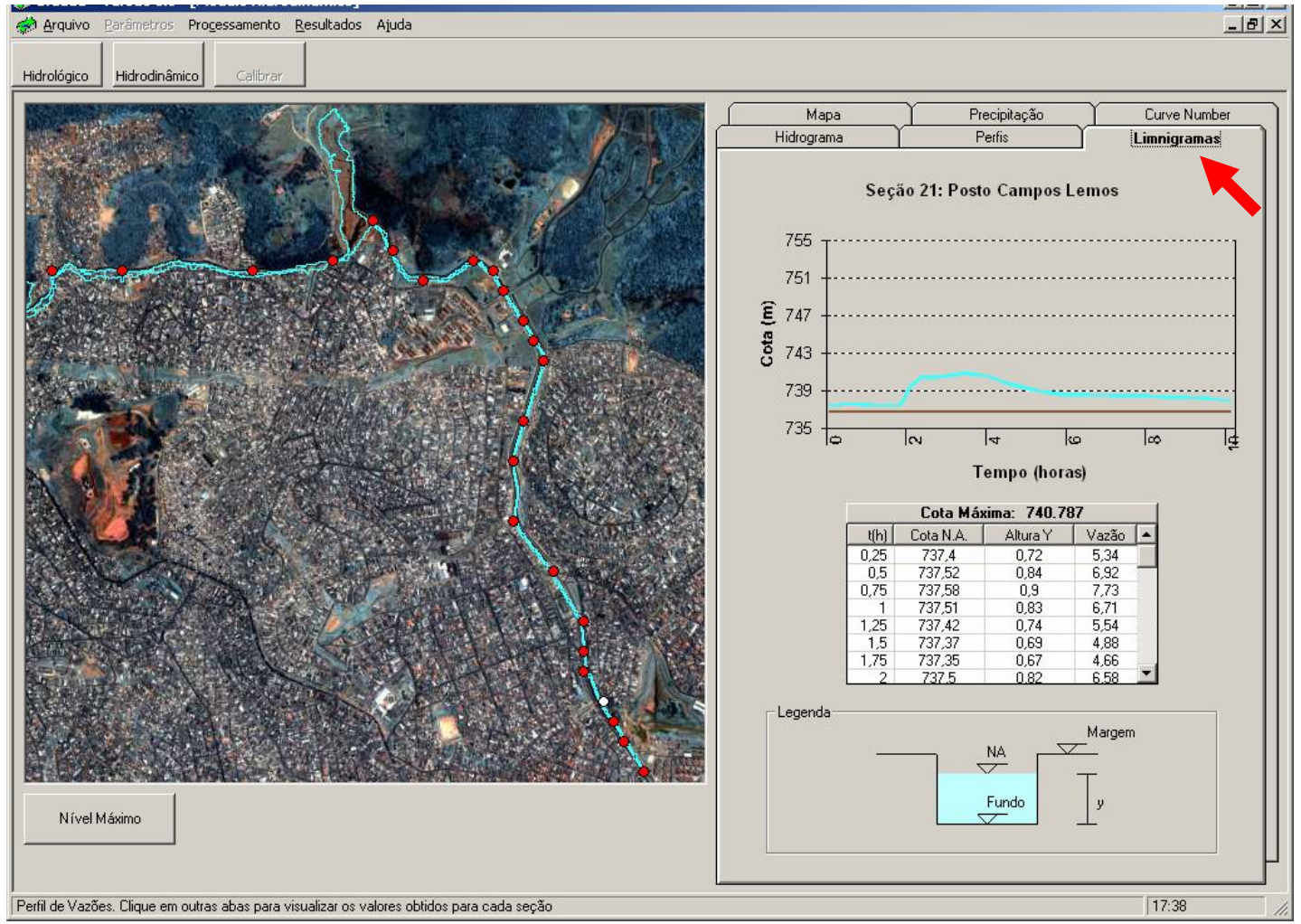

Figura 4.20 - Visualização do gráfico e tabela de Cota x Tempo da seção escolhida. 


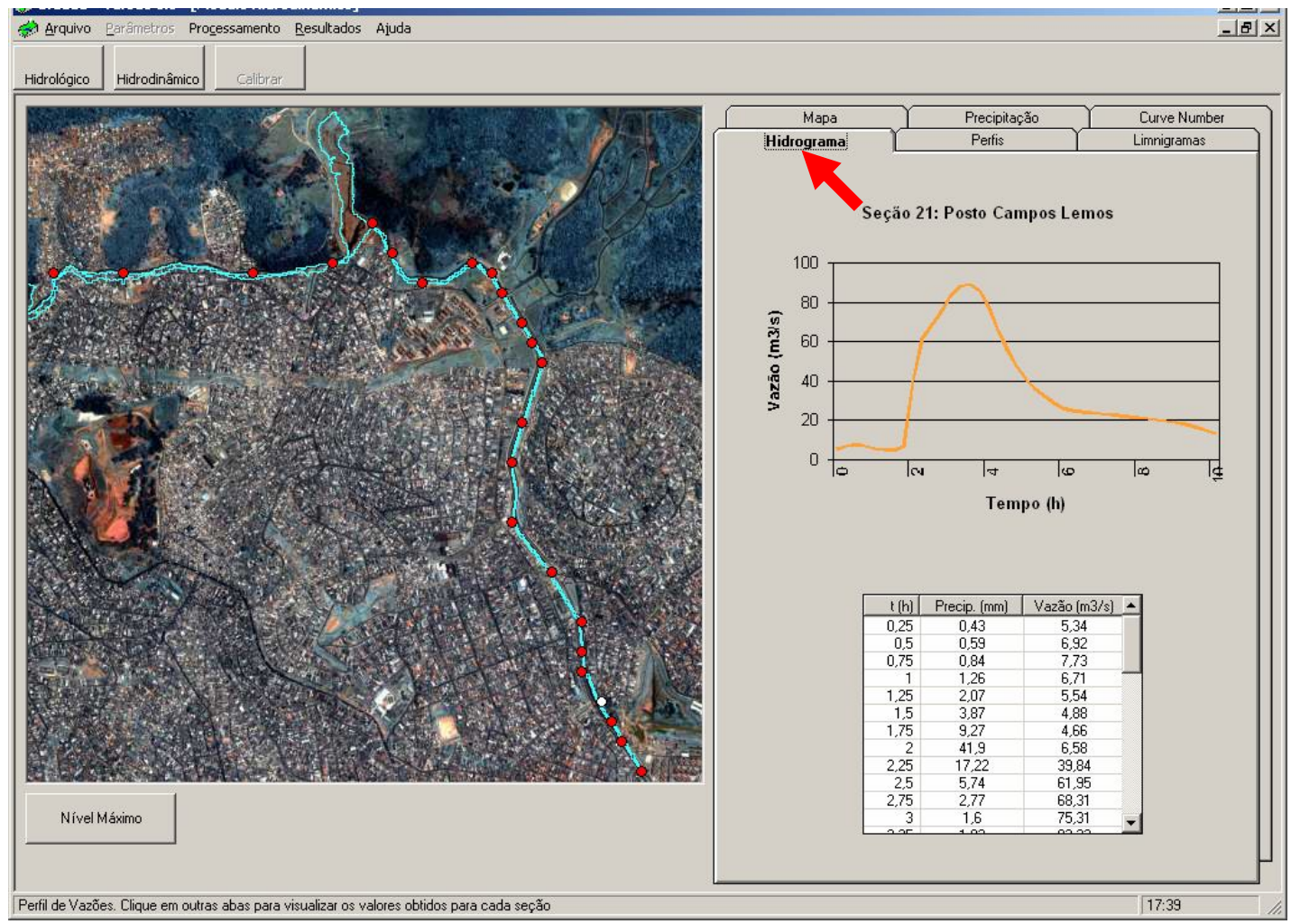

Figura 4.21 - Visualização do gráfico e tabela de Vazão x Tempo da seção escolhida.

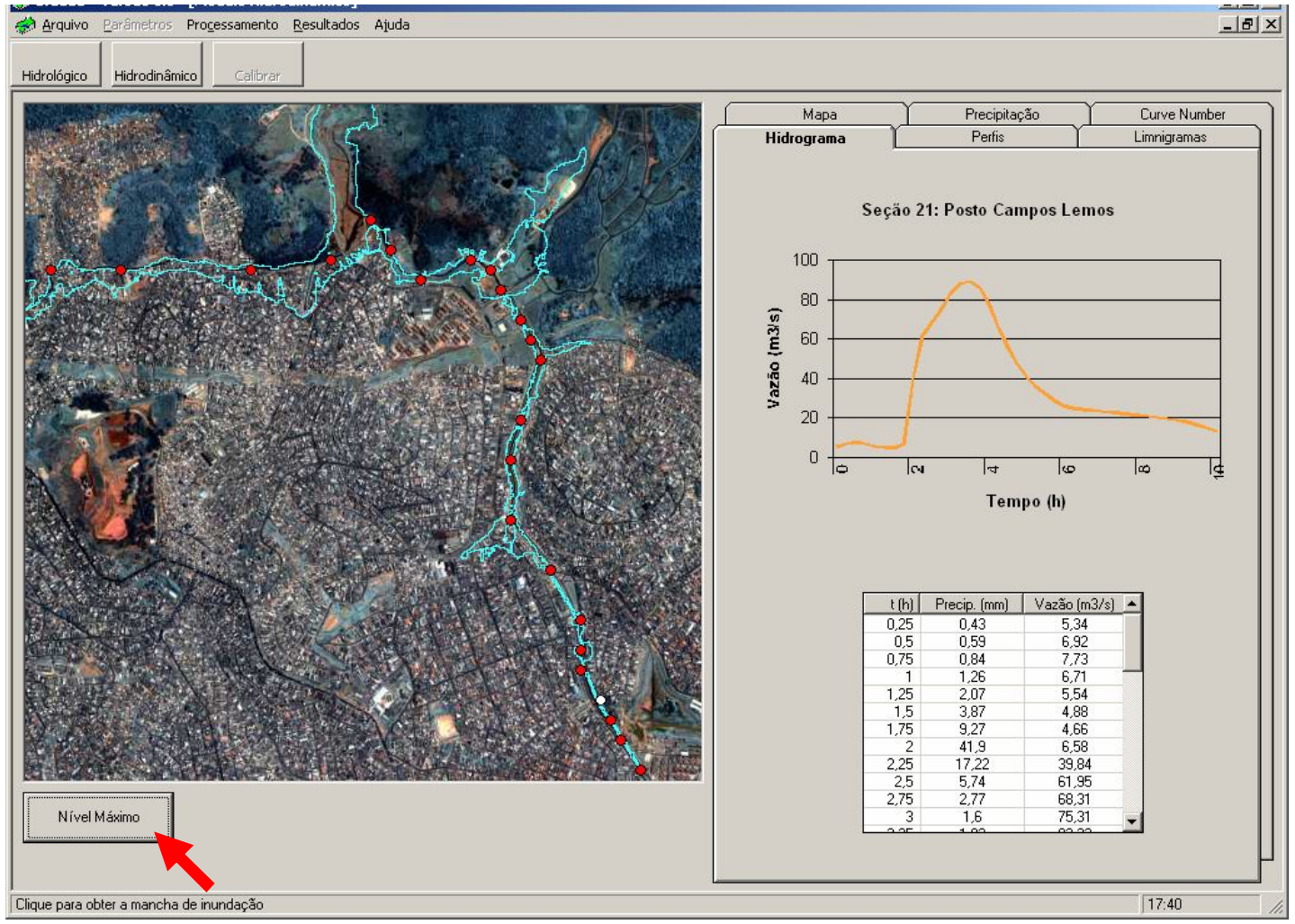

Figura 4.22 - Indicação do botão que mostra a envoltória de NA máximos. 
Para exportar a envoltória de inundação, deve clicar sobre "Resultados" e "Exportar DXF", como mostra na Figura 4.23. O arquivo exportado pode ser utilizado em outros softwares de análise e edição de desenhos vetoriais.

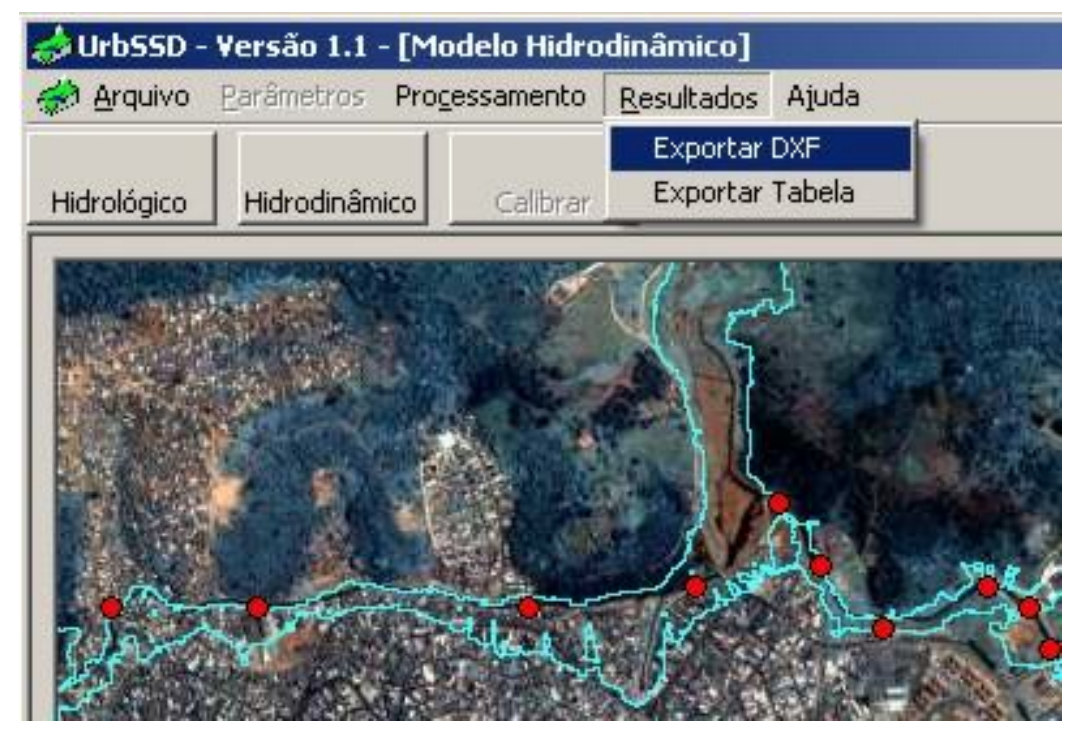

Figura 4.23 - Comando para exportar o DXF da mancha de inundação.

A seguir são detalhados os modelos de simulação hidrológica e hidráulica.

\subsection{Módulo Hidrológico}

De acordo com PORTO, TUCCI (1995), a metodologia dos estudos hidrológicos de drenagem urbana segue, na maioria dos casos, o procedimento ilustrado na Figura 4.24. Os passos 2, 3 e 4, respectivamente, a Determinação da Tormenta de Projeto, a Determinação da Chuva Excedente e a Determinação do Hidrograma de Projeto pertencem ao campo da hidrologia urbana. O passo 1, Escolha do Período de Retorno, situa-se em contexto sócioeconômico, enquanto que o passo 5, Dimensionamento de Estruturas Hidráulicas e/ou definição de outras ações, refere-se à fase de projeto das medidas a serem implantadas na bacia. 


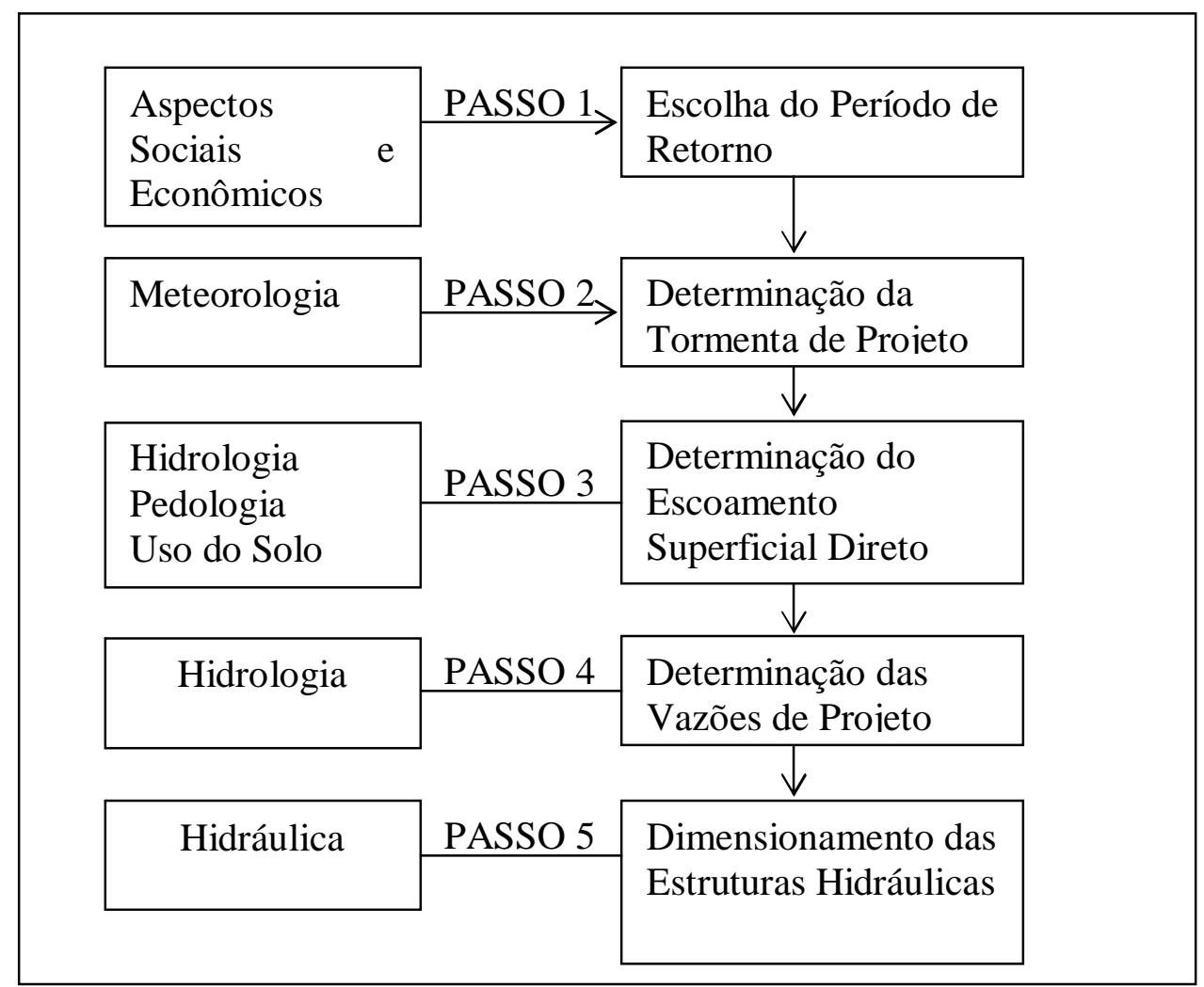

Figura 4.24 - Seqüiência de passos proposto para um estudo de drenagem urbana (Fonte: PORTO, 1995).

\subsubsection{Definição do hietograma}

Para a definição das chuvas, é adotado um hietograma de projeto para a bacia inteira. Por isso recomenda-se que a área de drenagem da bacia seja menor que $50 \mathrm{Km}^{2}$. Para bacias maiores, pode-se dividir o problema em sub-bacias e simular uma precipitação para cada sub-bacia correspondente a um ponto exutório e depois compor o hidrograma final.

Na determinação do Hietograma, pode ser utilizada uma das três opções a seguir:

- Utilizar um hietograma sintético, obtido pela equação de chuvas intensas ou Curva IDF (Intensidade - Duração - Freqüência) assim definido pelo período 
de retorno e o tempo de duração da chuva, que no SSD é limitado em seis horas. A Figura 4.7 exemplifica essa opção no URBSSD, disponibilizada pela equação obtida de WILKEN (1978) para a cidade de São Paulo:

$$
i=\frac{3462 \cdot T^{0,172}}{(t+22)^{1,025}}
$$

Onde: $\quad$ i - Intensidade Média em $\mathrm{mm} / \mathrm{h}$;

T - Período de Retorno (TR) em anos;

$\mathrm{t}$ - Tempo de duração da chuva em horas.

- Utilizar um evento de chuva em que ocorreram inundações, obtida dos postos pluviográficos localizados na sua área (Figura 4.8);

- Inserir "blocos de chuva", que correspondem a 15 minutos de precipitação. É uma opção em que o usuário deve criar um evento de chuva a seu critério, sem obedecer a uma série histórica ou equação de chuvas intensas (Figura 4.9);

No hietograma sintético, o método usado na desagregação de tormentas e composição da chuva de projeto é o Método dos Blocos Alternados, derivado do Método de Chicago, por KEIFER E CHU (1957). Neste método uma chuva de projeto sintética é construída a partir da hipótese de que o somatório dos volumes de precipitação, à medida que se acrescentam "blocos" de 15 minutos, coincide com o valor definido pelas curvas IDF correspondentes à soma dos tempos de cálculo (múltiplos de 15 minutos).

A ordenação dos blocos obedece a um critério conservador em que os blocos maiores são posicionados no centro do hietograma, ajustando os maiores picos alternadamente, onde o segundo maior bloco ocupe a posição de 15 minutos anteriores e o terceiro bloco na posição de 15 minutos posterior ao maior pico e assim por diante (ilustrado na Figura 4.7). 


\subsubsection{Cálculo do Escoamento Superficial}

Para a simulação do escoamento superficial, os dados são obtidos pelo banco de dados vetoriais do Sistema de Informações Geográficas para dar suporte à determinação do uso de ocupação do solo.

Estas informações são utilizadas para a determinação do escoamento superficial e geração de hidrogramas, desenvolvida pelo Soil Conservation Service (SCS) ${ }^{1}$ dos EUA. O parâmetro que regula a separação do escoamento superficial e está associado às condições de infiltração da bacia é o parâmetro Número de Curva ou CN (Curve Number).

O método de se obter as classificações do número $\mathrm{CN}$ é importar um tipo de arquivo de dados vetoriais, os shapefiles, ESRI (1997), com as áreas para cada uso e ocupação.

Estes shapefiles devem ser gerados através de outros softwares comerciais de edição, como o ArcMap ESRI (2007). Tais arquivos devem seguir um método de preenchimento de dados de acordo com cada variável. Ou seja, cada arquivo com o formato tabular (DBF) associado ao shapefile deverá ter um conjunto de atributos obrigatórios especificados no SSD, como área da bacia ou do trecho estudado $\left(\mathrm{em}^{\mathrm{Km}}{ }^{2}\right)$, tempo de concentração (em horas), comprimento do talvegue (em metros) e CN. A Figura 4.25 mostra a configuração básica do shapefile, mostrando os nomes das colunas.

A projeção cartográfica deve ser a Projeção Universal Transversa de Mercator (UTM), pois os posicionamentos estão em unidades métricas do Sistema Internacional (S.I.). O datum horizontal deve ser tanto nos elipsóides SAD-69 (utilizado como o antigo Referencial Geodésico Brasileiro² ${ }^{2}$ ), WGS-84 (utilizado como referência no Sistema de

\footnotetext{
${ }^{1}$ O nome "Soil Conservation Service" (SCS) do U.S. Department of Agriculture foi modificado recentemente como "National Resource Conservation Service" (NRCS)

${ }^{2}$ De acordo com a Resolução Presidencial de 1/2005 (IBGE, 2005), ficou estabelecido como novo
} 
Posicionamento Global - GPS) e Córrego Alegre (utilizado como referência nas Cartas do IBGE, datadas na maioria na década de 1970).

Caso os dados geográficos estejam em coordenadas geodésicas $(\phi, \lambda)$, devem ser transformadas em coordenadas planas retangulares UTM (N - Norte, E - Leste). De acordo com COAPS (2007), a interface MapWindow reconhece as coordenadas geodésicas como planas, ou seja, não diferencia os radianos com unidades métricas.

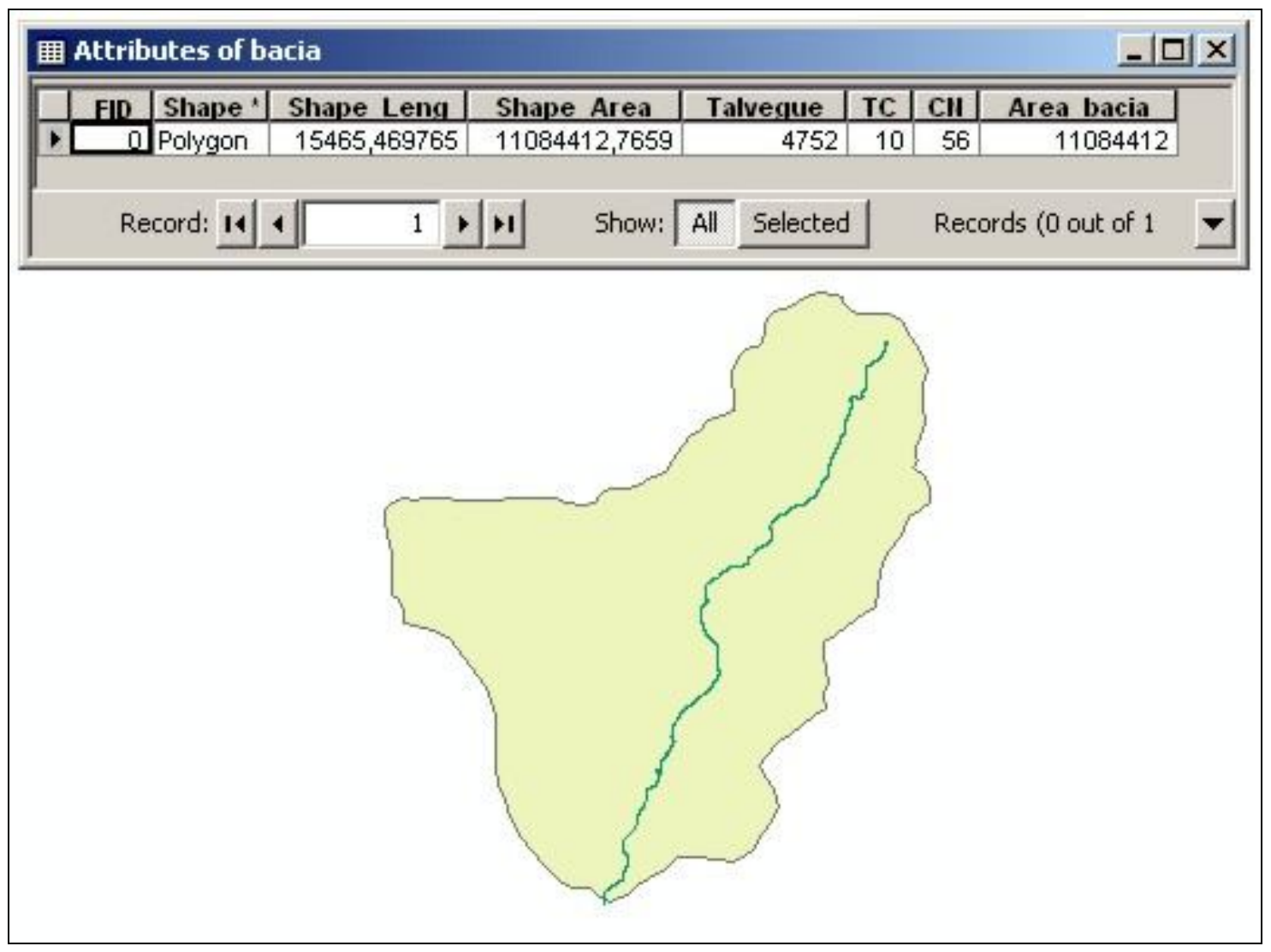

Figura 4.25 - Configuração da entrada de dados do shapefile (atributos)

Nos estudos hidrológicos voltados à drenagem urbana, principalmente em virtude da carência de dados fluviométricos que poderiam subsidiar análises estatísticas de cheias, realização do ano de 2000 (SIRGAS2000). Poderá ser utilizado em concomitância com o sistema SAD 69. 
normalmente são adotados modelos matemáticos do tipo chuva x vazão para a definição dos hidrogramas de projeto. Como foi utilizado no SSD do projeto Gerenciamento Integrado de Bacias Hidrográficas em Áreas Urbanas na bacia do Cabuçu de Baixo, em BARROS (2004), o modelo hidrológico utilizado no URBSSD é o CABC (Simulador Hidrológico de Bacias Complexas) desenvolvido pela Fundação Centro Tecnológico de Hidráulica, FCTH (2002).

O CABC é um modelo matemático de simulação hidrológica que emprega diferentes técnicas para determinação de chuvas excedentes e de hidrogramas de escoamento superficial. É um software dotado de uma interface gráfica para entrada de dados e visualização de resultados, rotinas para o cálculo do amortecimento em canais e reservatórios. Permite ainda a utilização de arquivos de imagem ou arquivos padrão DXF para entrada de dados topográficos e exportação da configuração geral da bacia hidrográfica, fornecendo total compatibilidade com sistemas de CAD. É um modelo que vem sendo aplicado a diversas bacias urbanas brasileiras. Seus principais parâmetros de calibração são os índices relacionados com as condições de infiltração, tais como o CN (Curve Number) do Soil Conservation Service (SCS) dos EUA e parâmetros associados às características físicas das bacias, para definição de hidrogramas. Com este modelo, é possível estimar a contribuição do escoamento superficial da bacia, para, em seguida, empregar o modelo hidráulico para determinação de áreas de inundação.

A fórmula proposta pelo SCS, assumindo-se que o armazenamento ao longo do tempo é proporcional ao volume precipitado, é mostrada a seguir:

$$
Q=\frac{\left(P-I_{A}\right)^{2}}{\left(P-I_{A}\right)+S_{D}}
$$

Onde: $Q$ : Deflúvio (Precipitação Excedente) (mm); 
$P$ : Precipitação (mm);

$I_{A}$ : Abstração inicial (mm) e

$S_{D}$ : Armazenamento máximo $(\mathrm{mm})$

KOHLER E RICHARDS (1962) verificaram que a abstração inicial $\left(\mathrm{I}_{\mathrm{A}}\right)$, na qual compreende a água precipitada interceptada pela vegetação, ou retida em depressões do terreno, infiltrada ou evaporada, pode representar $20 \%$ do armazenamento máximo. Substituindo na equação 4.3.1 resulta:

$$
Q=\frac{\left(P-0,2 \cdot S_{D}\right)^{2}}{\left(P+0,8 \cdot S_{D}\right)}
$$

Para obter o deflúvio, essa equação é válida apenas para precipitações maiores que a abstração inicial $\left(\mathrm{P}>0,2 \mathrm{~S}_{\mathrm{D}}\right)$. Alguns autores sugerem que o valor da abstração inicial seja de $0,1 \mathrm{~S}_{\mathrm{D}}$ para áreas urbanas, com porcentagem substancial de áreas impermeáveis, a fim de refletir o decréscimo de interceptação e de depressões que ocorre nas áreas urbanas, MAYS (2001).

Para determinar o armazenamento máximo $\left(\mathrm{S}_{\mathrm{D}}\right)$, foi necessário estabelecer uma relação empírica que visa correlacionar a capacidade de armazenamento da área considerada a um índice denominado número de curva ("Curve Number" - CN). Tendo uma mudança de variável:

$$
S_{D}=\frac{25400}{C N}-254
$$

Os valores $\mathrm{CN}$ dependem de fatores importantes do solo como a umidade antecedente, tipo e uso e ocupação. Tendo em vista que em geral as bacias urbanas são compostas por diversas sub-bacias de características hidrológicas diferentes, realiza-se usualmente uma média ponderada dos valores de $\mathrm{CN}$ com relação às respectivas áreas, para 
obtenção do valor médio, segundo CANHOLI (2005).

O SCS distingue em seu método cinco grupos hidrológicos de solos. PORTO E SETZER (1979) elaboraram um trabalho que adaptou os números CN para as condições de solo do Estado de São Paulo, suficientemente abrangente para ser aplicada a solos de outros estados. Conforme tabelado em USDA (1986), WANIELISTA E YOUSEF (1993), TUCCI (1993) e CANHOLI (2005), são classificados os grupos hidrológicos dos solos, associados com a capacidade de infiltração $(\mathrm{em} \mathrm{cm} / \mathrm{h})$, conforme a Tabela 4.1.

Tabela 4.1 - Classificação dos grupos hidrológicos dos solos e suas capacidades de infiltração (FONTE: CANHOLI, 2005).

\begin{tabular}{||c|c|c||}
\hline \hline $\begin{array}{c}\text { Grupo } \\
\text { Hidrológico } \\
\text { do Solo }\end{array}$ & Descrição do Solo & $\begin{array}{c}\text { Capacidade } \\
\text { de Infiltração } \\
\text { (cm/h) }\end{array}$ \\
\hline A & $\begin{array}{c}\text { Areias e cascalhos profundos }(\mathrm{h}>1,50 \mathrm{~m}), \text { muito permeá veis. } \\
\text { Possuem alta taxa de infiltração mesmo quando saturados. Teor de } \\
\text { argila até } 10 \%\end{array}$ & $1,20-0,80$ \\
\hline B & $\begin{array}{c}\text { Solos arenosos com poucos finos, menos profundos }(\mathrm{h}<1,50 \mathrm{~m}) \text { e } \\
\text { permeáveis. Teor de argila entre 10\% e 20\% }\end{array}$ & $0,80-0,40$ \\
\hline $\mathbf{C}$ & $\begin{array}{c}\text { Solos pouco profundos com camadas subsuperficiais que impedem } \\
\text { o fluxo descendente da água, ou solos com porcentagem elevada de } \\
\text { argila (entre 20\% a 30\%) }\end{array}$ & $0,40-0,15$ \\
\hline D & $\begin{array}{c}\text { Solos compostos principalmente de argilas (acima de 30\%) ou solos } \\
\text { com nível freático elevado, ou solos com camadas argilosas } \\
\text { próximas à superfície, ou solos rasos sobre camadas impermeáveis. }\end{array}$ & $0,15-0,00$ \\
\hline \hline
\end{tabular}

Determinado o grupo hidrológico do solo, é feito a estimativa do número $\mathrm{CN}$ na Tabela 4.2. em função do tipo de uso do solo e em seguida, corrigido para a condição de umidade do solo em que se encontra nas Tabelas 4.3. a 4.5. 
Tabela 4.2 - Estimativa de CN para áreas urbanas (FONTE: CANHOLI, 2005 Adaptado)

\begin{tabular}{|c|c|c|c|c|c|c|}
\hline \multirow{2}{*}{\multicolumn{2}{|c|}{ TIPO DE SOLO / OCUPAÇÃO PARA A CONDIÇÃO II }} & \multirow{2}{*}{$\begin{array}{c}\text { Área } \\
\text { Impermeável }\end{array}$} & \multicolumn{4}{|c|}{ Grupo Hidrológico } \\
\hline & & & $\mathbf{A}$ & B & $\mathbf{C}$ & D \\
\hline \multicolumn{7}{|c|}{ ÁREAS URBANAS } \\
\hline \multirow{3}{*}{ Áreas Livres } & $\begin{array}{l}\text { Condições ruins (gramados com área menor } \\
\text { que 50\%) }\end{array}$ & & 68 & 79 & 86 & 89 \\
\hline & $\begin{array}{l}\text { Condições normais (gramados com área } \\
\text { entre } 50 \% \text { a } 75 \% \text { ) }\end{array}$ & & 49 & 69 & 79 & 84 \\
\hline & $\begin{array}{l}\text { Condições excelentes (gramados com área } \\
\text { acima de } 75 \% \text { ) }\end{array}$ & & 39 & 61 & 74 & 80 \\
\hline \multicolumn{2}{|c|}{ Áreas Comerciais } & $85 \%$ & 89 & 92 & 94 & 95 \\
\hline \multicolumn{2}{|c|}{ Áreas Industriais } & $72 \%$ & 81 & 88 & 91 & 93 \\
\hline \multicolumn{7}{|c|}{ ÁREAS IMPERMEÁVEIS } \\
\hline \multicolumn{2}{|c|}{ Estacionamentos pavimentados, telhados } & & 98 & 98 & 98 & 98 \\
\hline \multirow{4}{*}{$\begin{array}{l}\text { Estradas e } \\
\text { Ruas }\end{array}$} & Pavimentadas com sistema de drenagem & & 98 & 98 & 98 & 98 \\
\hline & Pavimentadas sem sistema de drenagem & & 83 & 89 & 92 & 93 \\
\hline & Cascalho & & 76 & 85 & 89 & 91 \\
\hline & De Terra & & 72 & 82 & 87 & 89 \\
\hline \multicolumn{7}{|c|}{ ÁREAS RESIDENCIAIS } \\
\hline \multicolumn{2}{|c|}{ Área residencial Tipo 1} & $65 \%$ & 77 & 85 & 90 & 92 \\
\hline \multicolumn{2}{|c|}{ Área residencial Tipo 2} & $38 \%$ & 61 & 75 & 83 & 87 \\
\hline \multicolumn{2}{|c|}{ Área residencial Tipo 3} & $25 \%$ & 54 & 70 & 80 & 85 \\
\hline \multicolumn{2}{|c|}{ Área residencial Tipo 4} & $20 \%$ & 51 & 68 & 79 & 84 \\
\hline \multicolumn{2}{|c|}{ Área residencial Tipo 5} & $12 \%$ & 45 & 65 & 77 & 82 \\
\hline
\end{tabular}

De acordo com CANHOLI (2005), a estimativa da área impermeável nas áreas residenciais pode ser calculada com base na densidade populacional. CAMPANA E TUCCI (1994) apresentam uma relação empírica baseado em dados populacionais dos centros urbanos de São Paulo (SP), Curitiba (PR) e Porto Alegre (RS). Podem ser ajustadas pelas seguintes equações, onde $d$ é a densidade populacional em hab/ha:

$$
\begin{aligned}
& \frac{A_{\text {imp }}}{A_{\text {total }}}(\%)=-3,86+0,55 \cdot d \quad(\text { para } 7 \leq \mathrm{d} \leq 115 \mathrm{hab} / \mathrm{ha}) \\
& \frac{A_{\text {imp }}}{A_{\text {total }}}(\%)=53,2+0,054 \cdot d \quad(\text { para } 7 \leq \mathrm{d} \leq 115 \mathrm{hab} / \mathrm{ha})
\end{aligned}
$$


Tabela 4.3 - Condições de solo US SCS (FONTE: org. por TUCCI , PORTO E BARROS, 1995)

Condição I - Solos secos: As chuvas nos últimos dias não ultrapassam 15 mm.

Condição II - Situação muito freqüente em épocas chuvosas - as chuvas nos últimos 5 dias totalizam entre 15 e $40 \mathrm{~mm}$.

Condição III - Solo úmido (próximo da saturação): as chuvas nos últimos dias foram superiores a $40 \mathrm{~mm}$ e as condições meteorológicas foram desfavoráveis a altas taxas de evaporação.

A Tabela 4.3 para a obtenção de CN refere-se à Condição II. A transformação dos valores de $\mathrm{CN}$ obtidos para as outras condições de umidade é feita por meio da Tabela 4.4.

Tabela 4.4 - Correspondência entre os valores de CN para diversas condições de umidade do solo (FONTE: org. por TUCCI , PORTO e BARROS, 1995)

\begin{tabular}{||c|c|c||}
\hline \multicolumn{3}{||c|}{ Condições de Umidade } \\
\hline I & II & III \\
\hline 100 & 100 & 100 \\
\hline 87 & 95 & 99 \\
\hline 78 & 90 & 98 \\
\hline 70 & 85 & 97 \\
\hline 63 & 80 & 94 \\
\hline 57 & 75 & 91 \\
\hline 51 & 70 & 87 \\
\hline 45 & 65 & 83 \\
\hline 40 & 60 & 79 \\
\hline 35 & 55 & 75 \\
\hline 31 & 50 & 70 \\
\hline 27 & 45 & 65 \\
\hline 23 & 40 & 60 \\
\hline 19 & 35 & 55 \\
\hline 15 & 30 & 50 \\
\hline
\end{tabular}

A ocupação do solo é caracterizada pela sua cobertura vegetal e pelo tipo de defesa contra a erosão eventualmente adotada. A simplicidade e praticidade deste método tornaram-no extremamente popular e difundido entre profissionais de todo o mundo.

Utilizando as equações (4.3.3) e consequentemente, a (4.3.2), podem ser obtidos os 
hidrogramas parciais para cada bloco de chuva excedente correspondente a cada intervalo de tempo $\Delta \mathrm{t}$. A soma dos hidrogramas parciais para cada $\Delta \mathrm{t}$ determina um hidrograma final, obtido pelo Método do Hidrograma Unitário Adimensional do SCS, USDA (1986). Este método é o utilizado no modelo CABC do URBSSD.

A partir da observação de um grande número de hidrogramas unitários, o hidrograma unitário adimensional do SCS, também conhecido como hidrograma unitário curvilíneo (HUC-SCS), possui o tempo de base igual a cinco unidades do tempo de pico $\left(5 t_{p}\right)$ e cerca de $3 / 8(37,5 \%)$ do volume total escoado superficialmente ocorre antes do tempo de pico. Também sugere que o tempo de recessão $\left(t_{r}\right)$ seja de aproximadamente $1,67 t_{p}$

GENOVEZ (2001) indica que empiricamente o tempo de resposta $\left(\mathrm{t}_{1}\right)$ é aproximadamente igual a $60 \%$ do tempo de concentração $\left(t_{C}\right)$, sendo aproximadamente :

$$
\begin{aligned}
& t_{r}=1,67 \cdot t_{P} \\
& t_{l}=0,6 \cdot t_{C}
\end{aligned}
$$

Onde: $t_{r}, t_{l}, t_{p}$ e $t_{c}$ são tempos dados em horas

Os valores de $q_{p}$ e $t_{p}$ podem ser estimados, utilizando-se um modelo simplificado de um hidrograma unitário triangular (HUT-SCS) onde o tempo é dado em horas e as vazões $\left(q_{p}\right)$ em $\mathrm{m}^{3} / \mathrm{s.cm}$ (ou pes $3 /$ pol.). Como a área sob o hidrograma unitário deve ser igual ao volume de escoamento superficial direto de 1 centímetro, pode ser visto que:

$$
q_{P}=\frac{C \cdot A}{t_{P}}
$$

Onde $: C=2,083$ 


$$
\begin{aligned}
& A=\text { Área de drenagem em } \mathrm{Km}^{2} \\
& t_{p}=\text { Tempo de pico do hidrograma unitário em horas }
\end{aligned}
$$

Assim, o tempo de pico $t_{P}$ pode ser expresso em função do tempo de resposta $\left(t_{l}\right)$ e

da duração da chuva excedente (D).

$$
t_{P}=\frac{D}{2}+t_{l}
$$

Onde : $D=$ Tempo da chuva excedente em horas

$t_{l}=$ Tempo de resposta em horas

$t_{p}=$ Tempo de pico do hidrograma unitário em horas

Utilizando a Tabela 4.5, encontram-se os valores da abscissa $\left(t / t_{p}\right)$ e da ordenada $\left(q / q_{p}\right)$ do HUC-SCS. O hidrograma obtido é apresentado na Figura 4.26.

\begin{tabular}{|c|c|c|c|c|c|c|c|c|}
\hline$t / t_{p}$ & $q / q_{p}$ & $Q_{\mathrm{a}} / Q$ & $t / t_{p}$ & $q / q_{p}$ & $Q_{a} / Q$ & $t / t_{p}$ & $q / q_{p}$ & $Q_{\mathrm{a}} / Q$ \\
\hline 0,0 & 0,000 & 0,000 & 1,1 & 0,990 & 0,450 & 2,4 & 0,147 & 0,934 \\
\hline 0,1 & 0,030 & 0,001 & 1,2 & 0,930 & 0,522 & 2,6 & 0,107 & 0,953 \\
\hline 0,2 & 0,100 & 0,006 & 1,3 & 0,860 & 0,589 & 2,8 & 0,077 & 0,967 \\
\hline 0,3 & 0,190 & 0,012 & 1,4 & 0,780 & 0,650 & 3,0 & 0,055 & 0,977 \\
\hline 0,4 & 0,310 & 0,035 & 1,5 & 0,680 & 0,700 & 3,2 & 0,040 & 0,984 \\
\hline 0,5 & 0,470 & 0,065 & 1,6 & 0,560 & 0,751 & 3,4 & 0,029 & 0,989 \\
\hline 0,6 & 0,660 & 0,107 & 1,7 & 0,460 & 0,790 & 3,6 & 0,021 & 0,993 \\
\hline 0,7 & 0,820 & 0,163 & 1,8 & 0,390 & 0,822 & 3,8 & 0,015 & 0,995 \\
\hline 0,8 & 0,930 & 0,228 & 1,9 & 0,330 & 0,849 & 4,0 & 0,011 & 0,997 \\
\hline 0,9 & 0,990 & $0, \overline{300}$ & 2,0 & 0,280 & 0,871 & 4,5 & 0,005 & 0,999 \\
\hline 1,0 & 1,000 & $0, \overline{375}$ & 2,2 & 0,207 & 0,908 & 5,0 & 0,000 & 1,000 \\
\hline
\end{tabular}

Tabela 4.5 - Relações para o cálculo do hidrograma curvilíneo do SCS e de sua curva de massa

$q$ : vazão no tempo $t ; q_{p}$ : vazão de pico; $Q_{a}$ : volume acumulado no tempo $t ; Q$ : volume total; $t_{p}$ : tempo de pico do hidrograma. 


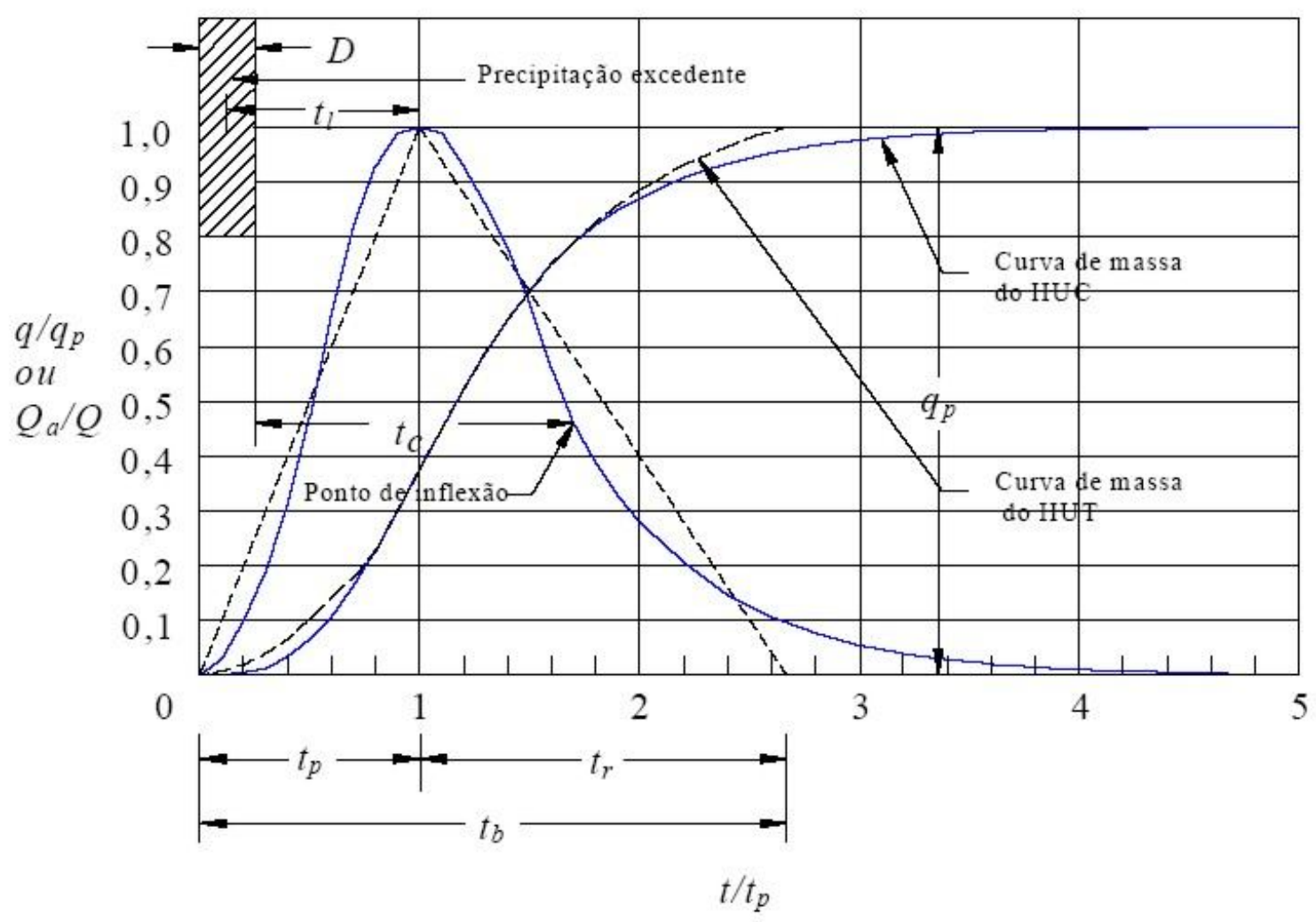

Figura 4.26 - Hidrograma Unitário Curvilíneo Adimensional e o Hidrograma Unitário Triangular Equivalente (Fonte: MCCUEN, 1989).

A limitação quanto à aplicação da equação 4.3.8, segundo MCCUEN (1989), é que a constante $25 / 12(\mathrm{C}=2,083)$ reflete um hidrograma unitário triangular que tem $3 / 8$ de sua área abaixo da curva de ascensão. Para bacias localizadas completamente ou parcialmente em regiões montanhosas, pode-se esperar um valor maior que $3 / 8$ e, portanto, a constante $\mathrm{C}$ pode se aproximar de 625/242 (C = 2,582). Para bacias planas, em áreas de brejo ou alagadas (banhados), pode ser da ordem de 625/484 (C = 1,291), de acordo com SARTORI (2004).

Quando se dispõe de um hidrograma unitário para uma chuva excedente com uma determinada duração unitária $\Delta \mathrm{t}$, podem-se obter os hidrogramas unitários para outras durações. Se essas durações forem múltiplas da duração dada, o novo hidrograma unitário 
pode ser obtido facilmente, aplicando-se os princípios da independência (ou superposição) e da proporcionalidade. Entretanto, para uma nova duração qualquer, pode-se aplicar um processo geral denominado "Método da Curva S".

A Curva S é um hidrograma resultante de uma chuva com intensidade unitária $(1 / \Delta t)$ e de duração infinita, obtido a partir da superposição de diversos hidrogramas unitários, cada um defasado de uma duração unitária em relação ao anterior.

Se a Curva $\mathrm{S}$ for desenhada com uma defasagem no eixo dos tempos igual à nova duração unitária pretendida (dt'), nota-se que a diferença de ordenadas em cada instante t corresponde à ordenada de um hidrograma de escoamento superficial direto, resultante de uma chuva excedente com intensidade 1/dt e duração dt'. Para se converter esse hidrograma em um hidrograma unitário basta utilizar o princípio da proporcionalidade, multiplicandose a diferença das curvas $\mathrm{S}$ por dt/dt'. Assim, pode-se considerar a chuva unitária de intensidade $1 / \mathrm{dt}$ ' e duração dt'.

Para a obtenção da Curva $\mathrm{S}$, basta recordar que no instante t seu valor corresponde à soma das ordenadas de hidrogramas unitários defasados da duração unitária dt, isto é:

$$
\begin{aligned}
& h^{\prime}(t)=\frac{d t}{d t^{\prime}}\left[S(t)+s\left(t+d t^{\prime}\right)\right] . \\
& S(t)=h(t)+h^{\prime}(t-d t)+h(t-2 d t) \ldots
\end{aligned}
$$

A curva de massa obtida pela equação 4.3 .9 poderá ser convertida em um hidrograma, exemplificado graficamente na Figura 4.1.

Para a simulação dos hidrogramas no modelo CABC, os dados de entrada são:

- Hietograma da bacia em formato de dados tabulares determinados como no Item 4.2, onde deve ser fornecido como precipitação (mm) e tempo (h) pelo 
próprio URBSSD.

- Características físicas da bacia estudada, descritos no Item 4.2., como os tempos de concentração (h), comprimentos dos talvegues (m), áreas dos trechos $\left(\mathrm{km}^{2}\right)$ e números $\mathrm{CN}$. O arquivo em shapefile a ser importado deverá ser criado e editado fora do ambiente computacional do SSD.

Como resultados das simulações, poderão ser fornecidos os hidrogramas em formato de gráficos e tabelas (vazões em $\mathrm{m}^{3} / \mathrm{s}$ e tempos em horas) para cada trecho calculado da bacia. Para essa interface, é adotado como exemplo a Figura 4.27.

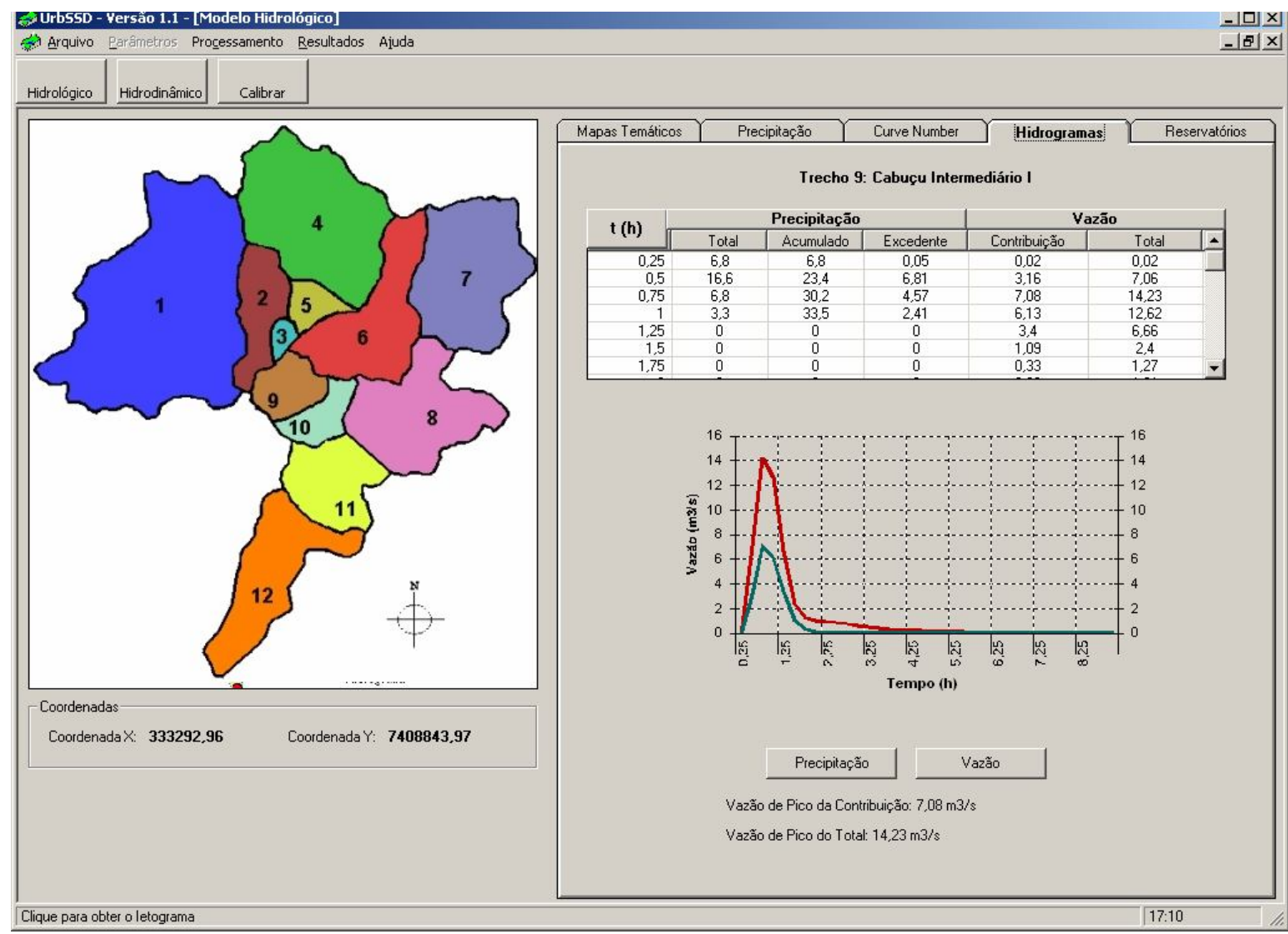

Figura 4.27 - Saída de dados do modelo hidrológico pelo módulo CABC 


\subsection{Módulo Hidráulico}

$\mathrm{Na}$ drenagem urbana são simulados os escoamentos permanentes e não permanentes, apesar das modelações de maior interesse serem os escoamentos não permanentes, para os estudos de translação de ondas de enchente nos canais e galerias. E dentro do campo da engenharia hidráulica fluvial, a modelação matemática torna-se indispensável, principalmente quando se trata do dimensionamento de canais a céu aberto, onde o estudo do escoamento pode envolver a necessidade de analisar aspectos de regime transitório de vazões e níveis d'água. CHOW (1959) demonstra as equações básicas de Saint-Venant, derivadas da aplicação das equações de Navier-Stokes. MARTINS, TUCCI, PORTO E BARROS (1995) e FCTH (2002) utilizaram as equações da Conservação da Massa (Equação 4.4.1.) e da Quantidade de Movimento (Equação 4.4.2.).

$$
\begin{aligned}
& \frac{\partial Q}{\partial x}+B \frac{\partial y}{\partial t}=q_{L} \\
& \frac{\partial Q}{\partial t}+\frac{\partial}{\partial x}\left(\beta \cdot \frac{Q^{2}}{A}\right)+g \cdot A \cdot \frac{d y}{d x}+g \cdot A \cdot S_{f}=q \cdot v \cdot \cos \gamma
\end{aligned}
$$

Onde: $x$ : Coordenada longitudinal;

$t$ : Tempo;

$Q$ : Vazão líquida;

y: Cota do nível da água;

$p$ : Perímetro molhado;

A: Área molhada;

$B$ : Largura à superfície livre;

$\beta$ : Coeficiente de Quantidade de Movimento;

$q_{L}$ : Vazão Líquida de contribuição lateral específica;

$S_{f}$ : Inclinação da linha de energia;

v: Velocidade da contribuição lateral líquida;

$\gamma$ : Ângulo da contribuição lateral com o eixo do canal.

A seguir, nas Figuras 4.28 e 4.29 são mostradas os esquemas da seção transversal e longitudinal, respectivamente. 


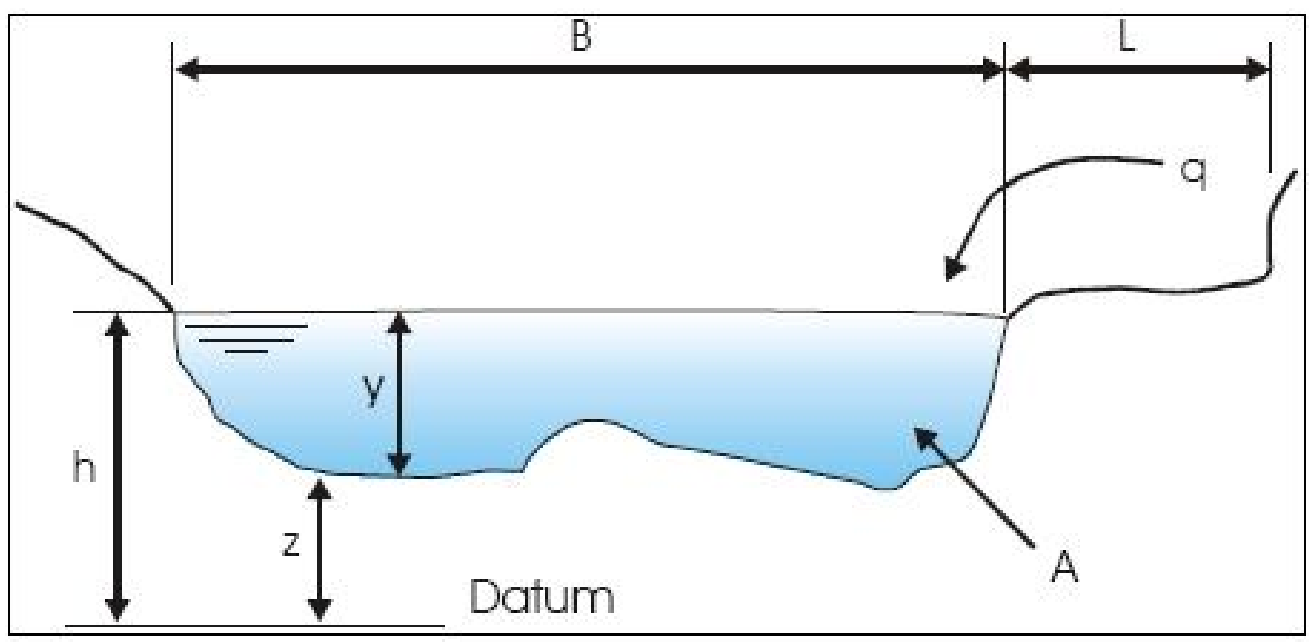

Figura 4.28 - Esquema da seção transversal (Fonte: ENGECORPS/HARZA, 2000).

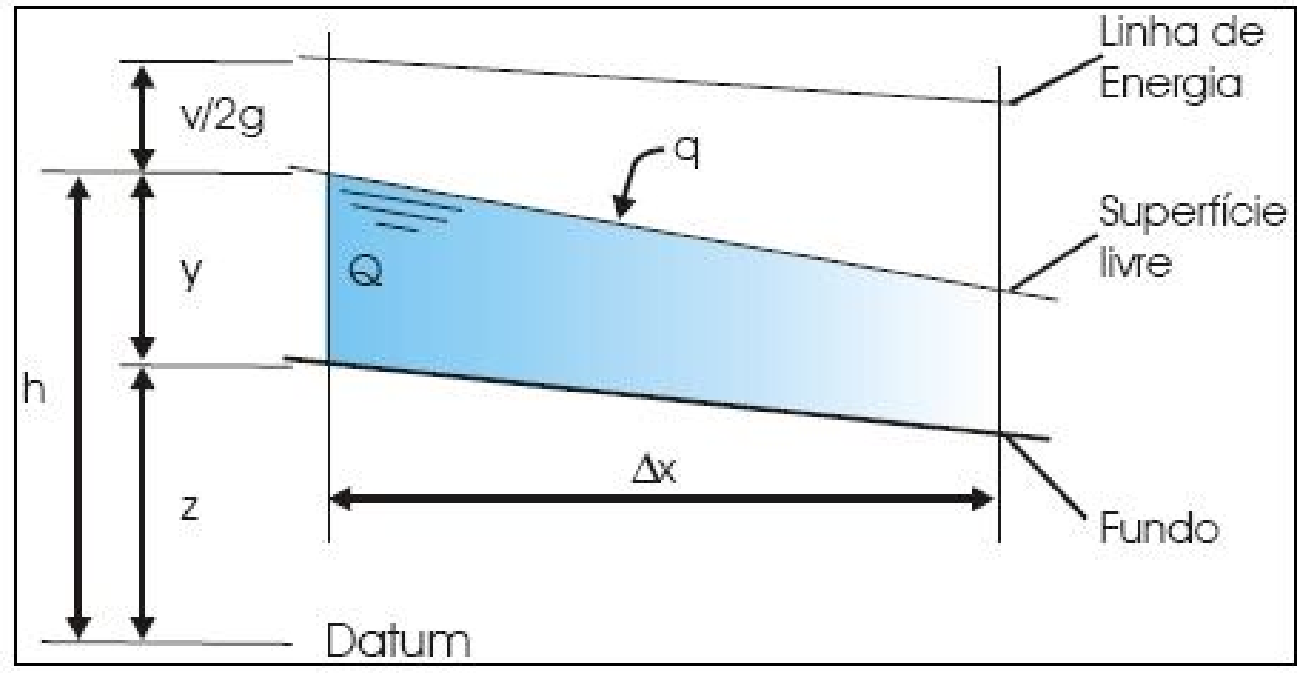

Figura 4.29 - Esquema em perfil (Fonte: ENGECORPS/HARZA, 2000).

De acordo com FCTH (2002), a equação da Conservação da Massa (Equação 4.4.1.) representa simplesmente o balanço de massa sobre um volume de controle e a segunda equação, a da Quantidade de Movimento (Equação 4.4.2.), representa o balanço das forças externas sobre o volume de controle, por unidade de peso. A solução dessas equações é feita por métodos numéricos diversos, como o método das características, de diferenças finitas, de elementos finitos, entre outros. 
O parâmetro $S_{f}$ representa as perdas de carga, usualmente calculadas pela Equação de Chézy, na forma:

$$
S_{f}=Q|Q| K^{-2}
$$

onde

$$
K=\mathrm{CA} \sqrt{\mathrm{R}_{\mathrm{h}}}
$$

A equação (4.4.2.) pode ser reescrita na forma:

$$
\begin{array}{r}
\frac{\partial Q}{\partial t}+\frac{Q^{2}}{A} \frac{\partial \beta}{\partial x}+2 \beta \frac{Q}{A} \frac{\partial Q}{\partial x}+g A\left(1-\beta F r^{2}\right) \frac{\partial y}{\partial x}+ \\
-\left.\beta \frac{Q^{2}}{A^{2}} \frac{\partial A}{\partial x}\right|_{\mathrm{y}=\text { const }}+g \mathrm{AS}_{\mathrm{f}}=\mathrm{q} \mathrm{v} \cos \gamma
\end{array}
$$

Onde

$$
F r^{2}=\frac{Q^{2} B}{g A^{3}}
$$

A Equação 4.4.6. é o quadrado do número de Froude $(F r)$ do escoamento.

\subsubsection{O Caso Particular do Escoamento Permanente}

Pode-se observar que a equação (4.4.5.), quando simplificada com as hipóteses de regime permanente e sem contribuições laterais com quantidade de movimento, permite o cálculo genérico do escoamento permanente:

$$
\begin{aligned}
& \frac{\partial Q}{\partial t}+\frac{Q^{2}}{A} \frac{\partial \beta}{\partial x}+2 \beta \frac{Q}{A} \frac{\partial Q}{\partial x}+g A\left(1-\beta F r^{2}\right) \frac{\partial y}{\partial x}- \\
& \begin{array}{cccc}
\downarrow & \downarrow & \downarrow \\
0 & 0 & \downarrow
\end{array}
\end{aligned}
$$

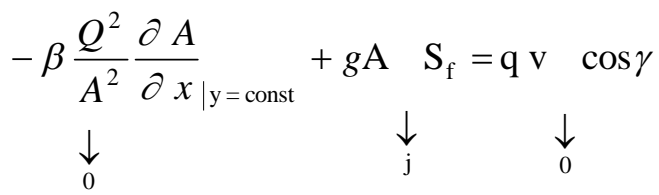


Da qual resulta:

$$
2 \beta \frac{Q}{A} q+g A\left(1-\beta F r^{2}\right) \frac{\partial y}{\partial x}+g A S_{f}=0
$$

\subsubsection{Interpretação física da equação do Escoamento Permanente}

A solução da equação geral do escoamento permanente nos canais admite diferentes interpretações físicas, relacionadas às condições do escoamento (vazão e perdas de carga) e às condições geométricas (seção e declividade). Para sua interpretação classificam-se os canais ou trechos de canais em cinco categorias, em função de sua declividade relativa: canais de declividade fraca, rápida, crítica, nula ou negativa.

Esta classificação é feita em função da posição relativa entre as profundidades notáveis, normal e crítica, conforme conceituado a seguir:

- Profundidade NORMAL ( $\mathrm{y}_{\text {normal }}$ ): aquela associada ao escoamento em regime uniforme;

- Profundidade CRÍTICA ( $\mathrm{y}_{\text {crítico}}$ ): associada ao escoamento com número de Froude $(F r)$ unitário.

As Figuras de 4.30 até 4.34 representam os comportamentos dos perfis possíveis de linha d'água associados a cada tipo de canal ou trecho de canal.

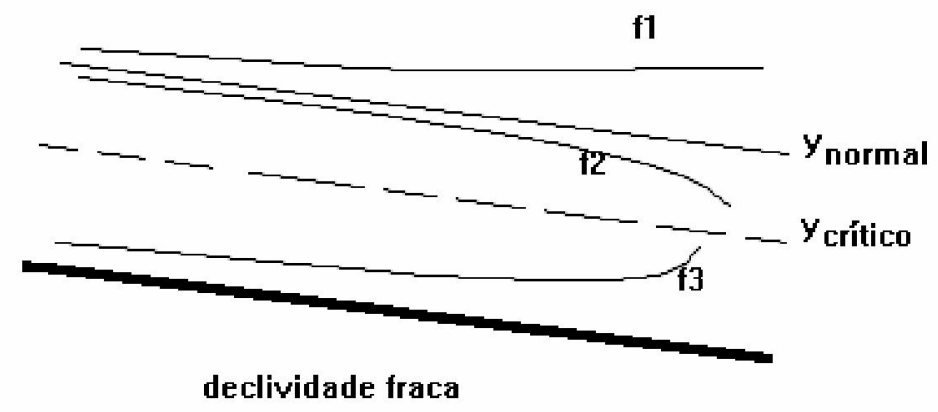

Figura 4.30 - Perfis de linha d' água em declividade fraca 


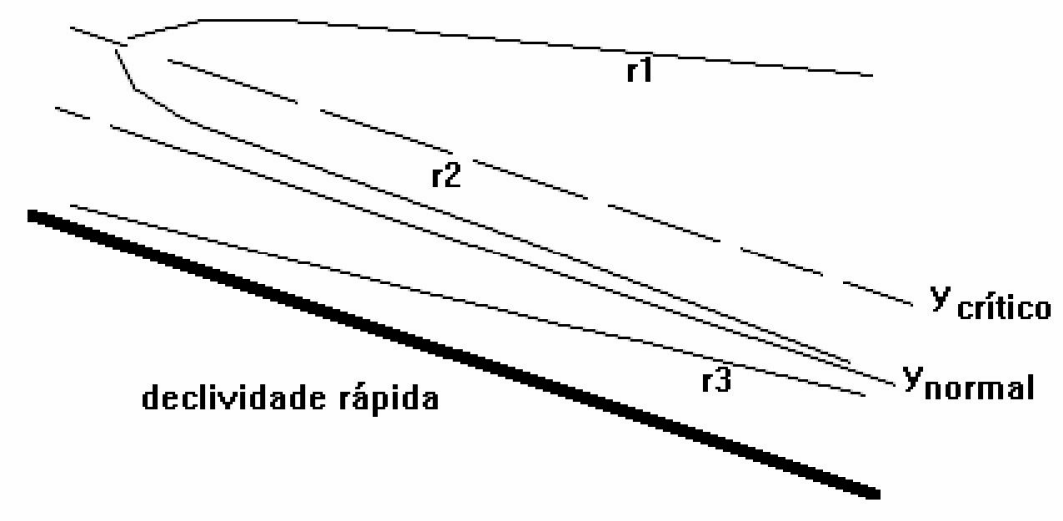

Figura 4.31 - Perfis de linha d' água em declividade rápida.

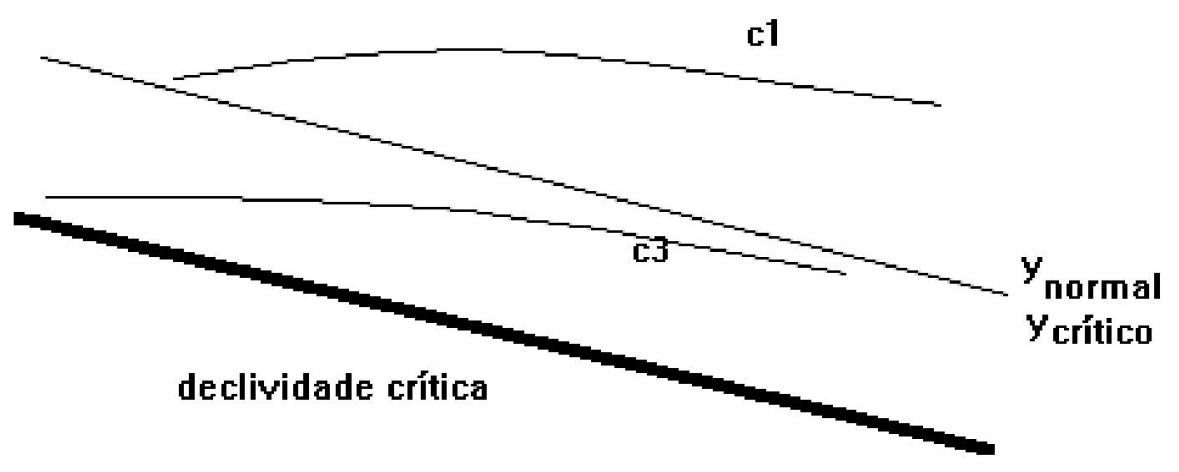

Figura 4.32 - Perfis de linha d' água em declividade crítica.

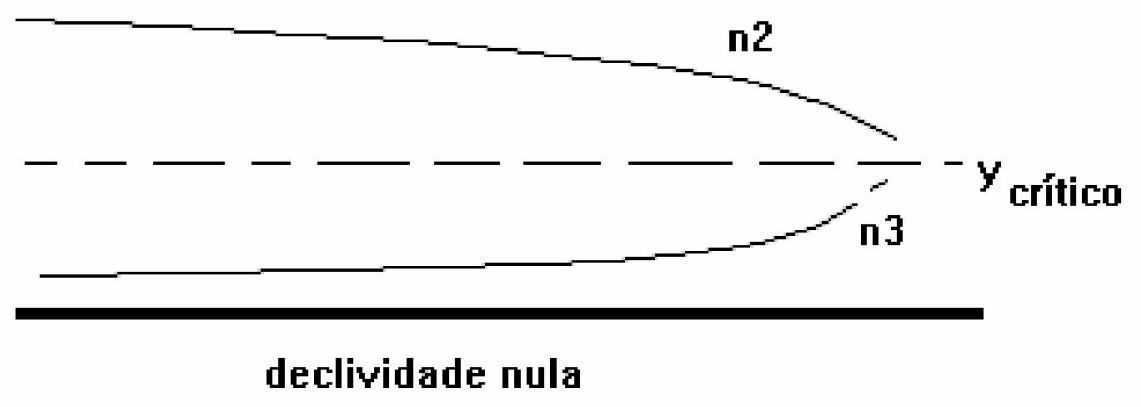

Figura 4.33 - Perfis de linha d' água em declividade nula. 


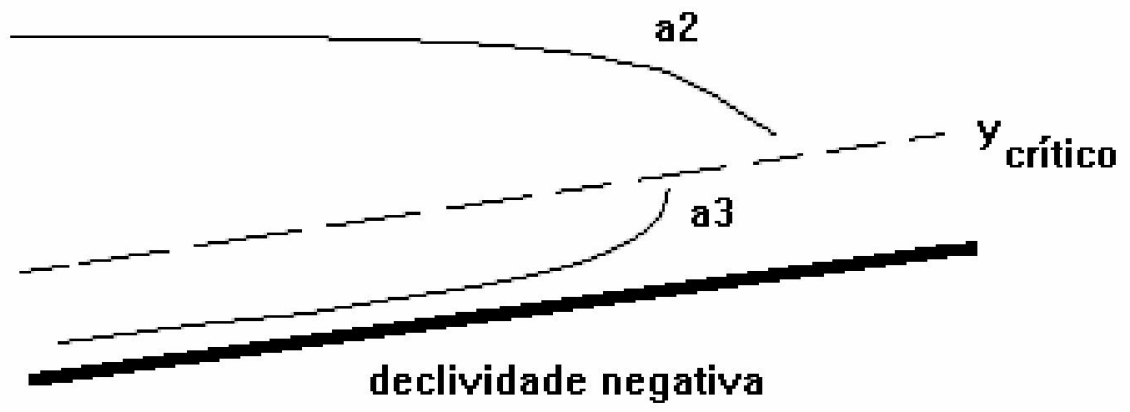

Figura 4.34 - Perfis de linha d' água em declividade negativa.

As 12 representações de curvas das figuras anteriores (f1, f2, f3, r1, r2, r3, c1, c3, n2, n3 e a2 e a3) podem ser combinadas das mais variadas formas nos casos práticos, resultando nas linhas d' água normalmente encontradas nos canais reais.

\subsubsection{Solução Numérica nos Escoamentos Permanentes}

As equações (4.4.1.), (4.4.2.) e (4.4.7.) necessitam ser resolvidas inicialmente para os casos de regime permanente, em todas as seções de interesse. Adota-se para tanto um método numérico de convergência de valores que permita o cálculo dos valores de y em cada ponto.

O método numérico aqui empregado se baseia na substituição das grandezas diferenciais da equação (4.4.7.) por diferenças finitas, onde cada variável será substituída por seu valor médio ponderado no espaço da forma:

$$
\begin{aligned}
& \frac{\partial \beta}{\partial x}=\frac{\beta_{i+1}+\beta_{i}}{\Delta x} \\
& \frac{\partial y}{\partial x}=\frac{y_{i+1}+y_{i}}{\Delta x} \\
& \bar{\beta}=\phi \cdot \beta_{i+1}+(1-\phi) \cdot \beta_{i} \\
& \bar{A}=\phi \cdot A_{i+1}+(1-\phi) \cdot A_{i}
\end{aligned}
$$




$$
\begin{aligned}
& \bar{F} r=\phi \cdot F r_{i+1}+(1-\phi) \cdot F r_{i} \\
& \bar{S} f=\phi \cdot S f_{i+1}+(1-\phi) \cdot S f_{i}
\end{aligned}
$$

Onde, na equação do Froude ao quadrado:

$$
F r^{2}=\frac{Q^{2} \cdot B}{g \cdot A^{3}}
$$

O parâmetro $S f$ pode ser estimado pela equação de Chèzy, pela expressão:

$$
\bar{S} f=\left(\phi \cdot \frac{Q_{i+1}^{2}}{K_{i+1}^{2}}+(1-\phi) \cdot \frac{Q_{i}^{2}}{K_{i}^{2}}\right)
$$

Onde:

$$
K_{i}=C_{i} \cdot A_{i} \cdot \sqrt{R h_{i}}
$$

Substituindo os termos de (4.4.11.) até (4.4.15.) na equação (4.4.7.), obtemos uma equação da forma:

$$
D_{i} \cdot y_{i+1}+B_{i} \cdot y_{i}=E_{i}
$$

Onde:

$$
\begin{aligned}
& D_{i}=g \cdot \frac{A_{i}}{\Delta x}\left(1-F r_{i}\right) \\
& B_{i}=-D_{i} \\
& E_{i}=q_{i} \cdot v_{i}-2 \frac{\bar{\beta}_{i} \cdot \bar{Q}_{i} \cdot q_{i}}{\bar{A}_{i}}-q \cdot \bar{A}_{i} \cdot \bar{S} f-\frac{\bar{Q}_{i}^{2}}{\bar{A} i}\left(\frac{\bar{\beta}_{i+1}+\bar{\beta}_{i}}{\Delta x}\right)
\end{aligned}
$$

A equação (4.4.17.) quando aplicada a um conjunto de n seções dá origem a um sistema de n-1 equações a n incógnitas em y. Admitindo-se uma condição de extremidade na primeira ou na última seção, obtém-se a solução do conjunto. 


\subsubsection{Algoritmo de Solução}

Na obtenção dos valores de y de cada seção, em cada instante de tempo deve-se efetuar um processo no qual são classificados os trechos de canais pelas suas declividades, conforme indicado no item 4.3.1.2.

Para tanto, são calculadas as profundidades normais e críticas de cada trecho entre duas seções, e determinados os tramos onde o escoamento é fluvial, ou seja, onde a profundidade da linha d'água é superior à profundidade crítica, e aquele onde o escoamento é torrencial, cuja profundidade é inferior à crítica.

Nos tramos onde o escoamento é fluvial, realiza-se o cálculo de jusante para montante, pois a profundidade à jusante é conhecida. $\mathrm{O}$ cálculo para os trechos com esta característica segue a fórmula de recorrência:

$$
y_{i}=\frac{E_{i}-D_{i} \cdot y_{i+1}}{B_{i}}
$$

Quando o trecho é torrencial, o cálculo é feito de montante para jusante, através da expressão:

$$
y_{+1}=\frac{E_{i}-B_{i} \cdot y_{i 1}}{D_{i}}
$$

Nas seções onde é constatada a mudança do regime (torrencial-fluvial ou fluvialtorrencial), a compatibilidade do escoamento é verificada pelas expressões da profundidade crítica:

- $\quad$ Escoamento Fluvial $\rightarrow$ Torrencial

$$
F r^{2}=\frac{Q^{2} \cdot B(y)}{g \cdot(A(y))^{3}}
$$

- $\quad$ Escoamento Torrencial $\rightarrow$ Fluvial 


$$
\frac{y_{f}}{y_{t}}=\frac{1}{2}\left(\sqrt{8 \cdot F r^{2}+1}-1\right)
$$

A Equação 4.4.24., expressão do ressalto hidráulico clássico, permite também o posicionamento da mudança de regime, no ponto onde a mesma ocorre.

\subsubsection{Escoamentos Não Permanentes}

\subsubsection{Método de Preissmann}

A solução das equações (4.4.1.) e (4.4.2.) em conjunto só é possível com a adoção de métodos numéricos potentes. Para os escoamentos não permanentes em canais, os métodos de diferenças finitas geralmente têm se mostrado de grande valia, e é hoje consagrado pela maioria dos pesquisadores na área.

Para sua utilização exige-se a adoção de um esquema de discretização temporal e espacial das grandezas envolvidas. Desta forma adotam-se operadores de diferenças finitas como:

$$
\begin{aligned}
& G(x, t)=\Theta\left(\frac{G_{i+1}+G_{i}}{2}\right)^{t+1}+(1-\Theta)\left(\frac{G_{i+1}+G_{i}}{2}\right)^{t} \\
& G(x, t)=\frac{\Theta}{2}\left(\Delta G_{i+1}+\Delta G_{i}\right)+\frac{1}{2}\left(G_{i+1}+G_{i}\right) \\
& \frac{\Delta G}{\Delta x}=\frac{\Theta}{\Delta x}\left(G_{i+1}-G_{i}\right)^{t+1}+\frac{1-\Theta}{\Delta x}\left(G_{i+1}-G_{i}\right)^{t} \\
& \frac{\Delta G}{\Delta x}=\frac{\Theta}{\Delta x}\left(G_{i+1}-G_{i}\right)+\frac{1}{\Delta x}\left(G_{i+1}-G_{i}\right) \\
& \frac{\Delta G}{\Delta t}=\frac{1}{2 \Delta t}\left(G_{i+1}^{t+1}-G_{i}^{t}\right)+\frac{1}{2 \Delta t}\left(G^{t+1}-G_{i}^{t}\right) \\
& \frac{\Delta G}{\Delta t}=\frac{\Delta G_{i+1}+\Delta G_{i}}{2 \Delta t}
\end{aligned}
$$




$$
\tilde{G}=\Theta\left(\frac{G_{i+1}^{*}+G_{i}^{*}}{2}\right)^{t+1}+(1-\Theta)\left(\frac{G_{i+1}+G_{i}}{2}\right)^{t}
$$

Sendo que o termo $\mathrm{G}$ indica uma grandeza genérica relacionada ao escoamento e o termo $\Delta$ indica a variação desta grandeza com o tempo. $\mathrm{O}$ índice $*$ indica que a grandeza assume o valor em $\mathrm{t}$ na primeira iteração de cálculo e de $\mathrm{t}+1$ nas demais iterações. $\mathrm{O}$ parâmetro $\theta$ representa um coeficiente de ponderação no tempo, denominado de implicidade.

Um esquema numérico assim definido é usualmente chamado de Quatro Pontos. A Figura 4.35 ilustra o esquema apresentado.

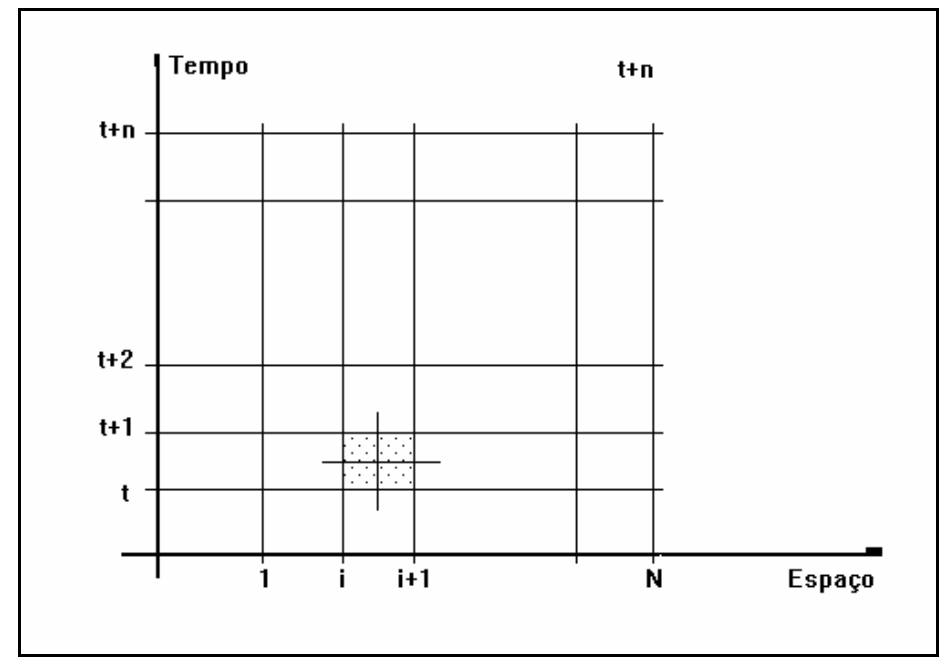

Figura 4.35 - Esquema de diferenças finitas de 4 pontos.

Aplicando-se os operadores de diferenças de (4.4.25.) à equação da continuidade, resulta:

$$
\begin{array}{r}
\frac{\Theta}{\Delta x}\left(\Delta Q_{i+1}-\Delta Q_{i}\right)+\frac{1}{\Delta x}\left(Q_{i+1}-Q_{i}\right)+\frac{\tilde{B}}{2 \Delta t}\left(\Delta y_{i+1}+\Delta y\right)+ \\
\frac{\tilde{p} e}{2 \Delta t}\left(\Delta z_{i+1}+\Delta z_{i}\right)=\tilde{q}
\end{array}
$$




$$
A_{i} \Delta Q_{i}+B_{i} \Delta y_{i}+C_{i} \Delta Q_{i+1}+D_{i} \Delta y_{i+1}=E_{i}
$$

Os coeficientes da equação (4.4.27.) podem ser escritos como:

$$
\begin{aligned}
& A_{i}=-2 \Theta \frac{\Delta t}{\Delta x} \frac{1}{\widetilde{B}} \\
& B_{i}=1 \\
& C_{i}=-2 \Theta \frac{\Delta t}{\Delta x} \frac{1}{\widetilde{B}} \\
& D_{i}=1 \\
& E_{i}=\left(\tilde{q}-\frac{1}{\Delta x}\left(Q_{i+1}-Q\right) \frac{\tilde{p} e}{2 \Delta t}\left(\Delta z_{i+1}+\Delta z_{i}\right)\right) \frac{2 \Delta t}{\widetilde{B}}
\end{aligned}
$$

Aplicando-se o mesmo procedimento à equação da quantidade de movimento obtém-se:

$$
\begin{aligned}
& \frac{\Delta Q_{i+1}+\Delta Q_{i}}{2 \Delta t}+\left(\frac{\Theta}{\Delta x}\left(\Delta Q_{i+1}-\Delta Q_{i}\right)+\frac{1}{\Delta x}\left(Q_{i+1}-Q_{i}\right)\right)+ \\
& +g \tilde{A}\left(1-\tilde{\beta} \tilde{\mathrm{F}}^{2}\right)\left(\frac{\Theta}{\Delta x}\left(\Delta y_{i+1}-\Delta y_{1}\right)+\frac{i}{\Delta x}\left(y_{i+1}-y_{1}\right)\right)+ \\
& +\left.\frac{\tilde{Q}}{\tilde{A}}\left(A_{i+1}-A_{i}\right)\right|_{\tilde{y}=\text { const }}+g \tilde{A} \tilde{\mathrm{S}}_{\mathrm{f}}=\tilde{q} \tilde{\mathrm{v}} \cos \gamma
\end{aligned}
$$

Resultando em:

$$
A_{i}^{\prime} \Delta Q_{i}+B_{i}^{\prime} \Delta y_{i}+C_{i}^{\prime} \Delta Q_{i+1}+D_{i}^{\prime} \Delta y_{i+1}=E_{i}^{\prime}
$$

Onde:

$$
\begin{aligned}
& A_{i}^{\prime}=1-4 \Theta \frac{\Delta t}{\Delta x} \tilde{\beta} \frac{\tilde{Q}}{\tilde{A}} \\
& B_{i}^{\prime}=-2 \Theta \frac{\Delta t}{\Delta x} g \tilde{A}\left(1-\tilde{\beta} \tilde{F}^{2}\right) \\
& C_{i}^{\prime}=1+4 \Theta \frac{\Delta t}{\Delta x} \tilde{\beta} \frac{\tilde{Q}}{\tilde{A}}
\end{aligned}
$$




$$
\begin{aligned}
& D_{i}^{\prime}=-2 \Theta \frac{\Delta t}{\Delta x} g \tilde{A}\left(1-\tilde{\beta} \tilde{F}^{2}\right) \\
& E_{i}^{\prime}=\left(\tilde{q} \tilde{v} \cos \gamma-g \tilde{A} \tilde{S}_{f}\right) 2 \Delta t-4 \frac{\Delta t}{\Delta x}\left(Q_{i+1}-Q_{i}\right) \tilde{\beta} \frac{\tilde{Q}}{\tilde{A}}- \\
& -2 \frac{\Delta t}{\Delta x} g \tilde{A}\left(1-\tilde{\beta} \tilde{F}^{2}\right)\left(y_{i+1}-y_{i}\right)
\end{aligned}
$$

As equações (4.4.27.) e (4.4.34.) quando aplicadas às $\mathrm{N}$ seções de um canal produzem um sistema de $2(\mathrm{~N}-1)$ equações a $2 \mathrm{~N}$ incógnitas em Q e y. A solução é obtida introduzindo-se dois valores conhecidos de $\mathrm{Q}$ ou $\mathrm{y}$, denominados de condições de extremidade, pois são usualmente conhecidos nas extremidades do canal.

\subsubsection{Algoritmo de Solução - Método de Preissmann}

O sistema de equações composto pelas equações (4.4.27.) e (4.4.34.) pode ser solucionado adotando-se como válida a lei:

$$
\Delta Q_{1}=F_{1} \Delta y_{1}+G_{1}
$$

Aplicando-se a relação (4.4.40.) às equações (4.4.27.) e (4.4.34.) obtém-se:

$$
\begin{aligned}
& A_{1}\left(F_{1} \Delta y_{1}+G_{1}\right)+B_{1} \Delta y_{1}+C_{1} \Delta y_{i+1}+D_{1} \Delta y_{i+1}=E_{1} \\
& A_{i}^{\prime}\left(F_{1} \Delta y_{1}+G_{1}\right)+B_{i}^{\prime} \Delta y_{1}+C_{i}^{\prime} \Delta y_{i+1}+D_{i}^{\prime} \Delta y_{i+1}=E_{i}^{\prime}
\end{aligned}
$$

De onde resulta:

$$
\begin{aligned}
& \Delta y_{i}=\underbrace{\frac{C_{i}}{A_{i} F_{i}+B_{i}}}_{H_{i}} \Delta Q_{i+1}-\frac{D_{i}}{\underbrace{A_{i} F_{i}+B_{i}}_{L_{i}}} \Delta y_{i+1}+\underbrace{\frac{E_{i}-A_{i} G_{i}}{A_{i} F_{i}+B_{i}}}_{M_{i}} \\
& \Delta y_{i}=\underbrace{\frac{C_{i}^{\prime}}{A_{i}^{\prime} F_{i}+B_{i}^{\prime}}}_{H_{i}^{\prime}} \Delta Q_{i+1}-\underbrace{\frac{D_{i}^{\prime}}{A_{i}^{\prime} F_{i}+B_{i}^{\prime}}}_{L_{i}^{\prime}} \Delta y_{i+1}+\underbrace{\frac{E_{i}^{\prime}-A_{i}^{\prime} C_{i}}{A_{i}^{\prime} F_{i}+B_{i}^{\prime}}}_{M_{i}^{\prime}}
\end{aligned}
$$

Igualando (4.4.41.) e (4.4.42.) resulta: 


$$
\Delta Q_{i+1}=\underbrace{\frac{L_{i}^{\prime}-L_{i}}{H_{i}^{\prime}-H_{i}^{\prime}}}_{F_{i+1}} \Delta y_{i+1}+\underbrace{\frac{M_{i}^{\prime}-M_{i}}{H_{i}^{\prime}-H_{i}^{\prime}}}_{G_{i+1}}
$$

O método por passos do cálculo é escrito da seguinte forma:

1. Adota-se para a primeira seção $\mathrm{F} 1$ e $\mathrm{G} 1$, em função da condição de extremidade;

2. Para as seções de 2 a N:

- Calcula-se A, B, C, D, E, A', B', C', D', E', H, L, M, H', L', M', Fi+1, $\mathrm{G}_{i+1}$;

- Armazena-se H1, L1, M1 e $\mathrm{F}_{\mathrm{i}+1}, \mathrm{G}_{\mathrm{i}+1}$;

3. Para a seção $\mathrm{N}$ obtém-se $\Delta \mathrm{y}$ ou $\Delta \mathrm{Q}$ e de (4.4.40.) calcula-se $\Delta \mathrm{Q}$ ou $\Delta \mathrm{y}$;

4. Para as seções N-1 até 1:

- $\operatorname{Com}$ (4.4.41.) calcula-se a partir de $\Delta \mathrm{Q}_{\mathrm{i}}$ o valor de $\Delta \mathrm{y}_{\mathrm{i}-1}$;

- $\operatorname{Com}(4.4 .43$.$) e \Delta \mathrm{y}_{\mathrm{i}-1}$ obtém-se $\Delta \mathrm{Q}_{\mathrm{i}-1}$;

5. Retorna-se ao passo 2 para a reiteração dos coeficientes no caso da primeira iteração;

6. Retorna-se ao passo 1 para o próximo passo de tempo.

\subsubsection{Esquema Explícito de MacCormack}

CHAUDRHY et al. (1991) e GARCIA-NAVARRO (1992) apresentaram estudos na aplicação do Esquema Explícito de MacCormack utilizada pelo CLIV em FCTH (2002), outro método numérico utilizado pelo URBSSD, por ter sido utilizado com sucesso no SSD do projeto Gerenciamento Integrado de Bacias Hidrográficas em Áreas Urbanas na bacia do Cabuçu de Baixo, em BARROS (2004). Estes estudos da aplicação do esquema de MacCormack obtiveram grande sucesso na simulação numérica dos escoamentos em canais regulares dotados de pontos singulares, ocorrência de ressaltos hidráulicos e variações de 
fundo.

A discretização numérica do esquema de MacCormack considera um grid espaçotempo, conforme o indicado na Figura 4.36 a seguir, e dois grupos de representações finitas, de segunda ordem de acuracidade, para uma grandeza genérica G, denominados "predictor" e "corrector". Espacialmente, o canal é discretizado através das seções transversais distanciadas de $\Delta \mathrm{x}$. O domínio do tempo é dividido em intervalos $\Delta \mathrm{t}, \mathrm{FCTH}$ (2002).

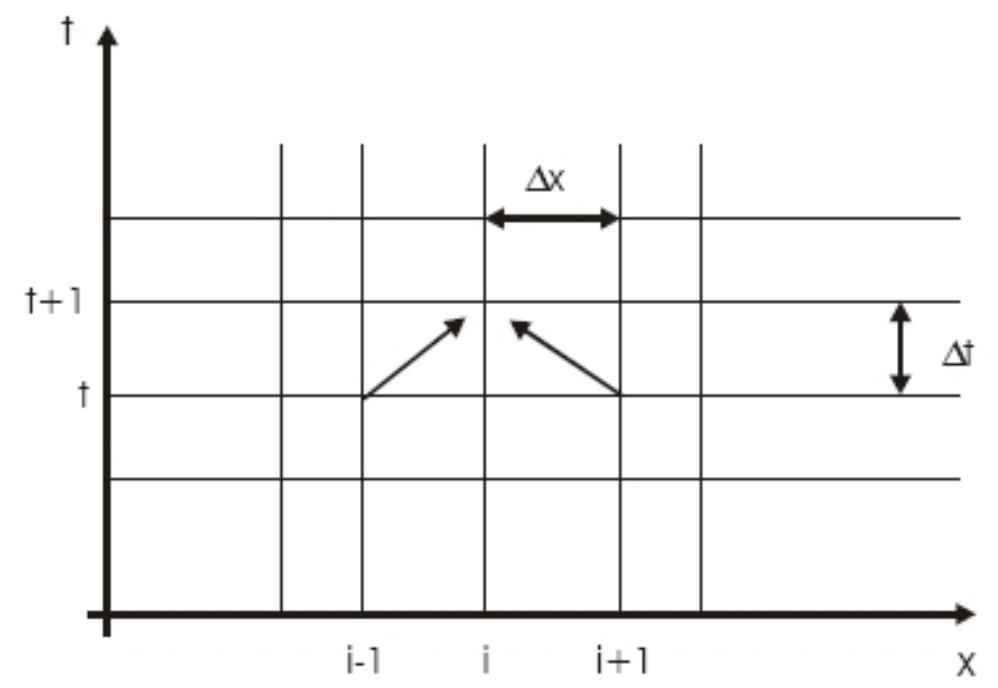

Figura 4.36 - Malha de diferenças finitas (Fonte: FCTH, 2002).

$$
\begin{aligned}
& \frac{\partial G}{\partial t}=\frac{G_{i}^{*}-G_{i}^{t}}{\Delta t} \ldots \frac{\partial G}{\partial x}=\frac{G_{i+1}^{*}-G_{i}^{*}}{\Delta x} \ldots \bar{G}=\frac{G_{i+1}^{t}-G_{i}^{t}}{2} \\
& \frac{\partial G}{\partial t}=\frac{G_{i}^{* *}-G_{i}^{*}}{\Delta t} \ldots \frac{\partial G}{\partial x}=\frac{G_{i}^{* *}-G_{i-1}^{*}}{\Delta x} \ldots \overline{\bar{G}}=\frac{G_{i}^{*}-G_{i-1}^{*}}{2}
\end{aligned}
$$

A aplicação das equações (4.4.44.) e (4.4.45.) às equações básicas define o passo de cálculo denominado "Predictor", da forma: 


$$
\begin{aligned}
& h_{i}^{*}=h_{i}^{t}+\frac{\Delta t}{\left(\bar{B}_{i+1}+\bar{L}_{i}\right)} \cdot\left(q_{s(i+1)}-\left(\frac{\bar{Q}_{i+1}^{t}-Q_{i}^{t}}{\Delta x}\right)\right) \\
& Q_{i}^{*}=Q_{i}^{t}-\Delta\left[\frac{Q_{i+1}^{-}}{\overline{A_{i+1}}}\left(\frac{\beta_{i+1}^{t}-\beta_{i}^{t}}{\Delta x}\right)+2 \beta_{i+1}^{-} \frac{Q_{i+1}}{A_{i+1}}\left(\frac{Q_{i+1}^{t}-Q_{i}^{t}}{\Delta x}\right)-g \overline{A_{i+1}}\left(1-\bar{\beta}_{i+1}^{-} F_{r_{i+1}}^{-}\right)\left(\frac{h_{i+1}^{t}-h_{i}^{t}}{\Delta x}\right)-g \overline{A_{i+1}} S_{f_{i+1}}^{-}\right] \\
& +q_{t_{i+1}}^{-} v_{i+1}^{-} \cos \gamma_{i+1}
\end{aligned}
$$

Aplicando-se novamente as equações (4.4.46.) e (4.4.47.), obtém-se o passo "Corrector":

$$
\begin{aligned}
& \left.h_{i}^{* *}=h_{i}^{*}+\frac{\Delta t}{\left(\overline{\bar{B}}_{i+1}+\overline{\bar{L}}_{i}\right.}\right) \cdot\left(\bar{q}_{s(i)}-\left(\frac{\bar{Q}_{i+1}^{*}-Q_{i}^{*}}{\Delta x}\right)\right) \\
& Q_{i}^{* * *}=Q_{i}^{*}-\Delta t \cdot\left[\frac{\overline{\bar{Q}}_{i}^{2}}{\overline{\bar{A}}_{i}}\left(\frac{\beta_{i}^{t}-\beta_{i-1}^{t}}{\Delta x}\right)+2 \cdot \overline{\bar{\beta}}_{i+1} \cdot \overline{\bar{Q}}_{i+1}\left(\frac{Q_{i}^{*}-Q_{i-1}^{*}}{\Delta x}\right)-g \cdot \overline{\bar{A}}_{i} \cdot\left(1-\overline{\bar{\beta}}_{i+1} \cdot \overline{\bar{F}}_{R i}^{2}\right)\left(\frac{h_{i}^{*}-h_{i-1}^{*}}{\Delta x}\right)-g \cdot \overline{\bar{A}}_{i+1} \cdot \overline{\bar{S}}_{F i}\right] \\
& +\bar{q}_{t i} \cdot \bar{v}_{i} \cdot \cos \gamma_{i}
\end{aligned}
$$

Os valores finais das incógnitas $Q$ e $h$ são calculados após os passos predictor e corrector da forma:

$$
\begin{aligned}
h^{t+1} & =\frac{h_{i}^{t}+h_{i}^{* *}}{2} \\
Q^{t+1} & =\frac{Q_{i}^{t}+Q_{i}^{* *}}{2}
\end{aligned}
$$

De acordo com BARROS (2004), muitos autores indicam que o cálculo das variáreis h e Q podem ser corrigidos através da introdução de uma viscosidade artificial, para amortecimento das oscilações numéricas de altas ordens derivadas do método de 
discretização. Esta correção é dada por:

$$
\begin{aligned}
& \varepsilon_{i}=\frac{\left|h_{i+1-}-2 h_{i}+h_{i-1}\right|}{\left|h_{i+1}\right|+2\left|h_{i}\right|+\left|h_{i-1}\right|} \\
& \varepsilon_{i-1 / 2}=k \frac{\Delta t}{\Delta x} \max \left(\varepsilon_{i-1}, \varepsilon_{i}\right) \\
& \varepsilon_{i+1 / 2}=k \frac{\Delta t}{\Delta x} \max \left(\varepsilon_{i}, \varepsilon_{i+1}\right) \\
& G_{i}^{t+1}=G_{i}^{t+1}+\varepsilon_{i+1 / 2}\left(G_{i+1}^{t+1}-G_{i}^{t+1}\right)-\varepsilon_{i-1 / 2}\left(G_{i}^{t+1}-G_{i-1}^{t+1}\right)
\end{aligned}
$$

O coeficiente de amortecimento k, segundo CAUDHRY (1991) deve ser adotado em cada caso sempre o menor possível, mas suficiente para amortecimento das oscilações de alta frequiência características. Sendo um método explicito, a estabilidade numérica é garantida ao serem obedecidas as condições de Courant-Friedrichs-Lewys, conforme indicado na equação (4.4.55.)

$$
C_{n}=(v+\sqrt{g y}) \frac{\Delta t}{\Delta x} \leq 1
$$

\subsubsection{Algoritmo de Solução - MacCormack}

O algoritmo de solução apresenta quatro etapas para cada passo de tempo:

- Predictor - Caracteriza o Passo Inicial.

- Calculam-se os valores de $\mathrm{Q}^{*}$ e $\mathrm{h}^{*}$ para os pontos $\mathrm{i}=1, \ldots \mathrm{n}-1$, utilizando-se a equação (4.4.46.) e a equação (4.4.47.)

○ Com as condições de contorno corrigem-se os valores de $\mathrm{Q}_{1}$ ou $\mathrm{h}_{1} \mathrm{e}$ $\mathrm{Q}_{\mathrm{n}}$ ou $\mathrm{h}_{\mathrm{n}}$.

- Corrector - Caracteriza o Passo de Correção:

○ Calculam-se os valores de $\mathrm{Q}^{* *}$ e $\mathrm{h}^{* *}$ para os pontos $\mathrm{i}=2, \mathrm{n}$, com as 
equações (4.4.48.) e (4.4.49.)

- Com as mesmas condições de contorno corrigem os valores de $\mathrm{Q}_{1} \mathrm{ou}$ $\mathrm{h}_{1}$ e $\mathrm{Q}_{\mathrm{n}}$ ou $\mathrm{h}_{\mathrm{n}}$

- Cálculo de h e Q

○ Calculam-se os valores de $Q t+1$ e $h t+1$ a partir da equações (4.4.51.) e (4.4.50.), respectivamente.

○ Com $\mathrm{Q}_{\mathrm{t}+1}$ e $\mathrm{h}_{\mathrm{t}+1}$ estima-se o novo $\Delta \mathrm{t}$ para cálculo do passo seguinte;

- Correção dos valores de Qt+1 e ht+1 através da equação (4.4.55.)

\subsubsection{Caracterização das Seções Transversais}

De acordo com BARROS (2004), a discretização do rio ou canal para o cálculo do regime permanente ou variado é sempre feita através de seções transversais típicas. A escolha do número de seções deve atender ao critério de se representar o máximo possível às variações do conduto, tanto em planta como em perfil. Uma maior acuracidade, ou uma menor distância entre as seções, para fins de estabilidade numérica pode ser obtida com critérios de interpolação a cargo do próprio software de cálculo CLIV.

A escolha de um número pequeno de seções pode levar a erros físicos muito grandes e, por outro lado, um número muito elevado de seções provoca grande quantidade de cálculos, aumentando a propagação de erros numéricos. O espaçamento ideal de seções deve ser entre 10 e 20 vezes a largura da seção à superfície. Trechos sinuosos ou com grandes variações de fundo devem ser representados por seções menos espaçadas, que traduzam as influências dos alargamentos e estreitamentos bruscos, soleiras de fundo e outros controles. 


\subsubsection{Canais Naturais}

As seções transversais dos canais naturais devem ter seus parâmetros bem avaliados, para cada cota assumida pelo nível d'água. Representando-se as seções através de pontos cartesianos, os parâmetros de interesse podem ser calculados através da subdivisão em lamelas verticais, como indica a Figura 4.37 a seguir:

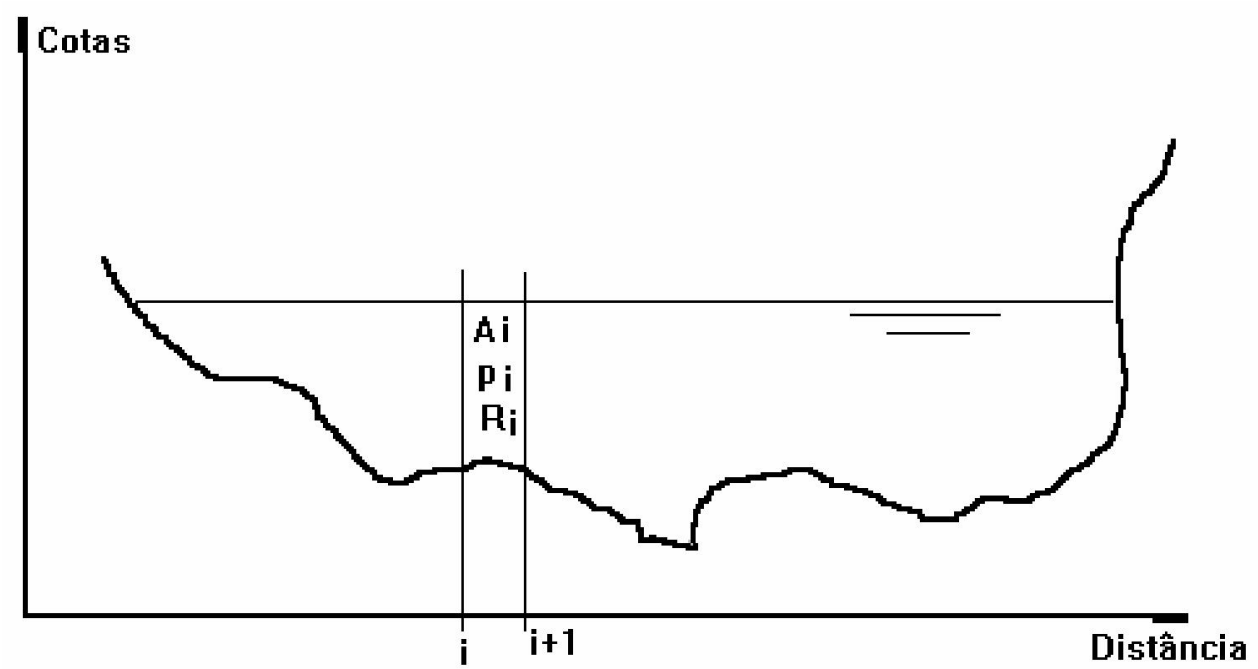

Figura 4.37 - Esquema de representação da seção transversal.

As características hidrogeométricas são obtidas pelas seguintes expressões:

- Área Molhada

$$
A m=\sum_{i+1}^{n} A_{i}
$$

- Perímetro Molhado

$$
p=\sum_{i+1}^{n} p_{i}
$$

- Raio Hidráulico Composto

$$
Q=\sum Q_{i}=\frac{1}{n} A R_{h}^{2 / 3} S_{f}^{1 / 2}=\frac{1}{n} \sum A_{i} R_{h_{i}}^{2 / 3} S_{f}^{1 / 2}
$$




$$
R_{h}=\left[\frac{\sum A_{i} R_{h_{i}}^{2 / 3}}{A}\right]^{3 / 2}
$$

- Raio Hidráulico de Engelund

$$
\begin{aligned}
& Q=\sum Q_{i}=C_{i} A_{i} R_{h}^{1 / 2} S_{f}^{1 / 2}=C A R_{E}^{1 / 1} S_{f}^{1 / 2} \\
& R_{E}=\left[\frac{\sum C_{i} A_{i} R_{h_{i}}^{1 / 2}}{C A}\right]^{2}
\end{aligned}
$$

- Coeficiente de Quantidade de Movimento

$$
\begin{aligned}
& \beta=\frac{\sum A_{i} V_{i}^{2}}{A V^{2}} \\
& \beta=\frac{\sum C_{i} R_{h_{i}} A_{i}}{C^{2} R_{E} A}
\end{aligned}
$$

\subsubsection{Implantação do Modelo CLIV}

Basicamente os dados de entrada a serem fornecidos ao modelo CLIV, pelo shapefile, referem-se a:

- A definição do traçado do trecho de canal em estudo será semelhante à importação de dados definidos no Capítulo 4.1. Estes dados são fornecidos pela importação dos shapefiles com as coordenadas (distâncias) horizontais relativas (x) entre as seções de cálculo. O modelo associa um nó de cálculo a cada seção fornecida. Para maior precisão nos cálculos de linha d'água, pode-se também estipular um número inteiro para indicar em quantos intervalos $\Delta \mathbf{x}$ se deseja subdividir um determinado trecho entre duas seções. 
- Fornecimento dos dados das seções transversais de cálculo. Os dados das características geométricas das seções serão fornecidos através de pares de valores $(\mathrm{x}, \mathrm{y})$, sendo $\mathrm{x}$, a coordenada que representa a largura e $\mathrm{y}$, representa a altitude da seção. Os dados também serão fornecidos através de tabelas a serem importados pelos shapefiles vetorizados em pontos com os respectivos atributos pelo URBSSD.

- Fixação das características hidráulicas do escoamento. O módulo hidrológico $(\mathrm{CABC})$ fornecerá as vazões no início do trecho e, caso houver, também devem ser fornecidas as vazões incrementais em cada seção subseqüente a jusante. Na simulação hidráulica, as características revestimento/cobertura das paredes do canal, através do coeficiente de rugosidade de Manning, são definidas pela calibração. De acordo com FCTH (2002), é possível definir diferentes rugosidades em diferentes elevações da seção de cálculo. Estes são os dados mínimos necessários para se calcular a linha d'água do canal em regime permanente e posteriormente os transitórios. As correspondências são definidas num arquivo TXT denominado "corresp.txt", criado durante a calibração.

- Fixação das condições de contorno do problema. Tanto para o cálculo em regime permanente quanto para o transitório, é necessário fornecer as chamadas condições de contorno do escoamento nas duas extremidades do canal em estudo. Estas condições de contorno referem-se, por exemplo, às imposições de níveis d'água a montante ou a jusante do canal, através de uma cota fixa ou limnigramas. O fornecimento de uma lei cota-descarga a 
jusante ou uma lei de abertura/fechamento de bombas ou turbinas também se constitui em condições que irão alterar, ao longo do tempo, as condições iniciais do escoamento em regime permanente.

- Definição da superfície de inundação. Para o cálculo da mancha de inundação, é necessário o fornecimento um arquivo em formato de três dimensões, como a Modelagem Digital de Terreno (MDT) no diretório próprio do programa.

Como resultados das simulações hidráulicas, poderão ser fornecidos os limnigramas em formato de gráficos e tabelas (cotas em metros e tempos em horas) para cada trecho calculado da bacia com o desenho da mancha de inundação sobre uma imagem qualquer (fotos de satélite ou de foto aérea devidamente georreferenciadas). A Figura 4.38 é uma interface de resultado.

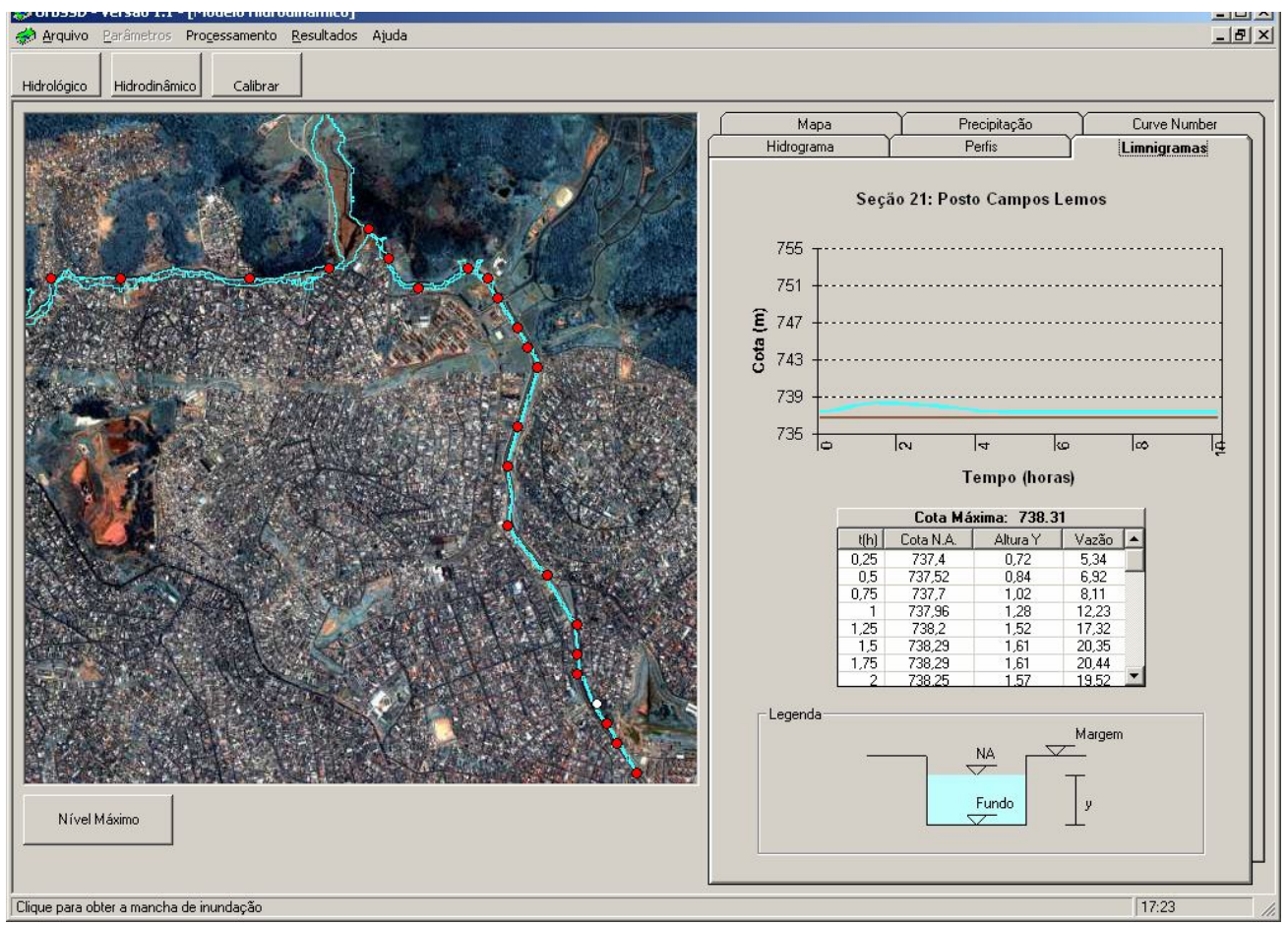

Figura 4.38 - Saída de dados do modelo hidráulico pelo módulo hidráulico. 
Os limnigramas podem ser substituídos pelos gráficos da Lamina d’ Água Mínimo e Máximo e a Cota do Terreno (Figura 4.39).

O SSD permite também a exportação de arquivos DXF do banco de dados espacial resultante para poderem ser usados em outros aplicativos SIG.

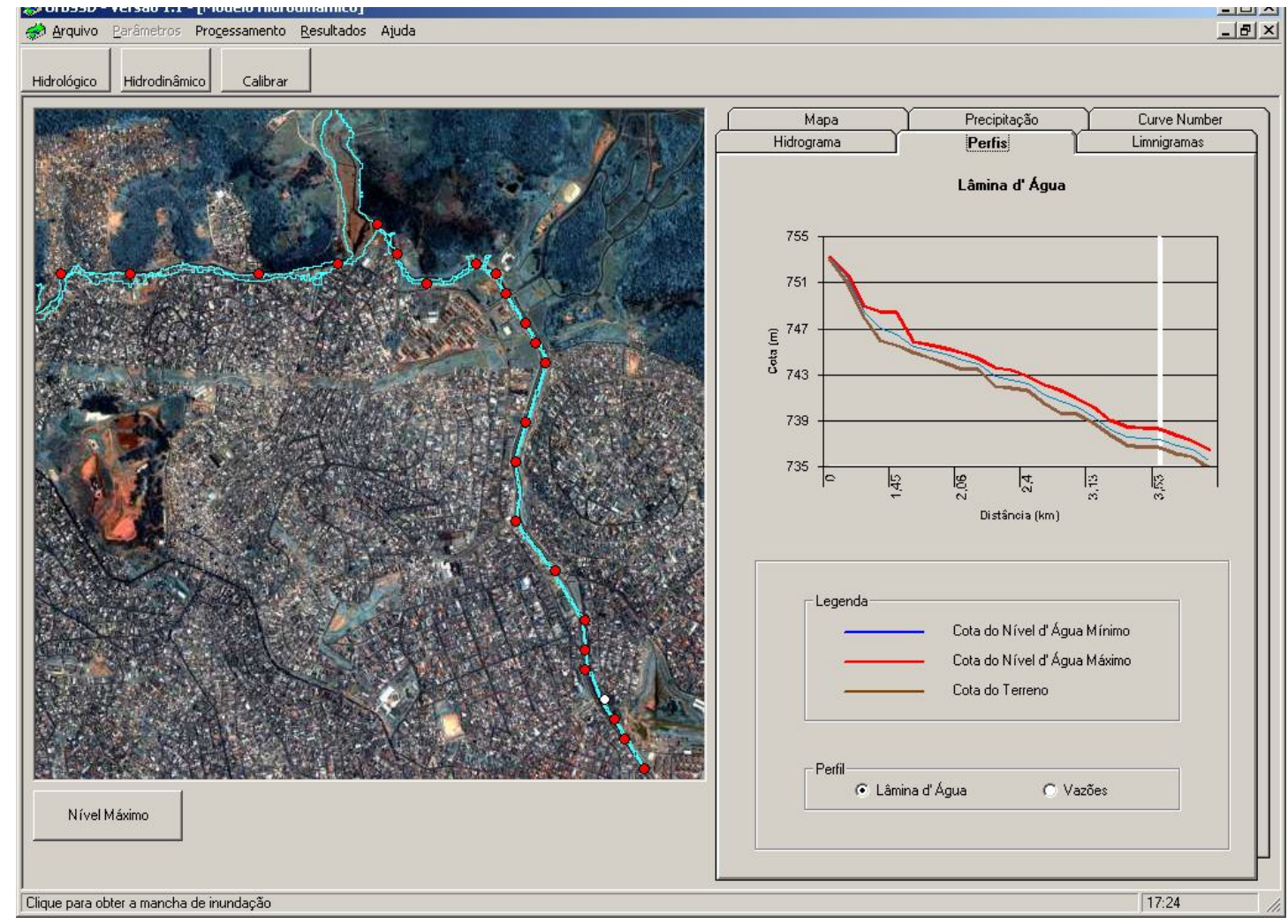

Figura 4.39 - Saída de dados do modelo hidráulico pelo módulo CLIV com o gráfico de perfil de lâmina d' água.

Podem ser utilizados os resultados de simulações hidráulicas e hidrológicas com períodos de retorno de variável para elaborar diversos produtos em diversas abordagens multidisciplinares provenientes, principalmente da geografia, ecologia, arquitetura e urbanismo, com a utilização e integração de conceitos de planejamento ambiental, ecologia da paisagem, corredores verdes (greenways) e "alagados construídos" (wetlands). 


\section{Estudo de Caso: Bacia do rio Cabuçu de Baixo}

A Região Metropolitana de São Paulo (RMSP) constitui uma das referências mais conhecidas dos problemas advindos da urbanização intensa, de um processo de descontrole e modificação hidromorfológica, que tende a se ampliar à medida que a população migra para áreas anteriormente ocupadas pelas várzeas ou pelas matas.

Por isso, foi escolhida como estudo a bacia do rio Cabuçu de Baixo, pois caracteriza muito bem o problema de água urbana das grandes cidades em ritmo de crescimento. Enfrenta problemas de ocupação irregular, áreas de risco de inundações e escorregamento de morro, falta de moradia adequada para boa parte dos seus habitantes, falta de infraestrutura urbana, geração de resíduos sólidos e líquidos lançados diretamente na rede hídrica, entre outros. Enfim é uma bacia que apresenta todos os tipos de fatores que contribuem para a degradação da água urbana e, conseqüentemente, do padrão de vida da população.

Segundo CANHOLI (2005), a população diretamente atingida pelas enchentes, por causa da inundação de suas moradias ou dos transtornos ao tráfego na Avenida Inajar de Souza, totalizava cerca de 300 mil pessoas. A população da área inundável era aproximadamente de 20 mil habitantes, sujeitos freqüentemente a perdas materiais. Eram perdidos gêneros alimentícios, móveis, eletrodomésticos e até mesmo vidas humanas. Em BARROS et al. (2004), foi até proposto para a comunidade um sistema de alerta a inundações como solução ao problema da alta velocidade de propagação das cheias. Além do problema das enchentes, ocorriam nessa área casos de mortes por afogamento e por leptospirose. 


\subsection{Características Físicas da Bacia}

A bacia do rio Cabuçu de Baixo é afluente da margem direita do rio Tietê, nas proximidades da ponte Freguesia do Ó, no bairro de mesmo nome. Estas unidades são mostradas na Figura 5.1. A declividade do talvegue é considerada alta, por localizar-se na encosta da Serra da Cantareira, variando entre $1,1 \%$ e $2,8 \%$.

A área de estudo possui uma área de aproximadamente $42 \mathrm{~km}^{2}$. Localiza-se na zona norte do município de São Paulo, entre os meridianos 46³7'00’' e 4644'00', Oeste e entre os paralelos $23^{\circ} 24^{\prime} 00^{\prime}$ ' e $23^{\circ} 32^{\prime} 00^{\prime}$ ' Sul. Abrange vários bairros da Zona Norte, tais como a Freguesia do Ó, Vila Nova Cachoeirinha, Vila Brasilândia e Jardim Damasceno.

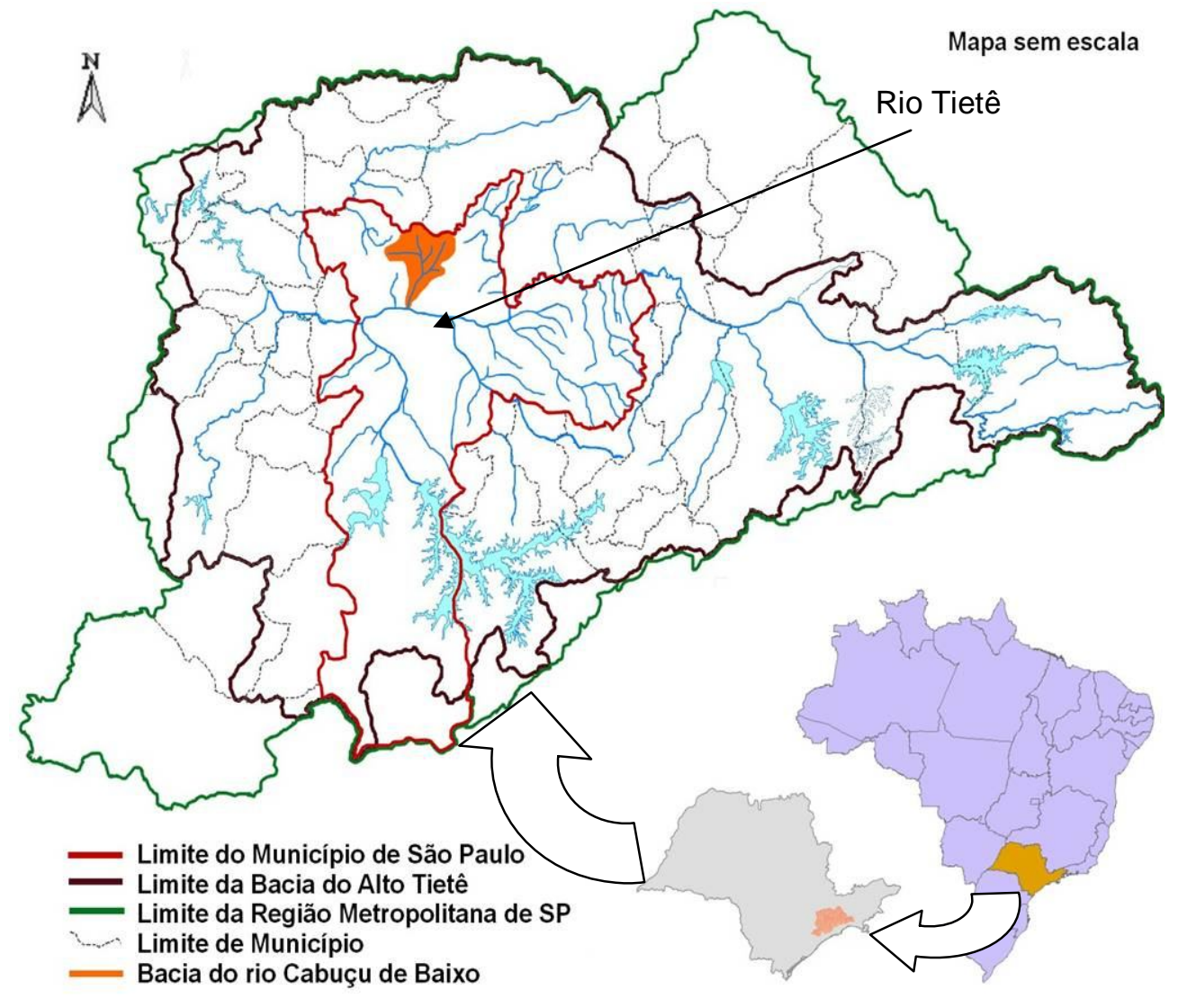

Figura 5.1 - Localização da bacia do rio Cabuçu de Baixo 
Do ponto de vista geomorfológico, a bacia do rio Cabuçu de Baixo pertence ao Planalto Atlântico, que juntamente com a Depressão Periférica, as Cuestas Basálticas e o Planalto Ocidental, formam as províncias geomorfológicas do estado de São Paulo, ALMEIDA (1974).

O local é caracterizado por terras altas, constituído por um planalto montanhoso, contemplando altitudes que variam entre $725 \mathrm{~m}$ na jusante da bacia, até $1205 \mathrm{~m}$, no topo dos morros. Esta grande diferença altimétrica se dá em função das características físicas locais, onde as altitudes se elevam progressivamente em direção ao norte da bacia, BARROS (2003).

De modo geral, notadamente em sua porção norte, apresenta um relevo do tipo denudacional, onde as vertentes e interflúvios possuem dissecação moderada. Nesse contexto, há um predomínio dos processos morfogenéticos sobre os pedogenéticos, fato que evidencia a instabilidade da área que esta sujeita desde desagregação mecânica até processos superficiais de escoamento difuso e concentrado, responsável pelo surgimento de sulcos, ravinas e voçorocas, RADAMBRASIL (1983). O IPT (1981) também ressalta a dinâmica instável da região.

Outro aspecto que reforçou a escolha desta área de estudo é que se observa ao longo das duas últimas décadas que a expansão urbana está aumentando. O mapa da Figura 5.2 mostra as mudanças no uso e cobertura da terra, entre 1985 e 2002, através da identificação de áreas urbanizadas e não urbanizadas, por BARROS (2003). 


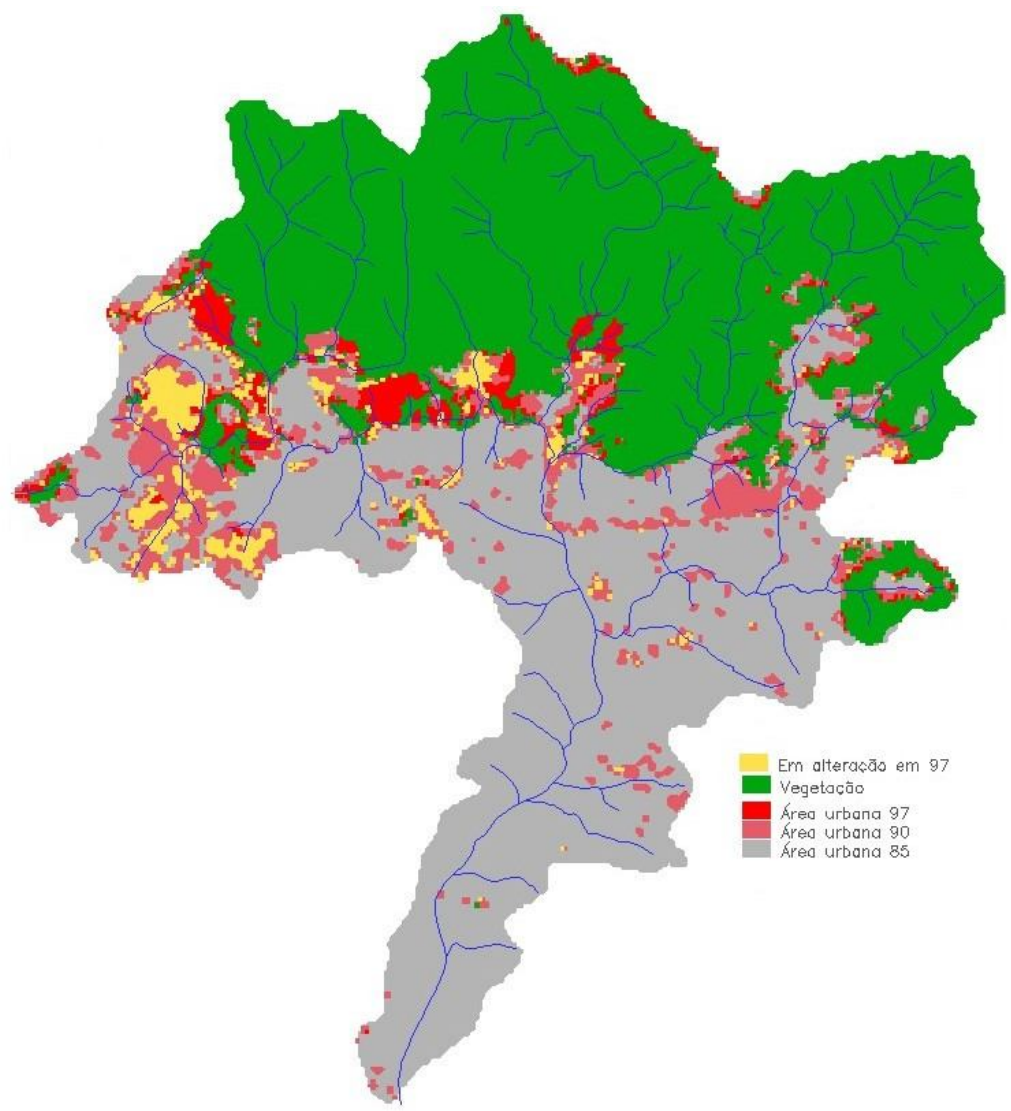

Figura 5.2 - Mapa da evolução do uso do solo 1985 - 1997 (BARROS, 2003).

Esses dados indicam que os processos de expansão e de urbanização ocorreram, sobretudo, ao longo da fronteira centro-norte da bacia, no entorno do Parque da Cantareira. E, embora a taxa média de expansão tenha sido de $1,5 \%$ ao ano, a mesma não ocorreu de maneira linear, onde foram encontradas as taxas de 1,8; 0,4 e 3,2 respectivamente para os períodos 1985-1990, 1990-1997 e 1997-2000. O dado referente ao ano 2000 é baseado na classificação de uso do solo realizada por foto interpretação na imagem Ikonos do mesmo ano.

Assim, a área urbanizada expandiu de 40\% em 1985 para 62\% em 2000. Como dado adicional, entre os anos de 2000-2002 foi realizado um novo levantamento da expansão urbana no período a partir da utilização de novas imagens Ikonos de alta 
resolução, do ano de 2002. Através desse levantamento, se verificou um incremento de apenas 0,06\% em relação à área até então construída, e não ocorreram novos avanços sobre a área do Parque da Cantareira. Cabe ressaltar, porém, que dos 0,06\% do incremento de áreas construídas, 62\% ocorreram em áreas de proteção legal, nas quais se incluem as margens de córregos e linhas de transmissão, PMSP (2003). Não tendo sido observado a ocorrência de novos loteamentos.

A expansão urbana verificada nas últimas décadas é sem dúvida expressiva e embora nos últimos três anos não tenham sido identificados novos avanços da mancha urbana sobre as áreas florestais da Serra da Cantareira, grandes loteamentos, que avançaram sobre áreas verdes adjacentes a Serra da Cantareira e que ainda não se encontram ocupados, estão em vias de serem regularizados. Além disso, esses loteamentos encontram-se em fase de consolidação de sua infra-estrutura (pontes de acesso, água e energia), o que consequentemente intensificaria a sua ocupação.

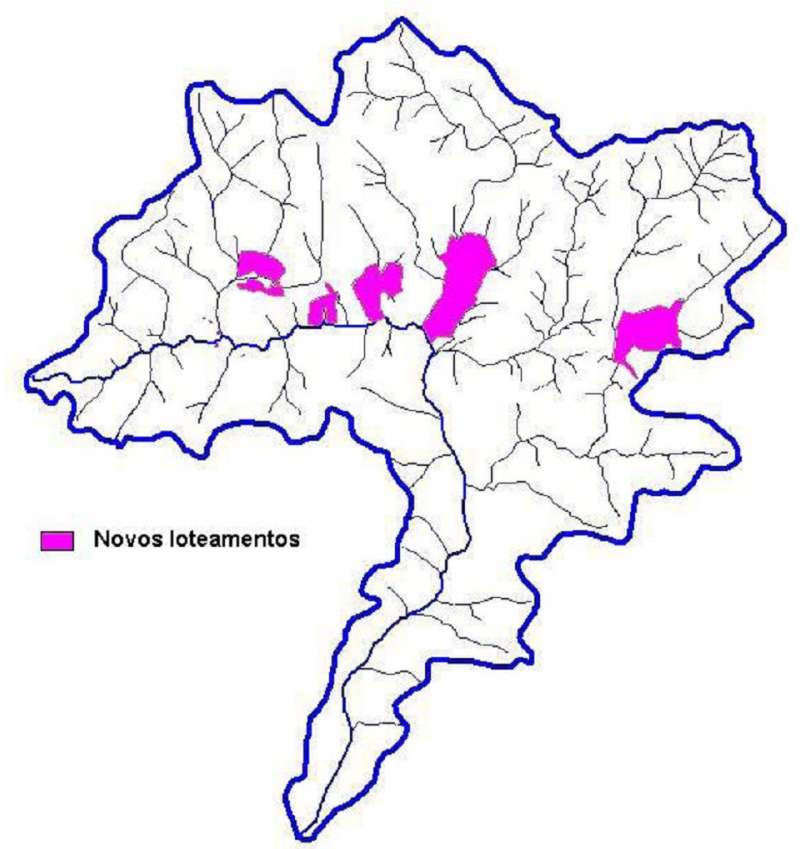

Figura 5.3 - Localização dos novos loteamentos em estudo realizado em 2002. (BARROS, 2003) 
De acordo com BARROS (2003), haveria um incremento de até 10,54\% em relação às áreas atualmente construídas e, portanto, impermeabilizadas (Figura 5.3).

Portanto, a expansão urbana justifica a implantação de um Sistema de Suporte a Decisão para esta bacia, pois a dinâmica da região recorre a um modelo chuva-vazão que contenha uma das variáveis o parâmetro CN do Soil Conservation Service, que envolve impermeabilização com uso do solo.

Em ONO et al. (2005), foram descritas as principais metodologias no processamento de dados vetoriais utilizados para obtenção de diversos produtos cartográficos, entre eles as manchas de inundação, mapa de declividade, mapa de uso do solo, mapas do Plano de Recuperação Ambiental e da Paisagem (PRAP), mapa de risco ambiental, etc. 


\subsection{Discretização da Bacia}

As sub-bacias, ou os principais cursos d'água da bacia do Cabuçu de Baixo são: córrego Bananal (1), córrego Itaguaçu (2), córrego Guaraú (3), córrego do Bispo (4) e rio Cabuçu de Baixo (curso inferior)(5), de acordo com a Figura 5.4. As particularidades de cada sub-bacia serão descritas nos subitens seguintes de um a cinco.

Existem dois reservatórios de contenção de cheias (piscinões): o Piscinão Bananal e o Piscinão Guaraú.

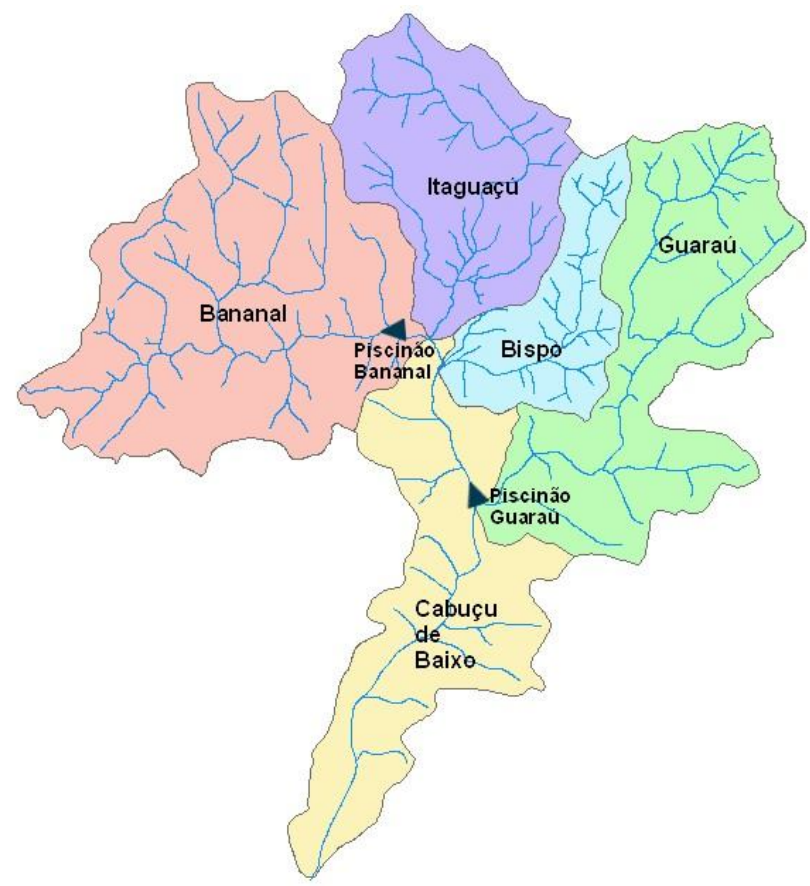

Figura 5.4 - Principais cursos d'água da bacia do Cabuçu de Baixo: Bananal, Itaguaçu, Guaraú, Bispo e Cabuçu de Baixo trecho final.

\subsubsection{Sub-bacia Córrego do Bananal}

A sub-bacia Córrego Bananal tem praticamente a metade de sua área urbanizada, a outra metade é coberta pelo Parque Estadual da Cantareira, o maior fragmento florestal urbano da Região Metropolitana de São Paulo (RMSP). A população da bacia é de 120.000 
habitantes, segundo o censo do IBGE de 2000, e de acordo com BARROS (2005), enfrentava sérios problemas de inundação. Observam-se processos de ocupação na borda florestal externa ao Parque da Cantareira, que possivelmente vão se ampliar, caso não sejam tomadas medidas de controle e deverão piorar ainda mais as inundações na região.

A Figura 5.5 mostra a sub-bacia do Bananal, com a localização dos principais córregos (Corumbé e Canivete) que formam a sub-bacia e a localização do já construído Piscinão Bananal e também do Piscinão Corumbé, proposto por BARROS (2005). As áreas delimitadas em azul estão os locais críticos de inundação, de acordo com as fotos da Figura 5.6.

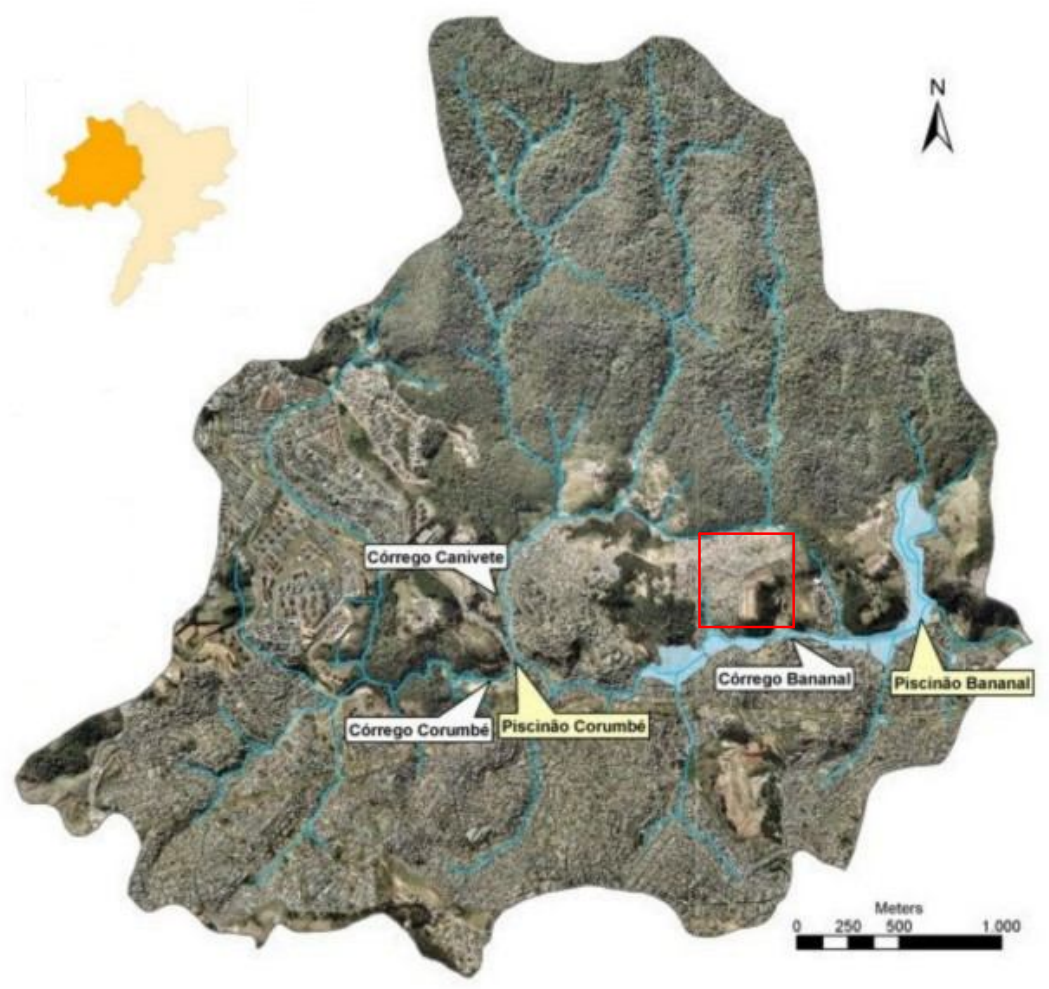

Figura 5.5 - Foto aérea da bacia do Bananal com a localização dos principais afluentes e piscinões construídos e propostos. 


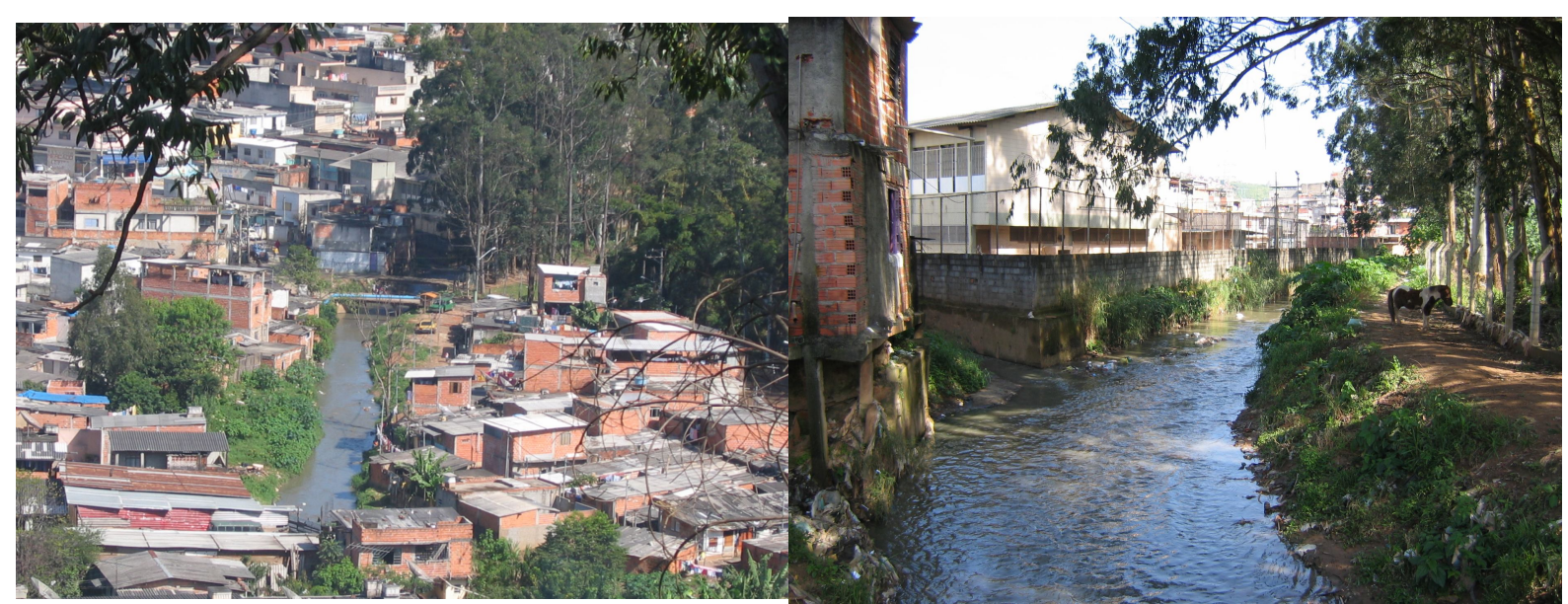

Figura 5.6 - Fotos das áreas críticas de inundações na sub-bacia do Bananal

A sub-bacia do Bananal é a que vem sofrendo seqüentes mudanças no seu uso e ocupação do solo, principalmente em áreas ribeirinhas. O quadrado em vermelho da Figura 5.5 é a Vila Paraná, limite territorial dos quadros da Figura 5.7, que demonstra a evolução da ocupação antrópica a menos de 100 metros das margens do córrego Bananal, próxima à Serra da Cantareira. Observa-se nesta figura a evolução aplicando uma seqüência de quatro imagens georreferenciadas, que foram importantes (exceto o último quadro) para a análise de uso do solo em BARROS (2004):

- Quadros 1 e 2: Mosaicos de imagens de satélite Ikonos dos anos 2000 e 2002, respectivamente, adquiridas no modo CARTERRA GEO Pancromática (PAN), com 1 metro de resolução espacial, e multiespectral (MSS), com 4 metros de resolução. Ambos os mosaicos cobrem toda a área da Bacia do Cabuçu de Baixo $\left(42 \mathrm{Km}^{2}\right)$.

- Quadro 3: Mosaico formado por 68 fotografias aéreas digitais de 2003, escala do vôo 1:8000, adquiridas em meio analógico (filme aéreo) e posteriormente digitalizadas através de um scanner fotogramétrico. As imagens digitais foram padronizadas em RGB 24 bit com 900 dpi, gerando 
arquivos da ordem de $210 \mathrm{MB}$ por imagem. O mosaico cobre apenas a área da sub-bacia do Bananal.

- Quadro 4: Imagem adquirida pelo software "Google Earth", GOOGLE (2007), disponibilizada para o domínio público. De acordo com o software, a imagem foi adquirida pela DIGITAL GLOBE (2008) no ano de 2008.

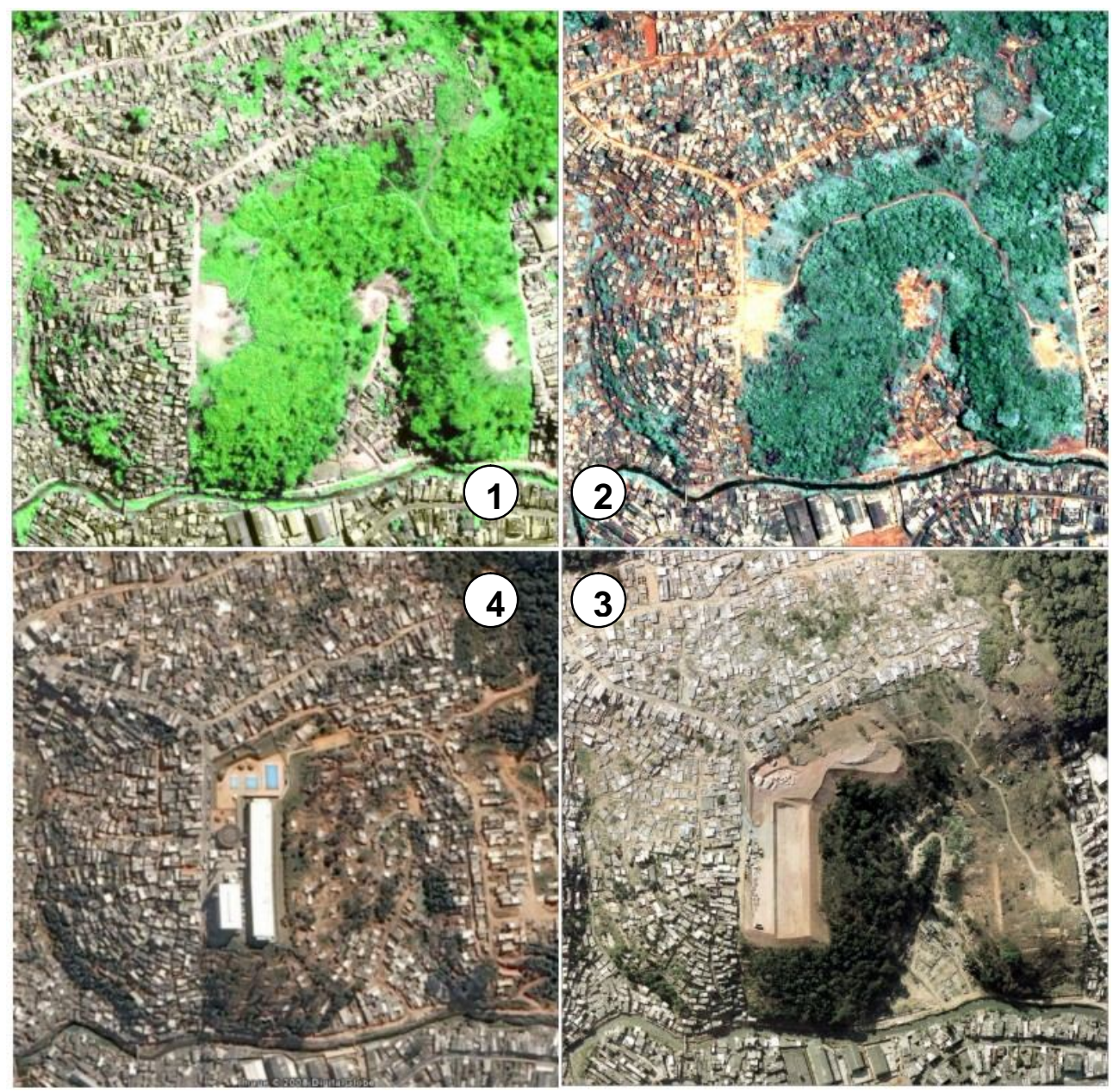

Figura 5.7 - Evolução da ocupação urbana, de acordo com a seqüência de quadros de 1 a 4 (anos 2000, 2002, 2003 e 2008) respectivamente, no sentido horário.

Na Figura 5.8 mostra a foto panorâmica dos quadros da Figura 5.7, que é o Centro Educacional Unificado Paz (CEU - Paz), localizada na Rua da Paz, 107 - Vila Paraná, Subprefeitura da Freguesia do Ó. A localização deste empreendimento público está muito próxima do Parque da Serra da Cantareira, que é um local de proteção ambiental. Tal 
construção demonstra que o uso e ocupação de solo da bacia do Bananal deve ser constantemente reavaliado para poder gerar o escoamento superficial, visto que em quatro anos uma relativa área da bacia transformou-se de área livre (ano de 2000) para solo exposto / área construída (ano de 2003) e posteriormente, para área construída com alta porcentagem de impermeabilização (a partir do ano de 2004).

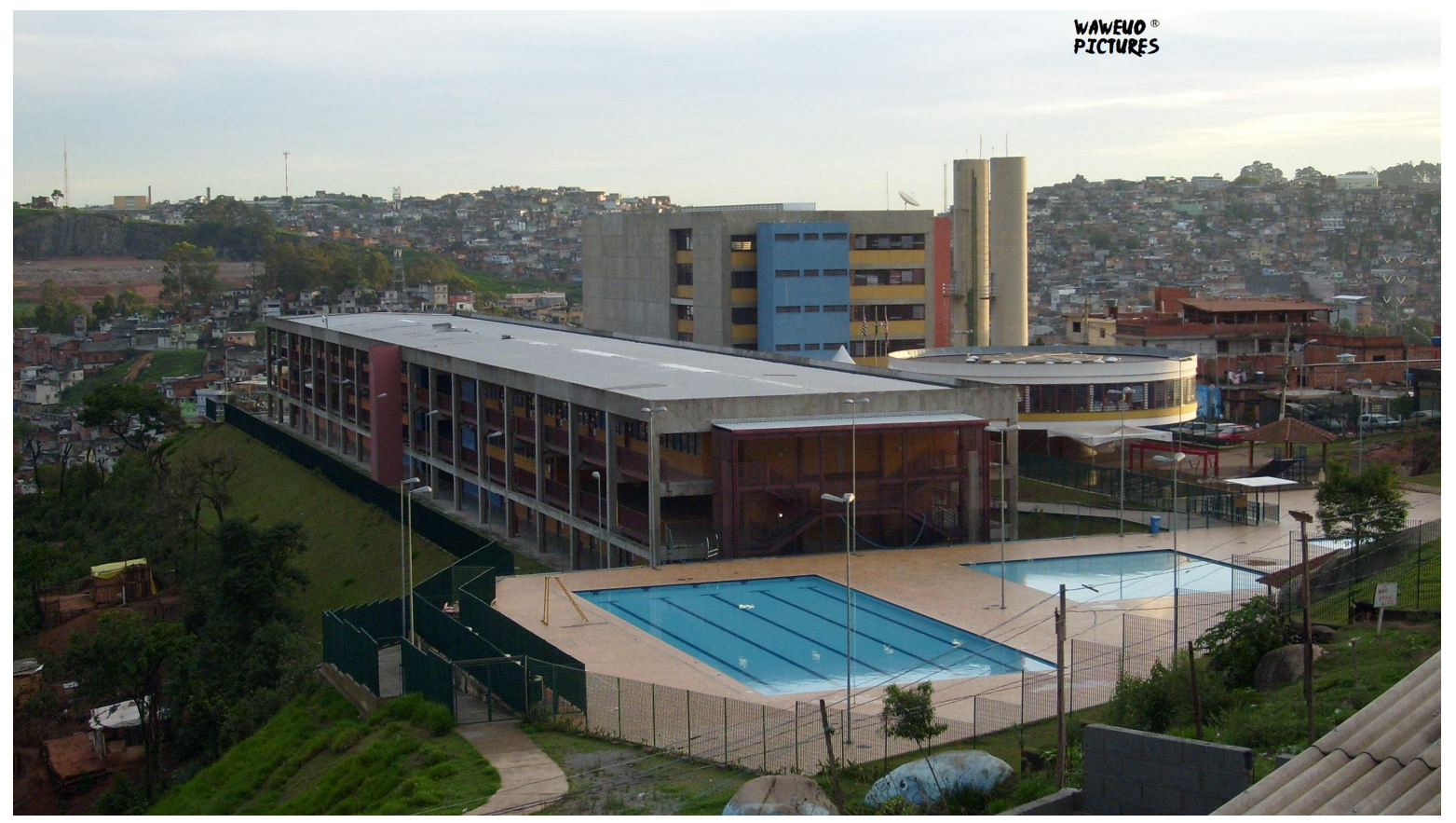

Figura 5.8 - Foto panorâmica do CEU-Paz (FONTE: GOOGLE, 2008).

\subsubsection{Sub-bacia Córrego Itaguaçu}

Encontra-se em grande parte na área preservada da Serra da Cantareira e, mesmo com o loteamento residencial proposto pela empresa Imobel, que é uma construção vertical e com muitas áreas verdes, não deverá agravar as enchentes. Desde o início do estudo, em 2000, as vendas do loteamento residencial não vêm obtendo sucesso, mesmo com as melhorias da Avenida Inajar de Souza, que liga o bairro Vista Alegre com a Marginal do Rio Tietê. A Figura 5.9 mostra uma foto do loteamento residencial e a Figura 5.10, a sua localização e foto aérea. 


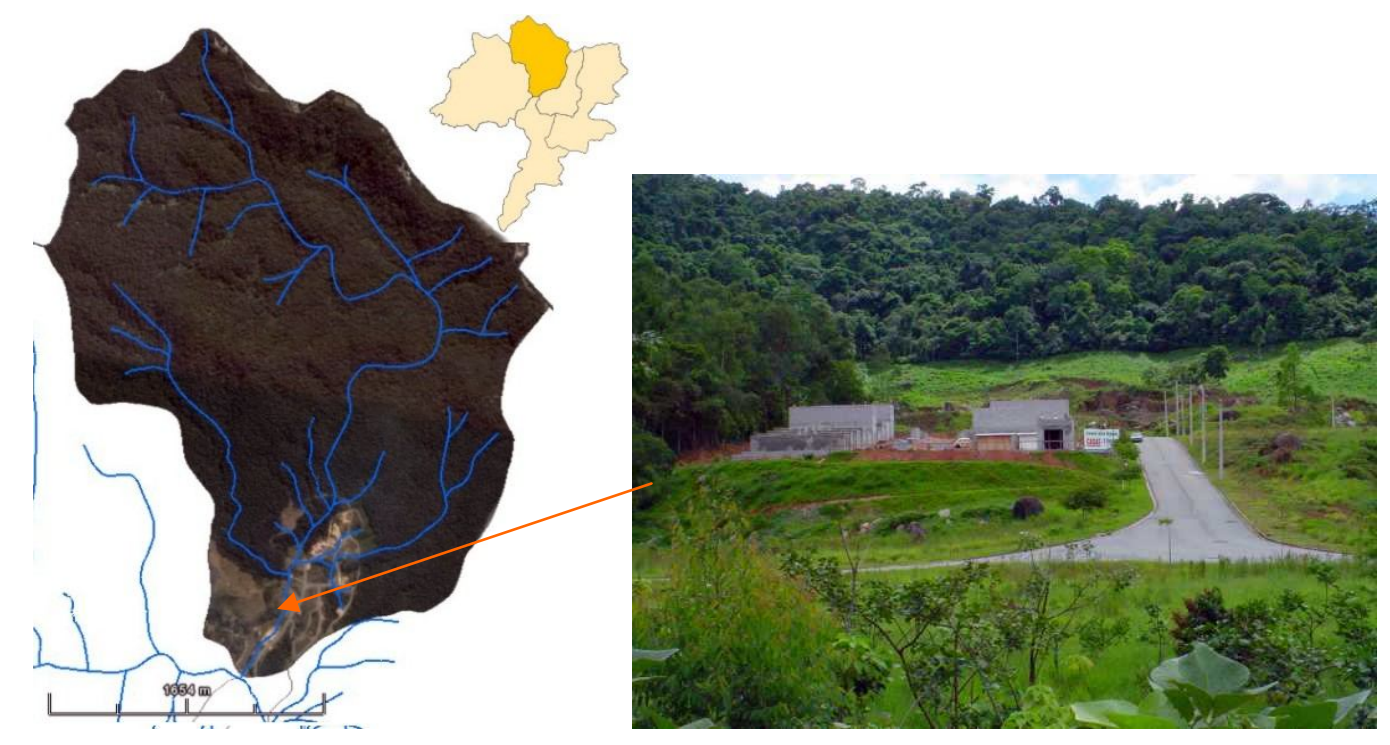

Figura 5.9 - Foto aérea da sub-bacia Itaguaçu e o loteamento residencial da empresa Imobel

\subsubsection{Sub-bacia Córrego do Bispo}

Não está canalizado e sua bacia encontra-se em grande parte na Reserva da Cantareira (margem direita). Contudo, a sua margem esquerda encontra-se densamente ocupada, em quase na sua totalidade, por favelas.

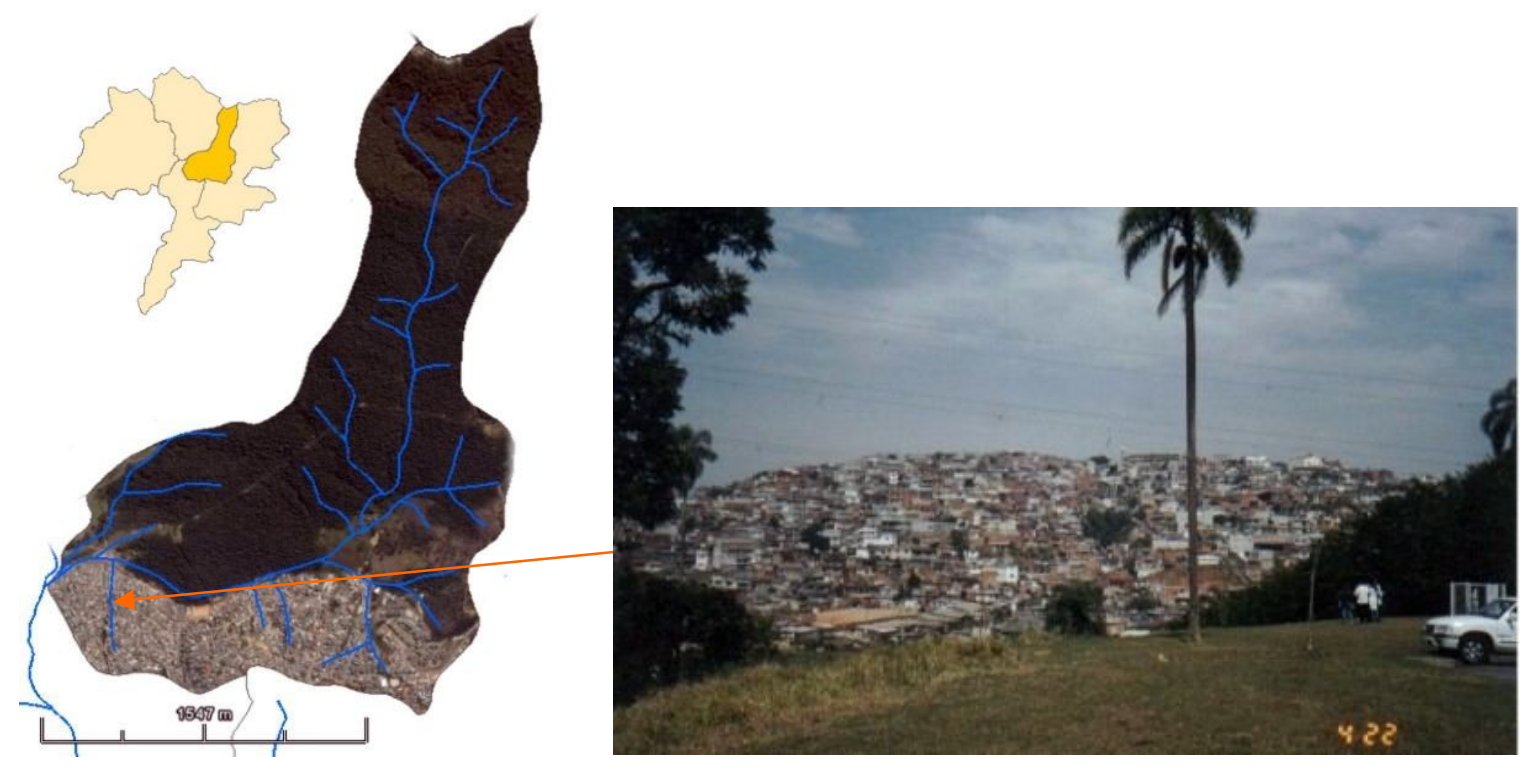

Figura 5.10 - Foto aérea da sub-bacia do Bispo e o detalhe da ocupação da margem esquerda. 


\subsubsection{Sub-bacia Córrego Guaraú}

Localiza-se nesta sub-bacia a E.T.A. Guaraú da SABESP, que conta com uma barragem que permite a laminação das vazões de cheia. Junto à sua foz o córrego encontrase canalizado numa extensão de $680 \mathrm{~m}$ por meio de galeria dupla quadrada de 2,25 m de lado. Na sua porção final a galeria recebe a contribuição do córrego Água Preta.
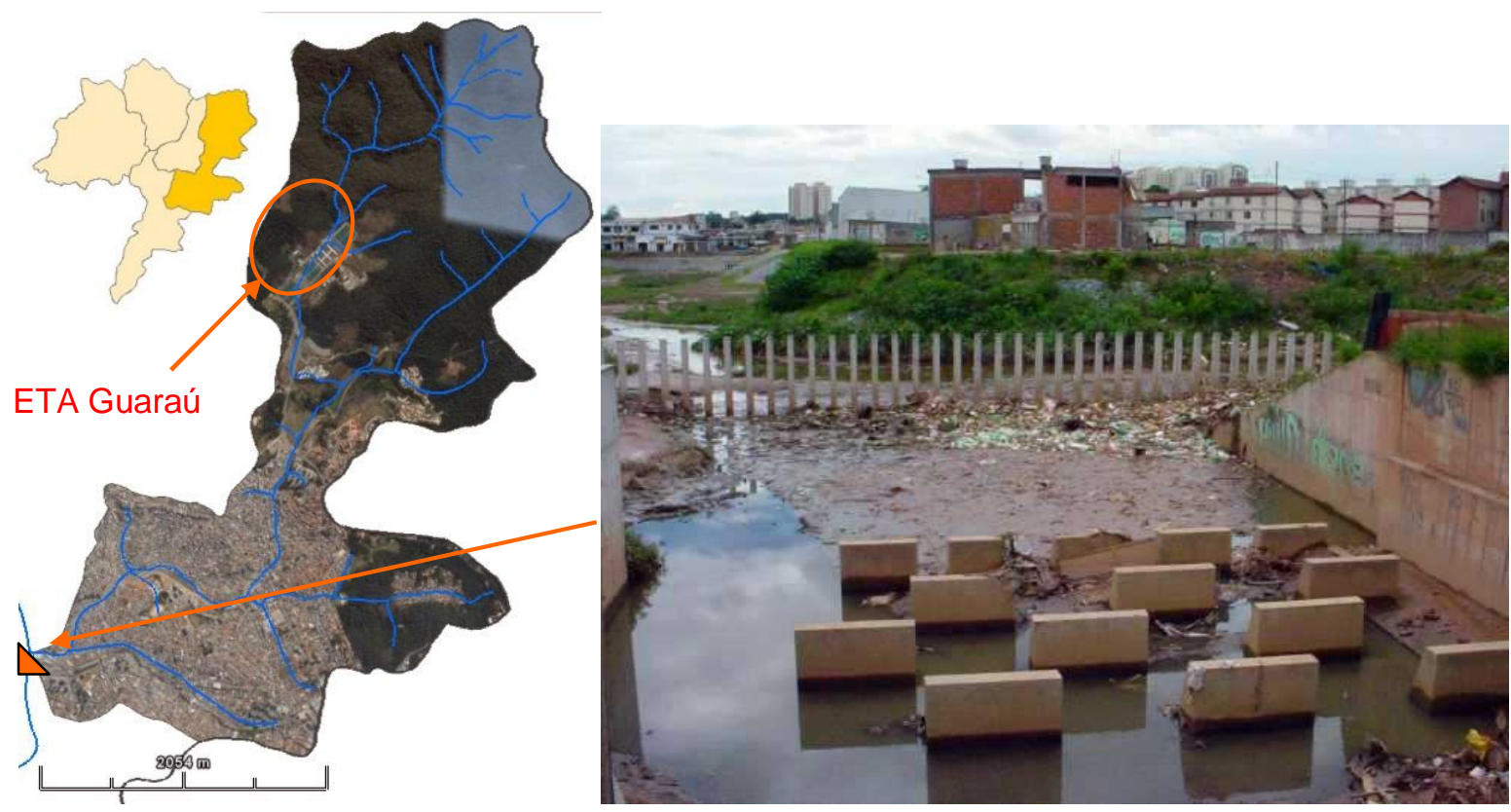

Figura 5.11 - Foto aérea da sub-bacia Guaraú e detalhe do Piscinão Guaraú

\subsubsection{Sub-bacia do rio Cabuçu de Baixo (curso inferior)}

Encontra-se praticamente todo canalizado em sua extensão, sob a Avenida Inajar de Souza, desde a foz no rio Tietê até a confluência do córrego Itaguaçu, num total de 7,0 km. Por muito tempo, a Avenida Inajar de Souza e suas transversais vinham sendo duramente castigadas pelas enchentes, tendo prejuízos elevados, com moradias e lojas inundadas e com a interrupção dessa importante artéria viária. A frequiência e a gravidade dessas inundações aumentavam ano a ano, gerando protestos dos moradores e das associações dos bairros atingidos, além de ações judiciais contra a prefeitura. 


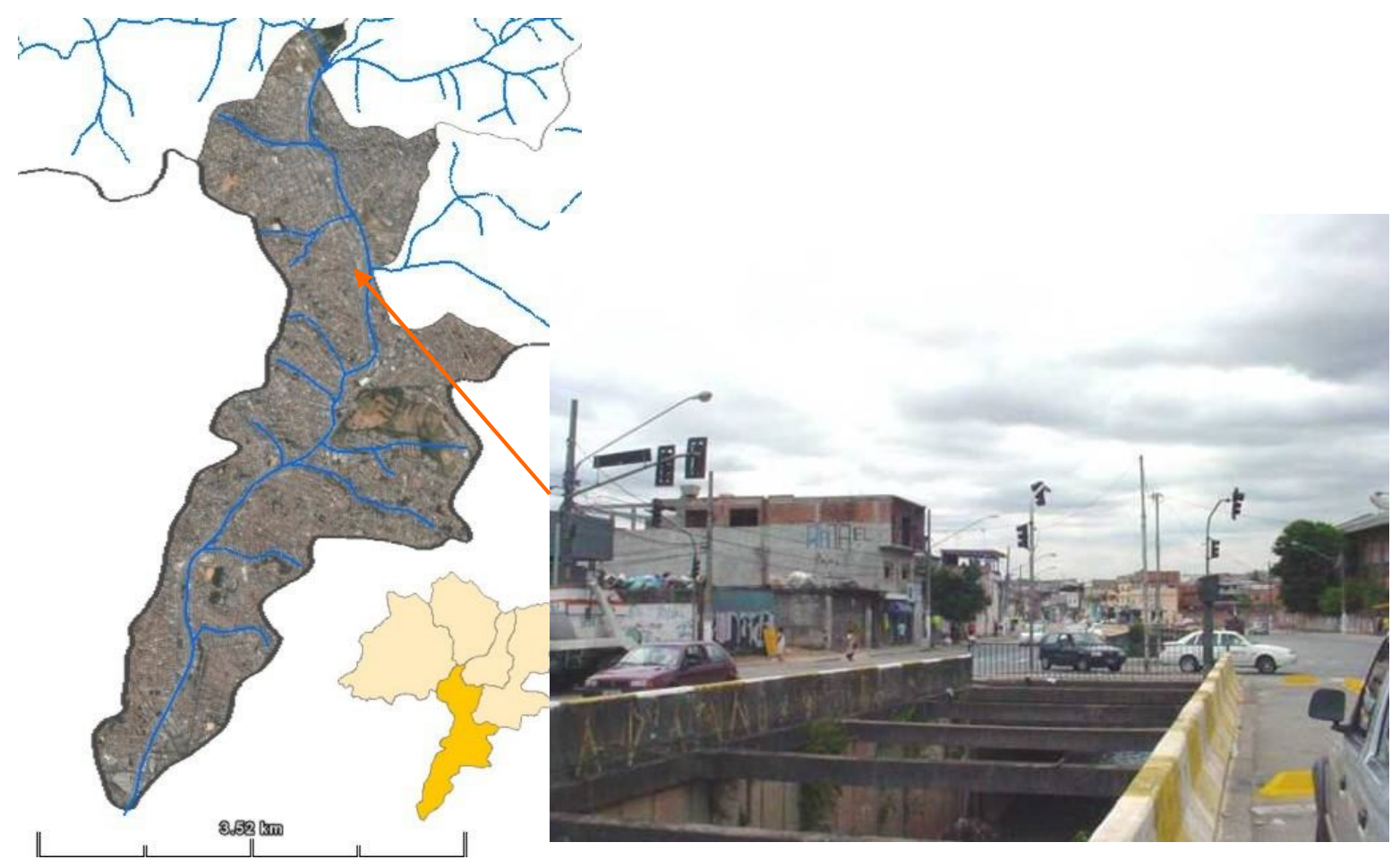

Figura 5.12 - Foto aérea da sub-bacia Cabuçu de Baixo e detalhe do canal.

\subsection{Dados Físicos da Bacia}

As sub-bacias supracitadas foram divididas em áreas de contribuição menores, de forma a se ter uma melhor representação dos mecanismos de formação de vazão no modelo hidrológico, e também para permitir o cálculo de vazões pelo modelo em pontos notáveis, tais como, os postos fluviométricos e locais de reservatórios, como é o caso do Piscinão Bananal e da barragem situada na ETA Guaraú da SABESP. A Figura 5.13 apresenta de forma esquemática a topologia, em termos de divisões de sub-bacias, adotada para a modelagem chuva-vazão. A Tabela 5.1 a seguir mostra todos os parâmetros levantados para as divisões das sub-bacias consideradas. 


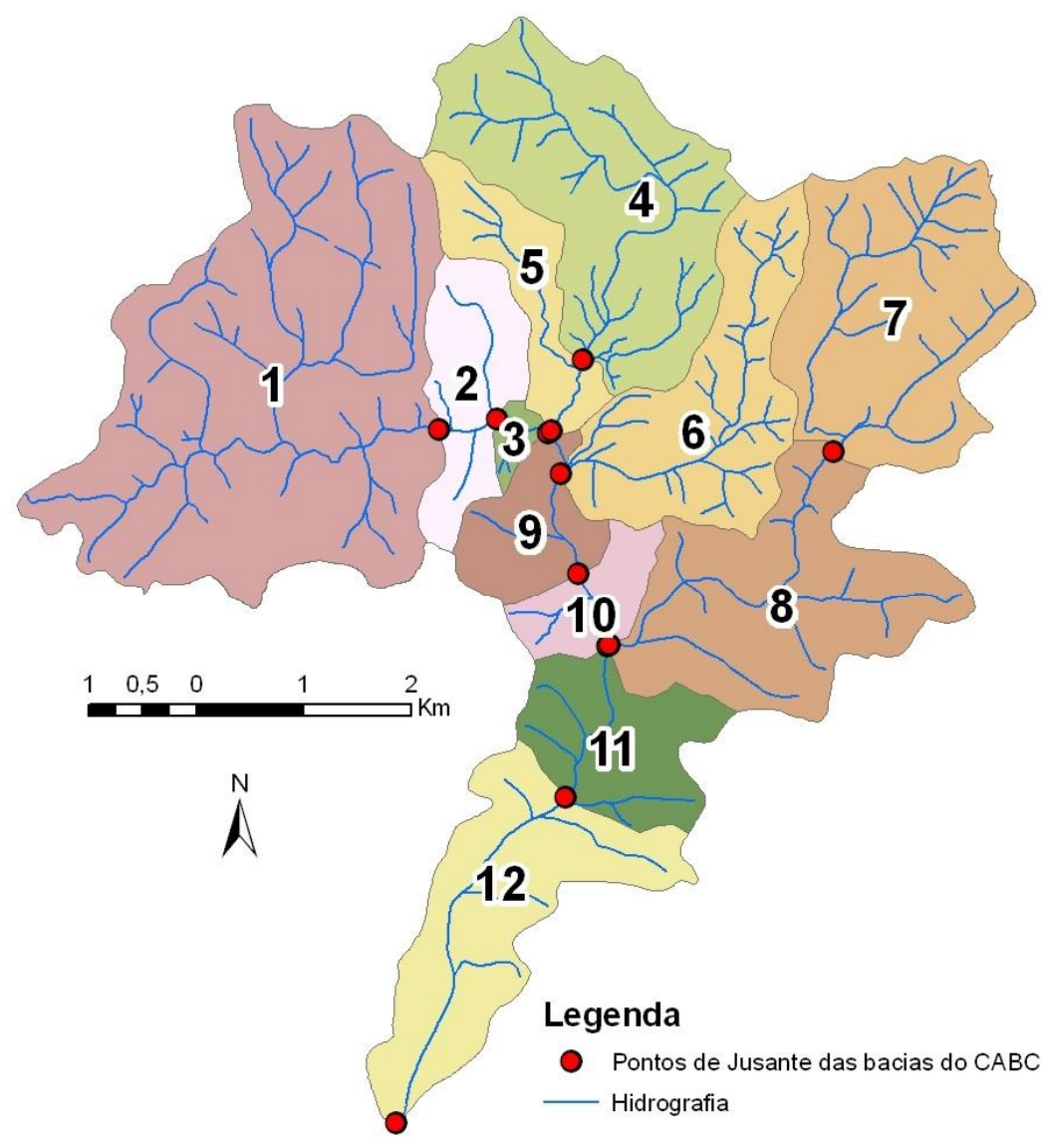

Figura 5.13 - Divisões das sub-bacias para serem utilizadas no modelo hidrológico

Para esses diversas divisões foram obtidas suas características físicas: Áreas de drenagem, comprimento dos talvegues, declividades, cotas do leito a montante e a jusante dos trechos de rio, características dos trechos canalizados, como seção transversal, declividades e coeficientes de rugosidade. As informações sobre as características das subbacias foram levantadas a partir das cartas do Sistema Cartográfico Metropolitano na escala 1:10.000. As demais informações sobre a rede de drenagem canalizada foram obtidas dos respectivos projetos fornecidos pela Prefeitura do Município de São Paulo. 
Tabela 5.1 - Parâmetros Físicos das Sub-Bacias de Drenagem (FONTE: BARROS, 2003)

\begin{tabular}{|c|c|c|c|c|c|c|c|c|c|c|c|c|c|c|}
\hline \multirow{2}{*}{ SUB- BACIA } & \multirow{2}{*}{ LOCALIZAÇÃO } & \multirow{2}{*}{$\begin{array}{c}\text { ÁREA DE } \\
\text { DRENAGEM } \\
\left(\mathrm{Km}^{2}\right)\end{array}$} & \multirow{2}{*}{$\begin{array}{l}\mathrm{CN} \\
(\mathrm{SIG})\end{array}$} & \multirow{2}{*}{$\begin{array}{c}\text { DECLIV. DO } \\
\text { TALVEGUE } \\
(\mathrm{m} / \mathrm{m})(2)\end{array}$} & \multirow{2}{*}{$\begin{array}{l}\text { COMP.DO } \\
\text { TALVEGUE } \\
(\mathrm{km})\end{array}$} & \multirow{2}{*}{$\begin{array}{l}\text { COEF. DE } \\
\text { MANNING } \\
\text { ADOTADO }\end{array}$} & \multirow{2}{*}{$\begin{array}{l}\text { LARGURA } \\
\text { DA BASE } \\
(\mathrm{m})\end{array}$} & \multirow{2}{*}{$\begin{array}{l}\text { LÂMINA } \\
\text { D'ÁGUA } \\
\text { ADOTA } \\
\text { DA }(m)\end{array}$} & \multicolumn{5}{|c|}{ TEMPO DE CONCENTRAÇÃO (horas) (4) } & \multirow{2}{*}{$\begin{array}{l}\text { VELOCIDA } \\
\text { DE MÉDIA } \\
\text { RESULTAN } \\
\text { TE }(\mathrm{m} / \mathrm{s})(5)\end{array}$} \\
\hline & & & & & & & & & Kirpich & \begin{tabular}{|c|} 
Califórnia \\
Culverts \\
Practice \\
\end{tabular} & Dooge & $\begin{array}{c}\begin{array}{c}\text { Fórmula } \\
\text { de } \\
\text { Manning }\end{array} \\
\end{array}$ & Adotado & \\
\hline Bananal Montante & $\begin{array}{c}\text { área a montante do posto Vista } \\
\text { Alegre }\end{array}$ & 11,76 & 75 & 0,0350 & 5,570 & & & & 0,91 & 0,66 & 1,77 & & 1,00 & 1,55 \\
\hline $\begin{array}{l}\text { Bananal } \\
\text { Intermediário }\end{array}$ & \begin{tabular}{|c|} 
área intermediária entre o posto \\
Vista Alegre e o Piscinão \\
Bananal (3) \\
\end{tabular} & 1,89 & 75 & 0,1213 & 1,850 & & & & 0,24 & 0,20 & 0,68 & & 0,35 & 1,47 \\
\hline Bananal Jusante & \begin{tabular}{|c|} 
área a jusante do Piscinão \\
Bananal até a foz do Itaguaçu \\
\end{tabular} & 0,28 & 75 & 0,0010 & 0,500 & 0,035 & 5,00 & 2,00 & 0,56 & 0,56 & 0,70 & 0,14 & 0,15 & 0,93 \\
\hline $\begin{array}{l}\text { Itaguaçu } \\
\text { Montante }\end{array}$ & área da bacia do Itaguaçu & 6,00 & 60 & \multirow{2}{*}{0,0376} & \multirow{2}{*}{6,455} & & & & \multirow{2}{*}{0,99} & \multirow{2}{*}{0,85} & \multirow{2}{*}{1,43} & & \multirow{2}{*}{1,20} & \multirow{2}{*}{1,49} \\
\hline Itaguaçu Jusante & $\begin{array}{c}\text { área entre o Itaguaçu e Cabuçu } \\
\text { Iterm. } 1\end{array}$ & 1,20 & 60 & & & & & & & & & & & \\
\hline Bispo & área da bacia do Bispo & 3,78 & 68 & 0,0371 & 8,305 & & & & 1,21 & 1,18 & 1,10 & & 1,30 & 1,77 \\
\hline $\begin{array}{c}\text { Cabuçu - Interm. } \\
1(1) \\
\end{array}$ & \begin{tabular}{|c|} 
área do Cabuçu entre a foz do \\
Itaguaçu/Bispo e o posto \\
Campos Lemos
\end{tabular} & 1,37 & 85 & 0,0030 & 1,500 & 0,020 & 7,00 & 3,70 & & & & 0,10 & 0,20 & 2,08 \\
\hline $\begin{array}{c}\text { Cabuçu - Interm. } \\
2(1) \\
\end{array}$ & \begin{tabular}{|c|} 
área intermediária entre o posto \\
Campos Lemos e a foz do \\
Guaraú
\end{tabular} & 1,06 & 85 & 0,0030 & 0,700 & 0,020 & 7,00 & 3,70 & & & & 0,05 & 0,10 & 1,94 \\
\hline \begin{tabular}{|l|} 
Guaraú - \\
Montante \\
\end{tabular} & $\begin{array}{c}\text { área a montante da barragem } \\
\text { da ETA Guaraú }\end{array}$ & 5,09 & 60 & 0,0443 & 4,170 & & & & 0,66 & 0,54 & 1,21 & & 0,80 & 1,45 \\
\hline Guaraú - Jusante & $\begin{array}{l}\text { área a jusante da barragem da } \\
\text { ETA Guaraú até a foz no } \\
\text { Cabuçu, exclusive a bacia do } \\
\text { Água preta } \\
\end{array}$ & 3,73 & 85 & 0,0075 & 3,820 & & & & 1,23 & 1,09 & 1,44 & & 1,00 & 1,06 \\
\hline $\begin{array}{c}\text { Cabuçu - Interm. } \\
3(1) \\
\end{array}$ & $\begin{array}{l}\text { área intermediária entre a foz } \\
\text { do Guaraú e a estaca } 183,3 \text {, } \\
\text { conforme projeto das galerias }\end{array}$ & 2,51 & 90 & 0,0016 & 1,700 & 0,020 & 7,60 & 2,70 & & & & 0,17 & 0,25 & 1,89 \\
\hline $\begin{array}{c}\text { Cabuçu - Jusante } \\
\text { (1) }\end{array}$ & $\begin{array}{c}\text { área entre a estaca } 183,3 \mathrm{e} \mathrm{a} \\
\text { foz no Rio Tietê }\end{array}$ & 3,86 & 90 & 0,0009 & 3,600 & 0,020 & 13,70 & 2,70 & & & & 0,43 & 0,50 & 2,00 \\
\hline
\end{tabular}

Observações:

(1) Trechos canalizados - dados das características das canalizações

(2) Para os trechos não canalizados, refere-se à declividade equivalente do talvegue

(3) Para cálculo do tempo de concentração foi considerado um afluente ao Piscinão do Bananal

(4) Para os trechos não canalizados, foram consideradas as fórmulas empíricas. Para os trechos canalizados optou-se pela fórmula de Manning

(5) Procurou-se adotar o tempo de concentração que resultasse em velocidades em torno de $1,5 \mathrm{~m} / \mathrm{s}$ para os trechos de montante, em torno de $1,0 \mathrm{~m} / \mathrm{s}$ para os trechos a jusante, e perto de $2,0 \mathrm{~m} / \mathrm{s}$ para os trechos canalizados. 
Um parâmetro importante, para orientar a modelagem chuva-vazão baseada no Hidrograma Unitário Triangular do SCS (HUT-SCS), é o tempo de concentração da bacia. Para tanto, foram utilizadas, nos trechos não canalizados, fórmulas empíricas consagradas como a de Kirpich, Califórnia Culverts Practice e de Dooge, TUCCI (2004). Para os trechos canalizados optou-se pela fórmula de Manning.

Foram adotados tempos de concentração que resultassem em velocidades médias de cerca de 1,5 m/s para os trechos de montante, que são mais próximos à Serra da Cantareira, $1,0 \mathrm{~m} / \mathrm{s}$ para os trechos a jusante, onde as declividades são menores, e perto de 2,0 m/s para os trechos canalizados, obtido por BARROS (2003).

Como descrito no Capítulo 4, outro parâmetro importante a ser utilizado na fase de modelagem hidrológica é o $\mathrm{CN}$ (Curve Number). Ambos os parâmetros foram calibrados através da comparação entre os hidrogramas gerados pelo modelo e os obtidos por meio de medições dos postos fluviográficos.

Os valores iniciais de $\mathrm{CN}$ mostrados na tabela a seguir foram obtidos a partir dos estudos de uso e ocupação do solo, gerados pela análise de foto interpretação pelo software Spring, INPE (2002), na bacia do rio Cabuçu de Baixo, por BARROS (2003). Este retrata as condições de cobertura e solo, no qual varia desde uma cobertura muito permeável (limite inferior) até uma cobertura praticamente impermeável (limite superior). A Figura 5.14 mostra a variação espacial do $\mathrm{CN}$ ao longo da bacia do rio Cabuçu de Baixo. 


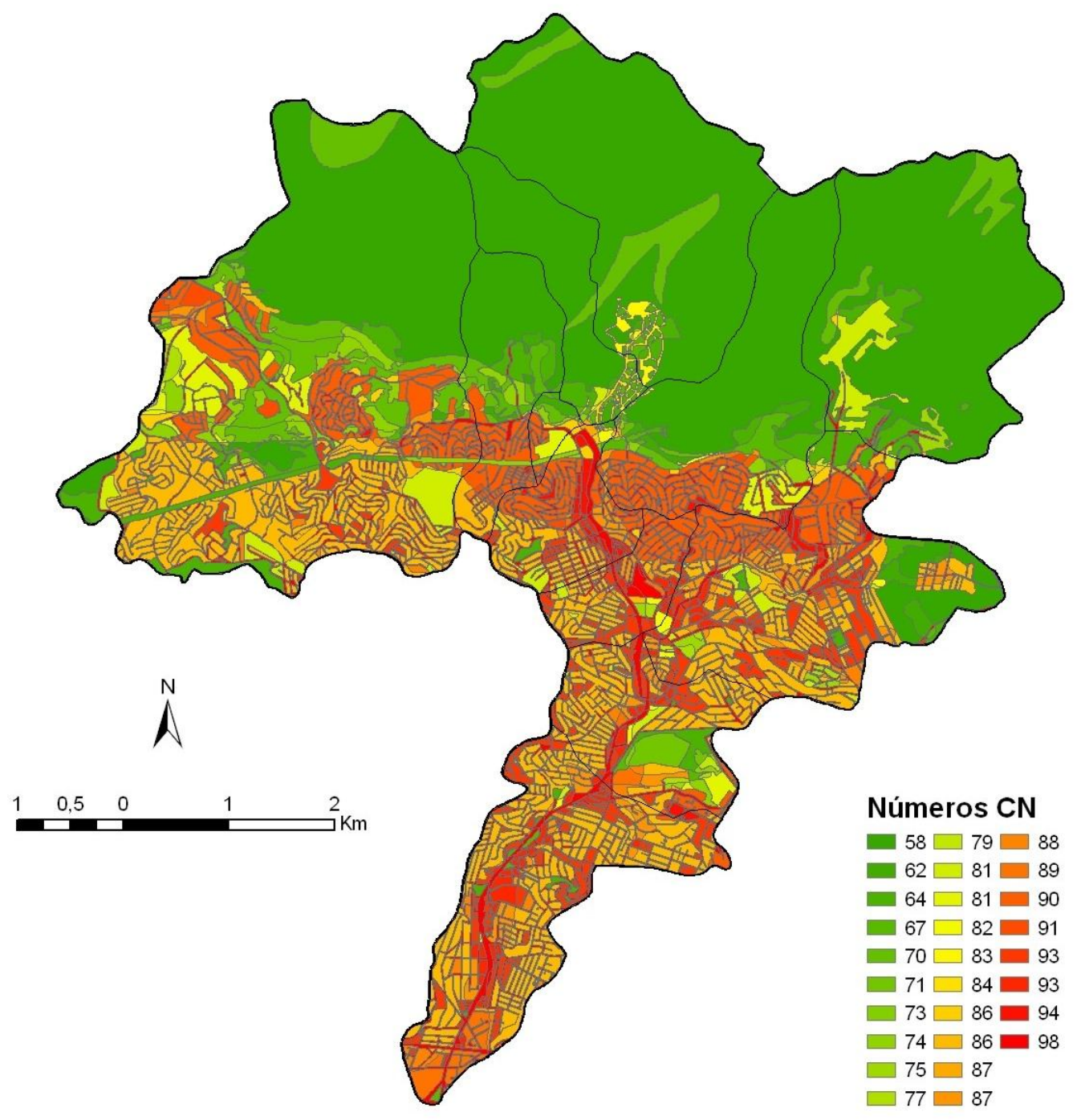

Figura 5.14 - Variação espacial do CN (FONTE: BARROS, 2003)

Nesse sentido, a forma e a densidade de ocupação do solo urbano são fundamentais para modelar e compreender o escoamento superficial da água. Tendo em vista atender as necessidades da modelagem hidrológica da bacia, foi determinado também o CN médio de cada divisão das sub-bacias pelo critério de ponderação de áreas. Esses valores estão indicados, para cada sub-bacia na Tabela 5.2. 
Tabela 5.2 - Valores do CN médio para cada sub-bacia.

\begin{tabular}{|c|c|c|c|c|}
\hline \multicolumn{5}{|c|}{ SUB-BACIAS } \\
\hline Bananal & Itaguaçu & Bispo & Guaraú & Baixo Cabuçu \\
\hline 74 & 60 & 68 & 73 & 90 \\
\hline
\end{tabular}

Em função da espacialização do CN, segundo cada sub-bacia, e considerando ainda as tendências de expansão urbana, pode-se constatar mais uma vez a importância de se preservar a área do Parque da Cantareira. Isso porque uma das sub-bacias de maior dimensão relativa, melhor conservada e dotada de maior declividade, qual seja, a sub-bacia do Bananal, possui expressiva área ocupada pelo mencionado parque e ao mesmo tempo representa uma das áreas mais sujeitas a expansão e a impermeabilização do solo.

A Tabela 5.3 apresenta as principais características físicas finais das divisões das sub-bacias dos principais cursos d' água a serem utilizadas como valores iniciais das simulações.

Tabela 5.3 - Características físicas das divisões das sub-bacias

\begin{tabular}{|c|c|c|c|c|c|c|c|}
\hline $\begin{array}{c}\text { NUMERO } \\
\text { CÁLCULO }\end{array}$ & NUMERO & NOME & $\begin{array}{c}\text { AREA } \\
\text { (KM2) }\end{array}$ & $\begin{array}{c}\text { TEMPO DE } \\
\text { CONC. } \\
\text { (HORAS) }\end{array}$ & CN & $\begin{array}{c}\text { COMP. } \\
\text { (KM) }\end{array}$ & $\begin{array}{c}\text { DIF COTA } \\
\text { (M) }\end{array}$ \\
\hline $\mathbf{1}$ & $\mathbb{1}$ & Bananal Montante & 11,76 & 1,00 & 85 & 5,570 & 442 \\
\hline $\mathbf{2}$ & 2 & Bananal Intermediário & 1,89 & 0,35 & 85 & 1,850 & 1 \\
\hline $\mathbf{3}$ & 3 & Bananal Jusante & 0,28 & 0,25 & 85 & 0,500 & 0,5 \\
\hline $\mathbf{4}$ & $(*)$ & $(*)$ & 0,00 & 0,25 & 65 & 0,023 & 3 \\
\hline $\mathbf{5}$ & 4 & Itaguaçu Montante & 6,00 & 0,90 & 65 & 6,000 & 352 \\
\hline $\mathbf{6}$ & 5 & Itaguaçu Jusante & 1,20 & 0,40 & 60 & 0,500 & 2,5 \\
\hline $\mathbf{7}$ & $\mathbf{6}$ & Bispo & 3,78 & 0,80 & 76 & 8,305 & 323,5 \\
\hline $\mathbf{8}$ & 7 & Guaraú Montante & 5,09 & 0,80 & 60 & 4,170 & 309 \\
\hline $\mathbf{9}$ & 8 & Guaraú Jusante & 4,58 & 1,00 & 85 & 3,820 & 39 \\
\hline $\mathbf{1 0}$ & 9 & Cabuçu Intermediário 1 & 1,37 & 0,60 & 90 & 1,000 & 1,5 \\
\hline $\mathbf{1 1}$ & $\mathbf{1 0}$ & Cabuçu Intermediário 2 & 1,06 & 0,25 & 90 & 0,040 & 5 \\
\hline $\mathbf{1 2}$ & $\mathbf{1 1}$ & Cabuçu Intermediário 3 & 2,51 & 0,50 & 90 & 0,076 & 6 \\
\hline $\mathbf{1 3}$ & $\mathbf{1 2}$ & Cabuçu Jusante & 3,86 & 0,50 & 90 & 0,156 & 3 \\
\hline
\end{tabular}

(*) Esta bacia fictícia é um artifício para que o modelo hidrológico possa receber no mesmo nó a contribuição de três bacias (Bananal, Itaguaçu e Bispo). O modelo CABC só admite a contribuição de duas bacias. 


\subsection{Monitoramento Hidrológico}

\subsubsection{Fluviometria}

De acordo com BARROS (2004), foram instalados limnígrafos mecânicos no córrego Bananal e no rio Cabuçu (Vista Alegre e Campos Lemos, respectivamente).

Por estar localizado próximo à jusante, foi escolhido como posto fluviométrico para calibração hidrológica o posto Campos Lemos (rio Cabuçu de Baixo). Ele está situado imediatamente a montante do início do trecho com galerias fechadas, no cruzamento da Av. Inajar de Souza e R. Déia de Campos Lemos. Este ponto controla quase 50\% da área de drenagem da bacia. Foi instalada a montante de uma ponte, na margem direita, sob coordenadas $23^{\circ} 27^{\prime} 45^{\prime \prime} \mathrm{S}$ e $46^{\circ} 40^{\prime} 22^{\prime \prime}$ W e entrou em operação no início de janeiro de 2000. A sua área de drenagem é de $19,08 \mathrm{Km}^{2}$.

O trecho que compreende o posto é totalmente canalizado, tendo seção retangular com paredes e fundo de concreto. Numa das paredes, foi instalado um limnígrafo A.OTT mecânico, com sistema de bóia e contrapeso, registro gráfico em papel com avanço de cinco milímetros por hora $(5 \mathrm{~mm} / \mathrm{h})$ e escala de $1: 10$, num abrigo confeccionado em chapa de ferro galvanizado sobre fuste de ferro fundido de 300 milímetros de diâmetro. Foram instalados também dois lances de escalas. O primeiro, de 0 a 1 metro, junto ao tubo do limnígrafo, e outro de 1 a 4 metros, fixado na parede do canal, oposta ao limnígrafo.

Devido à canalização em canal fechado logo a jusante, acima da cota de 4 metros ocorre o afogamento da seção, afetando o escoamento e, conseqüentemente, as medições.

O serviço de medições de vazão líquida deste local foi extremamente dificultado pela enorme quantidade de lixo que é lançada no curso d'água e que acumulava nas hélices do molinete e pela alta velocidade da água. Assim como os demais córregos da bacia já 
estão completamente comprometidos em termos de qualidade de água e ocupados até o limite de suas margens por habitações precárias e favelas. Apenas o córrego Itaguaçu, dentro do loteamento Imobel, conserva ainda a maior parte de suas características originais, em que existe boa cobertura de mata e com boa qualidade de água. É uma área de referência para medição dos impactos de urbanização.

A Figura 5.15 mostra a seção transversal do posto Campos Lemos, que é o posto de interesse das simulações.

SEÇÃO TRANSVERSAL - RIO CABUÇU DE BAIXO - POSTO CAMPOS LEMOS

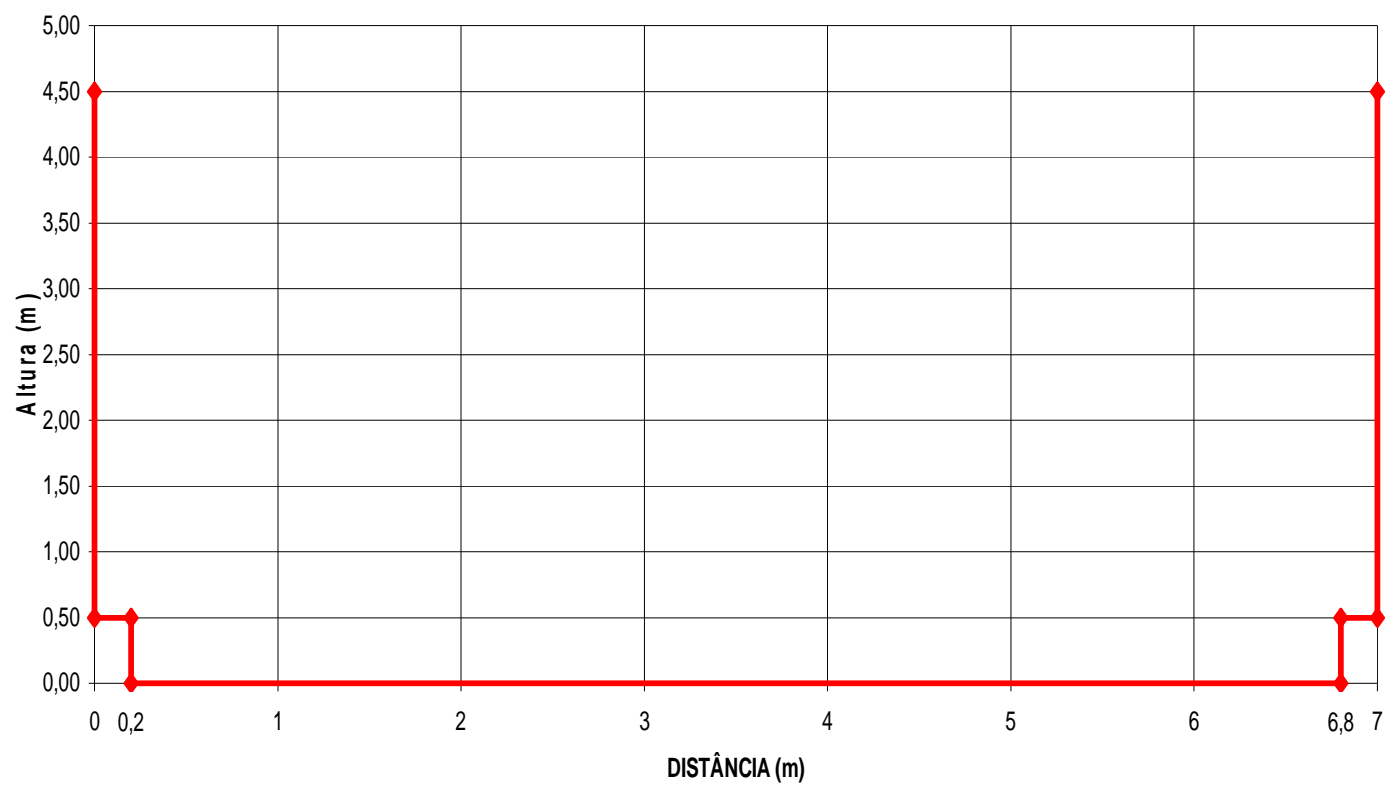

Figura 5.15 - Seção transversal do posto Campos Lemos (FONTE: BARROS, 2003) 


\subsubsection{Pluviometria}

Quanto ao regime pluviométrico, a região é extremamente diversificada devido à diversos fatores como diferença de altitudes, cobertura do solo, entre outros. Em BARROS et. Al. (2003), alterações no uso e ocupação do solo (impermeabilização do solo, edificações, etc.), geram mudanças na atmosfera local que se reflete no aumento da temperatura, fenômeno conhecido como ilha de calor, EPA (2008). As ilhas de calor podem ser definidas como uma anomalia térmica, onde o ar da cidade se torna mais quente que o das regiões vizinhas.

As características físicas da bacia, juntamente com fatores como a entrada de frentes, a brisa marítima, o efeito vale-montanha e a presença da Serra da Cantareira nos mostram que existe uma pluviosidade um pouco maior na parte superior da bacia, próximo à serra, como pode ser observado no gráfico da Figura 5.16. Esta apresenta a precipitação média para cada mês do ano em três postos pluviométricos: Horto Florestal E3-071, ETA Guaraú E3-262 e um posto localizado junto à sede da Sub-Prefeitura da Freguesia do Ó. Os dois primeiros localizam-se nas proximidades da Serra da Cantareira, sendo que o E3-071 situa-se à Leste da bacia, a cerca de $2 \mathrm{~km}$ do seu divisor de águas. Com base nos registros desses postos supracitados, a precipitação média anual na bacia é da ordem de $1600 \mathrm{~mm}$. 


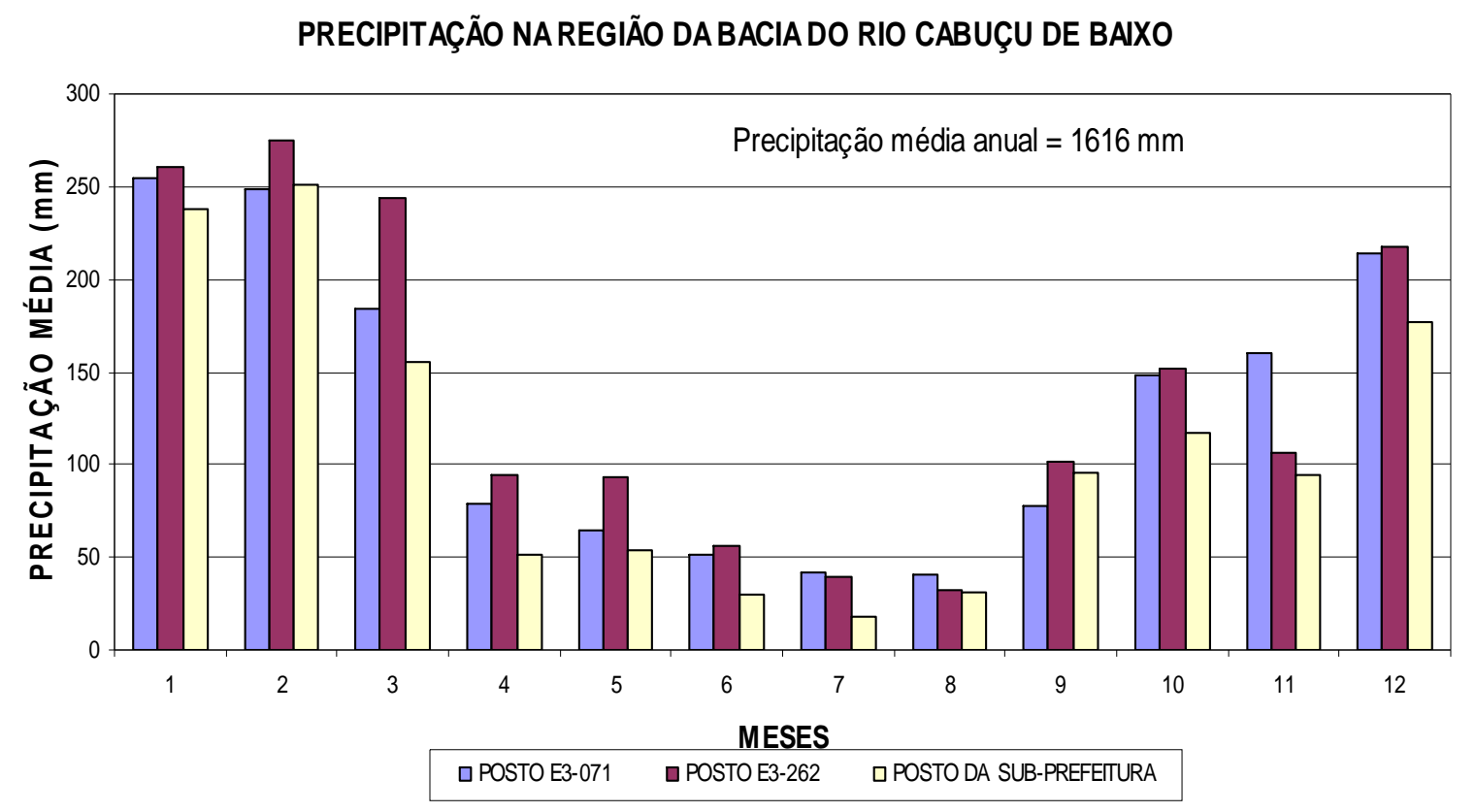

Figura 5.16 - Precipitação Média Mensal na Bacia do rio Cabuçu de Baixo (Fonte: BARROS, 2004)

Considera-se que estes três postos pluviométricos cobrem razoavelmente bem área da bacia, entretanto este tipo de equipamento, o pluviômetro, não é adequado para as simulações de chuva intensa. Sendo que neste tipo de chuva, normalmente ocorre em períodos menores que uma hora.

Desse modo, optou-se, durante o Projeto Gerenciamento Integrado de Bacias Hidrográficas em Áreas Urbanas, BARROS et al. (2004) em instalar aparelhos registradores contínuos (pluviógrafos) automáticos.

O primeiro posto pluviográfico foi instalado na sub-bacia do córrego Itaguaçu, dentro do loteamento Imobel, onde havia sido instalado em setembro de 2000 um pluviógrafo automático. Contudo, o equipamento apresentou defeitos, o que inviabilizou a coleta de chuvas na estação chuvosa 2000/2001. No final de 2001 foi instalado, no mesmo local, um pluviógrafo tipo sifão.

No final de 2002, foram instalados mais três pluviógrafos equipados com 
datalogger na bacia, um próximo ao divisor de águas a oeste da bacia na área de drenagem do córrego Bananal, outro na área do córrego Itaguaçu e outro na ETA Guaraú. Uma representação esquemática da localização desses postos é mostrada na Figura 5.17.

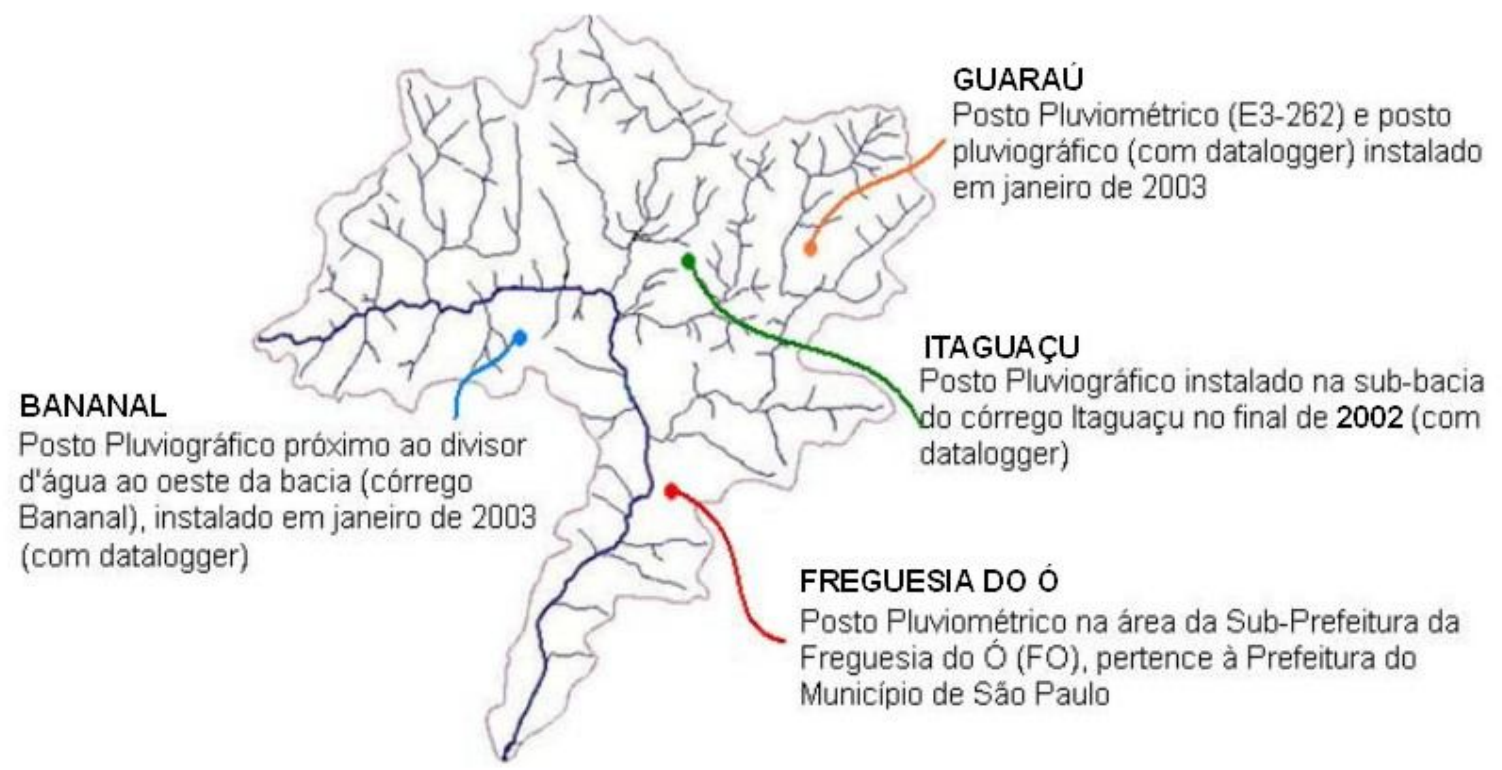

Figura 5.17 - Esquema dos postos pluviométricos e pluviográficos considerados no estudo.

Em meados de 2005, com a finalização do Projeto Plano de Bacia Urbana, BARROS, (2005), os postos com datalogger foram todos desativados. Inclusive o posto pluviométrico E3-262 do DAEE, de acordo com os dados disponíveis em SIGRH (2008).

Assim, foram considerados para as simulações hidrológicas apenas os eventos que compreende o ano hidrológico de 2002/2003, para que os mais significativos, em termos de precipitação efetiva, pudessem ser consistidos visualmente. A seguir, na Tabela 5.4 serão apresentados os eventos de chuva e vazão de 2002 e 2003 registrados pelo monitoramento de quantidade da água nos postos pluviográficos e o posto fluviográfico. 
Tabela 5.4 - Eventos significativos registrados pelo monitoramento de quantidade da água

\begin{tabular}{|c|c|c|c|c|c|}
\hline \multirow{3}{*}{ DATA } & \multirow{3}{*}{$\begin{array}{c}\text { FLUVIOGRÁFICOS } \\
\text { CAMPOSLEMOS } \\
\text { Cota Máxima do Evento (m) }\end{array}$} & & \multicolumn{3}{|c|}{ PLUVIOGRÁFICOS } \\
\hline & & & ITAGUAÇU & BANANAL & GUARAÚ \\
\hline & & & \multicolumn{3}{|c|}{ Precipitação Total do Evento (mm) } \\
\hline $08 / 01 / 2002$ & 0,72 & - & - & - & - \\
\hline $09 / 01 / 2002$ & 0,49 & - & - & - & - \\
\hline $13 / 01 / 2002$ & 0,74 & - & - & - & - \\
\hline $14 / 01 / 2002$ & 1,8 & - & - & - & - \\
\hline $25 / 01 / 2002$ & 1,02 & - & - & - & - \\
\hline $28 / 01 / 2002$ & 1,54 & - & - & - & - \\
\hline $07 / 02 / 2002$ & 0,55 & - & - & - & - \\
\hline $08 / 02 / 2002$ & 0,76 & - & - & - & - \\
\hline $13 / 02 / 2002$ & 0,48 & - & - & - & - \\
\hline $16 / 02 / 2002$ & 0,7 & - & - & - & - \\
\hline $22 / 02 / 2002$ & 0,54 & - & - & - & - \\
\hline $28 / 02 / 2002$ & 0,58 & - & - & - & - \\
\hline $02 / 03 / 2002$ & 2,46 & - & - & - & - \\
\hline $03 / 03 / 2002$ & 0,78 & - & - & - & - \\
\hline $07 / 03 / 2002$ & 0,6 & - & - & - & - \\
\hline $08 / 03 / 2002$ & 0,86 & - & - & - & - \\
\hline $15 / 03 / 2002$ & 1,35 & - & 33,5 & - & - \\
\hline $16 / 03 / 2002$ & 0,44 & - & - & - & - \\
\hline $21 / 03 / 2002$ & 1,18 & - & 53,6 & - & - \\
\hline $24 / 03 / 2002$ & 0,9 & - & 85,2 & - & - \\
\hline $27 / 03 / 2002$ & 1,92 & - & 46 & - & - \\
\hline $03 / 04 / 2002$ & 0,64 & - & - & - & - \\
\hline $06 / 04 / 2002$ & 0,8 & - & - & - & - \\
\hline $07 / 04 / 2002$ & 0,56 & - & - & - & - \\
\hline $18 / 05 / 2002$ & 1,1 & - & 26,1 & - & - \\
\hline $19 / 05 / 2002$ & 0,56 & - & 13,9 & - & - \\
\hline $21 / 05 / 2002$ & 0,62 & - & 19,9 & - & - \\
\hline $22 / 05 / 2002$ & 0,5 & - & 8,4 & - & - \\
\hline $31 / 08 / 2002$ & 0,72 & - & - & - & - \\
\hline $07 / 09 / 2002$ & 0,4 & - & - & - & - \\
\hline $20 / 09 / 2002$ & 0,64 & - & 27,7 & - & - \\
\hline $01 / 10 / 2002$ & 0,44 & - & - & - & - \\
\hline $09 / 10 / 2002$ & 0,5 & - & - & - & - \\
\hline $21 / 10 / 2002$ & 1,2 & - & - & - & - \\
\hline $25 / 10 / 2002$ & 1,26 & - & - & - & - \\
\hline $24 / 11 / 2002$ & 0,9 & - & 15,2 & - & - \\
\hline $26 / 11 / 2002$ & 0,64 & - & 17,3 & - & - \\
\hline $28 / 11 / 2002$ & 2,42 & - & - & - & - \\
\hline $05 / 12 / 2002$ & 1,1 & - & - & - & - \\
\hline $08 / 12 / 2002$ & 0,55 & - & - & - & - \\
\hline $13 / 12 / 2002$ & 0,55 & - & - & - & - \\
\hline $14 / 12 / 2002$ & 1,88 & - & - & - & - \\
\hline $15 / 12 / 2002$ & 0,7 & - & - & - & - \\
\hline $17 / 12 / 2002$ & 1,34 & - & - & - & - \\
\hline $20 / 12 / 2002$ & 2,6 & - & - & - & - \\
\hline $31 / 12 / 2002$ & 0,84 & - & - & - & - \\
\hline
\end{tabular}




\begin{tabular}{|c|c|c|c|c|c|}
\hline \multirow{3}{*}{ DATA } & \multirow{2}{*}{$\begin{array}{c}\text { FLUVIOGRÁFICOS } \\
\text { CAMPOSLEMOS }\end{array}$} & & \multicolumn{3}{|c|}{ PLUVIOGRÁFICOS } \\
\hline & & & ITAGUAÇU & BANANAL & GUARAÚ \\
\hline & Cota Máxima do Evento (m) & & \multicolumn{3}{|c|}{ Precipitação Total do Evento (mm) } \\
\hline $03 / 01 / 2003$ & 1,22 & - & - & - & - \\
\hline $10 / 01 / 2003$ & 0,92 & - & - & - & - \\
\hline $12 / 01 / 2003$ & 0,74 & - & - & - & - \\
\hline $21 / 01 / 2003$ & 0,98 & - & - & - & - \\
\hline $23 / 01 / 2003$ & 0,54 & - & - & - & - \\
\hline $27 / 01 / 2003$ & 0,8 & - & - & - & - \\
\hline $28 / 01 / 2003$ & 0,66 & - & - & - & - \\
\hline 29/01/2003 & - & - & 29,74 & 18,04 & 13,46 \\
\hline $30 / 01 / 2003$ & 0,5 & - & - & - & - \\
\hline $05 / 02 / 2003$ & - & - & 25,91 & 7,61 & 6,86 \\
\hline $06 / 02 / 2003$ & - & - & - & 59,45 & 64,95 \\
\hline $08 / 02 / 2003$ & - & - & 18,8 & 18,3 & - \\
\hline $09 / 02 / 2003$ & 0,6 & - & - & - & - \\
\hline $13 / 02 / 2003$ & 0,92 & - & 59,35 & 61,36 & 28,42 \\
\hline $17 / 02 / 2003$ & 2,3 & 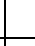 & 93,77 & 95,29 & 64,78 \\
\hline $21 / 02 / 2003$ & 0,68 & - & 32,65 & 27,1 & 22,07 \\
\hline $26 / 02 / 2003$ & 1,2 & - & - & - & - \\
\hline $03 / 03 / 2003$ & - & - & 34,66 & 22,78 & 15,96 \\
\hline $04 / 03 / 2003$ & - & - & 23,55 & 18,49 & 10,91 \\
\hline $05 / 03 / 2003$ & 4,5 & - & 92,38 & 90,7 & 80,08 \\
\hline $06 / 03 / 2003$ & - & - & 21,74 & 18,71 & 13,7 \\
\hline $07 / 03 / 2003$ & 1,2 & - & 118,29 & 97,83 & 48,16 \\
\hline $10 / 03 / 2003$ & - & - & 14,45 & 12,18 & 8,37 \\
\hline $12 / 03 / 2003$ & - & - & 11,68 & 10,4 & 8,38 \\
\hline $13 / 03 / 2003$ & - & - & 15,7 & 14,15 & 11,13 \\
\hline $17 / 03 / 2003$ & - & - & 18,78 & 10,66 & 8,89 \\
\hline $21 / 03 / 2003$ & - & - & 39,44 & 36,67 & 27,81 \\
\hline $29 / 10 / 2003$ & 0,78 & - & - & - & - \\
\hline $13 / 11 / 2003$ & 0,72 & - & - & - & - \\
\hline $17 / 11 / 2003$ & 0,49 & - & - & - & - \\
\hline $28 / 11 / 2003$ & 0,7 & - & - & - & - \\
\hline $05 / 12 / 2003$ & 0,6 & - & - & - & - \\
\hline $09 / 12 / 2003$ & 0,46 & - & - & - & - \\
\hline $20 / 12 / 2003$ & 0,68 & - & - & - & - \\
\hline $27 / 12 / 2003$ & 0,4 & - & - & - & - \\
\hline $28 / 12 / 2003$ & 0,78 & - & - & - & - \\
\hline Total de Eventos: & 70 & & 27 & 17 & 16 \\
\hline
\end{tabular}

Onde:

Eventos utilizados nas simulações do URBSSD

Eventos auxiliares, com medições de apenas um ou dois postos pluviográficos 
As simulações foram feitas adotando apenas um hietograma para a bacia inteira. Por isso, foram calculados para a bacia do Cabuçu de Baixo as áreas de influência de cada posto pluviográfico utilizando o método dos Polígonos de Thiessen, TUCCI (2004). As áreas foram determinadas utilizando a ferramenta de cálculo "Create Thiessen Polygons" do ArcMap 9.2, ESRI (2007). A Figura 5.18 e a Tabela 5.5 mostram a distribuição espacial e a porcentagem de área ocupada, respectivamente.

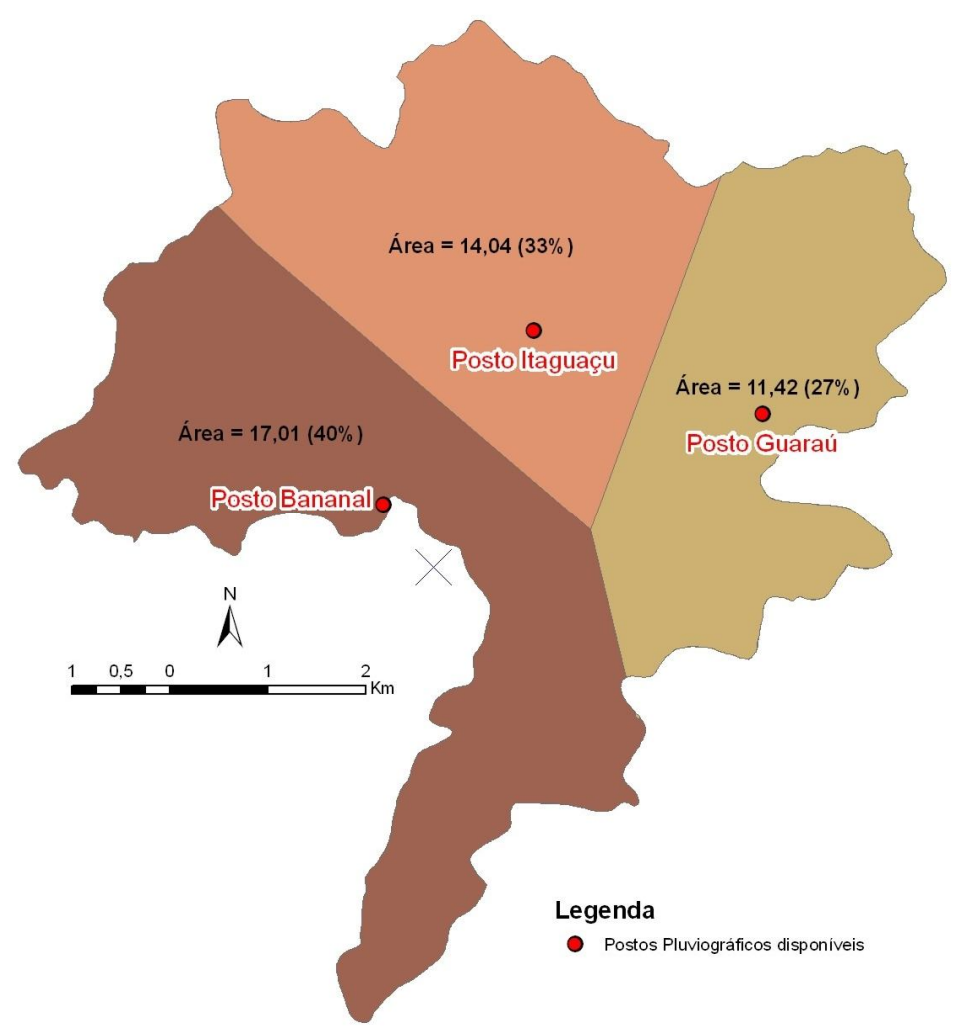

Figura 5.18 - Esquema de Thiessen dos postos pluviográficos considerados no estudo.

Tabela 5.5 - Área relativa para cada posto pluviográfico

\begin{tabular}{|c|c|c|}
\hline Nome & Área $\left(\mathbf{K m}^{\mathbf{2}}\right)$ & $\begin{array}{c}\text { Porcentagem em Relação à Área } \\
\text { Total }\end{array}$ \\
\hline Posto Itaguaçu & 14,04 & $33 \%$ \\
\hline Posto Bananal & 17,01 & $40 \%$ \\
\hline Posto Guaraú & 11,42 & $27 \%$ \\
\hline
\end{tabular}




\subsubsection{Estruturação hidrológica / hidráulica para aplicação dos modelos matemáticos}

Para a elaboração das simulações hidrológicas e hidráulicas, foi observado que foram construídos na área da bacia dois reservatórios de contenções de cheias ("piscinões"), que serão utilizados no cálculo dos hidrogramas como reservatórios in-line e com curvas de cota-descarga definidas. Um deles se localiza no córrego Bananal e o outro na foz do córrego Guaraú. No ambiente computacional do URBSSD, o usuário tem a opção de inserir ou não os reservatórios para amortecer os maiores volumes de chuva efetiva.

De acordo com BARROS (2004), para representar o sistema de macrodrenagem da bacia no modelo, foram levantadas as seções transversais dos cursos d'água no trecho entre o início do córrego Bananal (encontro dos córregos Corumbé e Canivete) e a confluência do rio Cabuçu de Baixo com o córrego Guaraú. Nesse trecho, que apresenta uma extensão aproximada de $4 \mathrm{~km}$, as seções transversais foram espaçadas a cada $200 \mathrm{~m}$ aproximadamente.

Para a determinação da mancha de inundação, foi utilizada a digitalização da planície de inundação do sistema de macrodrenagem, ao complementar as seções transversais para a geração das áreas inundáveis. Essa digitalização foi realizada a partir da geração de um modelo digital do terreno (MDT), baseado em técnicas de interpretação de fotos aéreas, escrito por NÓBREGA (2004).

A partir da aplicação do modelo CLIV, considerando o regime uniforme, foi definido o coeficiente de rugosidade " $\mathrm{n}$ " de Manning para o trecho em canal de concreto, desde a foz do córrego Itaguaçu até a confluência com o córrego Guaraú. Essa aferição foi feita com base na curva-chave do posto Campos Lemos. Dessa forma, foram levantadas algumas relações cota-vazão a partir do modelo, considerando valores alternativos do 
coeficiente n, obtido em CHOW (1959). A curva que mais se aproximou da curva-chave corresponde a $n=0,035$. O alto valor do coeficiente de Manning para esse trecho, cuja seção é de concreto e que normalmente apresenta valores de n entre 0,013 e 0,020, pode ser explicado pelo fato do acabamento da seção ser bastante irregular e com ranhuras laterais, o que tende a provocar uma maior turbulência no escoamento.

Para o trecho natural, situado a montante da foz do córrego Itaguaçu, que apresenta uma extensão de cerca de 2100 m, será adotado o valor de n de Manning para Canais Naturais com vegetação arbustiva. De acordo com CHOW (1959), optou-se por adotar um coeficiente $\mathbf{n}=0,050$. 


\subsection{Aplicação do Modelo URBSSD}

Para que o URBSSD obtenha os melhores resultados, serão utilizados os mesmos eventos hidrológicos aplicados no projeto "Gerenciamento Integrado de Bacias Hidrográficas em Áreas Urbanas”, BARROS (2004), implantando a ponderação de áreas obtidas pelo método de Thiessen para ser obtido o hietograma a ser aplicado para toda a bacia. Foram feitas as verificações do modelo hidrológico e hidráulico, para a obtenção do nível da água e hidrograma final, a fim de serem comparados com os resultados das medições fluviográficas do posto à jusante, Campos Lemos.

\subsubsection{Verificação do Modelo Hidrológico}

Os parâmetros que foram calibrados no modelo hidrológico foram o $\mathrm{CN}$ (Curve Number), que regula o processo de infiltração, e o tempo de concentração (Tc), que influi na forma do hidrograma unitário sintético. Estes dois parâmetros não foram inicialmente modificados.

A calibração foi realizada para as sub-bacias 1 a 7 do esquema topológico adotado para o modelo hidrológico, conforme indicado na Figura 5.13 e na Tabela 5.3. Essas subbacias são controladas pelos postos fluviográficos implantados no estudo, a saber, Jardim Vista Alegre, no córrego Bananal, Imobel, no córrego Itaguaçu, e Campos Lemos, no rio Cabuçu de Baixo. No entanto, as comparações entre hidrogramas observados, calibrados e modelados só foi feita para o posto Campos Lemos. Os parâmetros das demais sub-bacias não puderam ser calibrados uma vez que não foi possível instalar postos fluviométricos em outros locais de grande interesse. 
Foram verificados os eventos hidrológicos disponíveis entre os anos de 2001 e 2003. Durante o ano hidrológico de 2001/2002 foram registrados um total de 33 eventos sendo que apenas cinco desses eventos foram registrados pelos postos pluviográficos.

No período chuvoso de 2002/2003 foram registrados um total de 38 eventos sendo que os eventos compreendidos entre setembro e dezembro de 2002, 14 eventos, foram registrados somente pelos postos fluviográficos e pelo radar meteorológico de SAISP (2008). No período de janeiro a março de 2003 foram registrados 24 eventos nos postos pluviográficos, fluviográficos e no radar meteorológico.

Em sua maioria os eventos ocorridos na bacia do Rio Cabuçu de Baixo não vem causando grandes inundações, porém em 5 de março de 2003 houve um evento em particular que causou uma grande inundação na bacia.

Para as simulações, foram selecionadas três chuvas intensas registradas nos postos Itaguaçu, Bananal e Itaguaçu. Os hietogramas referentes a esses eventos, obtidas pela ponderação de áreas do Polígono de Thiessen e totalizados em intervalos de 15 minutos, são mostrados nos gráficos obtidos do módulo de precipitação da interface URBSSD nas Figuras 5.19 a 5.21. 


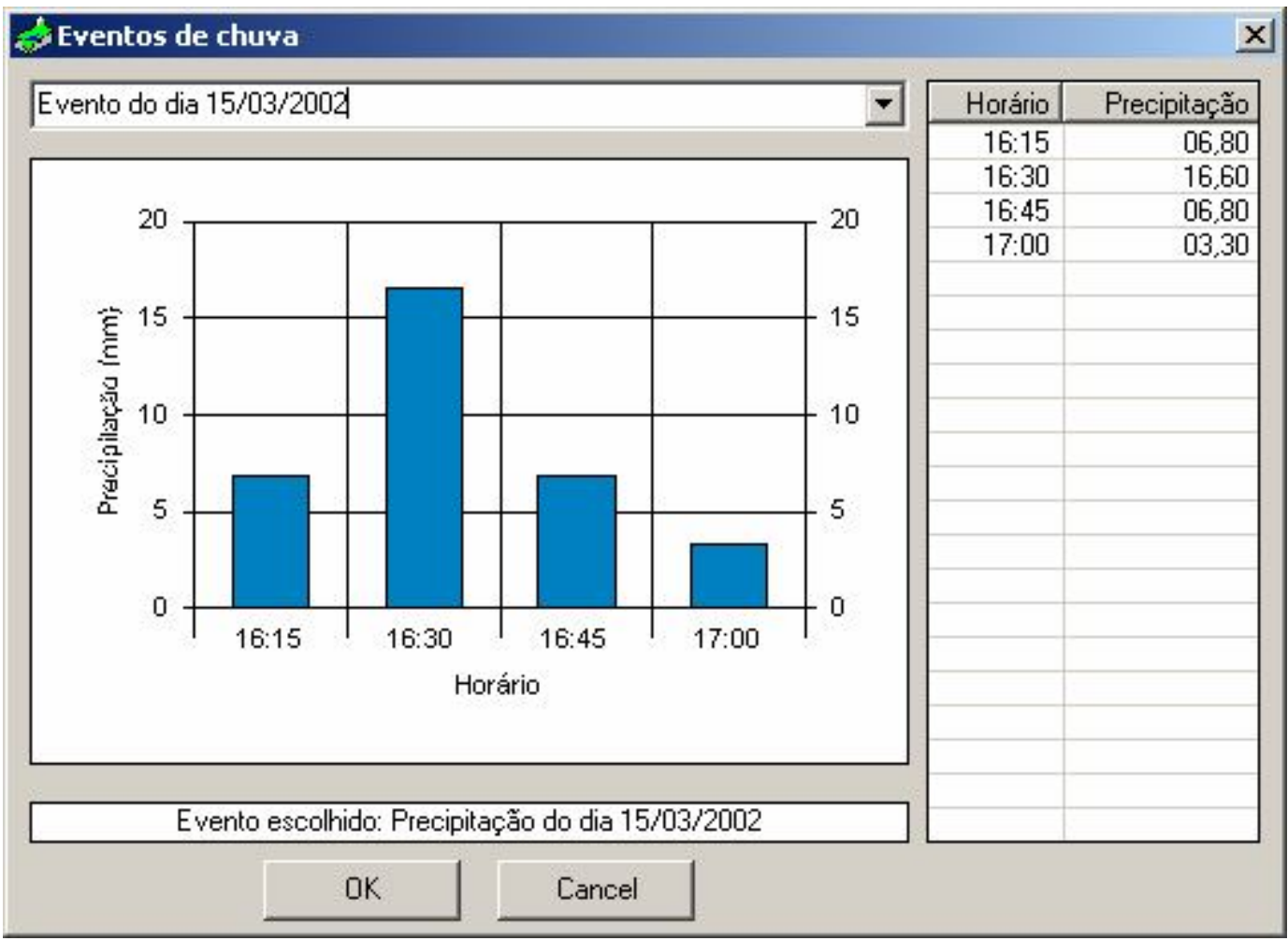

Figura 5.19 - Hietograma - Evento de 15/03/2002

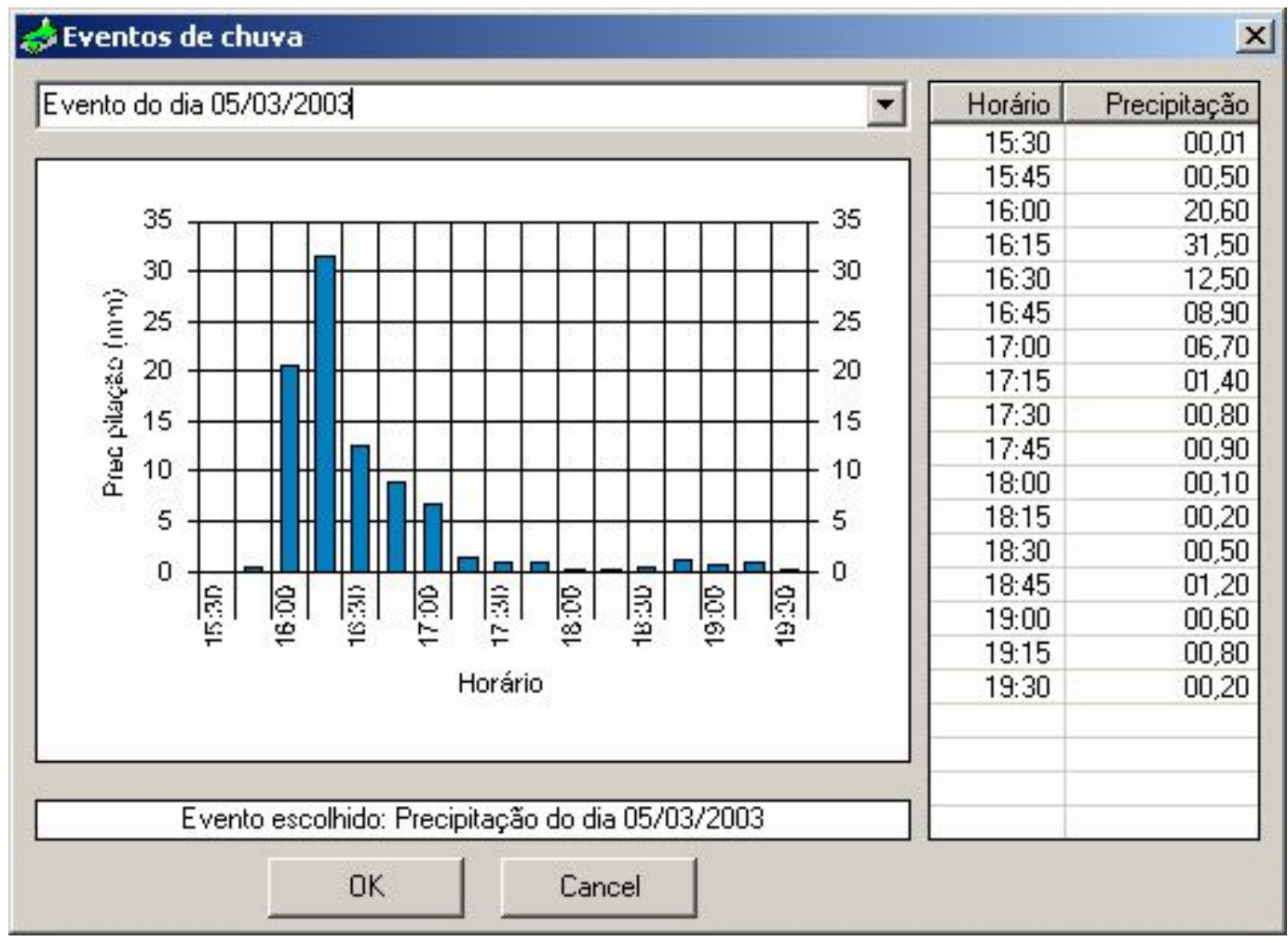

Figura 5.20 - Hietograma - Evento de 05/03/2003 


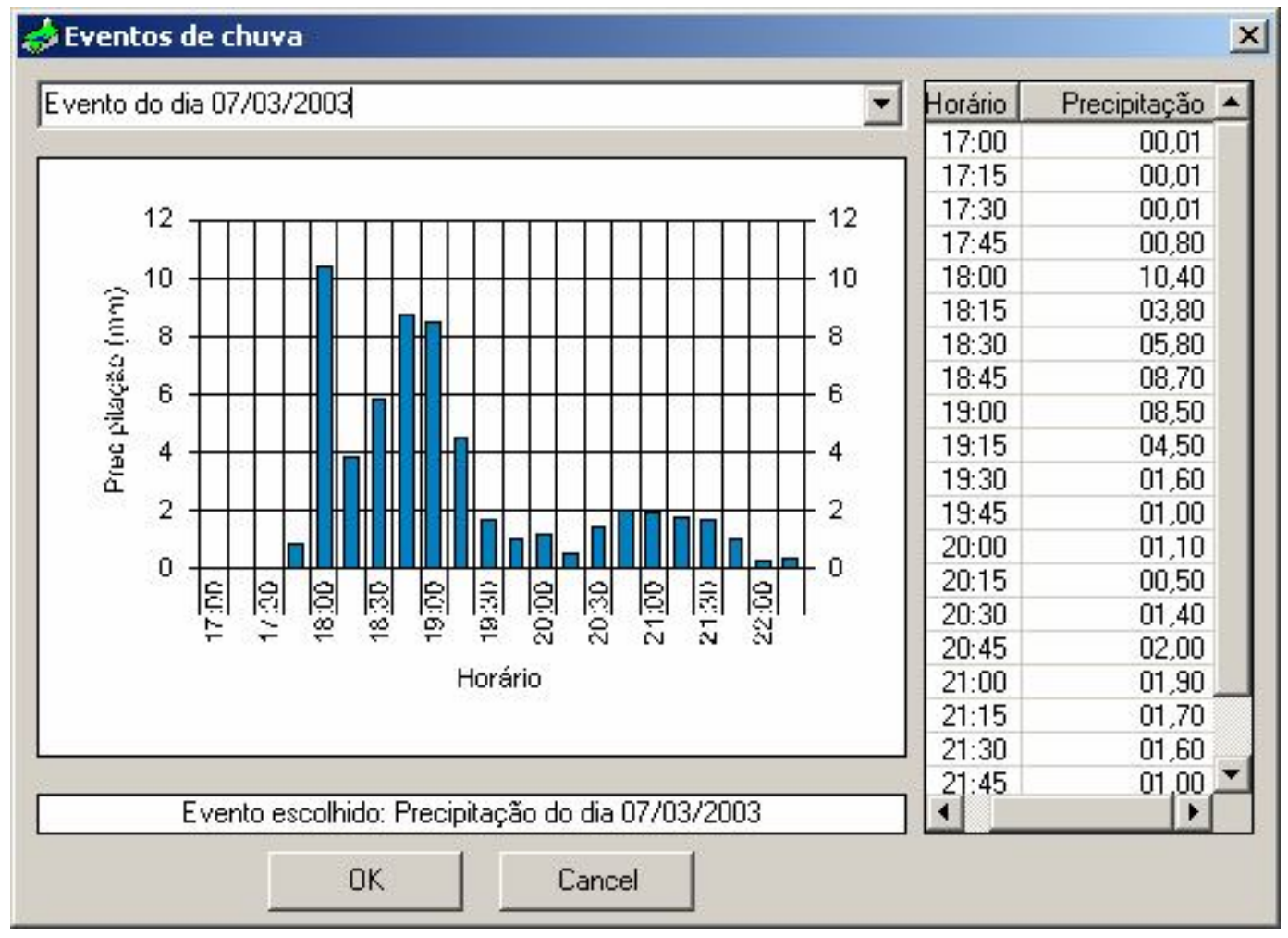

Figura 5.21 - Hietograma - Evento de 07/03/2003

Os resultados na interface e os hidrogramas gerados e observados são mostrados nas Figuras 5.22 a 5.25. Observar que os gráficos obtidos nas figuras da interface correspondem aos hidrogramas obtidos a jusante do trecho da bacia "Cabuçu Intermediário I", que corresponde à mesma área de drenagem do posto fluviográfico Campos Lemos. Os hidrogramas em vermelho são os hidrogramas calculados pelo URBSSD, quanto que os hidrogramas na cor verde correspondem aos hidrogramas de contribuição da bacia "Cabuçu Intermediário I" e os hidrogramas na cor azul nos gráficos comparativos são as observadas pelo posto Campos Lemos. 


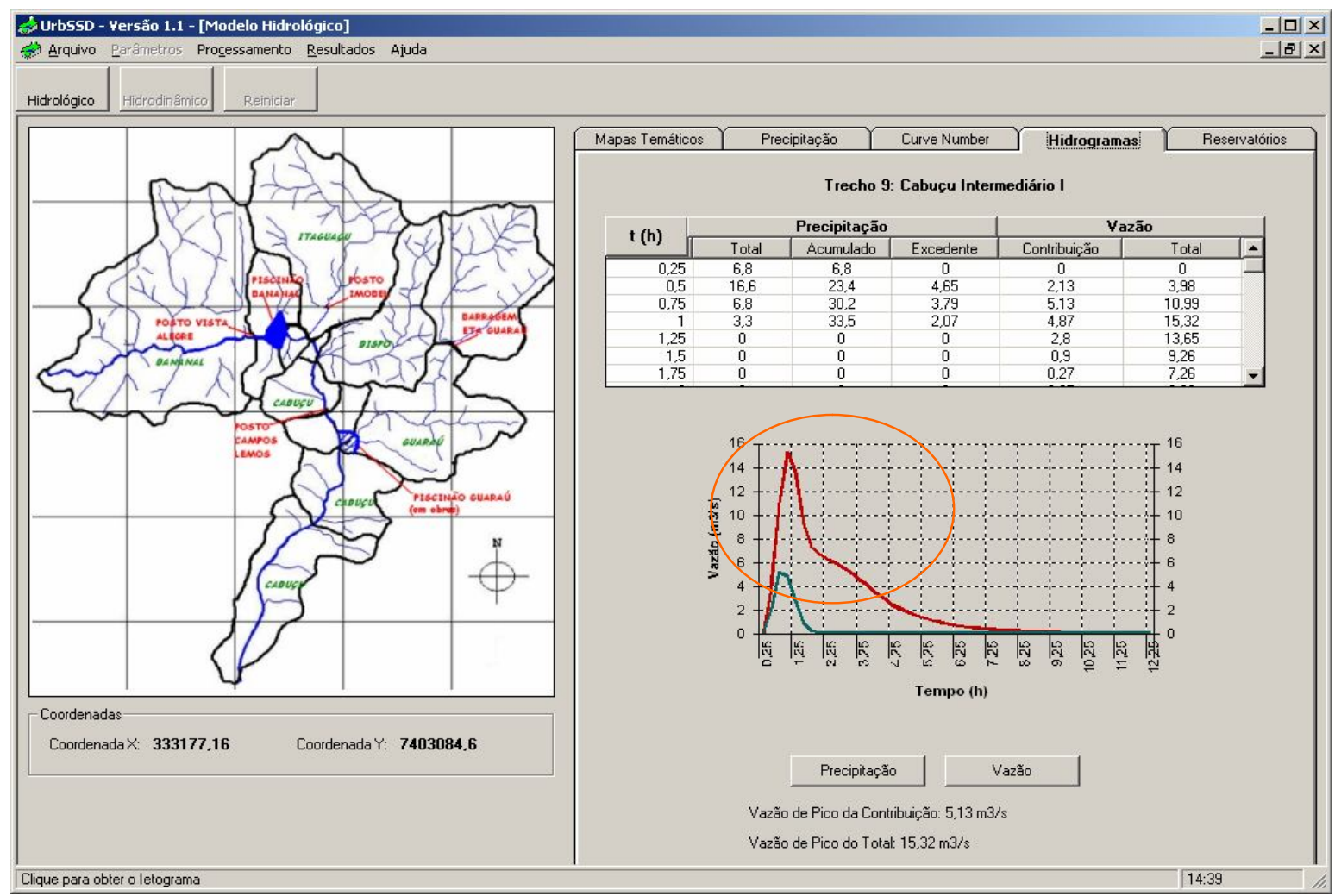

Figura 5.22 - Calibração na interface do Modelo Hidrológico - Evento 15/03/02

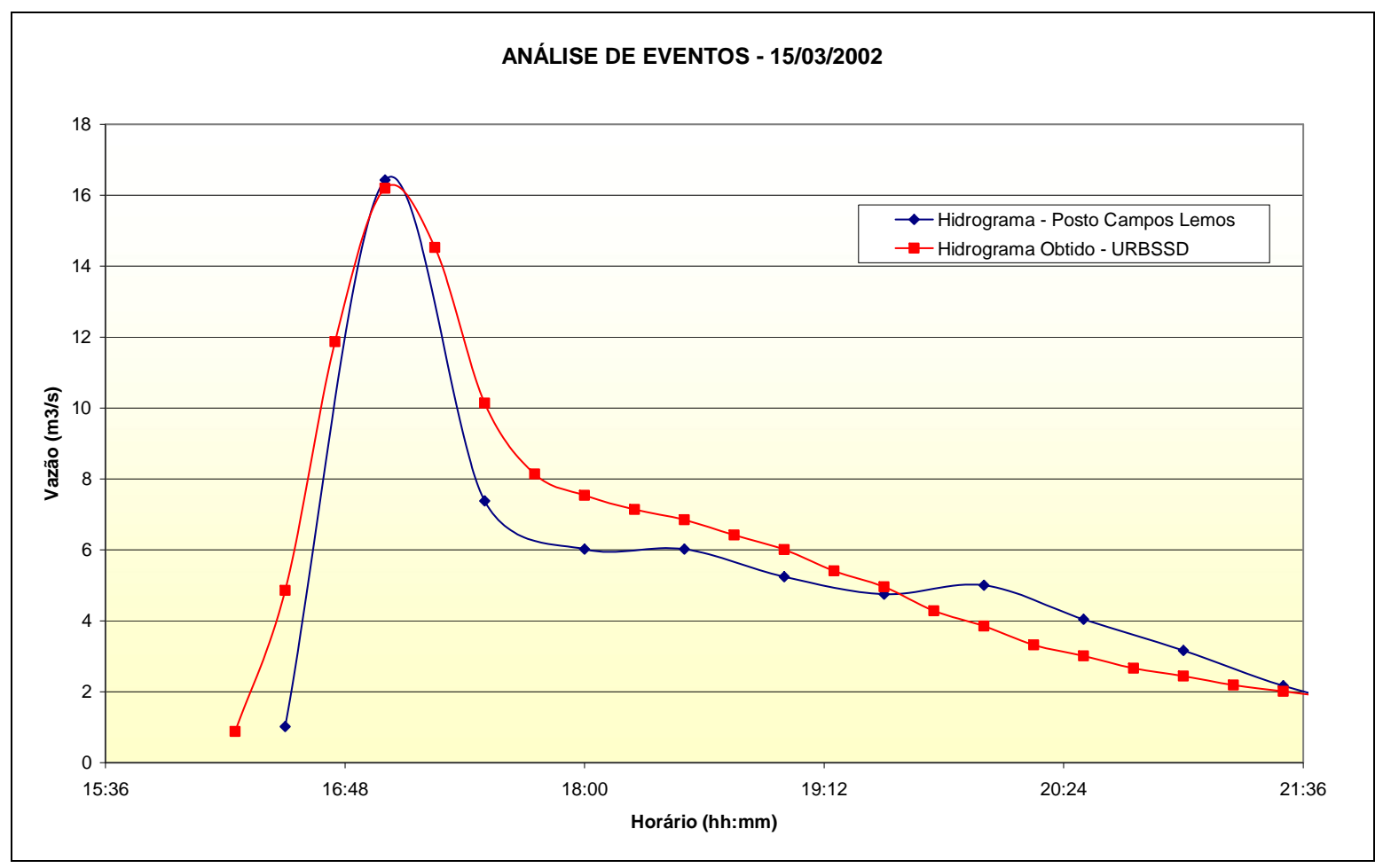

Figura 5.23 - Gráfico obtido na calibração do Modelo Hidrológico - Evento 15/03/02 


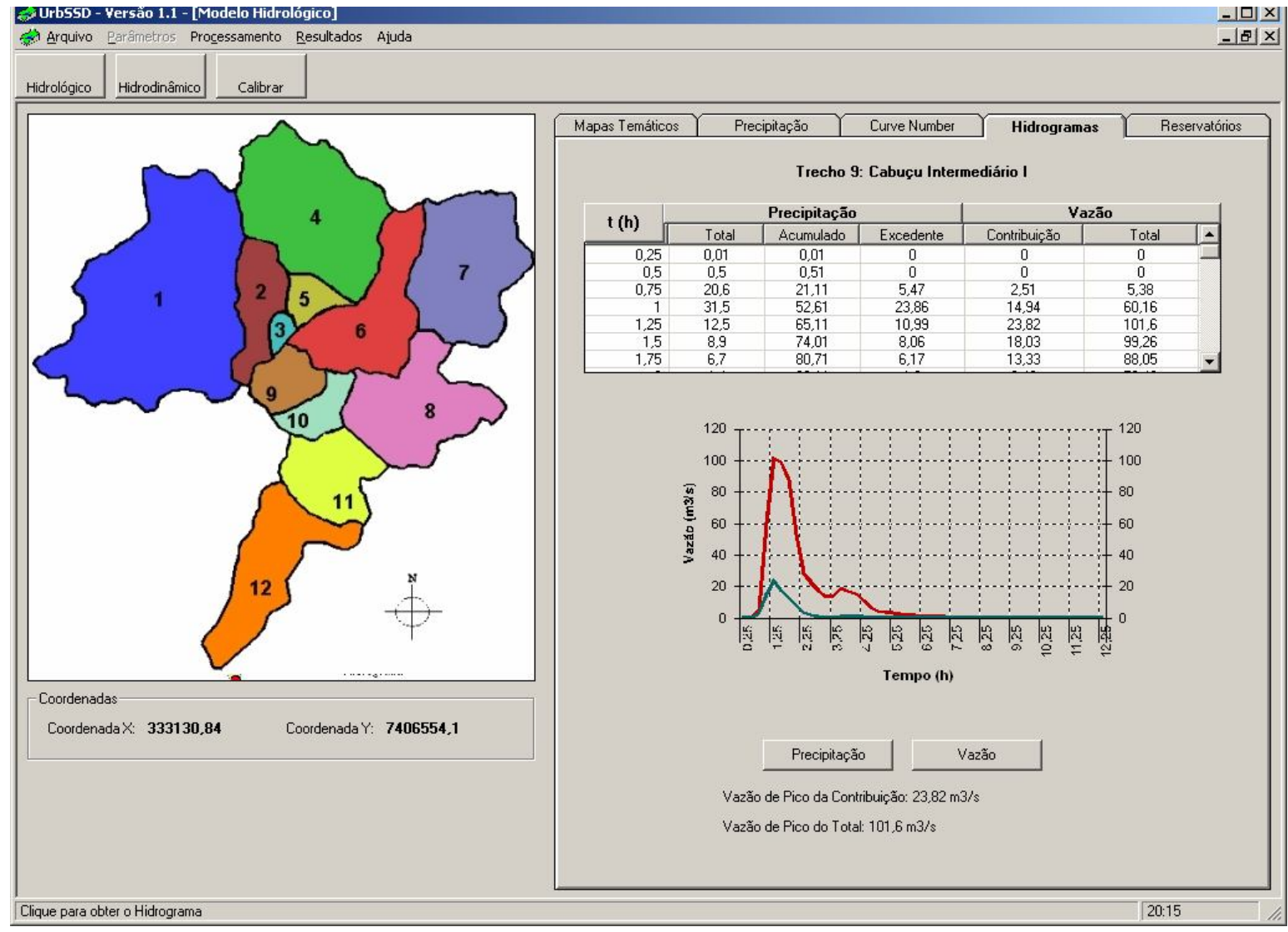

Figura 5.24- Calibração na interface do Modelo Hidrológico - Evento 05/03/03

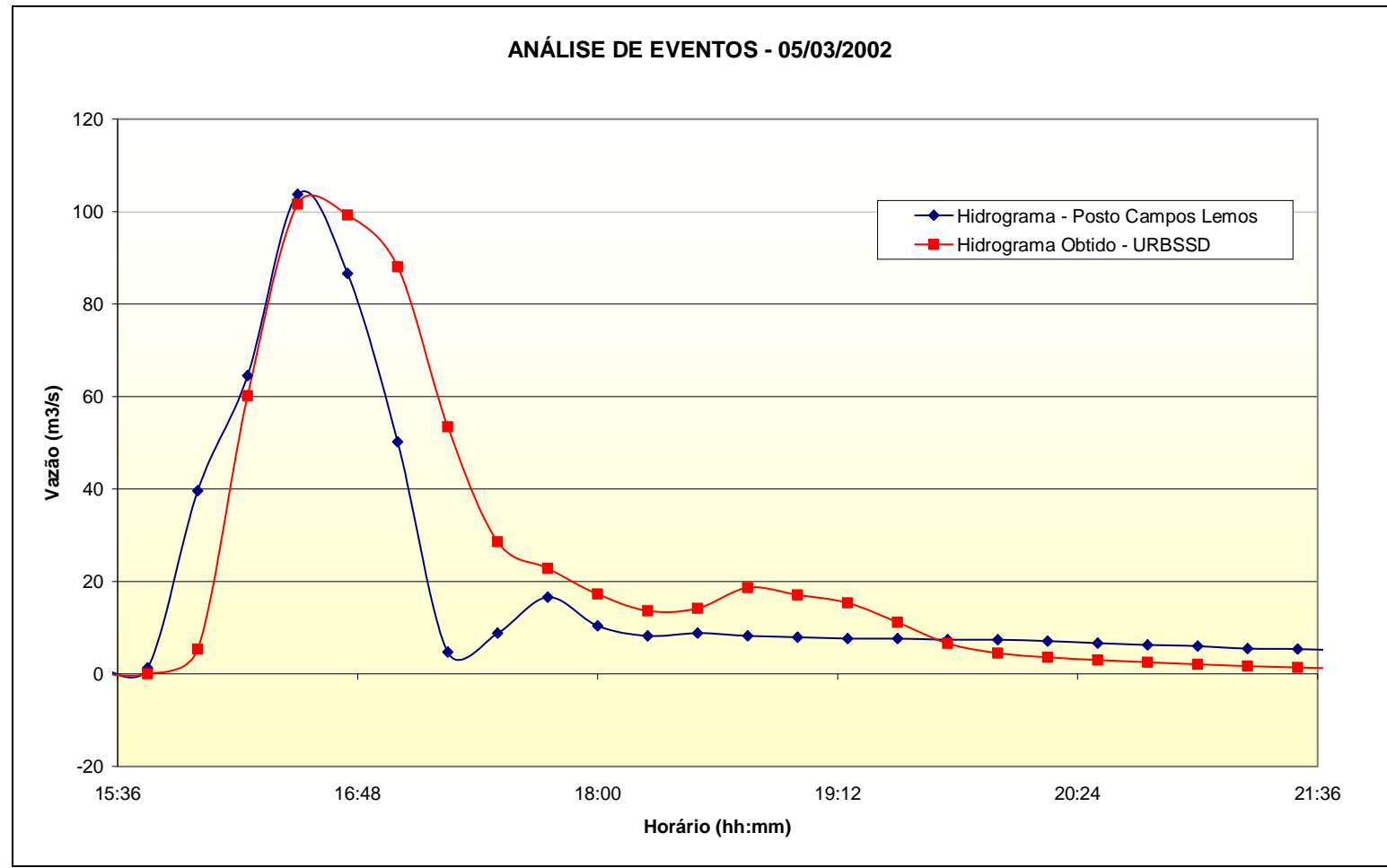

Figura 5.25 - Gráfico obtido na calibração do Modelo Hidrológico - Evento 05/03/03 
Os valores de $\mathrm{CN}$ e Tc obtidos a partir do processo de tentativa e erro são mostrados na Tabela 5.6.

Tabela 5.6 - Resultados da Calibração do Modelo Hidrológico

\begin{tabular}{|l|l|c|c|c|c|c|c|}
\hline \multirow{2}{*}{ SUB-BACIAS } & \multicolumn{5}{|c|}{ EVENTOS ANALISADOS } \\
\cline { 2 - 8 } & \multicolumn{2}{|c|}{$\mathbf{1 5 / 0 3 / 2 0 0 2}$} & 05/03/2003 & \multicolumn{2}{c|}{ MÉDIA } \\
\hline No & Nome & TC (horas) & CN & TC (horas) & CN & TC (horas) & CN \\
\hline 1 & Bananal Montante & 0,65 & 70 & 1,00 & 85 & $\mathbf{1 , 0 0}$ & $\mathbf{8 5}$ \\
\hline 2 & Bananal Intermediário & 0,50 & 81 & 0,36 & 85 & 0,43 & 83 \\
\hline 3 & Bananal Jusante & 0,30 & 85 & 0,21 & 85 & 0,26 & 85 \\
\hline 4 & Itaguaçu Montante & 1,80 & 72 & 0,76 & 57 & 1,28 & 65 \\
\hline 5 & Itaguaçu Jusante & 1,50 & 78 & 0,34 & 63 & 0,92 & 71 \\
\hline 6 & Bispo & 3,50 & 90 & 1,22 & 73 & 2,36 & 82 \\
\hline 7 & Cabuçu Intermediário 1 & 0,45 & 87 & 0,56 & 90 & 0,51 & 89 \\
\hline
\end{tabular}

Por dispor de poucos dados, foram adotados como parâmetros do modelo hidrológico os valores de Tc e $\mathrm{CN}$ médios aproximados indicados nessa última tabela.

Para a validação dos dois eventos anteriormente calibrados foi feito com o evento de 07/03/2003. A média dos valores de Tc e CN foram modificadas na sub-bacia Bananal Montante, ao admitir que o tempo de concentração correto foi obtido pelo evento de 05/03/2003, para que seja feita a validação, de acordo com as Figuras 5.26 e 5.27. 


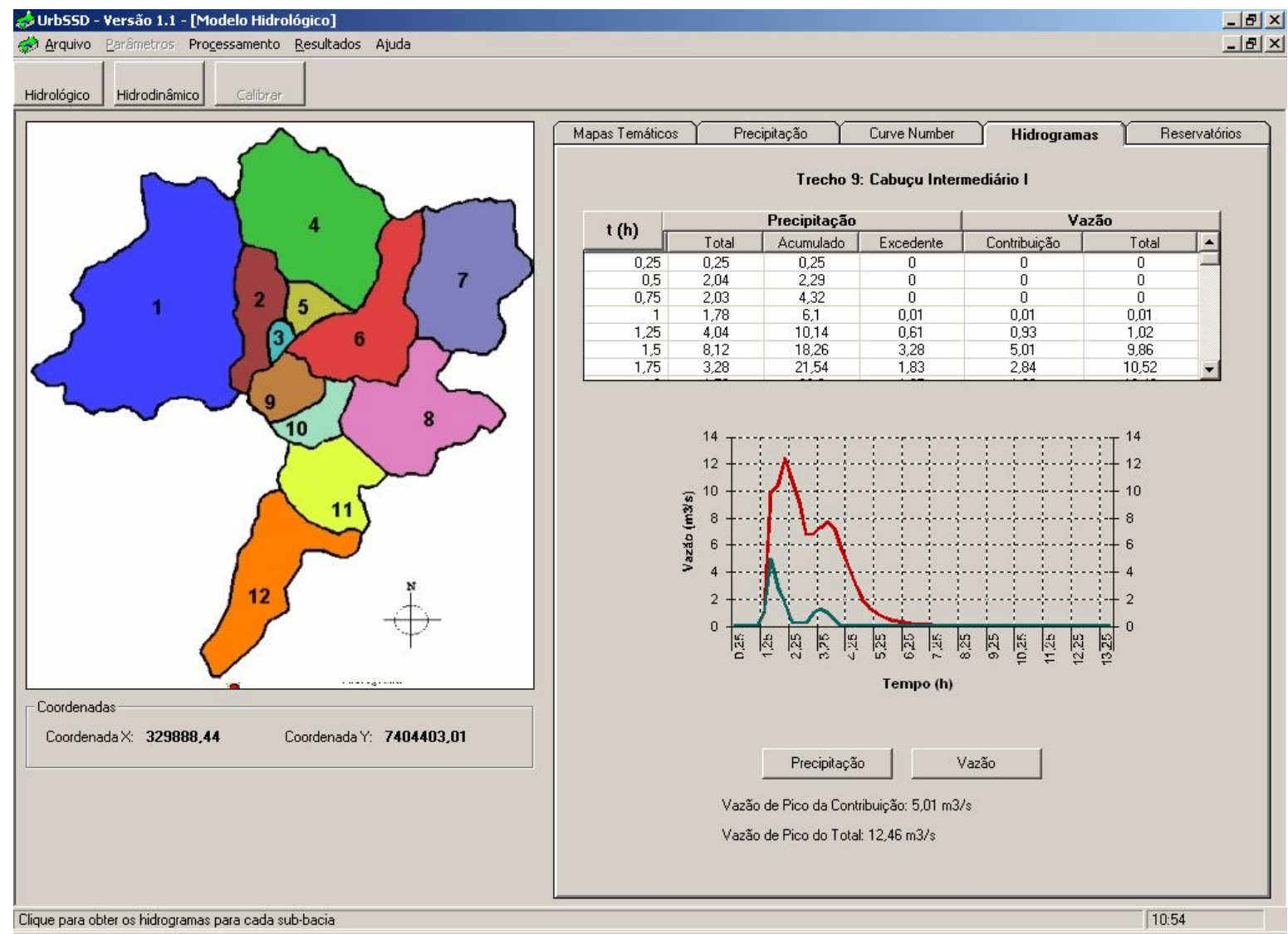

Figura 5.26 - Validação na interface do Modelo Hidrológico - Evento 07/03/03

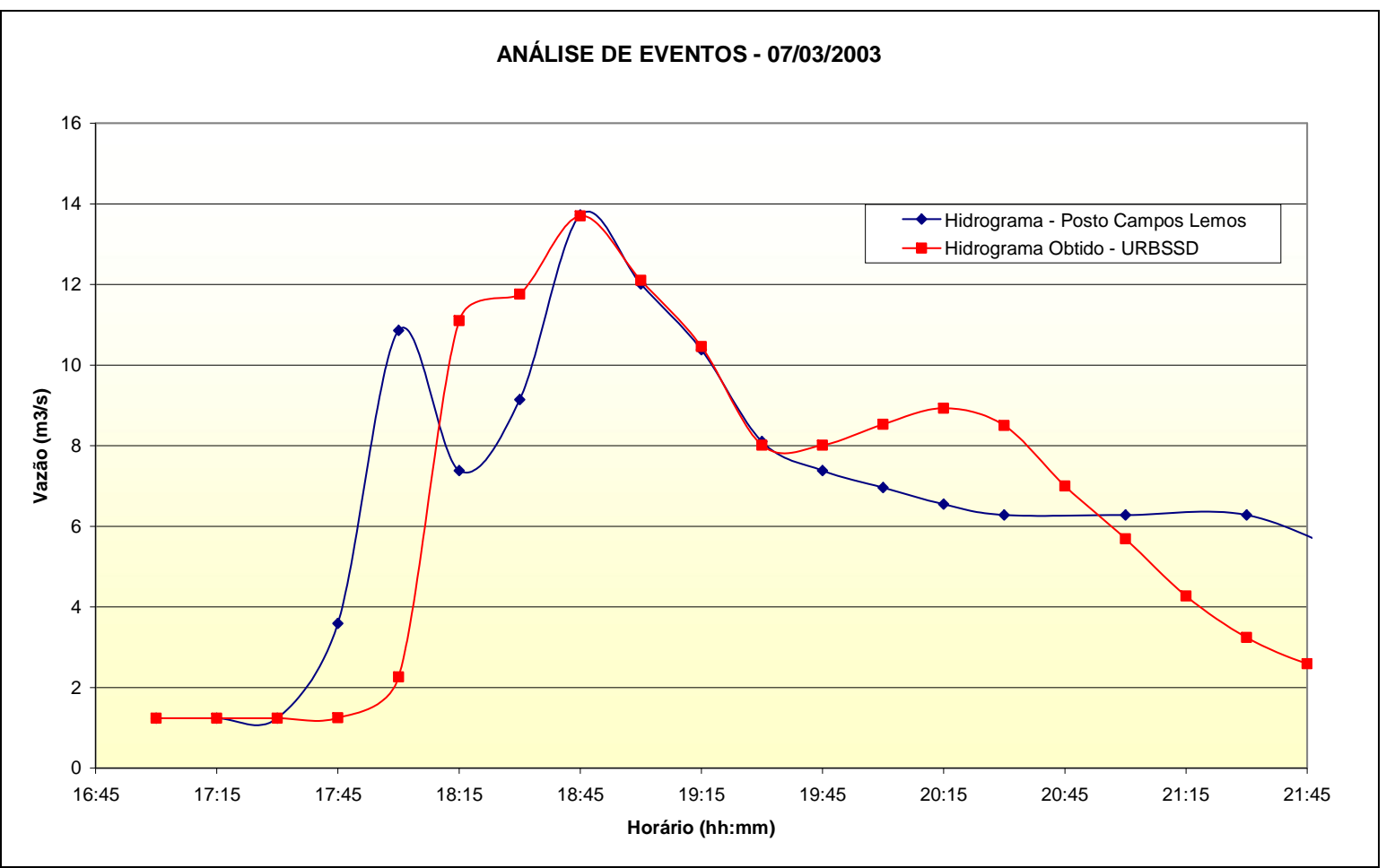

Figura 5.27 - Gráfico obtido na validação do Modelo Hidrológico - Evento 07/03/03 


\subsubsection{Verificação do Modelo Hidráulico}

De acordo com BARROS (2004), a calibração do modelo hidráulico foi feita a partir da aferição dos coeficientes de rugosidade "n" de Manning, aplicando o modelo CLIV. A seguir, nas Figuras 5.28 e 5.29, são mostradas as relações cota-vazão decorrentes da simulação hidrodinâmica para o evento de 15/03/2002.

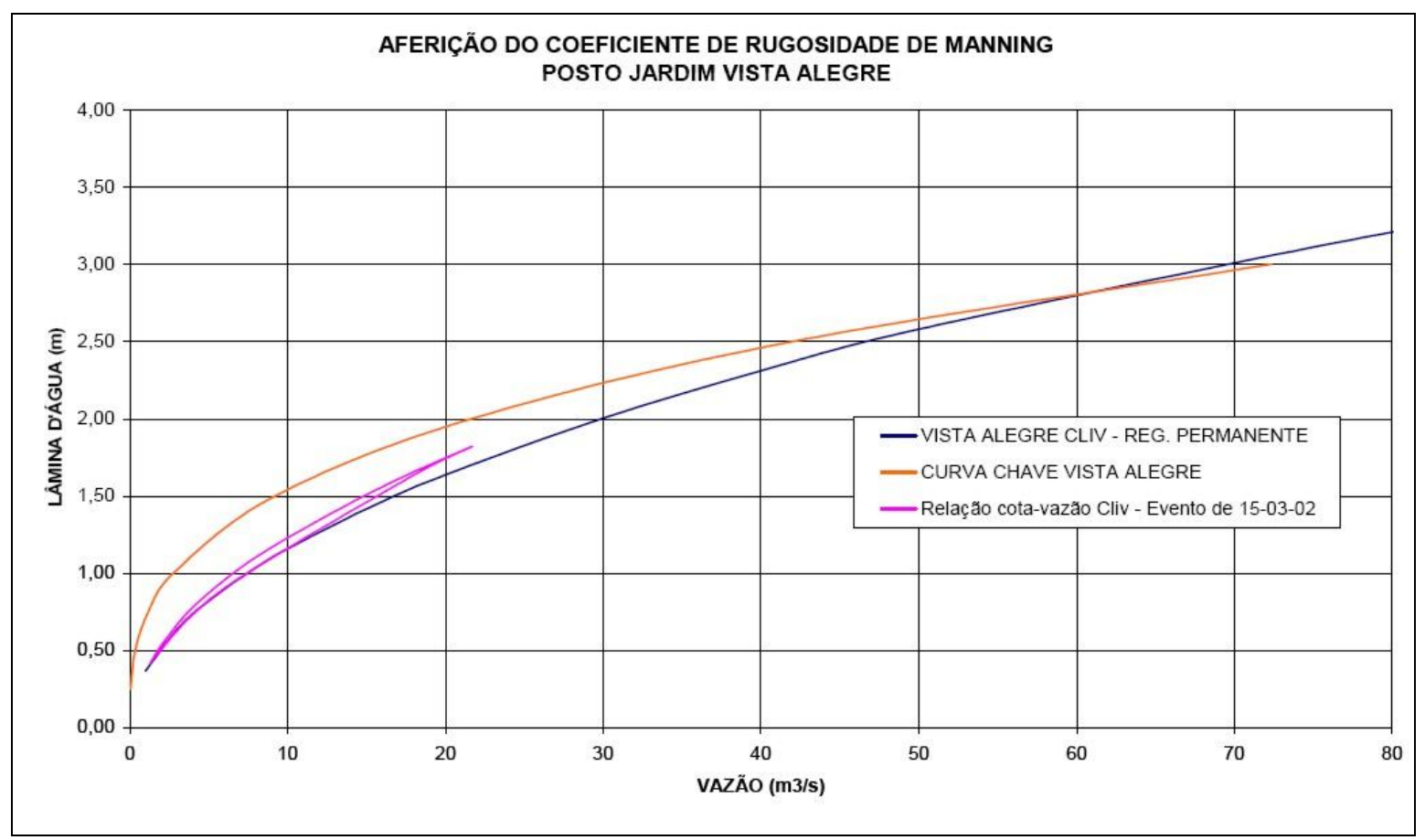

Figura 5.28 - Aferição do Coeficiente de Rugosidade - Posto Vista Alegre (FONTE: BARROS 2004) 


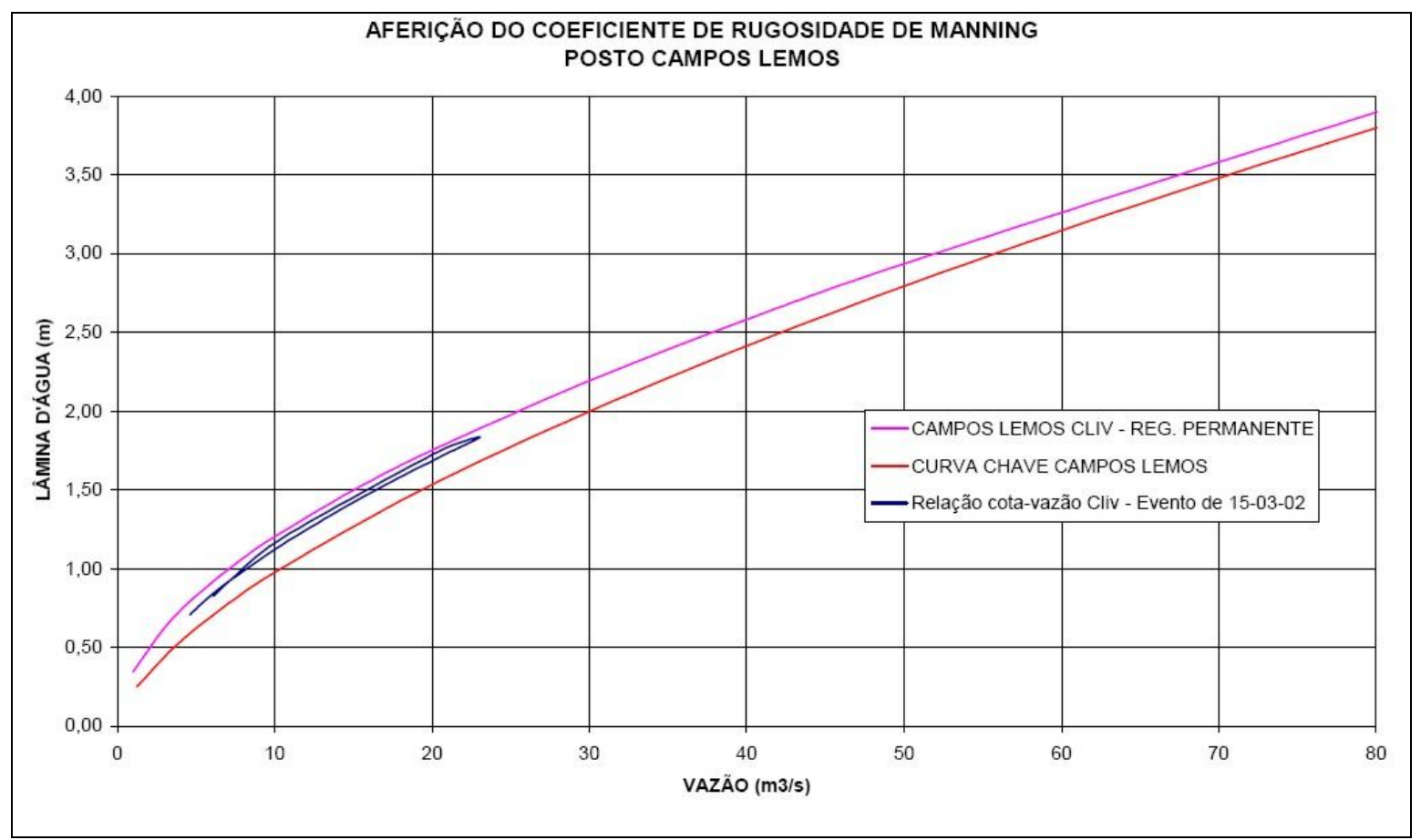

Figura 5.29 - Aferição do Coeficiente de Rugosidade - Posto Campos Lemos (FONTE: BARROS, 2004)

Utilizando a mesma calibração, foram feitas simulações para os mesmos eventos da simulação hidrológica, de acordo com as Figuras 5.30 a 5.35. 


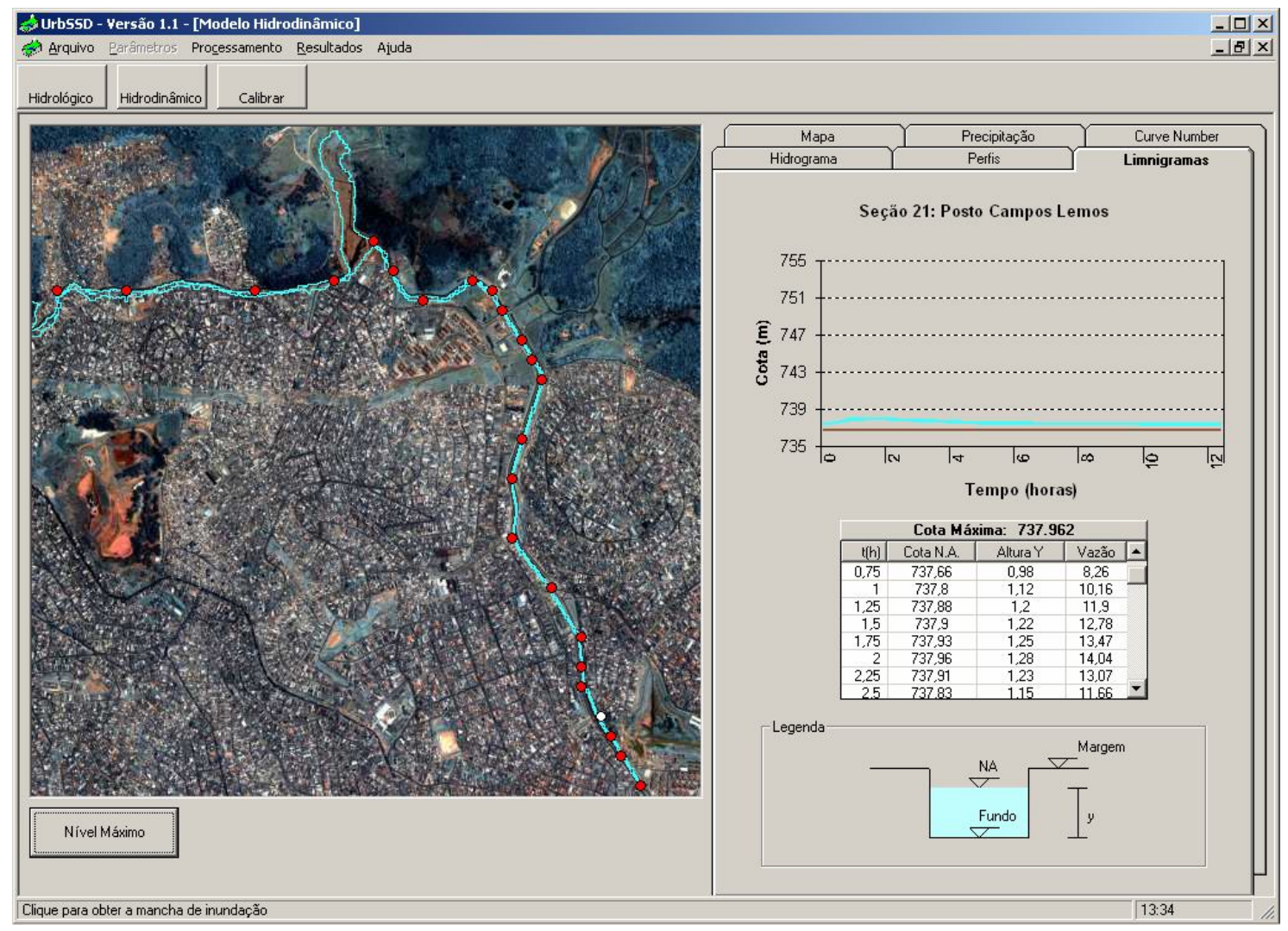

Figura 5.30 - Interface do Modelo Hidráulico - Evento 15/03/02

Limnigrama do Posto Campos Lemos em 15/02/2002

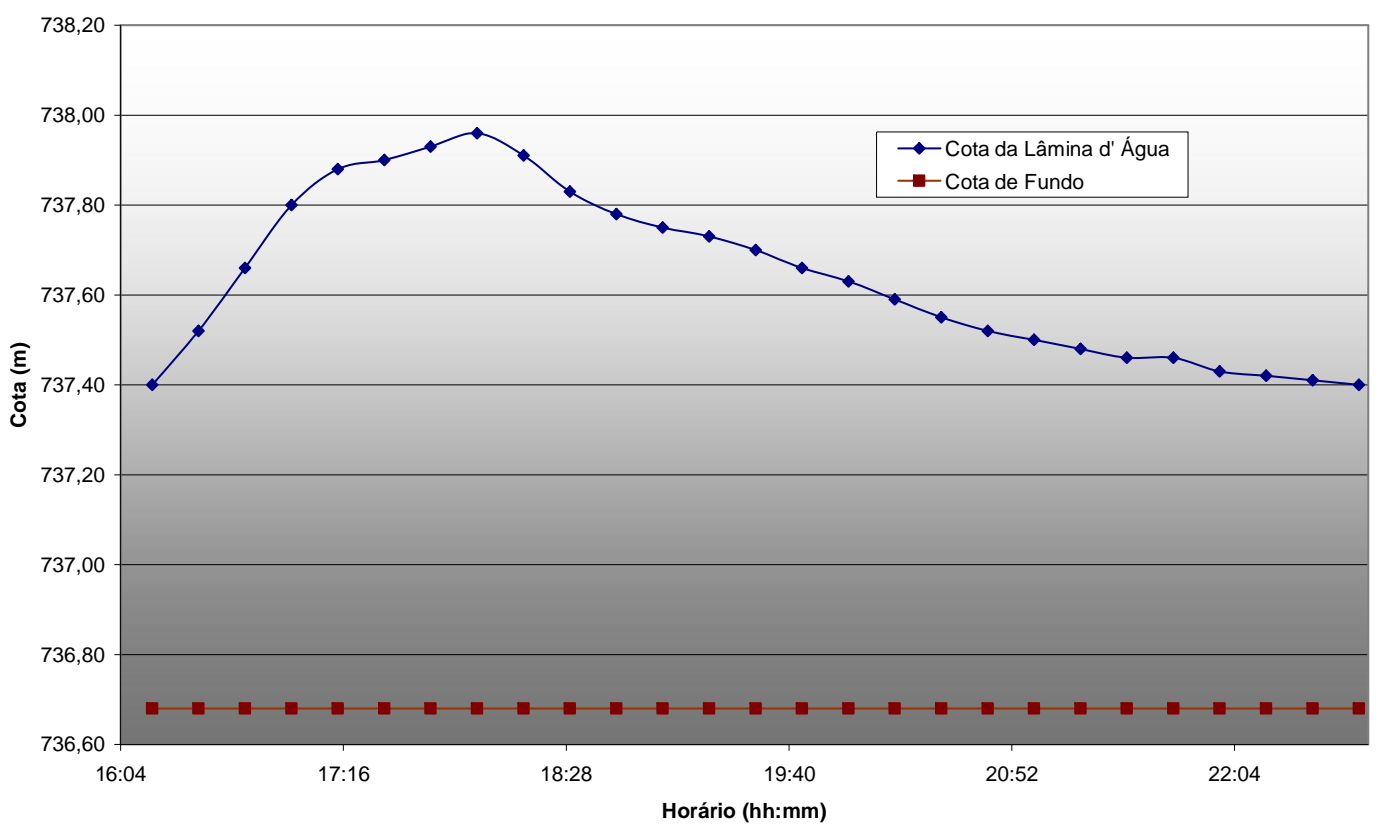

Figura 5.31 - Limnigrama final do Modelo Hidráulico - Evento 15/03/02 


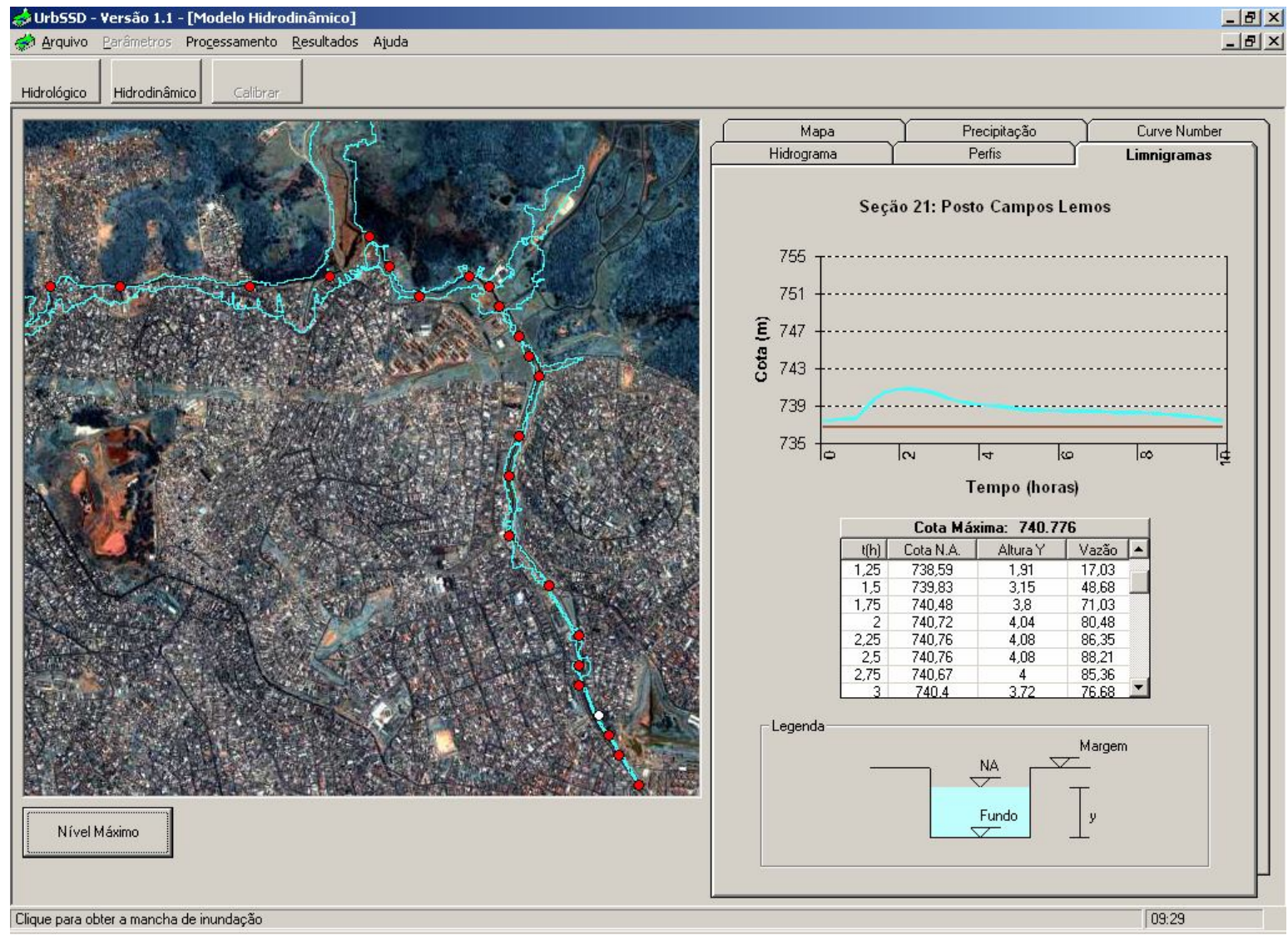

Figura 5.32 - Interface do Modelo Hidráulico - Evento 05/03/03

Limnigrama do Posto Campos Lemos em 05/03/2003

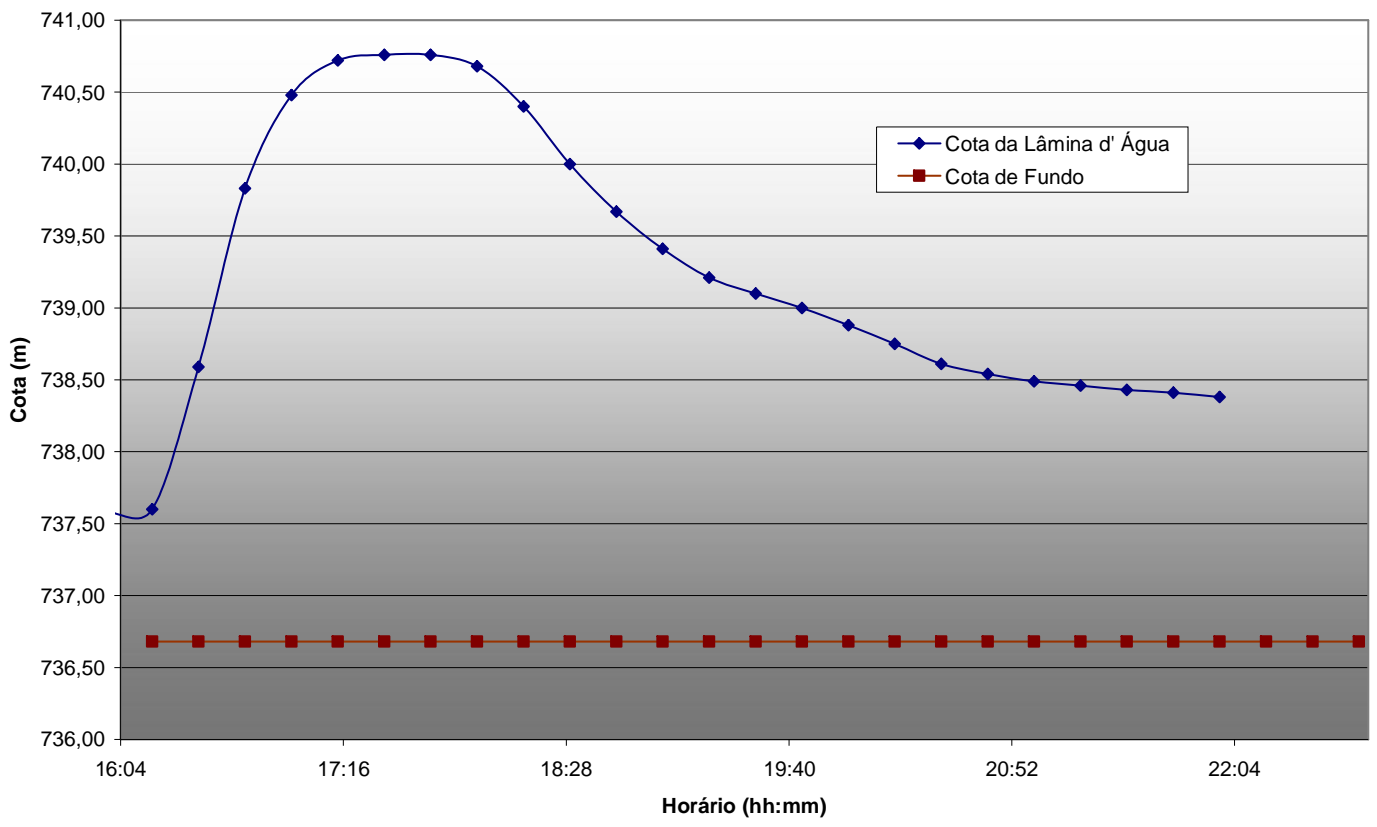

Figura 5.33 - Limnigrama final do Modelo Hidráulico - Evento 05/03/03 


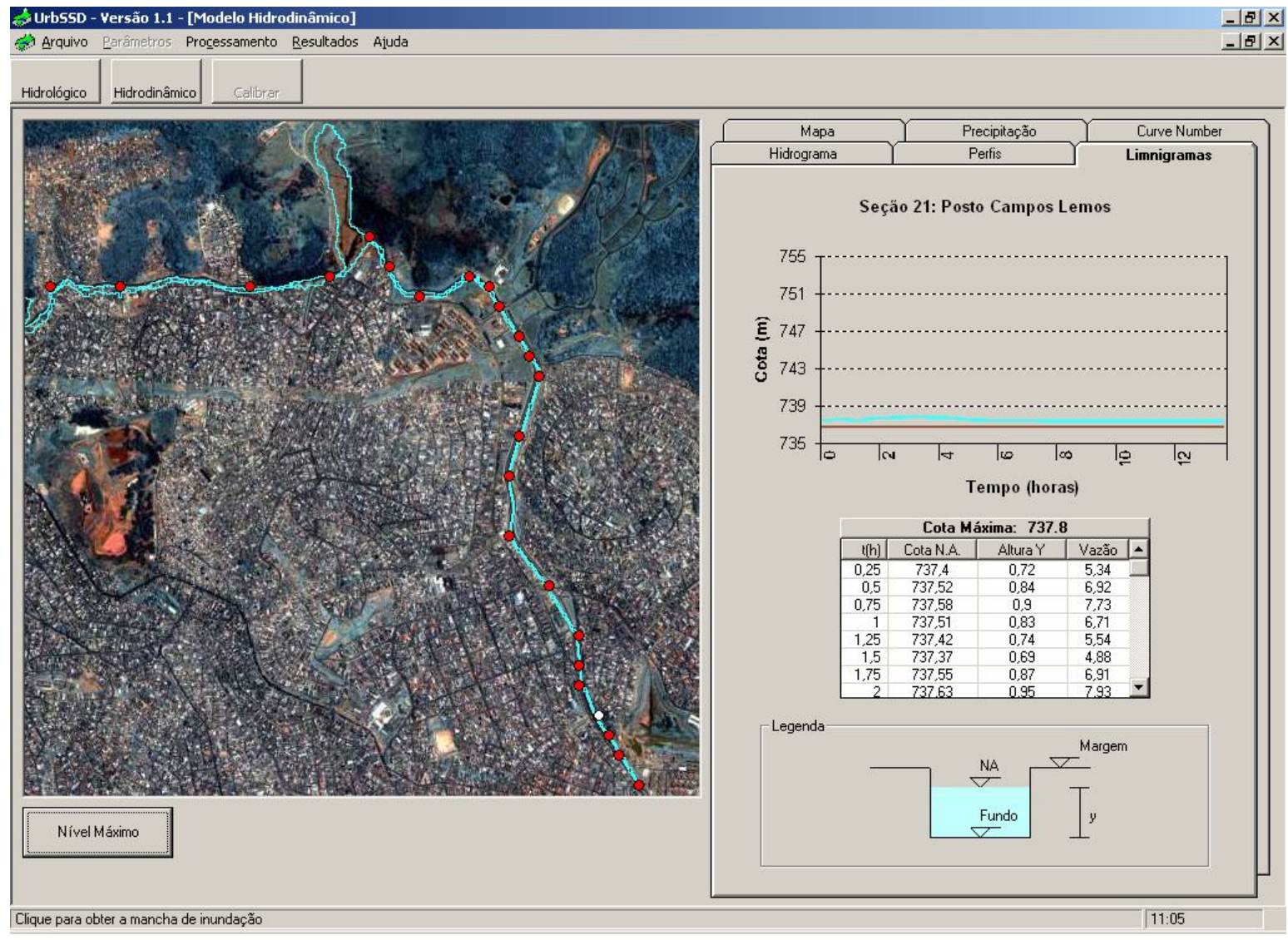

Figura 5.34 - Interface do Modelo Hidráulico - Evento 07/03/03

Limnigrama do Posto Campos Lemos em 07/03/2003

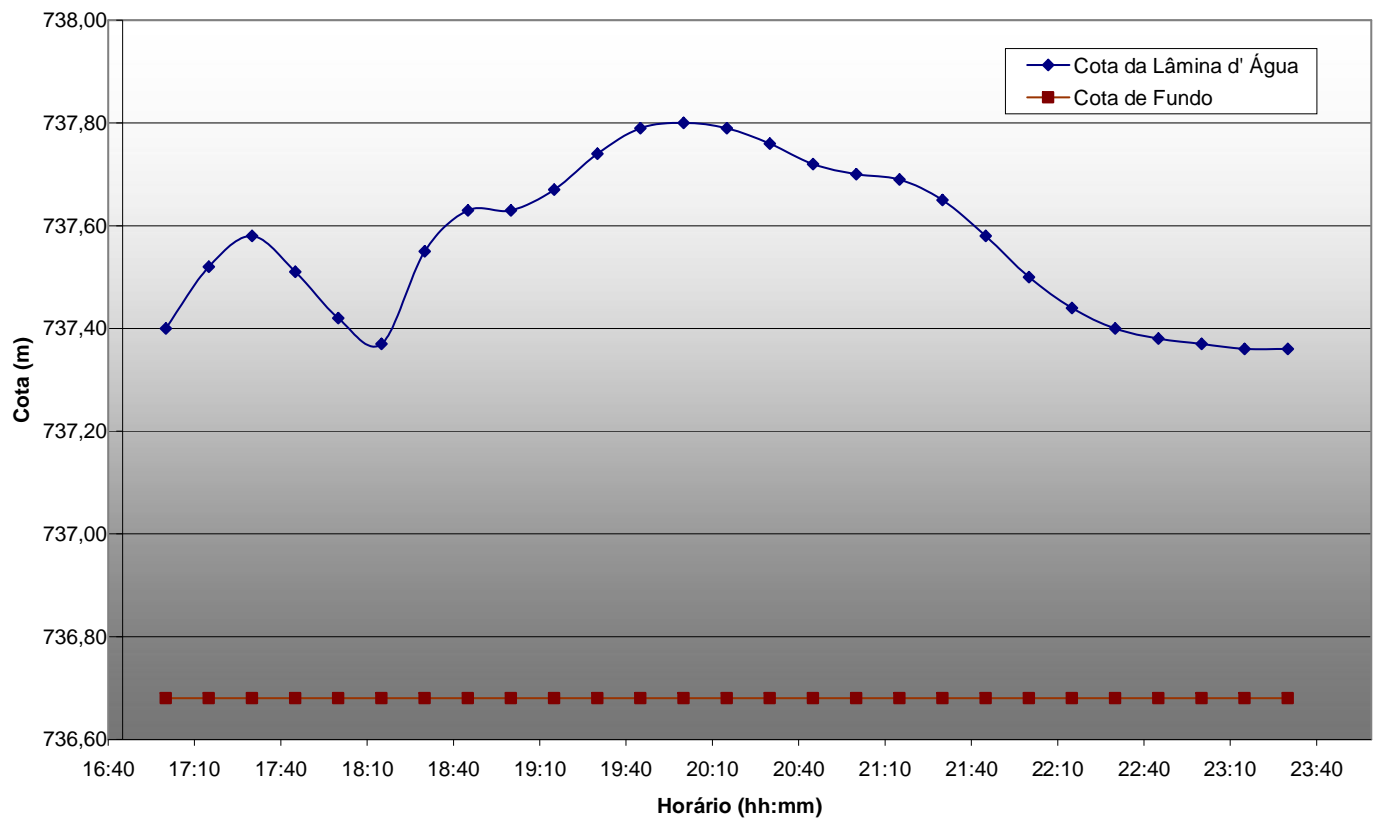

Figura 5.35 - Limnigrama final do Modelo Hidráulico - Evento 07/03/03 
Os produtos finais, além das tabelas de vazões amortecidas pelo modelo hidráulico e os limnigramas finais, são as áreas de inundações. Os polígonos destas áreas resultantes podem ser exportados em tabelas (por pontos georreferenciados) ou em formato CAD.

A mancha de inundação, como mostrado na tela em SIG da interface da Figura 5.36, poderá ser utilizada por várias linhas de pesquisa em planejamento urbano.

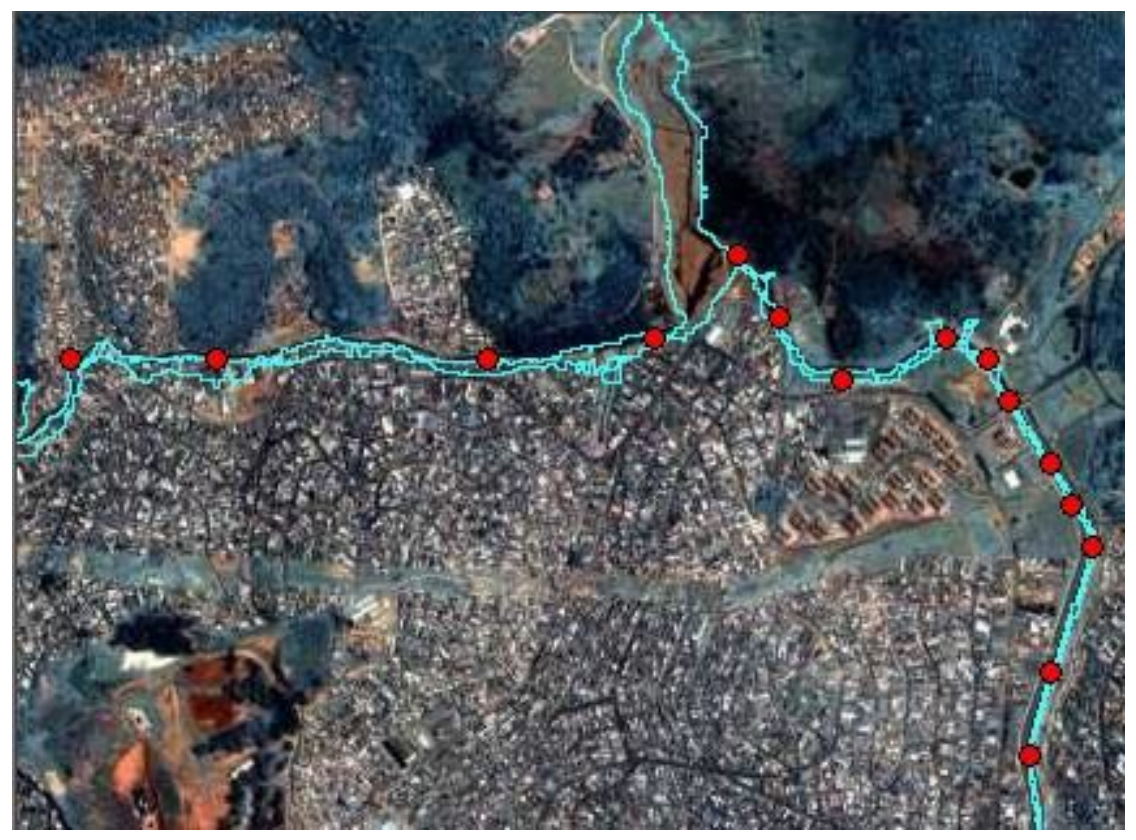

Figura 5.36 - Área de inundação no URBSSD - Evento 15/02/02

\subsubsection{Exemplos de aplicações das Áreas de Inundação}

Tendo o resultado do modelo, podem-se fazer diversas aplicações das áreas de inundação, em trabalhos multidisciplinares. No Projeto Plano de Bacia Urbana de BARROS et. al. (2005), foram feitas diversas aplicações das áreas de inundação. Podem ser destacados alguns produtos que foram obtidos a partir da definição de critérios de aptidão e do estabelecimento de zonas pela sobreposição de mapas temáticos, na qual os processos de planejamento / zoneamento foram baseados na vocação intrínseca das terras. Entre eles: o Mapa Síntese do PRAP (Programa de Recuperação e Preservação Ambiental), Mapa do 
Parque Linear e o Mapa de Risco. Além da área de inundação obtida pelo SSD com tempo de retorno de 25 anos, os três produtos utilizaram as seguintes informações, como na Tabela 5.7.

Tabela 5.7 - Informações espaciais utilizadas para gerar os produtos

\begin{tabular}{||l|l||}
\hline \hline Item & \multicolumn{1}{|c||}{ Informações } \\
\hline (a) & Área atendida por rede de abastecimento de água \\
\hline (b) & Áreas com declividade superior a $30 \%$ \\
\hline (c) & Situação da vegetação atual e áreas de solo exposto \\
\hline (d) & Hidrografia \\
\hline (e) & Topografia. \\
\hline \hline
\end{tabular}

\subsubsection{Mapa Síntese do PRAP}

O Programa de Recuperação Ambiental e da Paisagem (PRAP) baseia-se no delineamento e na proposição de diretrizes gerais visando à criação de uma infra-estrutura verde para as regiões onde existem ocupações antrópicas desordenadas.

Denomina-se infra-estrutura verde o conjunto de espaços abertos ou áreas verdes que ligam o meio urbano ao campo vizinho. Estes espaços não construídos podem ser em razão de seu estado inicial, seja em função de um manejo, situam-se no interior e nas proximidades dos setores reservados à construção, são predominantemente vegetados e bastante diversificados quanto as suas dimensões. Para a elaboração do Mapa Síntese do PRAP, como na Figura 5.37, partiu-se de uma base cartográfica digital formada pelo mosaico de fotografias aéreas e pela série de mapas, itens (a) até (e) da Tabela 5.7. Estes foram sobrepostos e trabalhados digitalmente no ArcMap em ESRI (2007). 


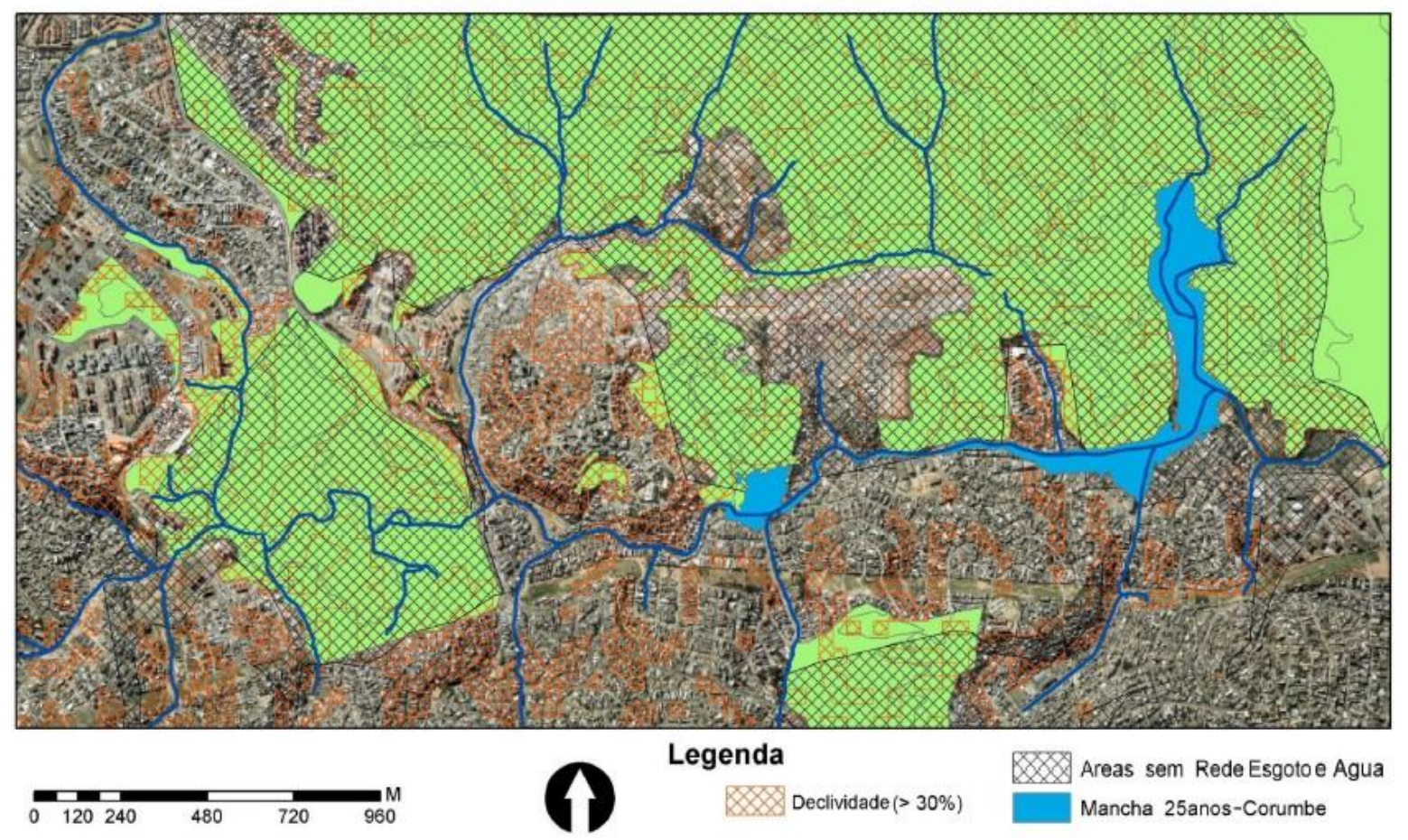

Figura 5.37 - Plano de Recuperação Ambiental e da Paisagem

São propostos: a relocação da população em área de risco de inundação para tempo de retorno de 25 anos, a relocação da população situada em locais de alta declividade e sem rede de abastecimento de água, a criação de zonas de transição entre as áreas florestais e a malha urbana, a criação de áreas de adensamento populacional, a delimitação de faixas com diferentes intensidades de manutenção nos reservatórios de cheias (piscinões) e a conexão das manchas verdes através de parques lineares.

\subsubsection{Mapa do Parque Linear}

O Parque Linear deve ser produzido a partir da implantação de projetos de recuperação da vegetação ciliar, de maneira a se minimizar a perda das funções hidrológicas e ecológicas comprometidas com a retirada da vegetação e a ocupação urbana.

Para criação do corredor verde, foi proposta por BARROS (2004) e PIRILLO, et.al.(2005) a remoção e a relocação de uma parcela da população que habita as áreas 
marginais aos cursos d'água. Foram pressupostas ainda a integração destas áreas com outras não ocupadas ao longo deste trecho do córrego e com as demais áreas lindeiras definidas pela cota de inundação de 25 anos. Na margem direita, nas quadras divididas por esta cota, foi assumida a primeira rua acima desta cota como limite, conformando um desenho de borda da área urbana mais densa e central claramente identificável, como na Figura 5.38.

Na margem esquerda, em áreas não ocupadas, foi assumida como limite a linha de inundação agregada das áreas de declividade superior a 30\% e manchas de vegetação significativa.

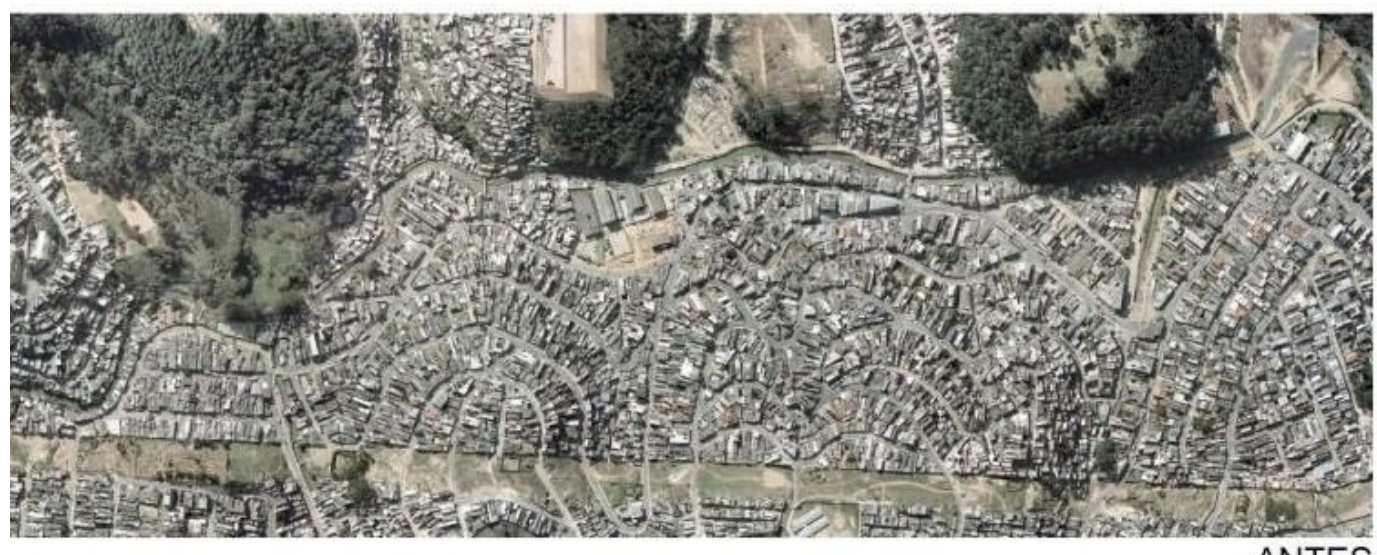

ANTES
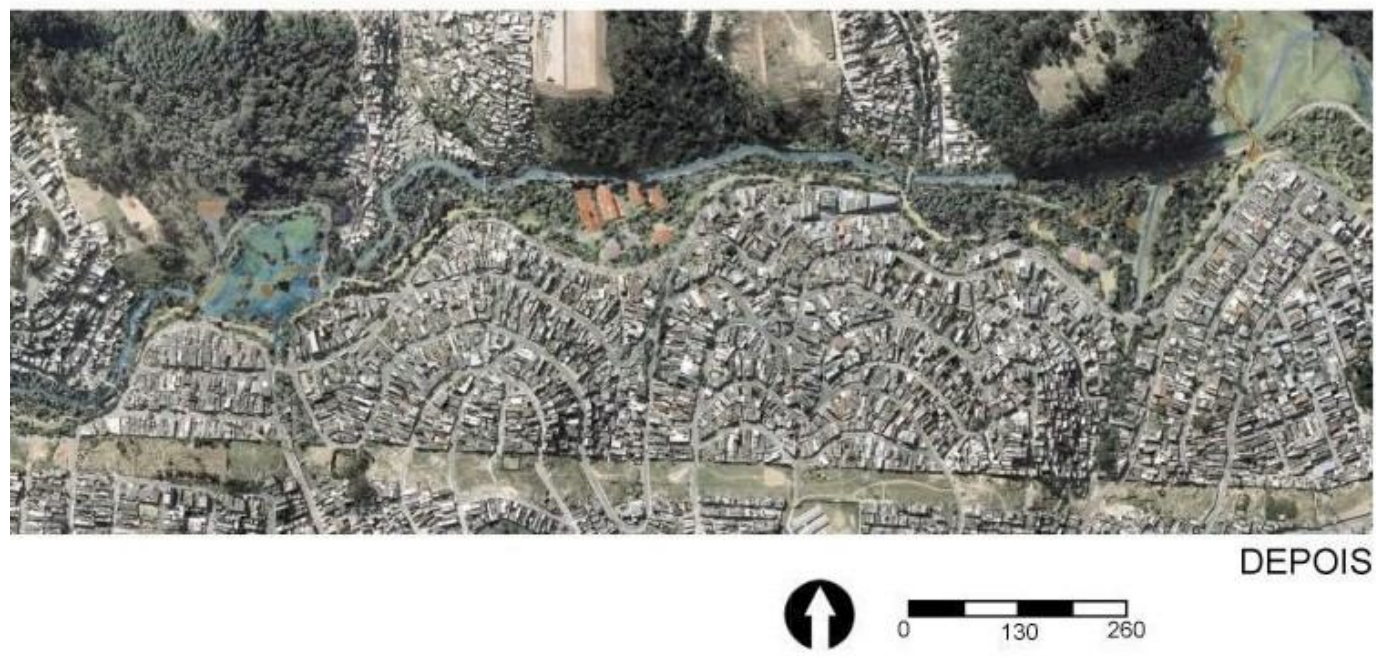

DEPOIS

Figura 5.38 - Parque Linear, antes e depois. 
As áreas já ocupadas por construções dentro destes limites são objetos de ações de relocação das funções de moradia e comércio para áreas próximas, com as subseqüentes etapas de demolição, com o tratamento, sempre que possível "in situ”, do entulho gerado e do material contaminado detectado; re-afeiçoamento topográfico e obras civis complementares. Ao término destas etapas, são propostas a implantação do projeto de recuperação das matas ciliares, das wetlands e da vegetação ornamental.

\subsubsection{Mapa de Risco}

Com os mapas de inundação, declividade e déficit de saneamento (áreas de inundação com os itens a e b da Tabela 5.7) foi possível montar um Mapa de Risco para Água Urbana ${ }^{3}$. Quando se fala em risco, está se referindo a probabilidade da ocorrência de um evento desfavorável, nos casos aqui tratados, os riscos foram estimados qualitativamente, com exceção dos riscos de inundação obtidos pelo SSD. Para elaboração do mapa, BARROS et. al (2005) admitiu uma escala de intensidade de risco em função do número de eventos a que uma determinada área está sujeita:

- Risco Amarelo: áreas onde pode ocorrer um dos três fatores de risco;

- Risco Vermelho: áreas onde pode ocorrer a combinação (dois a dois) dos três fatores de risco considerados;

- Risco Roxo: Áreas que estão sujeitas aos três fatores (áreas mais críticas).

A Figura 5.39 apresenta o resultado obtido por BARROS et. al. (2005) para a subbacia do Bananal, com as cores acima indicadas. A Tabela 5.8 mostra os resultados da análise de sobreposição de informações (Overlay).

\footnotetext{
${ }^{3}$ Pode ser definido risco para água urbana como sendo a probabilidade que um indivíduo, ou uma população, tem de sofrer algum tipo de problema associado à água urbana.
} 
Tabela 5.8 - Extensão e número de pessoas nas áreas de risco na sub-bacia do Bananal.

\begin{tabular}{||c|c|c|c||}
\hline & Área $\left.\mathbf{( m}^{\mathbf{2}}\right)$ & $\begin{array}{c}\text { \% Área Ocupada } \\
\text { por Habitações }\end{array}$ & $\begin{array}{c}\text { Número Estimado de } \\
\text { Pessoas }\end{array}$ \\
\hline Risco A (roxo) & 2.381 & $0,04 \%$ & 55 \\
\hline Risco B (vermelho) & 308.735 & $5,14 \%$ & 7.092 \\
\hline Risco C (amarelo) & 1.709 .378 & $28,48 \%$ & 39.265 \\
\hline
\end{tabular}

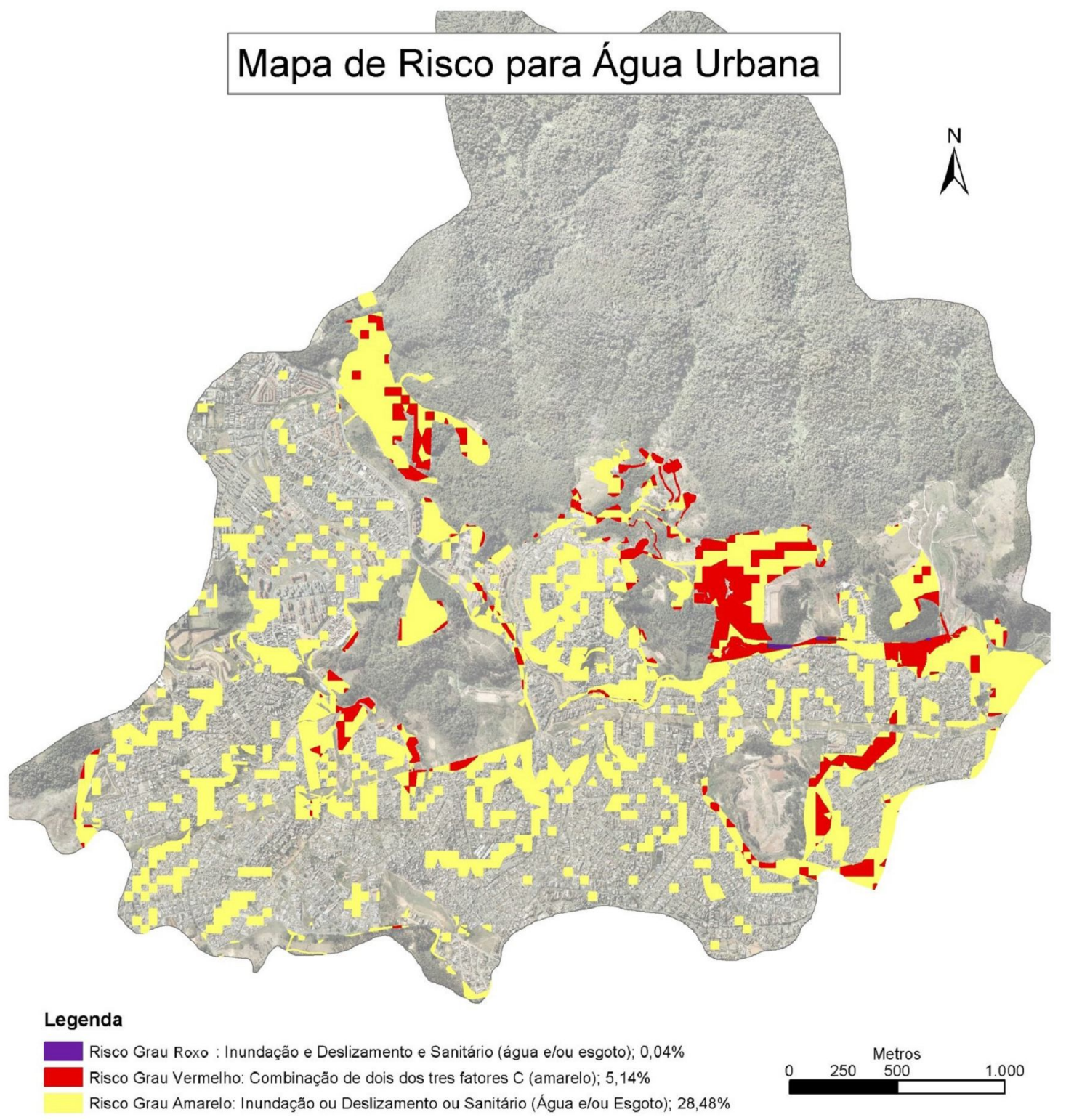

Figura 5.39 - Mapa de risco para água urbana na bacia do Bananal. 


\section{Conclusões e Recomendações}

O Sistema de Suporte a Decisão desenvolvido é uma metodologia diferenciada e importante na análise da bacia urbana para dar suporte à gestão de cidades em tudo a que se refere à água urbana superficial. Como produtos dos resultados de simulações de inundação com períodos de retorno variáveis, podem-se elaborar diversas abordagens multidisciplinares, principalmente da geografia, ecologia, arquitetura, saúde pública e urbanismo, com a utilização e integração de conceitos de planejamento ambiental, ecologia da paisagem, corredores verdes e wetlands.

Fundamentalmente, o URBSSD é uma ferramenta eficiente para o controle de cheias urbanas, pois os resultados das simulações hidrológicas e hidráulicas podem ser visualizados e exportados em formatos tabulares e vetoriais, próprios para serem usados em softwares de Sistema de Informação Geográfica. Proporciona ao decisor uma solução rápida para variadas tormentas em bacias urbanas.

Usualmente os profissionais utilizam um software de cada vez, como o uso de um modelo hidrológico que estuda vazões, um outro modelo para o cálculo de ondas de cheias, outro software para o processamento de imagens e assim por diante. A grande contribuição do URBSSD foi o desenvolvimento de um sistema ou ferramenta que integra dados e modelos, podendo gerar cenários para avaliação e suporte a decisões.

A implantação do sistema de visualização em SIG no modelo é importante para o gestor, que necessita modificar algumas condições de drenagem da bacia, como o Tempo de Concentração e o uso do solo no Curve Number (CN). Se for identificada uma diferença de ocupação, basta modificar as informações nos dados tabulares dos shapefiles. 
Uma das dificuldades foi definir o usuário final do URBSSD. Foi adotado um usuário com conhecimento suficiente de drenagem urbana, com a experiência de atribuir o grau de impermeabilização, tempo de concentração do deflúvio e conceitos SIG. Normalmente os gestores não possuem tais conhecimentos específicos, por isso recomendase que um profissional com bons conhecimentos em hidrologia e SIG acompanhe o processo de simulação.

Outras dificuldades foram encontradas, como na calibração do modelo hidrológico. Não foi possível calibrar os eventos de chuva com altos volumes em tempos diferentes, como uma chuva observada no dia 17/02/2003. O hidrograma resultante observado é composto por duas vazões de pico de mesma magnitude, o que não é fácil de obter num hidrograma unitário HUT-SCS aplicando uma chuva unitária em toda a bacia. A aplicação do método de Thiessen nesses casos tende a aumentar o volume de chuva distribuída e prejudica a distribuição de chuvas orográficas. Para poder gerar a segunda vazão de pico em uma chuva única para toda a bacia, deve ser modificado, entre outras, as condições de umidade adotado na obtenção do parâmetro $\mathrm{CN}$, impossível de ser feito durante a modelagem hidrológica.

Como recomendação para os modelos de cheias urbanas, o URBSSD deve ser adaptado para as diferentes bacias urbanas, mesmo sendo atualmente um software generalizado. A dinâmica do uso do solo é intensa em grandes cidades, não se pode ter a absoluta certeza de que as seções transversais medidas em dias anteriores vão permanecer as mesmas numa situação futura. A quantificação dos sedimentos carregados pelas chuvas dos solos expostos provocados pela ocupação desordenada nos mananciais é muito complexa, se levarmos em conta de que a ocupação antrópica é imprevisível. A inundação é uma conseqüência da ocupação desordenada, que impermeabiliza o solo ou a deixa 
exposto.

Existe também uma limitação quanto à configuração dos nós no modelo $\mathrm{CABC}$. $\mathrm{O}$ modelo não aceita a contribuição de deflúvio de duas ou mais bacias num único nó, por isso, justifica-se que o modelo de chuva-vazão e o modelo hidráulico devem ser adaptados para cada tipo de bacia urbana para que sejam aceitos os dados de entrada em shapefile.

Além disso, ao obter os resultados de cheias de canais, o modelo hidráulico CLIV se mostrou instável em algumas situações de chuvas, principalmente em precipitações intensas com altos volumes em um tempo de evento curto, que é a maioria das chuvas intensas que ocorrem na RMSP. Uma solução é a diminuição do tempo de cálculo dos hidrogramas para intervalos de tempo inferiores a quinze minutos, mas na maioria das vezes ocorrem erros de convergência ao aplicar o Método Implícito de Preissman ou o Método Explícito de MacCormack.

Utilizando a mesma metodologia aplicada no Gerenciamento Integrado de Bacias Hidrográficas em Áreas Urbanas, em BARROS (2004), o URBSSD pode ser utilizado como uma ferramenta de análise de qualidade da água e análise de sedimentos para outras bacias urbanas. Também pode ser uma ferramenta importante na previsão de inundações, ao aliar com uma ferramenta de previsão de chuvas, como o RADAR, SAISP (2008). Desde que o URBSSD esteja calibrado nas condições de uso e ocupação atuais.

Outra recomendação importante se refere ao monitoramento. $\mathrm{Na}$ bacia do rio Cabuçu de Baixo, os dados hidrológicos foram obtidos com uma utilização de três postos fluviográficos e três postos pluviográficos para uma área de aproximadamente $42 \mathrm{~km}^{2}$, o que é considerado como monitoramento intenso. Na maioria das bacias brasileiras, não existe um monitoramento desta magnitude. Por isso, ao implantar um URBSSD nas bacias urbanas, as medições de eventos de cheia são importantes, pelo menos um posto 
fluviográfico (ou telemétrico) à jusante e um posto pluviográfico com dados confiáveis. Sem um monitoramento completo e confiável, torna impossível o avanço nos estudos e aumenta a dificuldade de utilização dos modelos matemáticos.

Recomenda-se também em estudos futuros a implantação de outros módulos no ambiente do URBSSD, como um módulo de qualidade da água, módulo de carga de sedimentos, vetorização em 3 dimensões, interface com a internet, envios de relatórios online, integração com o RADAR, entre outros. O estágio atual do URBSSD pode ser aplicado em outras bacias, desde que sejam adaptadas algumas condições na leitura dos dados geográficos.

A escolha da bacia do rio Cabuçu de Baixo como caso de estudo foi muito importante, pois caracteriza muito bem o problema de água urbana das grandes cidades em ritmo de crescimento. Enfrenta problemas de ocupação desenfreada, áreas de alto risco de inundações e escorregamento de taludes em alta declividade, falta de moradia decente para boa parte dos seus habitantes, falta de infra-estrutura urbana, geração de resíduos sólidos e líquidos lançados diretamente na rede hídrica, entre outros. Enfim é uma bacia que apresenta todos os tipos de fatores que contribuem para a degradação da água urbana e, conseqüentemente, do padrão de vida da população. 


\section{Referências Bibliográficas}

ABBOTT, M. B., BATHURST, J. C., CUNGE, J. A., O'CONNEL, P. E., RASMUSSEN, J. An introduction to European hydrological system - System Hydrologique European (SHE). Journal of Hydrology, v.87, n.1, p. 61-77, 1986.

ABBOTT, M. B., IONESCO, F. On the Numerical Computation of Nearly Horizontal Flows, Journal of the Hydraulic Research, N. 2, pg 97-117, 1967.

ALMEIDA, C. N. Modelagem integrada de recursos hídricos com apoio de um Sistema de Informações Geográficas. Tese (Doutorado) - Escola de Engenharia de São Carlos, Universidade de São Paulo. São Carlos, 125p, 2006.

ALMEIDA, F. F. M. Fundamentos Geológicos do Relevo Paulista. IGEOG, São Paulo, 99p, 1974.

ANA. Agência Nacional de Águas. Superintendência de Gestão da Informação do Sistema Nacional de Informações de Recursos Hídricos (SGI - SNIRH). Em: http://snirh.ana.gov.br. 2007.

AZEVEDO, L. G. T., PORTO, R. L. L. e PORTO, M. F. A. Sistema de apoio à decisão para gerenciamento integrado de quantidade e qualidade da água: Metodologia e estudo de caso. Revista Brasileira de Recursos Hídricos, v.3, n.1, p.21-52, 1998.

AZEVEDO, L. G. T., BALTAR, A. M., RÊGO, M., PORTO, R. L. L. Sistemas de Suporte à Decisão para a Outorga de Direitos de Uso da Água no Brasil, in Série Água Brasil 2 - $1^{a}$ ed. Banco Mundial. Brasília, 2003.

BARBOSA, F.A.R., PAULA, J.A., MONTE-MÓR, R.L. A bacia hidrográfica como unidade de análise e realidade de integração disciplinar In: PAULA, J.A. (Coord.). Biodiversidade, população e economia: uma região de mata atlântica. Belo Horizonte: UFMG/Cedeplar; ECMVC; PADCT/CIAMB, 1997.

BARROS, M. T. L. et al. Gerenciamento Integrado de Bacias Hidrográficas em Áreas Urbanas: sistema de suporte ao gerenciamento da água urbana. Estudo de caso: Rio Cabuçu de Baixo, Cidade de São Paulo. Escola Politécnica da USP, v.1. 52p. São Paulo, 2004.

BARROS, M. T. L. et al. Gerenciamento Integrado de Bacias Hidrográficas em Áreas Urbanas. Relatório Parcial e Final. Projeto 02-CIAMB. Escola Politécnica da USP, São Paulo, 2003.

BARROS, M. T. L. et. al. Plano de Bacia Urbana Relatório Final. CT-HIDRO, Escola Politécnica da USP, São Paulo, 2005.

BARROS, M. T. L., BRANDÃO, J. L. B., SILVA, O. F., ONO, S. The Impact of Urban 
Sprawl on Flood Risk Areas. In: ASCE-EWRI Watershed Management 2005, Williamsburg, Virginia. Managing Watersheds for Human and Natural Impacts, 2005.

BARROS, M. T. L., PORTO, M. F. A., BRANDÃO, J. L. B., HAMBURGER, D. S., ONO, S. Sistema de Suporte ao Gerenciamento da Água Urbana. In: XV Simpósio Brasileiro de Recursos Hídricos v. 1. p. 161-162. Curitiba, 2003.

BRAGA JR., B. P. F. An Evaluation of StreamFlow Forecasting Models for Short-Range Multi-Objective Reservoir Operation. Tese de doutorado. Stanford University. 1979.

CANHOLI, A. P. Drenagem Urbana e Controle de Enchentes. Oficina de Textos. São Paulo, 2005.

CARVAlHO, M. A. Sistema de Suporte a Decisão para Alocação de Água em Projetos de Irrigação. Tese (Doutorado) - Escola Politécnica, Universidade de São Paulo. São Paulo. 219p., 2003.

CAUDHRY, M. H. Numerical Modeling of Aggradation and Degradation in Alluvial Channels, Journal of Hydraulics Division,, Vol 117, No. 9, Sept, 1991, p.1145-1164.

CGE Centro de Gerenciamento de Emergências. Somar Meteorologia. São Paulo. Disponível em: http://www.cgesp.com.br. Último acesso em Março de 2008.

CHOW, V. T. Open-channel hydraulics, McGraw-Hill, 1959.

COAPS. Introduction to MapWindow. Center for Ocean-Atmospheric Prediction Studies, Florida State University, Version 4.3, 157p. February, 2007. Disponível em http://www.mapwindow.org . Último acesso em Março de 2008.

CONGALTON, R.G., GREEN, K. The ABCs of GIS: an introduction to Geographic Information Systems. In Wetland and Environmental Applications of GIS. Lyon and McCarthy (eds.) CRC Press, Inc., Boca Raton. 16 p., 1995.

CPRM. Carta Geológica do Brasil ao Milionésimo. Mapoteca Virtual, Companhia de Pesquisa de Recursos Minerais. Disponível em: http://www.cprm.gov.br . Último acesso em Março de 2008.

DA COSTA, S.M.F., CINTRA, J.P. Environmental analysis of metropolitan áreas in Brazil. Journal of Photogrammetry \& Remote Sensing 54, pp. 41-9, 1999.

DAEE. Guia prático para projetos de pequenas obras hidráulicas. Secretaria de Estado de Energia, Recursos Hídricos e Saneamento. Departamento de Águas e Energia Elétrica de São Paulo, 2005.

DAEE. PDMAT - Plano Diretor de Macrodrenagem da Bacia do Alto Tietê. Secretaria de Estado de Energia, Recursos Hídricos e Saneamento. Departamento de Águas e Energia Elétrica de São Paulo, 1999. 
DEMISSIE, M., TIDRICK, M., The Illinois Rivers Decision Support System (IRLDSS). In: Proceedings: Decision Support Systems For Water Resources Management, Snowbird, Utah, American Water Resources Association and Universities Council on Water Resources, June 27-30, 2001.

DIGITAL GLOBE, An Imagery and Information Company. Disponível em: http://www.digitalglobe.com . Último acesso em Abril de 2008.

DWR \& CWCB - Colorado's Decision Support Systems (CDSS). Colorado Division of Water Resources and the Colorado Water Conservation Board. Disponível em: http://cdss.state.co.us . Último acesso em Dezembro de 2007.

ENGECORPS/HARZA. Projeto Transposição de Águas do Rio São Francisco para o Nordeste Setentrional. Relatório R12. ENGECORPS/HARZA. São Paulo, 2000, 289 p.

ENOMOTO, C. F. Método para elaboração de mapas de inundação estudo de caso na bacia do rio Palmital, Paraná. Dissertação (Mestrado) - Universidade Federal do Paraná. Curitiba, 2004.

EPA. Heat Island Effect. U. S. Environmental Protection Agency. Disponível em: http://www.epa.gov. Último acesso em Março de 2008.

ESRI. Introduction to Avenue. ESRI Educational Services, Environmental System Research Institute, Redlands, CA. 1995.

ESRI. ArcView 9.2 User's Guide. First Edition, Environmental System Research Institute, Redlands, CA. 2007.

FCTH. Manual dos programas CABC e CLIV. Disponível em: http://www.fcth.br. Fundação Centro Tecnológico de Hidráulica, 2002.

FCTH. Plano de Águas Pluviais de Nova Friburgo. Volume 2 - Formulação de Cenários, Diagnóstico e Prognóstico das Inundações. São Paulo, 2007.

GARCIA-NAVARRO, P. \& ALCRUDO, F. \& SAVIRÓN, J. M. 1-D Open-Channel Flow Simulation Using TVD-MacCormack Scheme, ASCE, v.118, No. 10, p.1359-1371, Out, 1992.

GENOVEZ, A. M. Avaliação dos métodos de estimação das vazões de enchente para pequenas bacias rurais do Estado de São Paulo. Tese (Livre Docência). Faculdade de Engenharia Civil, UNICAMP. Campinas, 1991

GOOGLE. Google Earth. Disponível em http://maps.google.com. Último acesso em Março de 2008.

HELLMEIER, A., Virtual 3D City and Landscape Models with Laser Scanning and Aerial Imagery. In: XII Simpósio Brasileiro de Sensoriamento Remoto v. 1. Anais do Simpósio. Florianópolis, 2007. Disponível em http://www.dsr.inpe.br/sbsr2007 . Último 
acesso em Setembro de 2007.

HIDROLOGIC ENGINEERING CENTER (HEC). Hidrologic Modeling System-HECHMS V3.0.0. U.S. Army Corps of Engineers, Davis, CA, 2005.

HIDROLOGIC ENGINEERING CENTER (HEC). River Analysis System-HEC-RAS V4.0.0 Beta. U.S. Army Corps of Engineers, Davis, CA, 2006.

IBGE. Caracterização do Sistema Geodésico Brasileiro. Instituto Brasileiro de Geografia e Estatística. R.PR.1/2005. São Paulo, 2005.

IBGE. Instituto Brasileiro de Geografia e Estatística. Disponível em http://www.ibge.br. Último acesso em Dezembro de 2007.

INPE. Instituto Nacional de Pesquisas Espaciais. Manual do Spring Versão 3.6.02, 2002.

IPT. Mapa Geomorfológico do Estado de São Paulo. Instituto de Pesquisas Tecnológicas do Estado de São Paulo. São Paulo, 1981.

KEIFER, C.J., CHU, H.H. Synthetic storm pattern for drainage design. Journal or the Hydraulics Division. American Society of Civil Engineers. New York, v.83, n.4, p.17888, 1957.

KOHLER, M.A., RICHARDS, M.M. Multi-Capacity Basin Accounting for Predicting Runoff from Storm Precipitation. Journal of Geophysical Research, Washington, p.518797, 1962.

LABADIE, J.W., SUlliVAN, C. H. Computerized Decision Support Systems for Water Managers. Journal of Water Resources Planning and Management, 112(3), p. 299-307, 1986.

LOPES, J.E.G.; BRAGA JR., B.P.F.; CONEJO, J.G.L. Simulação hidrológica: Aplicações de um modelo simplificado. In: Anais do III Simpósio Brasileiro de Recursos Hídricos, v.2, 42-62, Fortaleza, 1981.

MAGAlHÃES, L. P. C. Modelo Integrado para Simulação de Sistemas Hídricos. Dissertação (Mestrado). Universidade Federal do Rio de Janeiro. Rio de Janeiro, 2005.

MARCELLINI, S. S. Diretrizes para utilização de tecnologia de Sistemas de Informações Geográficas (SIG) na exploração de informações hidrológicas - exemplos de aplicação. Tese (doutorado). Escola Politécnica da USP. São Paulo, 2002.

MAYS, L.W. Stormwater drainage systems design handbook. McGraw Hill, 2001.

MCCUEN, R. H. Hydrologic Analysis and Design. New Jersey: Prentice Hall, 1989. 867p

MENDES, C. A. B., CIRILO, J. A. Geoprocessamento em recursos hídricos. Princípios, Integração e Aplicação. ABRH, Porto Alegre, 2001. 
MSDN. Microsoft Developer Network. Disponível em: http://msdn2.microsoft.com/pt-br, Último acesso em Março de 2007.

NAKAYAMA, P.T. Sistema de suporte à decisão: previsão de chuva e alerta a inundação com radar meteorológico. Tese (Doutorado), Escola Politécnica da USP. São Paulo, 170p, 1988.

NÓBREGA, R.A.A.; QUINTANILHA, J.A; BARROS, M.T.L. Emprego de Técnicas Digitais para a Concepção da base Cartográfica Precisa Utilizada no Sistema de Suporte a Decisões da Bacia Hidrográfica do Córrego Cabuçu de Baixo. Revista Brasileira de Recursos Hídricos, ABRH, Porto Alegre, 2004.

ONO, S., PORTO, R. L., OLIVEIRA, C. P. M., MARCELlinI, S. S. Previsão e Modelagem de vazões de cheias diárias para a bacia do Alto Tietê - Modelo MEL-AT. I Simpósio de Recursos Hídricos do Sul-Sudeste, Curitiba, ABRH, 2006.

ONO, S., BARROS, M.T.L., CONRADO, G.N., A Utilização de SIG no Planejamento e Gestão de Bacias Urbanas. Décimo Quinto Simpósio Brasileiro de Recursos Hídricos, ABRH, João Pessoa, 2005.

PEDROSA, B.M., CÂMARA, G. Modelagem dinâminca: conceitos básicos e exemplos de sistemas. In: Câmara, G. \& Monteiro, A.M.V. Introdução à modelagem dinâmica espacial. XI Simpósio Brasileiro de Sensoriamento Remoto, Belo Horizonte, 2003.

PIRILlO, F.C., BARROS, M.T.L., PELlEGRINO, P.R.N., GUEDES, P.P., ONO, S. Plano de Recuperação Ambiental e da Paisagem para Pequenas Bacias Urbanas. Décimo Quinto Simpósio Brasileiro de Recursos Hídricos, ABRH, João Pessoa, 2005.

PMSP. Plano Municipal de Habitação. Prefeitura Municipal da Cidade de São Paulo, Secretaria da Habitação e Desenvolvimento Urbano, São Paulo, Agosto de 2003.

PORTO, R. L., SETZER, J. Tentativa de avaliação do escoamento superficial de acordo com o solo e o seu recobrimento vegetal nas condições do Estado de São Paulo. Boletim Técnico DAEE, v.2, n.2, 1979.

PORTO, R. L. et al., Técnicas quantitativas para o gerenciamento de Recursos Hídricos, $1^{\text {a }}$ ed., ABRH-EUFRGS. Porto Alegre, 1997.

PORTO, R. L., Uso de Modelos de Simulação de Rede de Fluxo, UNICAMP. Campinas, 2002.

PORTO, R. L. et al. Sistema de suporte a decisão para análise de sistemas de recursos hídricos, in Métodos Numéricos em Recursos Hídricos 6. Org. Por da Silva, R. C. V., ABRH, Ed.UFRGS. Porto Alegre, pp. 93 - 240, 2003.

RADAMBRASIL. Levantamento de recursos naturais. Ministério das Minas e Energia, Rio de Janeiro, v.32, folha S/ F. 23/24, 1983. 
QUINTANILHA, J. A., FONSECA JR., E. S. Programa de incentivo à produção de material didático, SIG / GPS / Cartografia e Sensoriamento Remoto. Org. por ONO, S. e IWAI, O. K. Disponível em CD-ROM. SIAE-USP, 2002.

RENNÓ, C. D., SOARES, J. V. Conceitos básicos de modelagem hidrológica. In: Câmara, G. \& Monteiro, A.M.V. Introdução à modelagem dinâmica espacial. XI Simpósio Brasileiro de Sensoriamento Remoto, Belo Horizonte, 2003.

ROBERTO, A. N. e PORTO, R. L., O Sistema ModSimLS: um Modelo de Rede de Fluxo para Simulação de Bacias Hidrográficas, Décimo Quarto Simpósio Brasileiro de Recursos Hídricos, Aracaju, ABRH, 2001.

RODRIGUES, M. Sistemas de informação geográfica. In: Programa de transferência de tecnologia GIS. Workshops. Escola Politécnica da USP e SABESP, 1998.

RODRIGUES, R. B. O Sistema de Suporte a Decisão proposto para a gestão qualiquantitativa dos processos de outorga e cobrança pelo uso da água. Tese (doutorado). Escola Politécnica da USP. São Paulo, 2005.

SAISP Sistema de Alerta a Inundações de São Paulo. Centro Tecnológico de Hidráulica. Departamento de Águas e Energia Elétrica do Estado de São Paulo (CTH/DAEE). Disponível em: http://www.saisp.br . Último acesso em Março de 2008.

SARTORI, A. Avaliação da Classificação Hidrológica do Solo para a Determinação do Excesso de Chuva do Método do Serviço de Conservação do Solo dos Estados Unidos. Dissertação (mestrado). Faculdade de Engenharia Civil, UNICAMP. Campinas, 2004.

SCHARDONG, A. Aplicação de técnicas de Programação Linear e extensões para otimização da alocação de Água em Sistemas de Recursos Hídricos, utilizando métodos de Pontos Interiores. Dissertação (Mestrado). Escola Politécnica da USP. São Paulo, 2006.

SIGRH. Banco de Dados Pluviométricos do Estado de São Paulo. Sistema de Informações para o Gerenciamento de Recursos Hídricos do Estado de São Paulo. Departamento de Águas e Energia Elétrica do Estado de São Paulo (DAEE). Disponível em: http://www.sigrh.sp.gov.br . Último acesso em Março de 2008.

SINGH, V. P. Computer Models of Watershed Hydrology. Water Resources Publications. Baton Rouge, LA, 1995

SHAMSI U. M. GIS tools for water, wastewater, and stormwater systems, ASCE Press. Reston, VA, 2002.

TUCCI, C. E. M., PORTO, R. L. L, BARROS, M. T. L. Drenagem Urbana. Editora da Universidade/UFRGS, Porto Alegre, RS, 1995.

TUCCI, C. E. M. et al, Hidrologia: Ciência e aplicação - 3.ed., primeira reimpressão. Editora da UFRGS/ABRH, Porto Alegre, 2004 
UEHARA, K., ONO, S., MARTINS, V. H. R. Modelos de transformação Chuva-Vazão e seus campos de aplicação. Notas de aula (pós-graduação). Escola Politécnica da USP. São Paulo, 2002.

U. S. DEPARTMENT OF AGRICULTURE - Urban hydrology for small watersheds. $2^{\mathrm{a}}$ Ed. Technical Release n. 55, Washington, DC. 1986.

WANIELISTA, M.P., YOUSEF, Y.A. Stormwater management. John Wiley \& Sons, Inc., 1993.

WILKEN, P. S., Engenharia de drenagem superficial. CETESB. São Paulo, 1978. 477p. 